DE-ID/13612-F

\title{
Thin Wall Iron Castings
}

Final Technical Progress Report

$1999-2001$

Molding Capability Study

J.F. Cuttino, A. Kachru, S. Patterson and E. Morse

The University of North Carolina at Charlotte

T.S. Piwonka

The University of Alabama

\section{Microstructural Control and Modeling}

D. M. Stefanescu, R. Ruxanda, S. Charoenvilaisiri

C. Corbitt-Coburn, L. Dix

The University of Alabama

T.S. Piwonka, Program Manager

The University of Alabama

October 31, 2001

Metal Casting Technology Center

The University of Alabama

Tuscaloosa, AL 35487-0201

This report was prepared with the support of the U.S. Department of Energy (DOE) Award no. $D E-F C 07-981 D 13612$. However, any opinions, findings or recommendations expressed herein are those of the authors and do not necessarily reflect the views of DOE. 


\section{PREFACE}

This report summarizes the results of three years of research into the parameters, both molding and metallurgical, that will permit the production of thin-wall iron castings. "Thin-wall" is defined as castings having wall thicknesses down to $2.5 \mathrm{~mm}$. The purpose of producing such castings is to permit cast iron (gray, ductile, and compacted graphite) to be used in lightweight structures, especially in the automobile industry, where its strength, ductility, toughness, and high temperature properties promise low-cost high integrity cast components that can be made without compromising performance for weight.

The program was divided into two components: a molding capability study and a microstructural control and modeling study. The molding capability study was based on the realization that the benefits of thin-wall iron will not be realized unless the green sand molding process is able to reproducibly make molds having wall thicknesses as small as $2.5 \mathrm{~mm}$ with a small and reproducibly controllable variation. In this work, the object was to determine what current capability of green sand molding systems actually is in production foundries, and what molding parameters affect the variability of key dimensions. The microstructural control and modeling study was focused on developing melting and treatment practices to avoid the formation of iron carbide in thin sections, and to create solidification software capable of predicting the cast structure, for use in engineering design of iron casting gating systems.

This final report is divided into two sections, Molding Capability, and Microstructural Control and Modeling. In each section the report is composed of and introduction and the papers that have been accepted for presentation at the American Foundry Society Castings Congress in 2002. An extra paper in included in the Molding Capability section detailing the work to date of the round robin study, which is ongoing. As proposals have been made to continue this work, this report may be considered Phase I of a more extensive project, which will generate more information on thin wall cast iron in the future. 


\section{Table of Contents}

Molding Capability Study 1

Executive Summary 1

A Study of the Effects of Mold Placement on Dimensional

Variation in Thin Wall Iron Castings $\quad 8$

A Parametric Study of the Effects of Casting Parameters on Dimensional Variation Thin Wall Iron Castings 19

The Effects of Shot Blasting on Dimensional Variation in Castings

Current Thin Wall Molding Capability - A Round Robin Study

$\begin{array}{ll}\text { Microstructural Control and Modeling } & 60\end{array}$

$\begin{array}{lr}\text { Executive Summary } & 60\end{array}$

Thin Wall Compacted Graphite Iron Castings 62

Microstructure Characterization of Ductile Thin Wall Iron Castings

80

Tensile Properties of Thin Wall Ductile Iron 97 


\section{Thin Wall Iron Molding Capability Study}

\section{EXECUTTVE SUMMARY}

The goal of this work was to determine the effects that process parameters have on the dimensional variations of thin-wall iron castings fabricated in green sand molds. A number of activities have been undertaken to reach this goal over the last year. The most significant efforts included four different studies that were designed to understand the effects of process parameters on the thicknesses of thin features in the castings. The first study, the Parametric Study, was aimed at evaluating the effects of four major process parameters in controlling the dimensional variation and the nominal thickness by means of a $2^{4}$ factorial design. The second study, the Shot-blasting Study, was aimed at understanding the effect of shot peening on the casting dimensional variations. The third study, the Mold Placement Study, was aimed at understanding the dimensional variation in the castings as a function of placement in the mold and distance from the gating. The fourth study was established to determine the current capabilities of US foundries to produce thin-walled iron castings. In this study, a pattern with thin wall features (1.3 - $6 \mathrm{~mm}$ thickness) was fabricated and delivered to various foundries in a Round Robin study.

The results are summarized below. The detailed final reports are included as separate reports. Three of the reports have been submitted to the American Foundry Society for publication in $A F S$ Transactions. The principal conclusions are that clay content and pour temperature were the most sensitive parameters affecting dimensional variation and nominal dimension. Increases in clay content and pour temperature both increased the dimensional variation, and an increase in pour temperature decreased the nominal dimension while increases in clay content increased the nominal dimension. The dimensional variation tends to increase as the distance of the feature from the gating and adjacent features increases. Finally, the shot blasting study revealed that shot blasting decreased both the dimensional variation and the nominal dimensions in castings, but that the thin wall castings were much more susceptible to warping and cracking.

\section{Shot Blasting Study}

The study of surface finish conducted in this project involved castings that were shot blasted by various degrees of shot intensity and measured. The data collected showed that the dimensional variation of the castings decreases non-linearly with additional shot blasting, as shown in Figure 1. In this figure, the $x$-axis depicts the intensity and duration of the shot blasting to which the castings have been subjected.

During the shot blasting process, the nominal dimension of all of the 108 features decreased by $0.2 \mathrm{~mm}$. This result raises questions as to the measurement of the actual bulk material. For example, was the benchmark measurement artificially large due to surface asperities, or is the material compressed through the shot blasting process? If the variation decreases because the surface finish is improved, the measurement of the variation in the "bulk" dimension is flawed and the variation is simply due to surface asperities that provide no structural contribution anyway. If, however, variation is being decreased by the shot blast process, it may provide a very economical solution to reducing variation and subsequently the design dimension, casting weights, and scrap rates. This advantage would be countered, however, by the change in material properties that accompanies shot blasting, as has been studied by other researchers. In addition, extremely thin castings will be subject to excessive warping and fracture. 
A Measurement System Variation Analysis (Gage R\&R Study) was also conducted for each of the finish runs executed in the project. The purpose of this task was to determine if the effects of surface finish and dimensional variation could be separated, and if the variation analysis could be used as an indicator of expected improvements in dimensional variations. The conclusion from the Gage R\&R studies is that the technique is insufficient for determining the presence of bulk material versus surface asperities. Standard forms of determining measurement system variation are therefore not adequate for predicting the effects of surface finish on dimensional variation, indicating that an alternative approach is required.

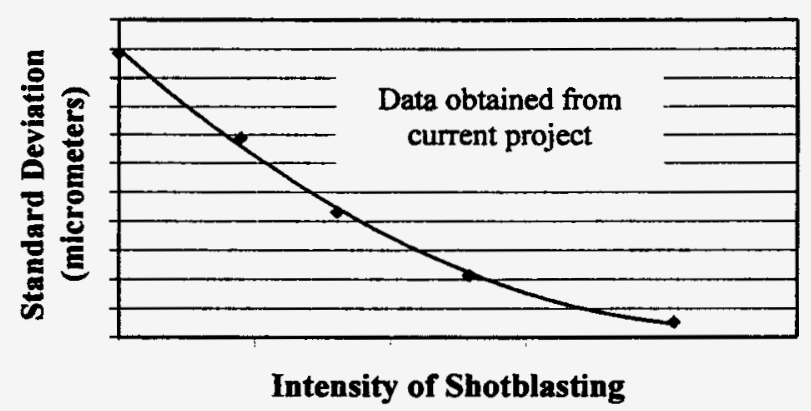

Figure 1: Standard Deviation vs. Shot Blasting Intensity

These results of this study led to the submission of a proposal to DOE to quantify the interaction of coordinate metrology and part geometry when used for quality assessment and process diagnosis. Pilot data, described above, have shown that post-casting processing results in a decrease of variability across a population of parts. The proposed continuation of work will separate the apparent effects of this processing - and other process parameters - into three distinct categories: bulk geometry (wall thickness, for example), surface finish (height and distribution of surface asperities), and measurement effects (stylus size, sampling strategy). This separation is critical as it allows us to distinguish between strength-related bulk properties and the bias that may be introduced by either the surface finish of the parts or the measuring method selected by the inspection department. This bias, if analyzed incorrectly, could result in the acceptance of parts or processes that provide insufficient strength or stiffness, or, conversely, the rejection of acceptable parts and over-design.

\section{Parametric Study}

The Parametric study examined the effects of four foundry parameters on the dimensional variation and the nominal dimension of thin wall iron castings. The parameters studied included clay content, pouring temperature, sand compaction, and shakeout time. A design of experiments was created for execution at a research foundry and the resulting castings measured at the Center for Precision Metrology at UNC Charlotte. Statistical analyses were conducted and are presented in this work.

The two most dominant parameters or interactions affecting the nominal dimension of each fin are plotted in Figure 2. This figure represents a top view of the casting looking down on the surface of the horizontal fins. The diagonal lines represent the cope and drag fins, numbered 1 through 4 . The two most dominant parameters or interactions affecting the nominal dimension at the respective locations are shown in parentheses. For example, in the case of Horizontal Fin 1, Shakeout Time (D) and Pour Temperature (B) are the two most sensitive effects from the Pareto's Chart. For Cope Fin 1, Clay Content (A) and Pour temperature (B) are the two most dominant effects.

Clay content (A) is dominant for vertical fins 1 and 2 in both the cope and the drag, and the clay / pour temperature interaction $(\mathrm{AB})$ follows for three of those four fins. The pour temperature $(B)$ is 
dominant on vertical fins 3 and 4 in the drag and 3 in the cope. These locations represent the furthest points from the gate, where pour temperature (B) may have its largest impact. The horizontal fins do not show as strong of a pattern, although fins 1 and 3 are dominated by shakeout time (D).

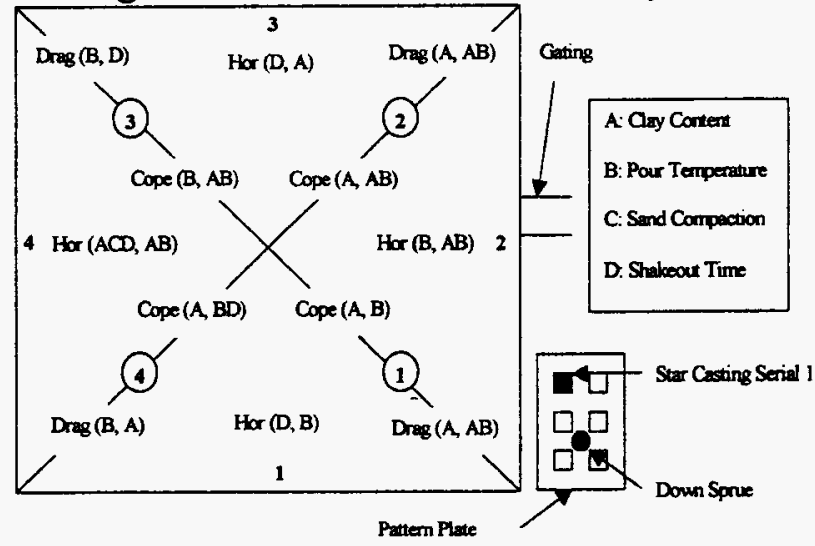

Figure 2: Summarized Effects from Pareto's Chart for Nominal Dimension

The study shows that the dimensional variation and nominal dimension are effected by varying the process parameters. In terms of the dimensional variation, clay content has the highest effect in the cope, whereas pour temperature has the highest effect across the parting line and in the drag (although to a lesser degree). An increase in clay content always increases the dimensional variation, but the effect of pour temperature depends on the elevation of the feature in the casting. As the pour temperature is increased, the standard deviation in the cope decreases while that in the drag increases, and that across the parting line falls in between the two extremes. This effect, however, is less pronounced in the cope than in the drag and may be due to the dynamics of fluid motion during fill. An opposite trend is seen for shakeout, where an increase in shakeout time increases the dimensional variation in the cope, decreases variation slightly across the parting line, and decreases it more in the drag. An increase in sand compaction results in a slight increase in the dimensional variation for most cases. The dimensional variation is dependent on the nominal dimension and increases as the nominal dimension increases.

In terms of the nominal dimension, clay content has the highest effect in the cope and drag, while pour temperature is dominant across the parting line. Increases in clay always increased the nominal dimensions, but increases in pour temperature decreased the nominal dimension. Shakeout time had a negligible effect in the cope but had a relatively high effect across the parting line and in the drag. An increase in shakeout increased the nominal dimension across the parting line and in the drag. Sand compaction had a very small and varying effect in the drag and across the parting line, but it had a stronger effect in the cope, where higher sand compaction decreased the nominal dimension. Pour temperature seemed to have a dominating effect near the gating of the casting where the metal is still the hottest.

The findings presented here will contribute to future efforts to reduce the variation in cast iron parts fabricated using green sand molds. The results indicate that control of clay content and pouring temperature are of utmost importance for reducing feature variation.

\section{Mold Placement Study}

This study examined the impact that position in the mold had on dimensional variation. The study was facilitated by the fact that the six of the CERP castings were made per mold. Documentation of the positions of each casting allowed for examination of the effects that location within the mold had on dimensional variation. 
Figure 3 shows the locations of the measured thicknesses on the horizontal fins of the casting. Note that the locations of points fell on one of 6 distinct radii from the center of the casting. Observations of the variation data showed that proximity to adjoining fins had an impact, an intuitive result. This observation was verified in Figure 4, which shows the standard deviation of the various thicknesses of the horizontal parting line fins as a function of the radial distance from the junction. In this figure, the points around the circumference of the circle at a particular radial distance were averaged to obtain a single value. The six values recorded for each radial distance represent the six serials for each mold. The variation shows a strong dependence on distance to the center of the casting, dropping off rapidly as the distance increases. Little change was seen for distances higher than $60 \mathrm{~mm}$. However, it should be noted that the point located $90 \mathrm{~mm}$ from the center of the casting showed the lowest average deviation and is the one furthest away from any adjoining fin. This indicates that variation is not only a function of distance from the center of the casting (which in this case also represents the location of the largest bulk of material), but is also a smaller function of distance from any adjoining fin.

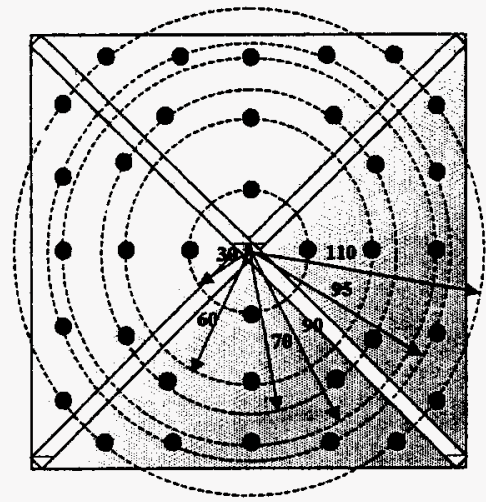

Figure 3: Location of points on the horizontal parting line surface of a single star

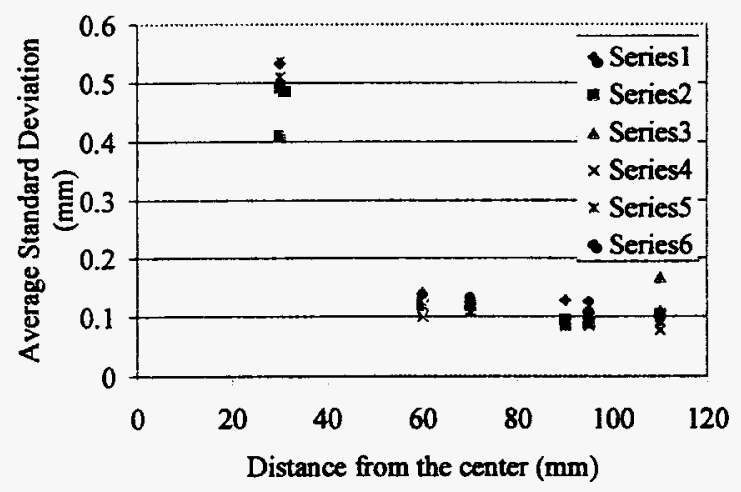

Figure 4: Variation of the averaged horizontal surface locations for the six serials

Similar results were seen in the cope and drag portions of the castings. Here, all of the data points were taken along the outer edge of the fins. For this portion of the study, the variation of the thickness was plotted as a function of distance from the nearest adjacent fin as shown in Figure 5 and Figure 6. The variation is sensitive to the increase in distance from the adjacent fins up to a point and decreases with the increase in distance.The standard deviation tended to start high when close to adjacent fins and to decrease as the distance from adjoining features was increased.

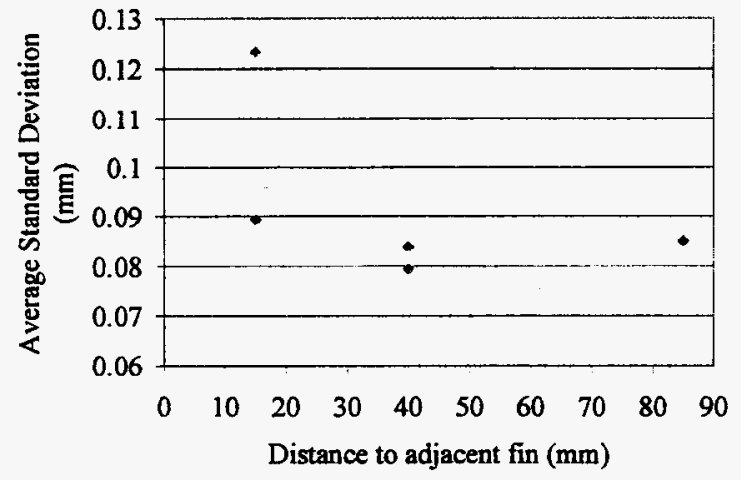

Figure 5: Variation of drag as a function of distance from the adjacent fin

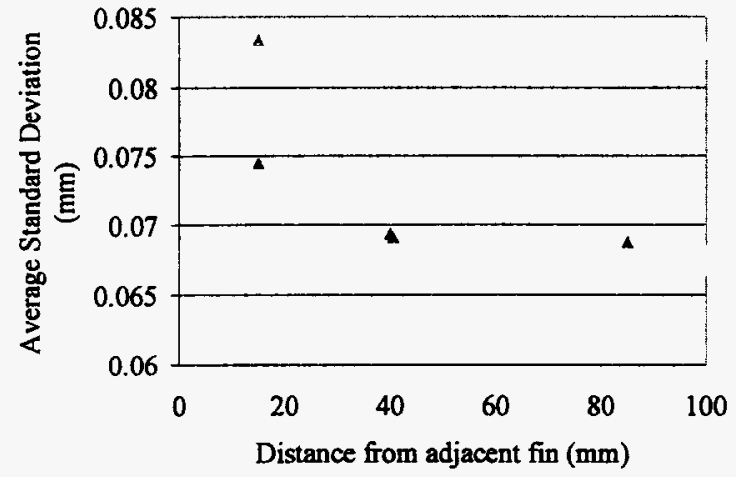

Figure 6: Variation of cope as a function of distance from the adjacent fin

Dimensional variation tends to increase as the distance from the gating increases showing its dependence on the placement in the mold. As the distance from the location of merging features increases the variation decreases. The dimensional variation in the cope is uniform and comparable to the variation in the drag except for some exceptions in the drag. The variation in the cope fins is less dependent on placement in the mold than the variation in the drag fins. The variation increases toward 
the center of the casting where the metal flow merges. The result is exaggerated because of the presence of burn-in contributing highly to the dimensional variation. The variation of one side of the mold tends to be less than on the other side. The variation of the features shows no correlation to the mold hardness.

\section{Round Robin Study}

In this study, a test pattern was fabricated to conduct a round robin study of current foundry capabilities. The pattern is shown in Figure 7, and a representative casting is shown in Figure 8 . The test casting was designed to compliment the three previous studies carried out at the Cast Emissions Reduction Program (CERP).

The new pattern was designed to fit on the smallest of the DISA machines, the 2013, so that it could be run on virtually any DISA vertically parting machine using a bolster if necessary. Recalling that the CERP castings were run on a horizontally parted machine using a 6-on pattern and gated through the horizontal webs, significant modifications were required for the Round Robin castings. First, in order to fit on the 2013 plate, the overall casting size was reduced to $75 \%$ that of the CERP castings. In order to bracket the dimensions of interest, the fin thicknesses were reduced to $1.3 \mathrm{~mm}$ to $6 \mathrm{~mm}$ rather than the constant $6 \mathrm{~mm}$ fin thicknesses on the CERP castings. The reduced thicknesses were designed to provide experimental identification of the threshold for the fabrication of sound thin-walled castings. The gating was designed to come up through the center of the casting in a 1.25" cylinder rather than to enter the casting cavity through one of the fins.

The castings showed very interesting casting problems, including chill on the thinner fins and evidence of white iron in the thinner fins. The pattern proved to be a good design, bracketing thickness values between 2.5 and $4 \mathrm{~mm}$ in $0.5 \mathrm{~mm}$ steps. The hope was that we would have some fins that did not pour well and some that did in order to give a good representation of the threshold thickness.

Figure 9 shows close up views of the imperfections in the casting. This was one of the best castings obtained, since there was a high occurrence of damage to the castings in the shakeout and cleanup processes. The castings were shot blasted minimally to remove the mold sand, but even that amount caused damage to the thinner fins. Shot blasting was conducted only long enough to knock of the green sand, without attempting to "smoothen" the surface finish. A casting instrumented with Almen strips was included in the process for later comparisons with other foundry runs.
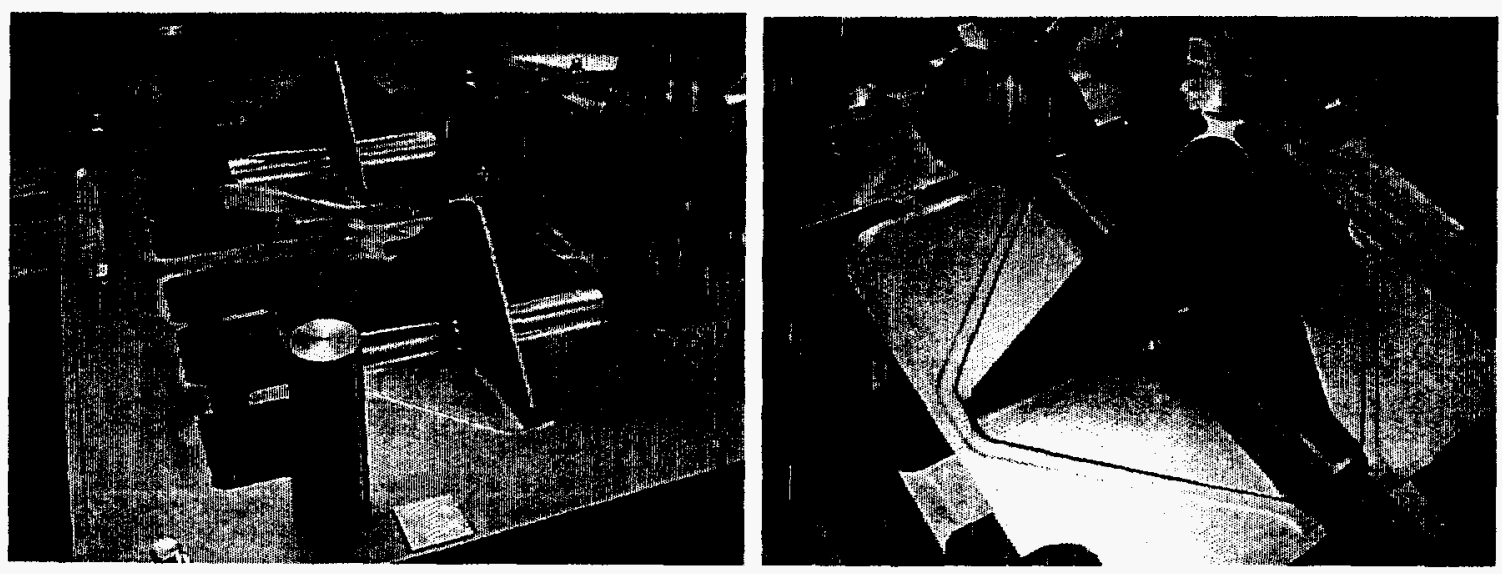

Figure 7: 2-on Pattern 
The orientation of the stars in the mold also played an important role. The pattern was designed to be non-symmetric, with serial 1 having its thinnest fins adjacent to the down sprue and serial 2 having its away from the sprue, near the exterior surface of the mold. In nearly every case, the $1.3 \mathrm{~mm}$ fins in serial 2 were extremely warped and torn following shot blasting, whereas they were only slightly warped and in-tact in the serial 1 castings. This confirms that the different heat transfer rates in the various locations in the mold play a significant role in the ability to produce thin castings. Apparently, the heat of the downsprue slowed cooling in the serial 1 fins and resulted in a tougher casting.
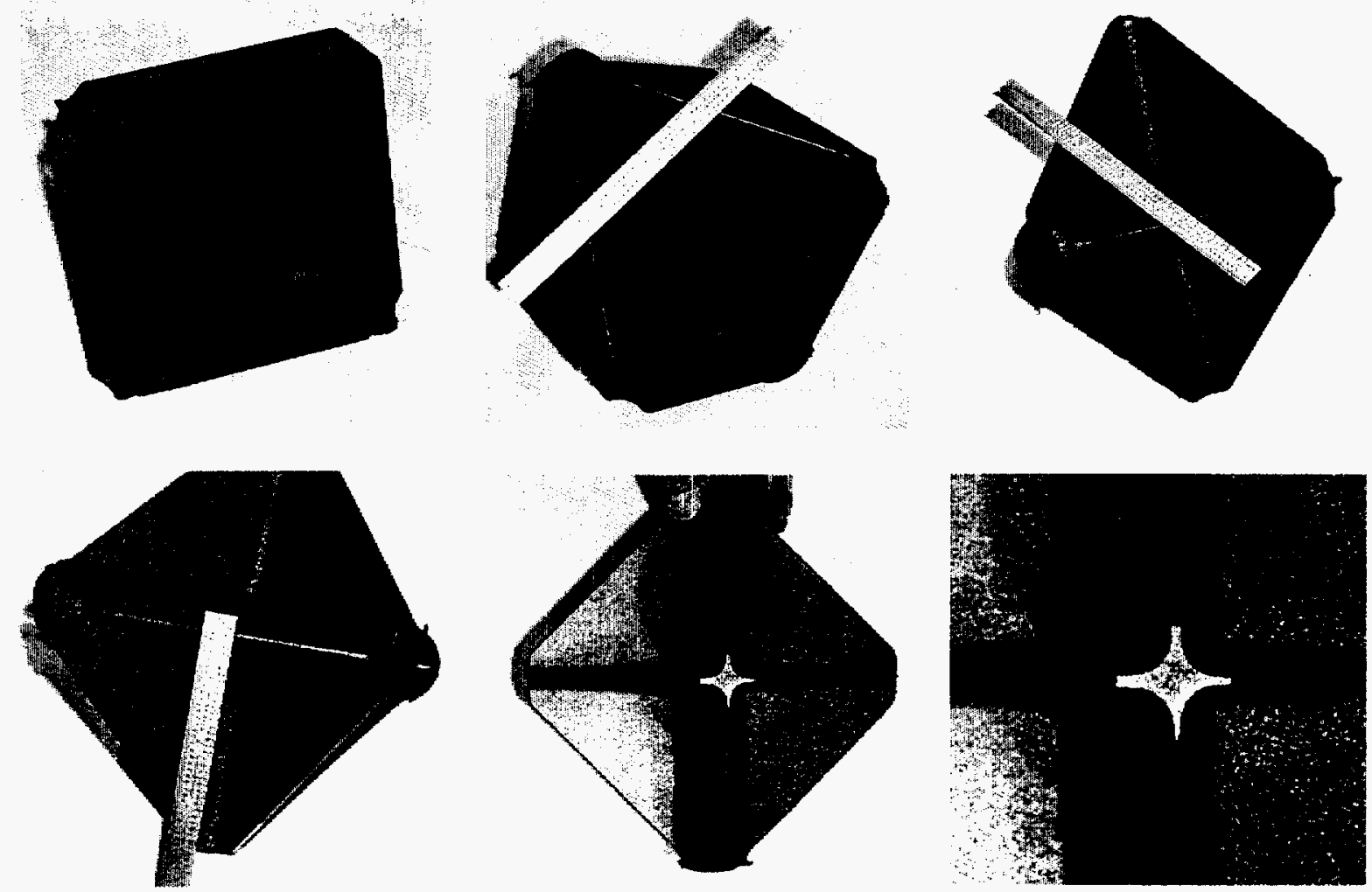

Figure 8: Representative casting
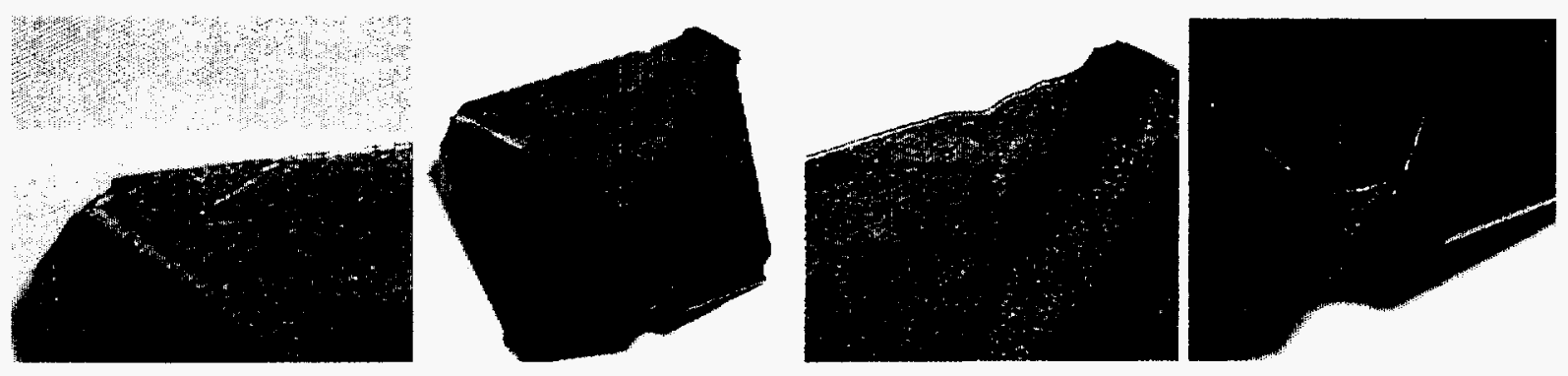

Figure 9: Imperfections in Casting

The round robin study verified, for the most part, the results seen in the Parametric study conducted at CERP. The round robin did indicate that the vertically parted molding machines are more 
successful at reducing variations, as indicated by the fact that the variations in the round robin castings fell between 40 and 60 micrometers while the CERP castings were between 80 and 96 micrometers.

Clay content proved to have less of an impact on variation for the round robin than for the CERP study, but this is likely due to the much higher percentages of clay used in the Disamatic machines than in horizontally parted molding machines. The pouring temperature trends shown in the CERP study were verified in the round robin, and the insensitivity to shakeout time and compactability were also verified.

Proximity to adjacent bulk molten metal was verified with the CERP study as having a significant impact on variation. Some of the mold placement data backed the conclusion that variation is lower in the cope than in the drag, although the horizontal fins showed less variation than those in the CERP study (probably because the gate in the CERP study came in at the horizontal fins, where the gate for the round robin study came up from the bottom of the casting in a more optimized arrangement).

The round robin allowed examination of the effects of metal composition on dimensional variation. In this case, the variation was shown to increase with carbon, phosphorus, and manganese, but decreased with silicon. The variation was also verified to be strongly dependent on point thickness and average web thickness. Flatness was significantly affected by thickness for features less than $3 \mathrm{~mm}$ thick. 


\title{
A Study of the Effects of Mold Placement on Dimensional Variation in Thin Wall Iron Castings
}

\author{
J. F. Cuttino \\ The University of North Carolina at Charlotte, Charlotte, NC \\ A. Kachru, \\ Cummins, Inc., Columbus, IN \\ T.S. Piwonka \\ The University of Alabama, Tuscaloosa, AL
}

Copyright 02001 American Foundry Society

\begin{abstract}
This study examines the impact that position in the mold has on the dimensional variation of thin wall castings. The study was conducted by measuring the dimensional variation of thin features of "star-like" castings poured in a research foundry. The pattern contained six cavities, allowing for comparisons based on location within the mold.

The results clearly show that proximity to adjoining fins has a significant impact on dimensional quality. Dimensional variation increases as the distance from the gating increases, showing its dependence on mold placement. As the distance from the location of merging features increases, the variation decreases. Dimensional variation in the cope is uniform and comparable to the variation in the drag with few exceptions. Variation in the cope fins is less dependent on placement in the mold than the variation in the drag fins. The variation increases toward the center of the casting where the metal flow merges. The variation of the features shows no correlation to the mold hardness.
\end{abstract}

\section{INTRODUCTION}

Cast iron has long been a popular material for production of products in the transportation industry. Since the 1990's, however, demands for improved gas mileage and reduced emissions have led to efforts to reduce weight in castings. Reduction of weight can be achieved in one of two ways, by using lighter materials or by reducing the amount of material necessary in a casting. Numerous works have been published on both accounts (see, for example, Katz, 1997; Moore, 1999; Cuttino, 1999; Belloci and LaGarde, 1987; Bailey, 1981; Dobbener and Best, 1987; Chandley, 1983). These works have documented trends ranging from the use of aluminum and magnesium in engine blocks to alternative molding techniques for iron castings. Many advances have been successfully made, but all have disadvantages, not the least of which are high material and manufacturing costs.

Given the proven history of cast iron produced using green sand molds, the American Foundry Society formed the Thin Wall Iron Group to investigate the feasibility of producing thin wall features in cast iron using the economical green sand molds. The biggest challenges to be met were to determine a) how thin features could be cast while still maintaining structural integrity, and b) how to improve the fabrication of green sand molds to reduce dimensional variations.

This work describes one of three studies conducted to reduce dimensional variations in green sand molds. Many companies have attempted to optimize casting geometry and reduce weight, since castings are often oversized to allot for variations in the manufacturing process. The problem is more difficult, however, than simply taking steps to reduce the amount of "oversizing" designed into castings. As feature thicknesses are reduced, it becomes more and more difficult to control the cooling rates of the castings, resulting in undesirable material characteristics such as the formation of white iron. In addition, variations of ${ }^{ \pm} 1 \mathrm{~mm}$ are not uncommon in thin castings cast in green sand molds. This constitutes a significant amount of unnecessary weight if a feature only requires, for example, $3 \mathrm{~mm}$ of material to be structurally sound. In that case, the specified dimension would then have to be $4 \mathrm{~mm} \pm 1 \mathrm{~mm}$, meaning that many may have $5 \mathrm{~mm}$ thicknesses, $66 \%$ more than the desired $3 \mathrm{~mm}$. This study concentrates on the effect of location within the mold on dimensional variations.

\section{BACKGROUND}

For this mold placement study, articles related to gating flow, sand compositions, compactability, heat transfer, and other related topics were searched. Since thin walled castings constitute a somewhat new trend, few articles were found directly relating to the topic. Those described below are examples of the works found. 
With regard to gating of the mold, numerous works are available. However, those related to dimensional variation and mold placement are limited. Davis and Begg (1992) document pertinent works in the relationships between flow lengths, design of the running system, mold coatings, and metal types. In addition, they emphasize the importance of different sand binders and thermally insulating materials in molding sand composition. Previous studies by other researchers have also shown that its is essential to examine fundamental concepts of alloy fluidity and liquid flow when identifying problems in the production of thin walled castings (Campbell, 1988). A study by van der Graf, et al. (1993), has shown that uniform temperature distribution of the melt and smooth changes in the flow configuration are important for turbulence- free mold filling in thin walled sections. They also point out the importance of mold density, which usually corresponds inversely with the permeability of the mold, and the levels of carbonaceous matter that affect the fluidity levels. All of these parameters have a strong influence on misruns, cold shuts, trapped gases, chilled edges and blow holes in thin wall automotive castings.

One pertinent reference that was found is a technical subcommittee report given at the British Foundrymen Conference in 1971(TS71, 1971). This report presents various factors that influence dimensional consistency in sand castings and the major causes of dimensional variation. The authors present a regression equation relating dimensional consistency and molding layout. The importance of careful pattern design to the prevention of warping and variation in section thickness has also been documented (Unknown, 1970). Moore (1970) provides input for maintaining dimensional accuracy in an eight-step process. No references were found dealing directly with dimensional accuracy and thin wall castings.

\section{EXPERIMENTAL APPROACH}

The molding placement study was conducted at Technikon, LLC (formerly the Cast Emissions Reduction Program) in Sacramento, CA. A single pattern was used and molds were fabricated on a George Fisher DISA horizontally-parting machine. The pattern contained six cavities of the test casting, allowing for comparisons with many parameters such as relative location and proximity to the downsprue.

\section{CASTING USED IN THE STUDY}

Fig. 1 shows the front view of the star casting used in the study, depicting the cope, drag and horizontal parting-line fins. These star-shaped castings were used to bring the green sand up to operating temperature and were therefore designed to have thin sections with high surface area. The castings have 12 fins arranged in a star-like pattern, four of which lie in the cope half of the mold, another four in the drag half and the final four across the horizontal parting line. A total of six nominally similar serials ( 1 through 6 ) are cast in a single mold as depicted in Fig. 2.30 castings from each serial were measured for the study totaling 180 castings.
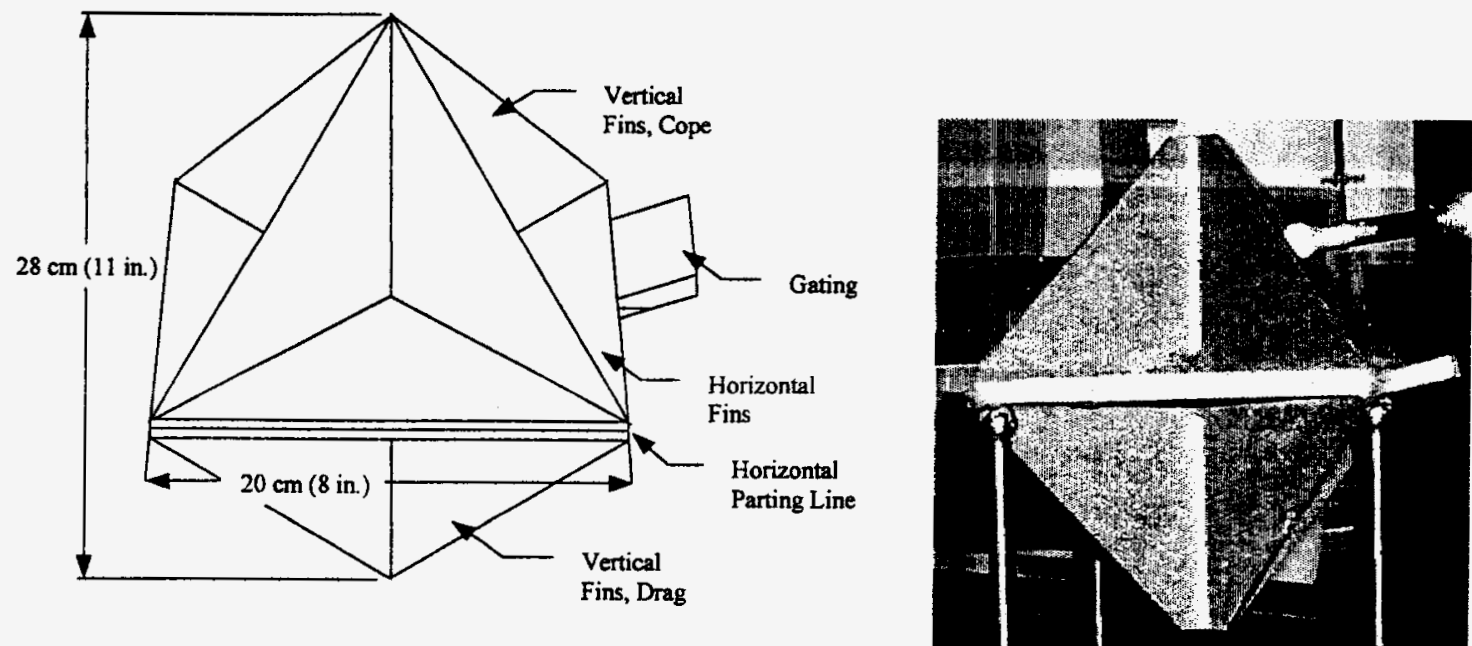

Fig. 1: Outline of the Star Casting showing the Cope, Drag and Horizontal fins. 


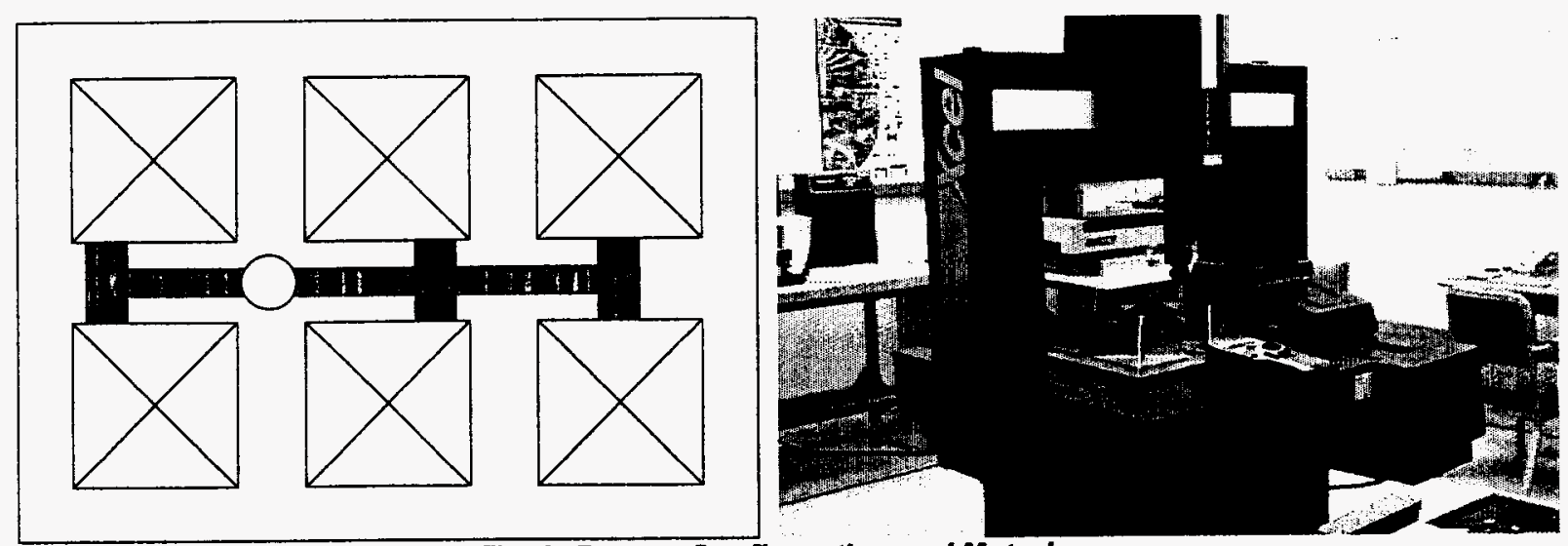

Fig. 2: Pattern Configuration and Metrology

\section{METROLOGY OF THE STAR CASTING}

A Brown and Sharpe $765 \mathrm{Xcel}$ CMM was used for measuring the star castings. Fifteen different probe orientations were required to access the various features on the casting with a PH9 probe head. An $18 \mathrm{~mm}$ ceramic probe tip was used to average out the effects of relatively high roughness values on the star castings. A kinematic fixture was used to restrain the casting in six degrees of freedom on the CMM as shown in Fig. 3.

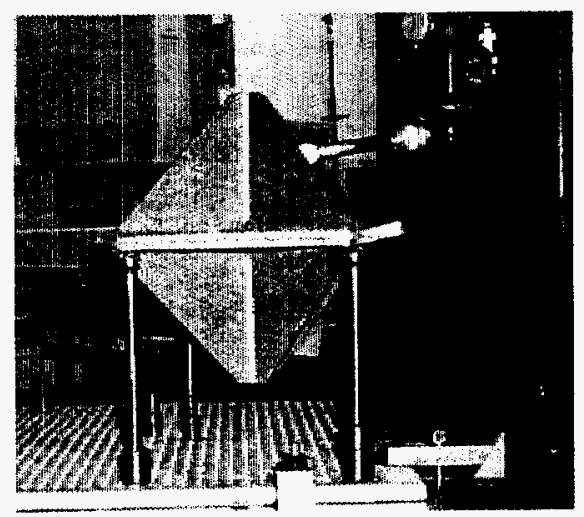

Fig. 3: Setup for the measurement of Star Casting on the CMM

The program measured 108 thickness values at different points on the star casting and wrote them to a file for subsequent analysis in a database. Nine points were measured on each fin as shown in Fig. 4. Out of these nine points, five were measured towards the outer most edge in a nominally straight line. The selection of 5 points along the free plane ensures that up to a forth order deformation can be determined, as shown in Fig. 5. In analyzing the data, all nine points were used for each of the horizontal (parting line) fins, while only the five points (1 and 5-8) were used on the vertical fins to allow the generation of "topographical" maps of the variation.

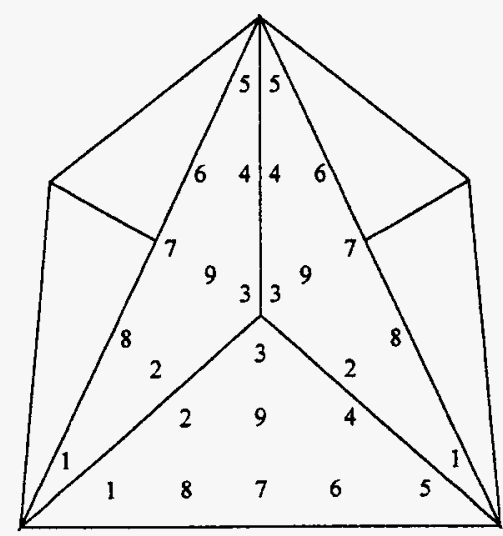

Fig. 4: Locations of the measured points on the test castings

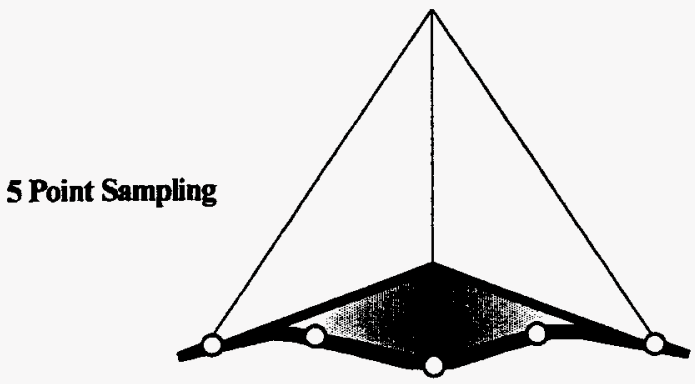

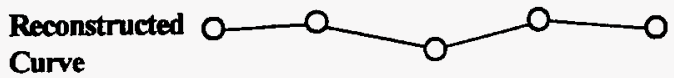

Fig. 5: Possible deformation modes of each web surface 
Experiments were conducted to optimize sampling strategy and a three-point sampling was compared with one point sampling. In three-point sampling, three points surrounding the point of interest are measured and averaged to yield the "calculated" measurement. The advantage to using three-point sampling is that it generally averages out the effects of surface roughness and provides better repeatability. However, in this study, similar filtering was achieved by using an 18 $\mathrm{mm}$ ceramic probe tip in lieu of the standard $6 \mathrm{~mm}$ ruby tip. Since the ceramic tip provided averaging, the benefits of using three-point sampling were minimized. The repeatability using three-point sampling was $5 \mu \mathrm{m}$ while that using one-point sampling was $4 \mu \mathrm{m}$, a difference of only $1 \mu \mathrm{m}$. Since the gain was minimal and the three-point sampling technique more than doubled measurement time, one-point sampling was deemed adequate.

The repeatability of measurements was quite sensitive to the definition of the coordinate system of the casting. A routine was therefore programmed to define the coordinate system off of the part in four steps. In this procedure, an initial coordinate system was identified by operating the CMM in manual mode and touching off of the three balls on the fixture. This initial coordinate system was then verified and modified by repeating the procedure using direct computer control. The part was then placed on the fixture and a new part coordinate system was defined relative to the modified fixture coordinate system under direct computer control. The final coordinate system was established by re-sampling the part using the part coordinate system, thereby providing for iterative improvements in the definition of the coordinate system.

In order to test the machine for its capability of measuring the true value of the measurand, a Gage Repeatability and Reproducibility Study (Gage R\&R) was conducted prior to measuring the batch of 180 star castings. A random sample of 10 stars was selected from the batch of 180 stars and was marked for performing the Gage Repeatability and Reproducibility Study. The results of the analysis are presented in Table 1.

Table 1: Machine Capability Analysis

\begin{tabular}{|l|c|c|c|c|c|c|}
\hline Analysis Description & \multicolumn{2}{|c|}{ Horizontal Point } & \multicolumn{2}{c|}{ Vertical Fin-1 Point } & \multicolumn{2}{c|}{ Vertical Fin-2 Point } \\
\cline { 2 - 7 } & $\mu \mathrm{m}$ & $(\%)$ & $\mu \mathrm{m}$ & $(\%)$ & $\mu \mathrm{m}$ & $(\%)$ \\
\hline Repeatability & 14.7 & 2.6 & 19.5 & 6.6 & 21.1 & 4.8 \\
\hline Reproducibility & 6.8 & 1.2 & 5.8 & 2.0 & 4.0 & 0.9 \\
\hline $\begin{array}{l}\text { Repeatability \& } \\
\text { Reproducibility }\end{array}$ & 16.2 & 2.9 & 20.3 & 6.9 & 21.5 & 4.8 \\
\hline Part Variation & 556.7 & 99.96 & 293.4 & 99.76 & 444.7 & 99.8 \\
\hline Total Variation & $\mathbf{5 5 6 . 9}$ & & 294.0 & & 445.2 & \\
\hline
\end{tabular}

A worst case Repeatability and Reproducibility of the order of $21.5 \mu \mathrm{m}$ was observed for one of the vertical fins. The goal of the study was to control the dimensional variation to within $\pm 0.5 \mathrm{~mm}$. A sampling accuracy of $50 \mu \mathrm{m}$ in measurement uncertainty was deemed appropriate, representing an order of magnitude improvement.

\section{RESULTS}

Fig. 6 shows the standard deviations of the horizontal surfaces. The graph depicts the four horizontal surfaces of each of the six serials, 1 through 6 . The peak of each of the stars towards the center shows that the standard deviation is maximum in the center, due mostly to severe burn-in that occurred on the castings near the junction of the various surfaces.

Fig. 6 shows that Serial No.5 had the lowest dimensional variation of the surface, peaking at $412 \mu \mathrm{m}$. For comparison, Serial No. 2 had a peak value of $511 \mu \mathrm{m}$. An interesting trend is that Serials 1,2 and 3 collectively had higher variation, and all of these are on one side of the mold. Also the stars that had center gating (Serial No.'s 1 and 4) had collectively lower average variations (particularly if the points located near the junction of the fins were neglected) than stars with gating located on one end of the castings (Serials 2,3,5, and 6). Again, Serials 2 and 3, the castings with gating oriented towards one end of the castings, had higher variations than the rest of the stars, even when the center points were neglected. 


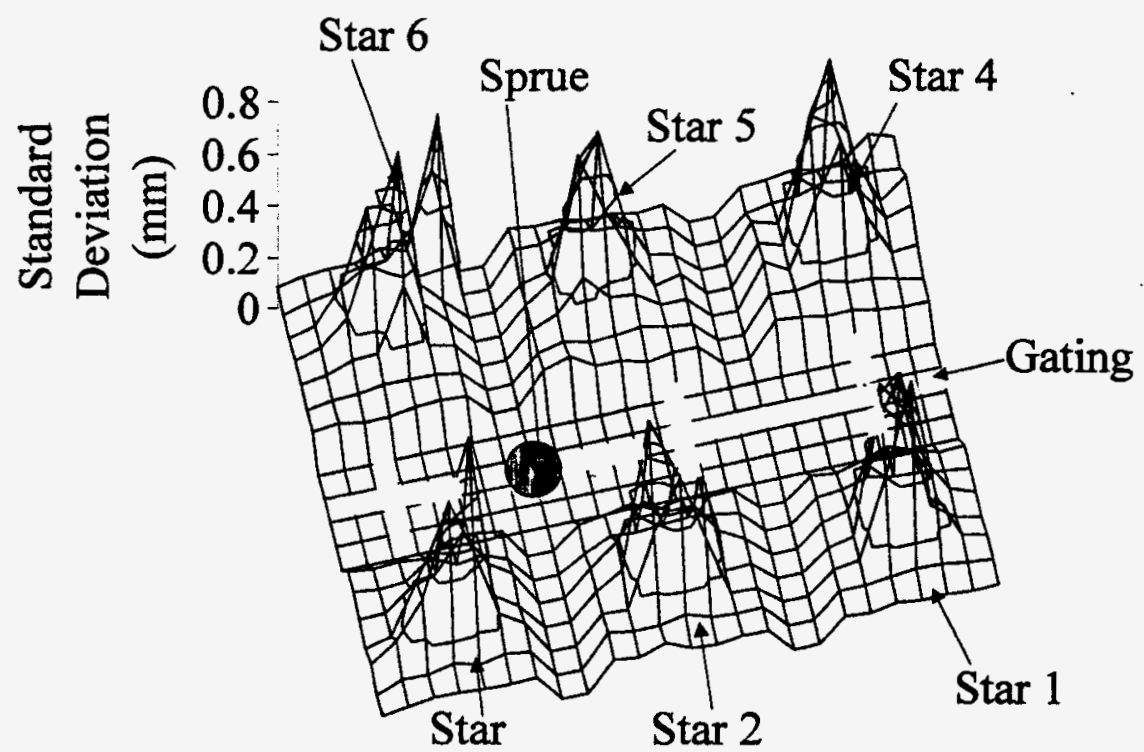

Fig. 6: Variation of points on horizontal parting line fins

Fig. 7 shows the variation of the thicknesses along the free edges of the vertical fins located in the drag as a function of location in the mold. The spread of the data is large, with extreme peaks of $732 \mu \mathrm{m}$ and $250 \mu \mathrm{m}$ (on Serials 5 and 6), but nominal peaks of less than $100 \mu \mathrm{m}$ at most other locations. The graph shows that Serials 1,2 , and 3 have lower variations overall than Serials 4,5, and 6, a trend that is opposite that noted for the horizontal fins. Examination of the path of metal flow through Serials 4,5 , and 6 indicates that the portions of the castings requiring the longest metal flow path have greater variation as well. For example, the very high peak shown on Serial 6 is located at the farthest point from the sprue since the gate is located on the side nearest the mold edge. This result is less obvious for Serials 1 through 3.

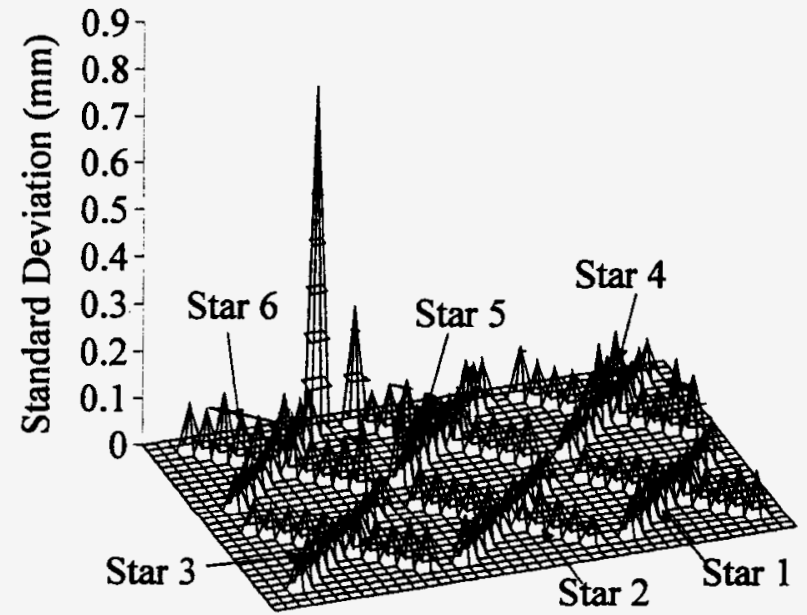

Fig. 7: Variation of the thicknesses along the free edges of the vertical fins (drag)

Fig. 8 shows similar variations for the vertical fins located in the cope. The most notable result here is that the cope contains nominal variations of around $85 \mu \mathrm{m}$, similar to those for the drag with the exception of the excessively high peaks caused by erosion and other mold dynamics. It is apparent from Fig. 7 and Fig. 8 that the errors increase as one approaches a junction between fins, a result that is intuitive. The Fig. also seems to indicate that fins located in the cope are less dependent on gating placement, since the variation seems somewhat uniform over the whole mold. 


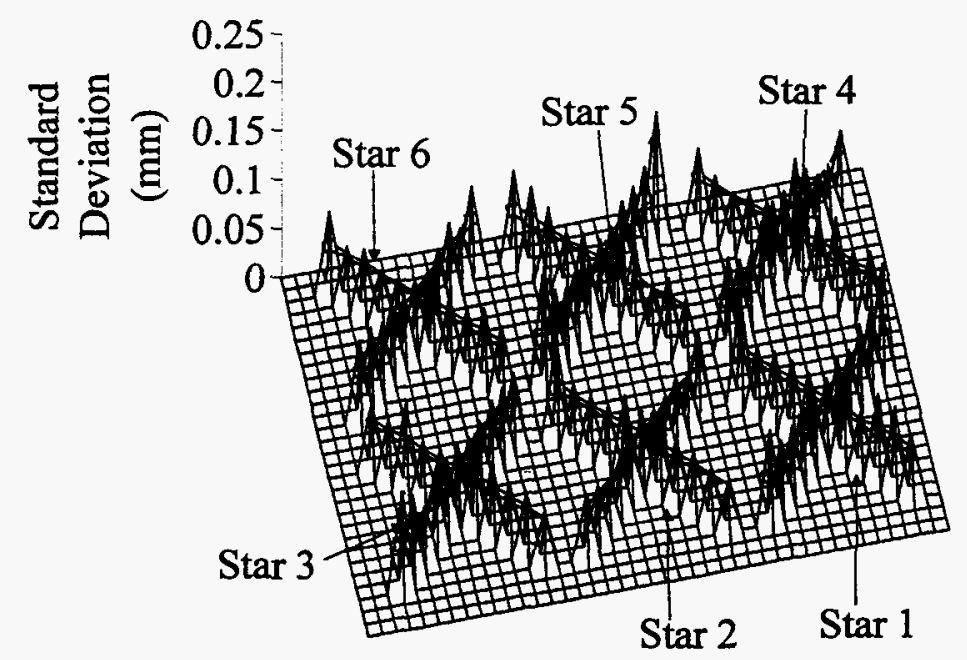

Fig. 8: Variation of the thicknesses along the free edges of the vertical fins (cope)

\section{FIN JUNCTION EFFECT}

An analysis was conducted to examine the effects of proximity of nearby adjoining features with larger cross-sections on dimensional variation. The relationships were examined twice, once as a function of the radial distance from the center of the casting (and location of the largest cross-sectional area) and once as a function of distance from adjoining features.

Fig. 9 shows the relative locations of the sampled points with respect to the radial distance from the center of the casting on the horizontal, parting-line surface. The measured thicknesses at a common radial location were averaged to obtain a single representation of variation for each of the six serials. The results are shown in Fig. 10. The results were conclusive, showing a strong dependence on the proximity of thick-sectioned areas.

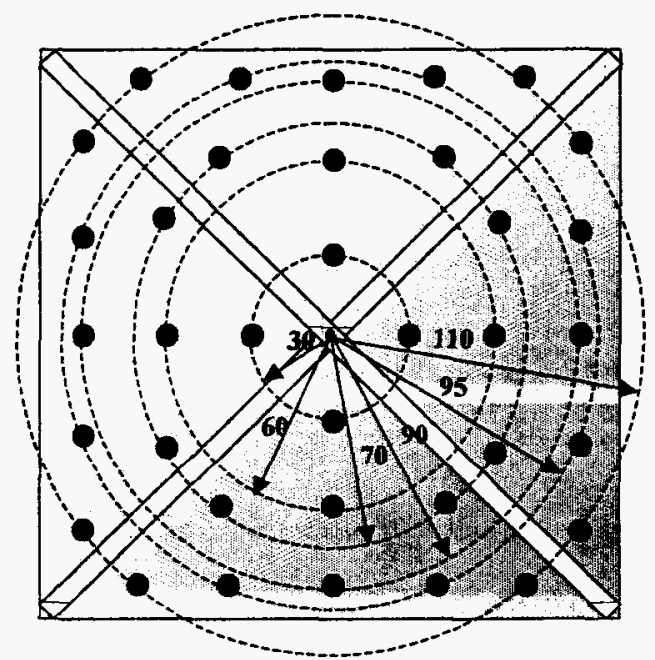

Fig. 9: Location of points on the horizontal parting line surface 


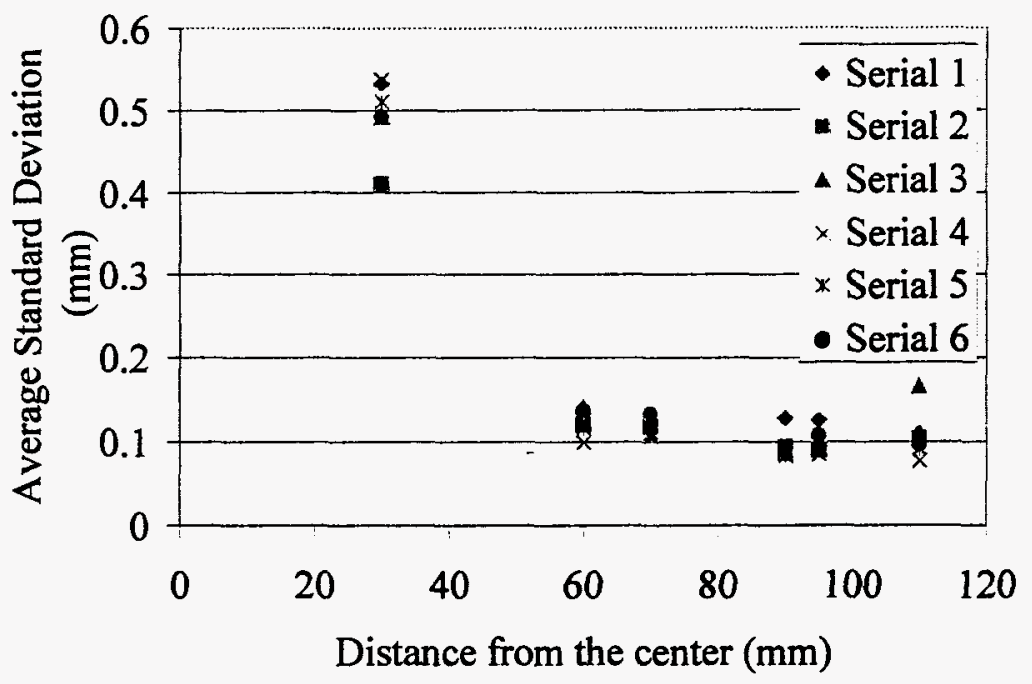

Fig. 10: Variation of the averaged horizontal surface locations for the six serials

Fig. 11 represents the average of the 6 values (representing 6 serials) plotted in Fig. 10. The location at a distance of $30 \mathrm{~mm}$ from the center of the casting has the highest variation at $0.5 \mathrm{~mm}$. This high value is likely due to the presence of the burn-in material on some star castings near the junction. As the location distance increases to 60,70 and $90 \mathrm{~mm}$, the variation continues to decrease with values of $0.125,0.118$ and $0.095 \mathrm{~mm}$ respectively. As the distance increases to 95 and $110 \mathrm{~mm}$, the variation shows a very slight increase to 0.1 and $0.108 \mathrm{~mm}$ respectively. In general the variation decreases as the location of the averaged thicknesses from the center of the casting increases. It should be noted, however, that the points located at 90 $\mathrm{mm}$ from the center are nearer to an adjacent fin than the rest. This indicates that the variation is a function of at least two parameters, a) the distance from the center of the casting (where the largest amount of bulk material is present and b) the distance from any adjoining feature.

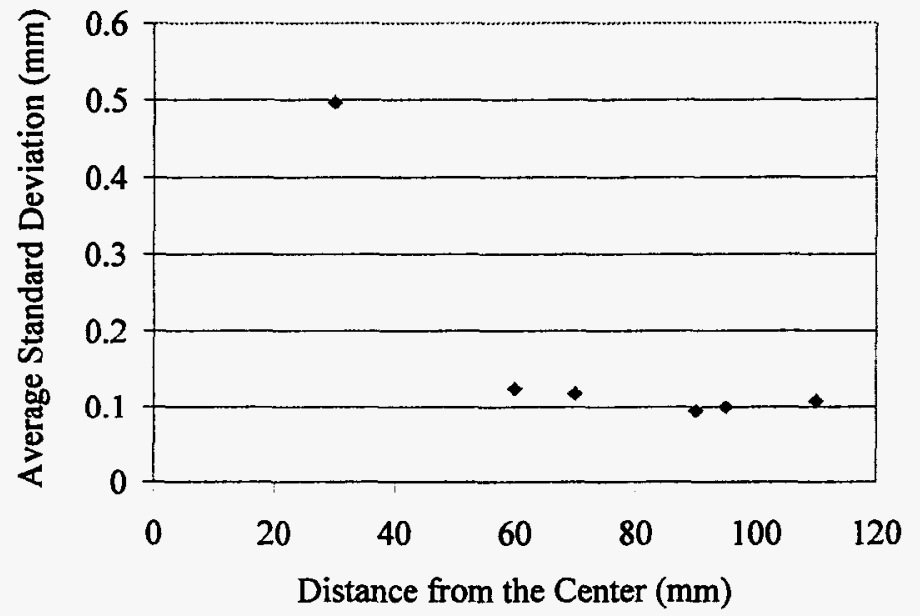

Fig. 11: Variations of horizontal parting line locations at increasing distance from the junction

Fig. 12 represents the variation of thickness at the various locations measured on the horizontal fins as a function of the perpendicular distance from the adjacent fin. The distances of the points from the adjacent fins for one horizontal fin are shown in Fig. 13. Intuitively, the two adjacent fins should have a stronger effect on the points closest to the center of the casting. Therefore an "effective" distance was arbitrarily chosen to be the square root of the perpendicular distance from the two adjacent fins. The values for points that are equidistant from the adjacent fins were averaged. The high value of deviation at a distance of $7 \mathrm{~mm}$ from the adjacent fins is due to the presence of burn-in material at that location. The variations at distances of 21,42 , and $63 \mathrm{~mm}$ are $0.113,0.112$ and $0.095 \mathrm{~mm}$, respectively. The variation continues to decrease as the distance of a point from its adjacent fin increases. 


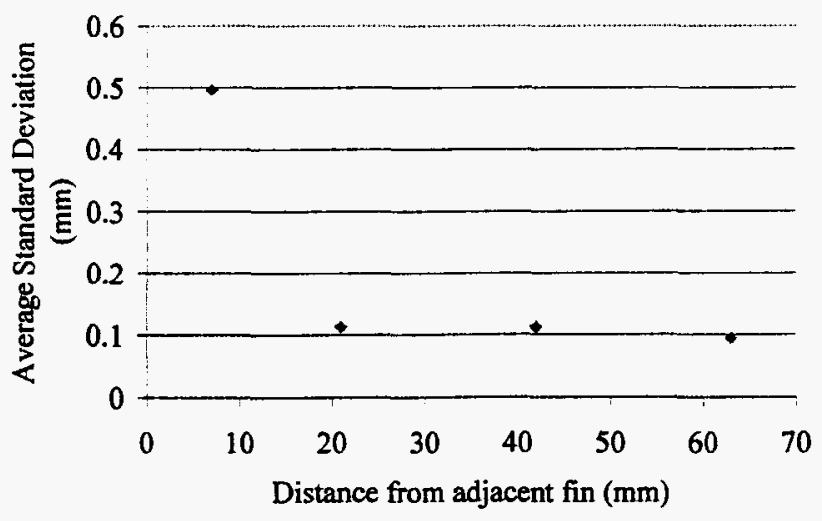

Fig. 12: Variation of locations on horizontal surface as a function of distance from adjacent fins

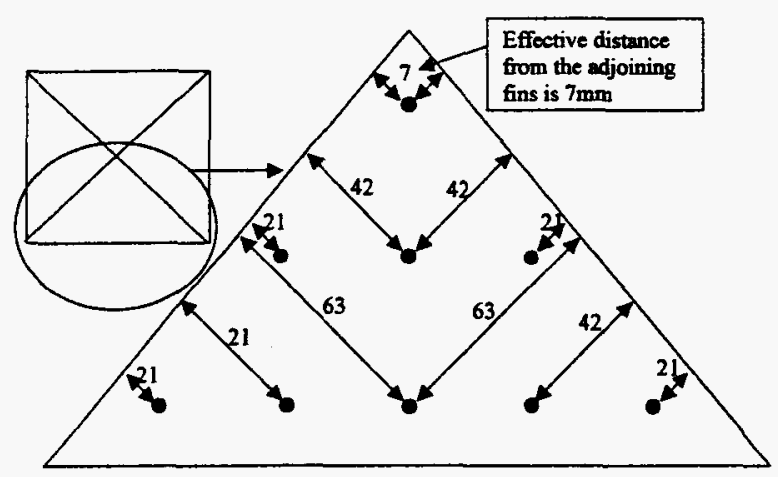

Fig. 13: Distance of points on a single fin of horizontal parting line surface from its adjacent fins

The vertical fins were analyzed by examining only the points along the outer edge of the fins in order to facilitate graphical analysis of the data. The values are averaged for the six serials. The locations are illustrated in Fig. 14. Point 1 is located adjacent to the junction of the four drag fins, and Point 5 is located nearest to the junction of the horizontal parting line and the vertical drag fins. Locations represented by points 2, 3 and 4 are on the outer edge of the drag fins.

Fig. 15 illustrates the averaged dimensional variation for the drag. Point 5 has the highest variation of $0.122 \mathrm{~mm}$ and is nearest to the junction of the parting line and drag fins. Point 1 , located at the bottom of the mold and at the point where the 4 vertical fins join also exhibits a large variation of $0.090 \mathrm{~mm}$. Points 2,3 and 4 have the lowest variations of $0.079,0.085$ and $0.083 \mathrm{~mm}$, respectively. They are also the farthest away from the junction of the parting line fins and the drag fins. In general the variation of a location decreases as the distance from adjacent fins increases.

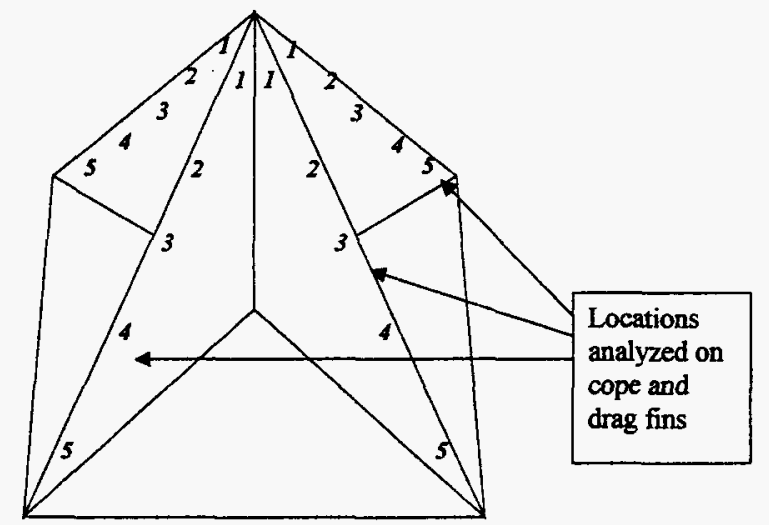

Fig. 14: Location of features on Cope and Drag Fins

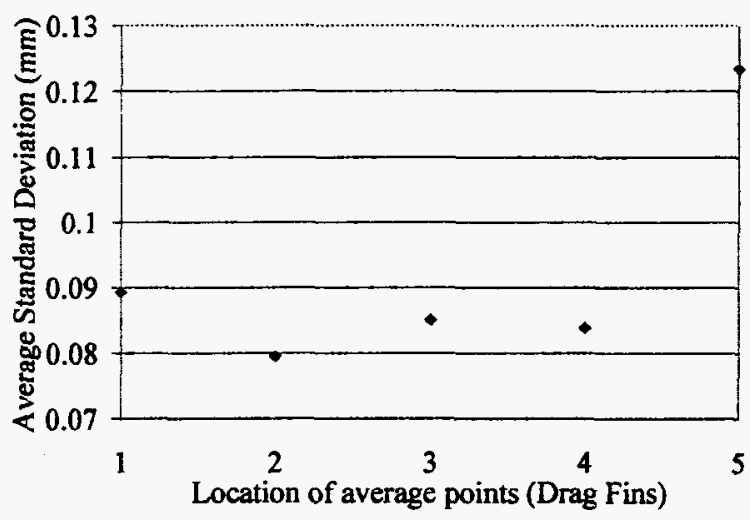

Fig. 15: Variation at different distances from the junction of fins in Drag (Refer to Fig. 14)

Fig. 16 plots the dimensional variation as a function of distance from any adjacent fin. Note that points 1 and 5 are equidistant from adjacent fins $(15 \mathrm{~mm})$ as are points 2 and $4(40 \mathrm{~mm})$. Points 1 and 5 show the largest variations, with 0.089 $\mathrm{mm}$ and $0.123 \mathrm{~mm}$, respectively. These values are significantly higher than the variations of the features at distances greater than $40 \mathrm{~mm}$. For example, points 2 and 4 exhibit variations of only $0.079 \mathrm{~mm}$ and $0.083 \mathrm{~mm}$, respectively. As the distance increases further there is no appreciable change in variation. 


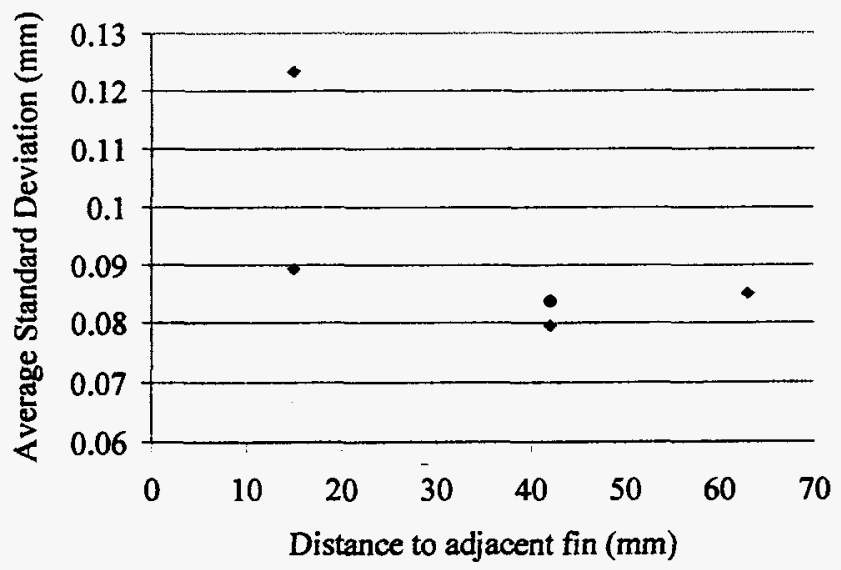

Fig. 16: Variation of drag as a function of distance from the adjacent fin

Fig. 17 shows similar results for the cope. Again, point 5 has the highest variation at 0.083 mm and is nearest to the junction with the parting line fins. Point 1 has a variation of $0.074 \mathrm{~mm}$ and is also near the junction of the cope fins. Points 2,3 and 4 have the lowest variations and are further away from adjoining features. Fig. 18 verifies this relationship in a plot of the variations as a function of their distance from adjacent fin. Clearly, the variation decreases nonlinearly as distance from adjoining features is increased.

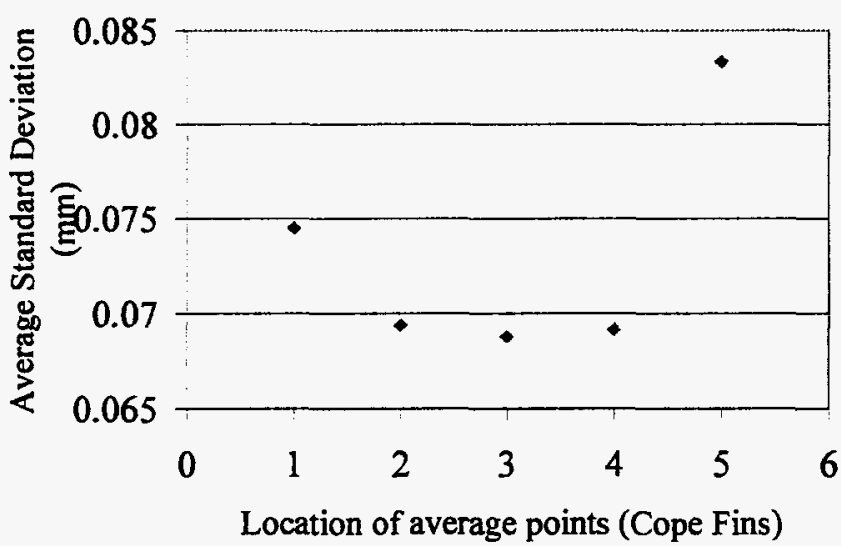

Fig. 17: Variations at different distances from the junction of fins in Cope (Refer to Fig. 14)

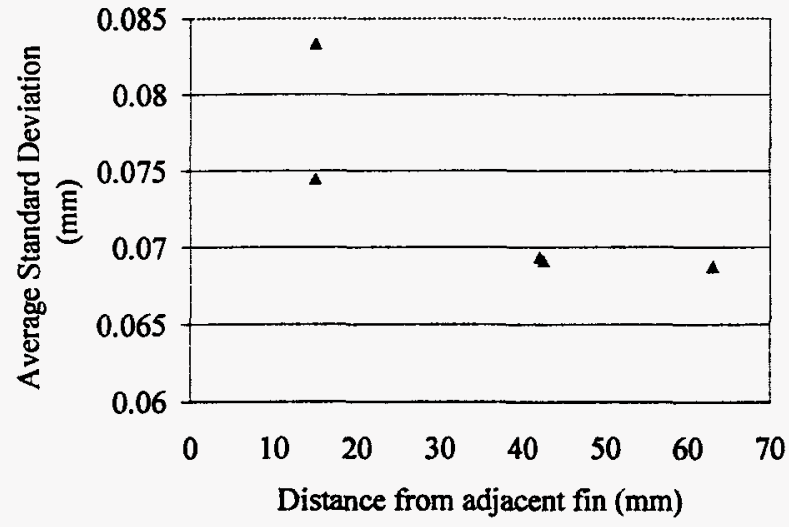

Fig. 18: Variation of cope as a function of distance from the adjacent fin

The results from the three graphs for the horizontal parting line, cope and the drag have been combined in Fig. 19. The high variation of $0.5 \mathrm{~mm}$ in the case of the horizontal parting line fins is for the location near the junction of the fins. Again the variation of the locations decreases with increasing distance.

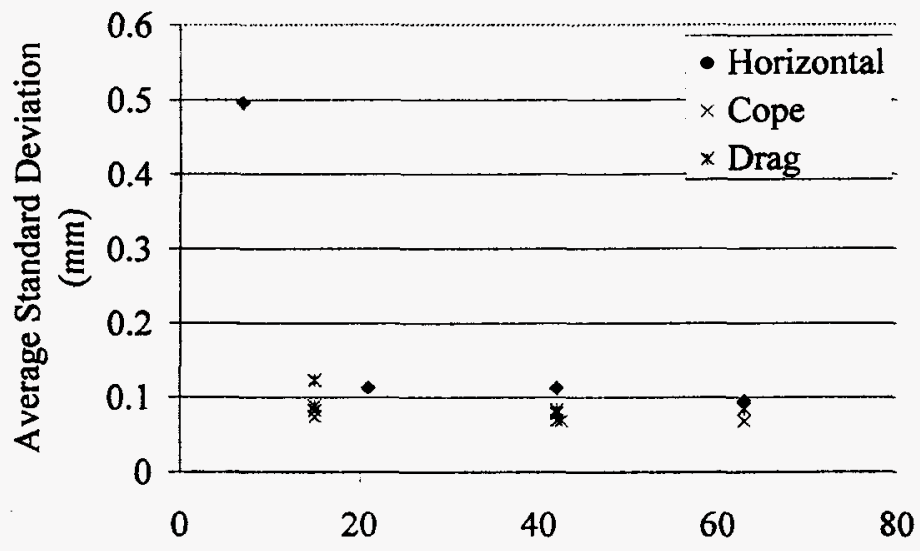

Distance to adjacent feature

Fig. 19: Variation of horizontal parting line, cope and drag fins as a function of distance from adjacent fins 
An analysis of the localized mold hardness values was conducted to determine if the mold hardness had a direct effect on the variation. Fig. 20 represents the values for the mold harness at various locations on the horizontal parting line surface. The accompanying graph shows the variation of the features on the horizontal surface. The finer the grid in Fig. 20 the higher the variations at that location of the mold. The mold hardness numbers were recorded at twenty locations around the six serials in the mold as shown. Five of the locations were on the cavity created by the gating. The mold hardness numbers show no apparent correlation with the variation of the horizontal surface of the castings.

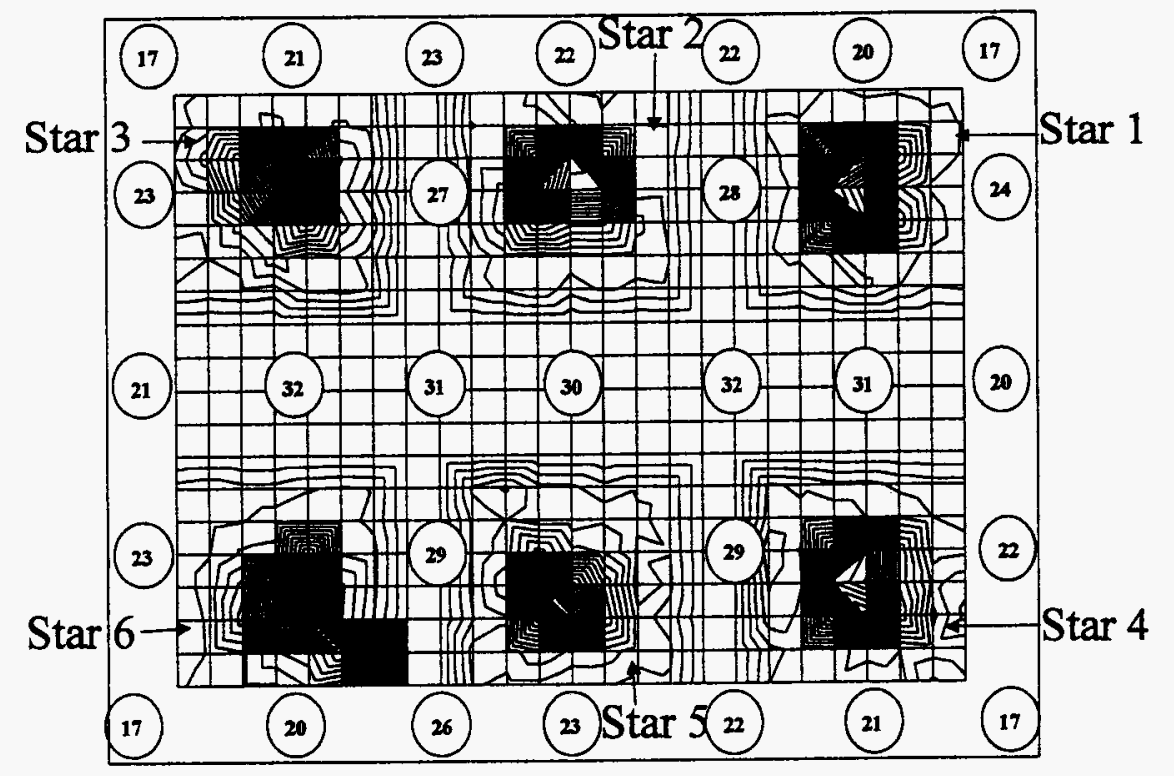

Fig. 20: Hardness of the mold at various locations of the horizontal parting line surface

\section{CONCLUSIONS}

Dimensional variation tends to increase as the distance from the gating increases, showing its dependence on the placement in the mold. As the distance from the location of merging features increases the variation decreases. The dimensional variation in the cope is generally uniform and slightly lower than the variation in the drag. The variation in the cope appears to be less dependent on placement in the mold than in the drag. The variation increases toward the center of the casting where the metal flow merges. The result is exaggerated because of the presence of burn in contributing highly to the dimensional variation. The variation of the features shows no correlation to the mold hardness at that location.

\section{ACKNOWLEDGE MENT}

This project was funded partially by Cooperative Agreement DE-FC07-98ID13612 with the United States Department of Energy. The opinions expressed in this paper are those of the authors and not necessarily those of the Department of Energy. The authors would like to thank the US DOE, the Thin Wall Iron Group of the American Foundry Society, and particularly the Molding Capability Steering Committee. In addition, special thanks are due to Technikon, LLC (formerly the Cast Emissions Reduction Program, CERP) for providing the castings and data for the study.

\section{REFERENCES}

Bailey, R., "Thin Wall Casting Program Spells Success for Holmes Foundry," Modern Casting 71 (12), 37-39, 1981.

Belloci R., and Y. Lagarde, "FM: A New Iron and Steel Casting Process," Modern Casting 77 (12), 26-28, 1987.

Campbell, J., "Thin Wall Castings," Material Science and Technology 4, $194-204,1988$.

Chandley, G.D., "Automatic Counter Gravity Casting of Shell Molds," AFS Transactions 23, 199-203, 1983.

Cuttino, J.C., J. R. Andrews, and T. S. Piwonka, "Developments in Thin - Wall Iron Casting Technology," AFS Transactions 99, 363-372, 1999.

Davis, J.L., and J. Begg, "Dimensional accuracy and mechanical properties of thin section grey iron castings," in BCIRA Technology, pp. 10-12, 1992. 
Dobbener, R., and K. J. Best, "Foundry Experiences In The Use Of Late Mould_Inoculation for Production of Thin Walled S.G. and C.G. Iron Castings," presented at the The Next 40 years - BCIRA Conference, University of Warwick, Apr 7 9, 1987.

Kachru, A., Molding Capability Study for Thin Wall Iron Castings, Master's Thesis, University of North Carolina at Charlotte, 2001.

Katz, S., "Thin Wall Iron Castings - Planning the Future," Foundry Management \& Technology, pp. 34-36, 1997.

Moore, C.M., K. Rouhrig, and R. Deike, “Auto Aluminum, Is it really cost effective?" Foundry International, pp. 37-42, 1999.

Moore, V.H., "Thoughts on the Dimensional Accuracy of Castings," Casting Engineering, v 2, n 4, pp. 11-12, 14,16,18, 1970.

Peters, F.E., R. Velaga, and R.C. Voigt, "Assessing Dimensional Repeatability of Metalcasting Processes," AFS Transactions 224, 181-190, 1996.

TS71 Subcommittee, "Second Report of Technical Sub-Committee TS71- Dimensional Tolerances in Castings," British Foundrymen Conference, Abstract No. 19710685, 1971.

Unknown author, "Some Notes on the Dimensional Stability of Gray Iron Castings," Casting Engineering, pp. 21-22, Abstract No. 19700402, 1970.

van der Graf, G., H. E. A. van der Akker, and L. Katgerman, "Flow Phenomenon of Mould Filling for Thin Wall Castings," 60th World Foundry Congress, Netherlands, 1-9, 1993. 


\title{
A Parametric Study of the Effects of Casting Parameters on Dimensional Variation in Thin Wall Iron Castings
}

\author{
J. F. Cuttino \\ The University of North Carolina at Charlotte, Charlotte, NC \\ A. Kachru, \\ Cummins, Inc., Columbus, IN \\ E. Morse, S. Patterson \\ The University of North Carolina at Charlotte, Charlotte, NC \\ T.S. Piwonka \\ The University of Alabama, Tuscaloosa, AL
}

Copyright $\bigcirc 2001$ American Foundry Society

\section{ABSTRACT}

The effects of four foundry parameters on the dimensional variation and the nominal dimension of thin wall iron castings are presented. A design of experiments was conducted to determine the impact that changes in clay content, pouring temperature, sand compactability in the mold, and shakeout time had on the dimensional quality of castings. The study was conducted using a six-on "star-shaped" casting fabricated at an experimental foundry.

Results show that different casting parameters have dominant effects on dimensional variations in the cope, across the parting line, and in the drag. In the cope, clay content was the most significant factor affecting dimensional variations. In contrast, pouring temperature is shown to be the dominant factor in the drag.

Clay content has the highest effect on the nominal dimension in the cope and drag, while pour temperature is dominant across the parting line. Increases in clay always increased the nominal dimensions, but increases in pour temperature decreased the nominal dimension.

Results are presented for each parameter in terms of dimensional variation and nominal dimension. Conclusions are also presented to give the foundryman design rules to reduce variation in thin wall castings.

\section{INTRODUCTION}

Cast iron has long been a popular material due to the many advantages it provides both in material properties and ease of production. Despite its many advantages, however, the demand for cast iron has declined recently due to the need to reduce weight in automotive applications. Components such as engine blocks and suspension members have been replaced with materials such as aluminum in efforts to reduce casting weight.

In many of these applications, weight reductions have been realized at the cost of other desirable mechanical properties. Properties of cast iron that make it desirable include high proof stress, stiffness, wear resistance, damping capacity, and fatigue life. The coefficient of thermal expansion of cast iron is lower than that of aluminum and is comparable to steel, making it particularly advantageous in assemblies where components must be rigidly attached to steel. The nation's capacity to produce cast iron is well established, particularly for green sand molding facilities (Katz 1997, Moore 1999).

Although aluminum has a density $40 \%$ that of cast iron, design factors including fatigue life and stiffness often dictate that component dimensions be significantly increased, thereby diminishing the benefits of lower densities. Although weight savings as high as $35 \%$ have been reported by some in the automotive engine community, others have found little or no weight savings to counter the order of magnitude increase in production costs. Manufacturers of diesel engines have experienced significant disadvantages in aluminum due to the extreme heat and compressions involved. These factors led to the formation of the Thin Wall Iron Group (TWIG) of the American Foundry Society (AFS) to study the feasibility of reducing weight in iron castings by improving dimensional control and curtailing practices of "overdesign."

Efforts to produce thin-wall iron castings repeatably have been numerous and are well-documented. Cuttino et al. (1999) provide a review of numerous efforts to produce thin wall castings. Several other processes have been developed to manufacture thin wall iron castings and are documented by Stroebel (1993), Dobbener (1987), Chandley (1983), 
Okamura (1999), Binichi (1999), and Hornung (1995). Many of these studies represent significant departures from traditional green-sand molding techniques.

Previous studies have tested different parameters that play a role in affecting dimensional variability. Davis and Begg (1992) have shown that different sand binders and thermally insulating materials play a significant role in casting variations. Peters, et al. (1996) identified feature length and casting weight as important parameters in controlling dimensional repeatability; however, it is unclear as to whether these parameters were the primary factors or secondary affects of other factors. Engler et al. (1973) examined how progressive movement of the mold and metal surfaces during pouring, cooling and solidification influence the mold cavity and subsequently dimensional accuracy. Stefanescu et al. (1979) and Hummer (1984) have both examined mold wall movement in the mold cavity by measuring displacement of the walls using displacement sensors. Winter, et al. (1984) studied gap formations in cast iron. The question of how much pressure is exerted by the expanding iron was investigated by El-Ashram (1971), and Yang and Alhainen (1992) measured the expansion of ductile iron. Gedeonova $(1991,1996)$ explored movement of the casting-mold interface during solidification of nodular graphite cast iron. Viets et al. (1999) attempted to study the solidification process by observing the infrared signature of the mold during solidification. Unfortunately, this process was subject to measurement inaccuracies and lack of resolution due to the thermal inertia of the mold itself.

This paper describes the first in a series of studies aimed at optimizing the production of green sand molds for thin wall iron castings. In this study, the effects of changes in process parameters on the dimensional variation and the nominal dimension were examined using castings produced at Technikon (formerly the Cast Emissions Reduction Program, CERP), a research foundry located in Sacramento, CA. Four principal foundry parameters were identified that were considered to have the largest effect on casting variations and that were controllable in the research foundry. A design of experiments was conducted, and resulting dimensional variations analyzed. The results are presented in this paper.

\section{EXPERIMENTAL PROCEDURE}

\section{TEST ARTIFACT}

The "test artifact" used in the study was a star casting with a high surface area to volume ratio as illustrated in Fig. 1. The castings consist of 12 thin webs, four of which are in the cope side, four in the drag side and four across the horizontal parting line. The nominal dimension of the horizontal surfaces across the parting line is $12.5 \mathrm{~mm}$. The vertical fins are drafted at $3^{\circ}$ and have a nominal dimension at the edge of $6 \mathrm{~mm}$. The castings are made in green sand molds and are used to test the effects of changing the process parameters under controlled conditions on emission levels.
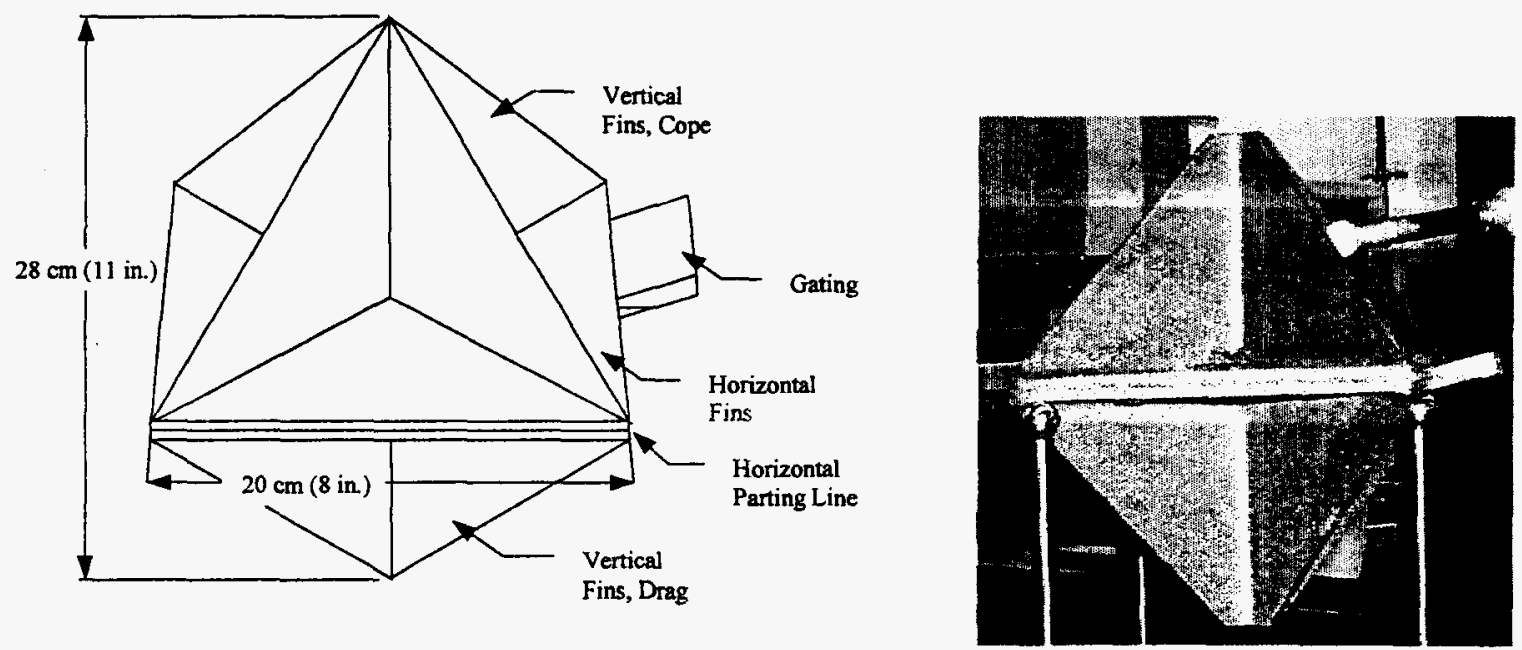

Fig. 1: Outline of the Star Casting showing the Cope Side, Drag Side and Horizontal Parting line fins.

\section{METROLOGY OF THE STAR CASTING}

A Brown and Sharpe 765 Coordinate Measuring Machine (CMM) with a volumetric performance of $10 \mu \mathrm{m}$ was used to measure the castings. A CNC program was written in QUINDOS, a versatile and powerful CMM language. A Renishaw indexable PH9 probe head was used for the various probe orientations and an $18 \mathrm{~mm}$ ceramic probe tip was used to 
average out the effects of relatively high roughness values on the test parts. A kinematic fixture was used to restrain the casting in six degrees of freedom on the CMM. The fixture is shown in Fig. 2. It consists of three precision balls mounted on posts. Each ball contacted the casting on two orthogonal sides constraining motion on all degrees of freedom.

For this study, a single thickness was measured on each of the 12 fins on the casting and was considered to be representative of the variations of that fin. The points were measured midway between the vertices of each fin along the outermost edge as shown in Fig. 3. The program output the data into a file where they could be downloaded and opened in a spreadsheet for analysis.

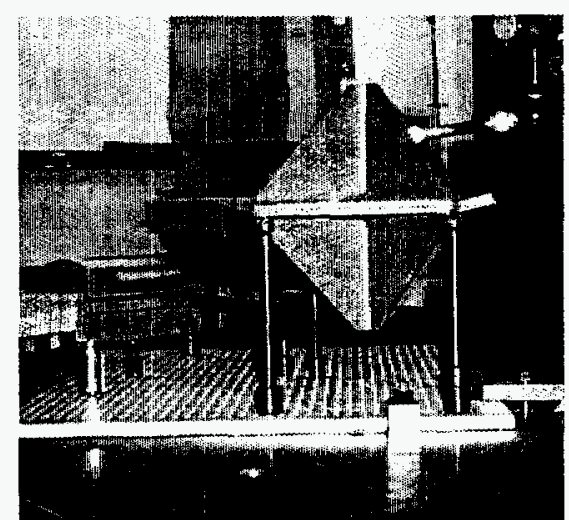

Fig. 2: Setup for the measurement of Star Casting on the CMM

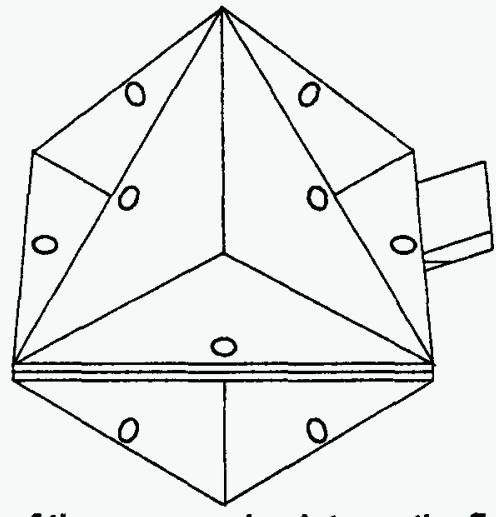

Fig. 3: Locations of the measured points on the fins of the castings

Experiments were conducted to optimize sampling strategy. Because of the high surface roughness of the castings, experiments were conducted to compare three-point sampling to one-point sampling. In three-point sampling, three points surrounding the point of interest are measured and averaged to yield the "calculated" measurement. The advantage to using three-point sampling is that it generally averages out the effects of surface roughness and provides better repeatability. However, in this study, similar filtering was achieved by using the $18 \mathrm{~mm}$ ceramic probe tip in lieu of the standard $6 \mathrm{~mm}$ ruby tip. Since the ceramic tip provided averaging, the benefits of using three-point sampling were minimized. The repeatability using three-point sampling was $4 \mu \mathrm{m}$ while that using one-point sampling was $5 \mu \mathrm{m}$, a difference of only $1 \mu \mathrm{m}$. Since the gain was minimal and the three-point sampling technique more than doubled the measurement time, one-point sampling was deemed adequate.

Metrology of the castings was also found to be quite sensitive to definition of the coordinate systems. Therefore a fourstep routine was programmed to define the coordinate system with respect to the part. In this procedure, an initial coordinate system was identified by manually operating the CMM to locate the three balls on the fixture. This initial coordinate system was then verified and modified by repeating the procedure using direct computer control (DCC). The part was then placed on the fixture and a new part coordinate system was defined relative to the modified fixture coordinate system under direct computer control. The final coordinate system was established by re-sampling the part using the part coordinate system, thereby providing for iterative improvements in the definition of the coordinate system. 
The measurement criteria, established prior to the study, were based on the goal of achieving castings with dimensional variations of less that $0.5 \mathrm{~mm}$. Given that specification, it was determined that an order of magnitude improvement in measurement accuracy, or 50 micrometers, would be adequate for a target accuracy.

The CMM performance was first verified using standard calibration procedures from the ASME B89 standards including the 49 point-to-point probing performance test, multiple tip probing performance test, an XXX ring gage test, and a repeatability study. A worst-case uncertainty of $20 \mu \mathrm{m}$ was observed in the setup, which was well below the specified criterion of $50 \mu \mathrm{m}$.

Gage Repeatability and Reproducibility studies were also conducted in order to test the capability of the CMM to consistently measure the casting features compared to the required accuracies (since this is greatly affected by the part being measured). The purpose of a Gage R\&R analyses is to decouple the instrument's ability to reproduce a measurement from variable operating conditions and the actual variations in the work piece. The technique is standard practice in industry and is based on a statistical analysis of a regimented sampling sequence of a small population. Repeatability determined by the Gage R\&R analysis yields information concerning the ability of the CMM to repeat a measurement accurately under the same conditions of measurement. Reproducibility measures the influence that variable conditions have on the measurements. The repeatability and the reproducibility value (Gage $R \& R$ ) is a combination of the various errors, and is useful for distinguishing from the variation in the part and the variation in the measuring process.

A random sample of 10 castings was selected from a batch of 160 castings measured and was marked for performing the Gage Repeatability and Reproducibility Study. Three points located on different, orthogonal fins were used for the Gage $R \& R$ tests, one on a horizontal fin, and 2 on vertical fins. The results of the analysis are presented in Table 1.

Table 1: Machine Capability Analysis

\begin{tabular}{|l|c|c|c|c|c|c|}
\hline \multirow{2}{*}{ Analysis Description } & \multicolumn{2}{|c|}{ Horizontal Point } & \multicolumn{2}{c|}{ Vertical Fin-1 Point } & \multicolumn{2}{c|}{ Vertical Fin-2 Point } \\
\cline { 2 - 7 } & $\mu \mathrm{m}$ & $(\%)$ & $\mu \mathrm{m}$ & $(\%)$ & $\mu \mathrm{m}$ & $(\%)$ \\
\hline Repeatability & 11 & 1.4 & 10 & 3.1 & 35 & 10.5 \\
\hline Reproducibility & 0 & 0 & 0 & 0 & 0 & 0 \\
\hline Repeatability \& Reproducibility & 11 & 1.4 & 10 & 3.1 & 35 & 10.5 \\
\hline Part Variation & 752 & 99.9 & 315 & 99.9 & 329 & 99.4 \\
\hline Total Variation & 752 & 100 & 315 & 100 & 331 & 100 \\
\hline
\end{tabular}

A worst-case Gage R\&R of $35 \mu \mathrm{m}(70 \%$ of the specified criteria of $50 \mu \mathrm{m})$ was observed for Vertical Fin-2. The Repeatability and Reproducibility for the parting line (horizontal) fins and vertical fin-1 were $10 \mu \mathrm{m}$ and $11 \mu \mathrm{m}$, respectively, falling well within the $50 \mu \mathrm{m}$ target for uncertainty The part variation represented over $99 \%$ of the total variation for all three fins, validating the results. Because the $R \& R$ and part variation are assumed to be independent, the root-sum-square of these values gives the total variation.

\section{METROLOGY OF THE PATTERN}

The pattern consisted of six nominally identical stars and is as shown in Fig. 4. The pattern was also measured on the Brown \& Sharpe 765 Xcel CMM in order to compare the change in the feature thickness of the star casting to that of the pattern. The pattern was measured at locations that directly corresponded to the locations measured on the castings. The pattern for the star casting consisted of a cope plate and a drag plate for a Georg Fischer-Disa horizontally parted cope/drag impact mold machine. The drag half of the pattern is shown in Fig. 4. The thicknesses of the cope or drag portions of the parting line fins were calculated by determining the distance between a measured point on the fin and a best fit plane defined by points on the pattern plate that surrounded the star pattern. The thicknesses of the cope and drag portions were then combined to provide the relative thickness of the horizontal fins on the patterns.

The program for the pattern measured a total of 108 feature thickness values on the pattern. A $6 \mathrm{~mm}$ ruby tip with a 185 $\mathrm{mm}$ extension was used for clearance, and a single, vertical orientation of the indexable PH9 head was used to give the best accuracy and repeatability. 


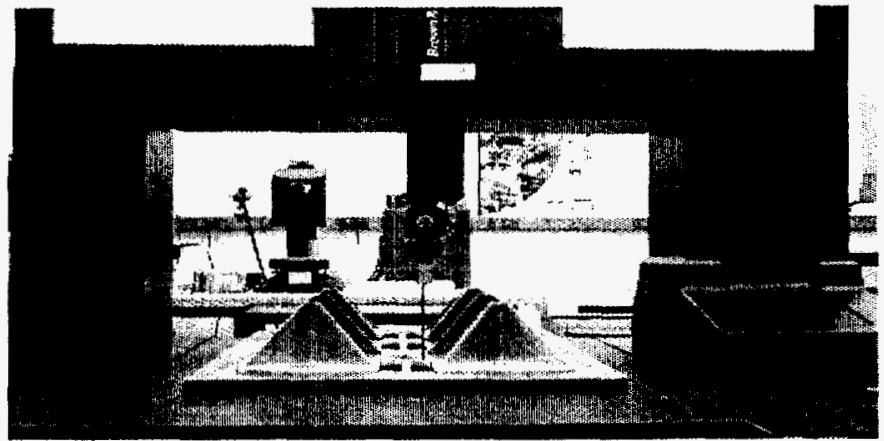

Fig. 4: Setup of the drag side of the pattern on the CMM

\section{DESIGN OF EXPERIMENTS}

Sixteen different process parameter combinations were identified for the study (Kachru, 2001). Ten star castings were fabricated at Technikon for each process combination. The sixteen different process combinations were selected on the basis of a 24 Full Factorial design of experiments. The four factors were selected after some preliminary data analysis and extensive consultation with the project steering committee. The selection was based on the ability to control and monitor the process at Technikon. The four factors chosen for the study were clay content, pouring temperature, sand compactability, and shakeout time. Two levels for each factor were chosen, a "low level" and a "high level." The levels of these factors are listed in Table 2 and were chosen to be representative of typical levels found in the foundry. A list of the 16 process combinations used in the design of experiments is shown in Table 3.

Table 2: Low and High levels of the four factors

\begin{tabular}{|l|c|c|}
\hline Process Parameters & Low Level & High Level \\
\hline Clay Content (\%) & 6 & 9 \\
\hline Pour Temperature ( ${ }^{\circ}$ F) & 2550 & 2750 \\
\hline Sand Compactability (\%) & 32 & 42 \\
\hline Shakeout Time (min.) & 30 & 60 \\
\hline
\end{tabular}

The pattern consisted of six star components, or serials, as shown in Fig. 4. Thickness values were measured for each of the 12 fins on the star casting. For each fin, the measurement was taken along the outer edge at the point located midway between the vertices of the casting as shown in Fig. 3. A preliminary study was conducted to find which of the six serials provided the lowest variation amongst the star castings. Serial No.1 provided the least variation at $100 \mu \mathrm{m}$ and was therefore chosen for the study.

Table 3: Process Combinations of the 16 Runs

\begin{tabular}{|c|c|c|c|c|}
\hline $\begin{array}{c}\text { Combination } \\
\text { Number }\end{array}$ & $\begin{array}{c}\text { Nominal Clay } \\
\text { Content } \\
(\%)\end{array}$ & $\begin{array}{c}\text { Nominal Pour } \\
\left.\text { Temperature ( }{ }^{\circ} \mathbf{F}\right)\end{array}$ & $\begin{array}{c}\text { Nominal Sand } \\
\text { Compatibility } \\
(\%)\end{array}$ & $\begin{array}{c}\text { Nominal } \\
\text { Shakeout Time } \\
\text { (min) }\end{array}$ \\
\hline 1 & 6 & 2750 & 42 & 30 \\
\hline 2 & 6 & 2750 & 32 & 30 \\
\hline 3 & 6 & 2550 & 42 & 30 \\
\hline 4 & 6 & 2550 & 32 & 60 \\
\hline 5 & 6 & 2750 & 32 & 60 \\
\hline 6 & 6 & 2750 & 32 & 60 \\
\hline 7 & 6 & 2550 & 42 & 60 \\
\hline 8 & 6 & 2550 & 42 & 30 \\
\hline 9 & 9 & 2750 & 32 & 30 \\
\hline 10 & 9 & 2750 & 32 & 30 \\
\hline 11 & 9 & 2550 & 42 & 30 \\
\hline 12 & 9 & 2550 & 42 & 60 \\
\hline 13 & 9 & 2750 & 32 & 60 \\
\hline 14 & 9 & 2750 & 32 & 60 \\
\hline 15 & 9 & 2550 & 42 & 60 \\
\hline 16 & 9 & 2550 & & 30 \\
\hline
\end{tabular}




\section{EXPERIMENTAL RESULTS}

The data collected from the star parts were analyzed using two different measurands. The first analysis consisted of studying the effects of changing process parameters on dimensional variability. The second analysis examined the effects of changing process parameters on the nominal dimension of the star casting. The two approaches are presented in the following sections.

\section{DIMENSIONAL VARIABILITY STUDY}

This study examined the effects of the process parameters on the dimensional variability of the star casting. The effects are presented separately for four groupings:

a) the horizontal fins located across the parting line,

b) the vertical fins formed in the cope,

c) the vertical fins formed in the drag, and

d) all of the fins together.

For the case where all of the fins were analyzed together, software restrictions required that the fins be paired rather than treated separately so as not to exceed the limitation of 10 replicates (in this case, the opposing fins in the same subset, cope, drag or horizontal, were paired). Average values of the standard deviation were therefore calculated for each pair, resulting in 6 replicates rather than the original 12 . The results from the analysis are presented with the aid of three different types of graphs, a Pareto Chart, a Main Effects plot and an Interaction Plot.

Grouping of the fins into the cope, drag, parting line, and "all" categories first required that the samples were similar. Before combining the data, extensive pair-wise f-tests were conducted using $95 \%$ confidence intervals to ascertain that differences in the variability of the population were not statistically significant. Peters, et al. (1996) have noted a dependence of dimensional variability of a casting on the weight of the casting and the length of the feature. In the study presented in this paper, however, the variation data were normalized with the nominal dimensions (principally thickness) of the corresponding features measured on the pattern.

Fig. 5 presents Pareto charts for each group. The Pareto Charts compare the relative magnitude and the statistical significance of both main and interaction effects of each parameter being studied. The plots display the parameters in descending order of impact on the standard deviation. The horizontal axis is a function of the statistical t-value and can be thought of as the product of the sensitivity of the standard deviation to that parameter and the calculated precision of the results. For example, a statistical analysis may determine that the metric (standard deviation) is sensitive to a parameter, but that correlation of the results is low. The high sensitivity value would therefore be counteracted by the lower value of precision. In addition, a vertical reference line included in the charts denotes which of those effects are considered to be significant. The reference line is a function of the assumed significance level, which in this case was $10 \%$. For any effect that extends beyond this line, there is a $90 \%$ probability that the effect is real, and, conversely, a $10 \%$ chance that the parameter has no real affect.

These indications are illustrated in Fig. 5. For example, in Fig. 5a, clay content (A) has the highest impact on the standard deviation in the cope fins and is considered to be significant. In addition, the interaction between clay content. pouring temperature, and sand compactability $(\mathrm{ABC})$, and the interaction between all four parameters $(\mathrm{ABCD})$ are also deemed significant since they protrude extend past the reference line, although clay content $(A)$ is clearly the predominant parameter. On the other hand, clay content (A) alone is not considered to be a significant factor in the drag, since its value falls below the reference line. In the author's opinions, however, it may be more appropriate to look for obvious differences between the parameters. Clay (A), for example, far exceeds the effects of the remaining parameters and combinations which change in small increments.

Fig. $5 \mathrm{~b}$ shows that the drag is affected mostly by interactions, with the clay content / shakeout interaction (AD) being dominant. However, it is also important to note that the values along the horizontal axis are also smaller (maximum of 2.9 for the drag vs. 4.8 for the cope), indicating that the sensitivities of variations to those parameters are lower or that the precision of the analysis is lower. The dominant parameter in the horizontal fins is also the clay content / shakeout interaction (AD), which is the only parameter that is considered significant as determined by the reference line. However, despite the fact that the pouring temperature (B) falls below the reference line, it still appears to have a potential effect on the variation. 
The large amount of information represented in Fig. 5 made it difficult to determine which of the parameters were of most importance in reducing variation. The data in Fig. 5a through Fig. $5 \mathrm{c}$ were therefore combined and analyzed in Fig. 6 to determine which effects were dominant. The magnitudes of the effects were calculated by taking the square root of the sum of the squares of the data in Fig. 5 . The resulting figure indicates that clay content (A) is clearly the dominant parameter resulting in increased variations in the castings. Pouring temperature (B) is the second most significant parameter, although its effect is roughly half of that of clay content (A). However, this simply indicates a smaller sensitivity to the pouring temperature. If the difference in the two temperatures selected for the study had been twice as large, it would likely challenge the effect of clay content. Also, interactions between clay (A), pouring temperature (B), and other parameters had higher effects than pouring temperature alone.

The three highest significant effects have also been listed in Table 4 in order to segregate the dominant and the common process parameters. Clay $(A)$ has the highest effect on the dimensional variation of the castings as can be seen by its presence in all but two significant process parameter interactions in Table 4. Pouring temperature (B) also shows significance. Shakeout (D) and clay (A) show minimal effectiveness in controlling the dimensional variation of the castings and occur randomly in some interactions. The combination of clay content and shakeout (AD) were dominant for the drag and horizontal fins. The interaction of all four process parameters, $A B C D$, is also significant in the cope and drag fins.

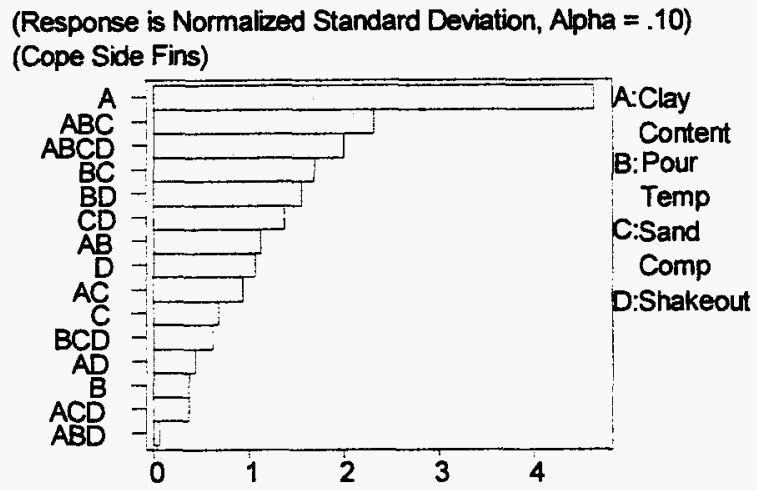

(A) Cope Side Fins

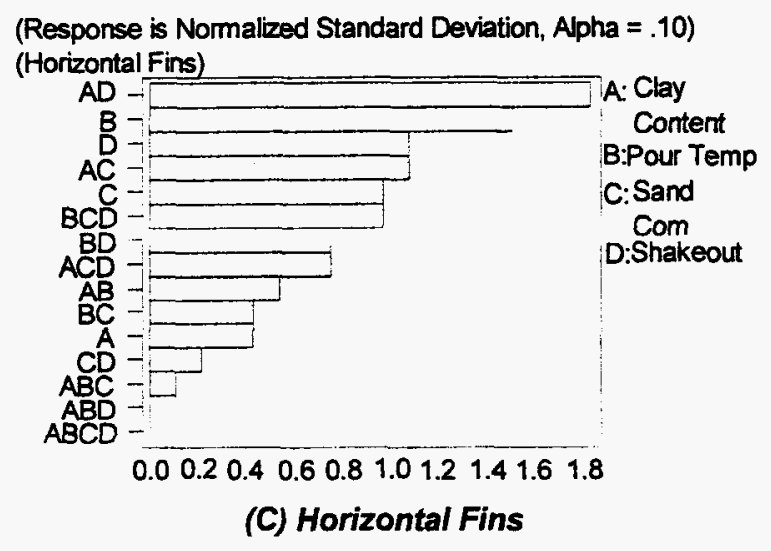

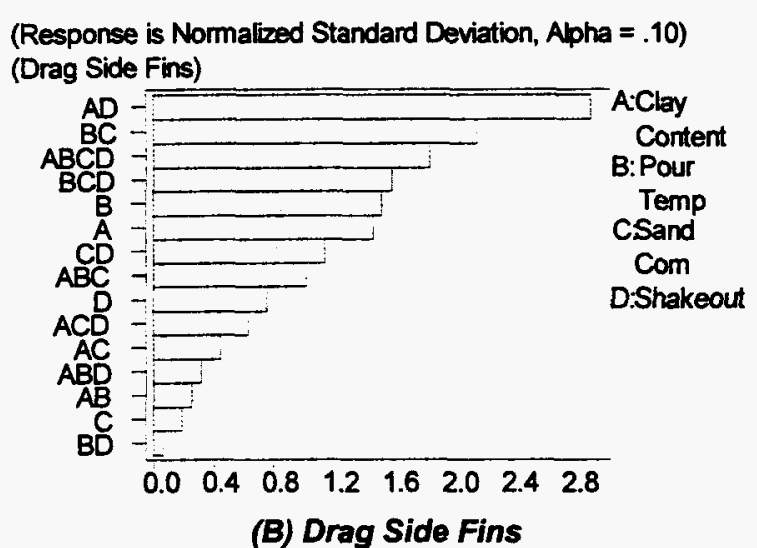

(Response is Normalized Standard Deviation, Alpha $=.10$ ) (All Fins)

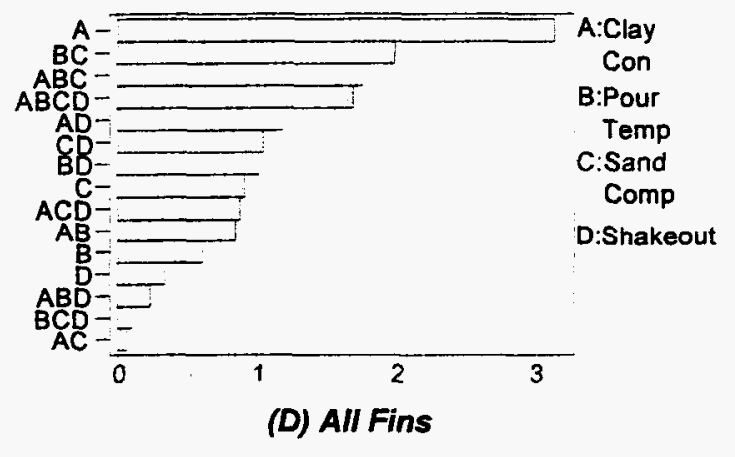

Fig. 5: Pareto's Chart for dimensional variation of Horizontal Fins 


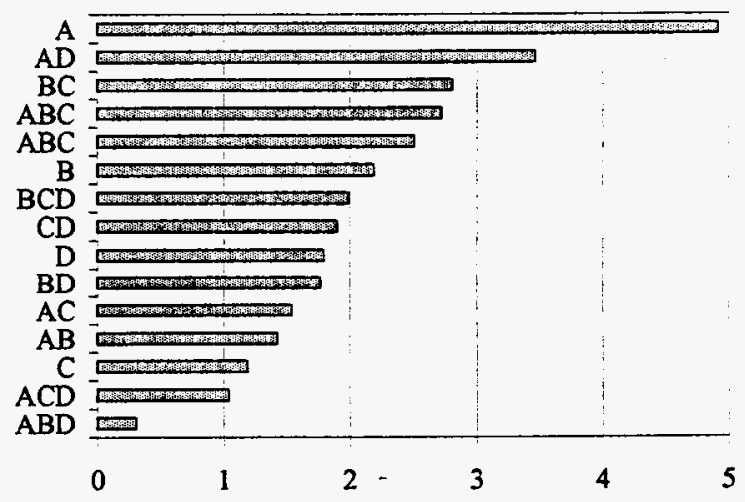

Fig. 6: Magnitude of combined effects in cope, drag, and horizontal fins

Table 4: Comparison Table for Pareto's Effects Plot

\begin{tabular}{|l|c|c|c|}
\hline Grouped Fins & \multicolumn{3}{|c|}{ Dominant Process Parameters or Interactions } \\
\hline & Highest & Second & Third \\
\hline Cope & $\mathrm{A}$ & $\mathrm{ABC}$ & $\mathrm{ABCD}$ \\
\hline Drag & $\mathrm{AD}$ & $\mathrm{BC}$ & $\mathrm{ABCD}$ \\
\hline Horizontal & $\mathrm{AD}$ & None & None \\
\hline All & $\mathrm{A}$ & $\mathrm{ABCD}$ & $\mathrm{BC}$ \\
\hline
\end{tabular}
A: Clay Content
B: Pour Temperature
C: Sand Compactability
D: Shakeout Time

Fig. 7 provides a breakout of the effects of the individual parameters in the Main Effects Plot. Note that the vertical axes in the plots show the standard deviation in micrometers and that the ranges are constant for all of the plots. For example, Fig. 7a shows the standard deviation changing from 10.4 to $14.9 \mu \mathrm{m}$ due to a change in clay content (A) from 6 to $9 \%$. Clay content (A) was also the dominant factor in all fins combined. The results from the Main Effects Plots are summarized in Table 5. Columns 3, 4, 5 and 6 in Table 5 show the effect of each process parameter on the dimensional variation of the Cope, Drag, Parting line and "All fins" combined. Column 7 averages the effect of each process parameter on the Cope, Drag and the horizontal parting line fins. The table reaffirms the previous results Clay (A) has the highest average effect on the standard deviation at $2.2 \mu \mathrm{m}$, followed by pour temperature (B), which contributes an average change of $1.4 \mathrm{~km}$. Sand compactability (C) and shakeout time (D) contribute only $0.4 \mu \mathrm{m}$ and $0.8 \mu \mathrm{m}$ in the average change of standard deviation. Also clay (A) is the most dominant parameter in the cope whereas pour temperature $(B)$ is the most dominant in the drag and across the parting line.

The slopes of the effects also show some interesting trends as illustrated in Fig. 7. Increase in clay (A) always increases the dimensional variation of the castings, whereas a decrease in sand compactability $(C)$ increases the variation. The effect of pour temperature (B) appears to be a function of the elevation; an increase in pour temperature (B) decreases the dimensional variation in the cope, increases it marginally in horizontal fins, and increases it even more in the drag, as illustrated in Fig. 7a through Fig. 7c. This results in lower variations in the cope, moderate variations across the parting line, and higher variations in the drag. The shakeout time (D) also is an elevation-based effect with an increase in shakeout (D) increasing the dimensional variation of the castings in the cope, decreasing it marginally in the horizontal fins, and more in the drag fins. 


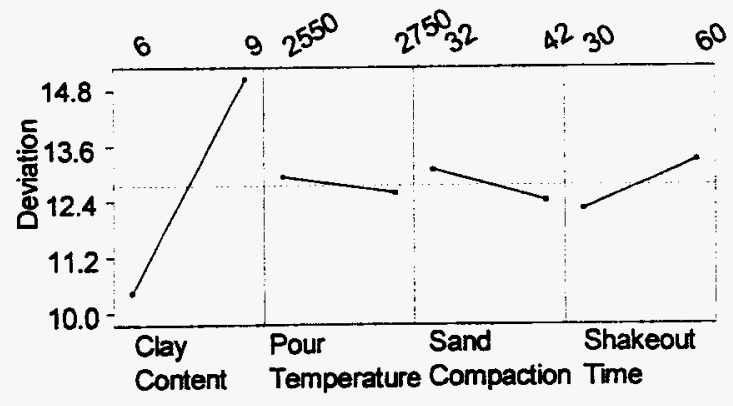

(a) Cope Side Fins

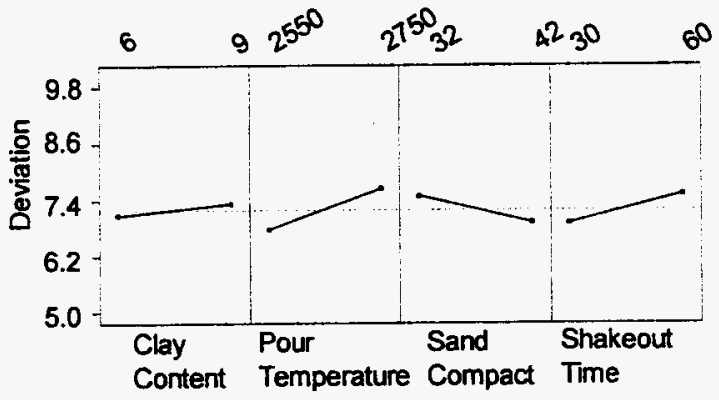

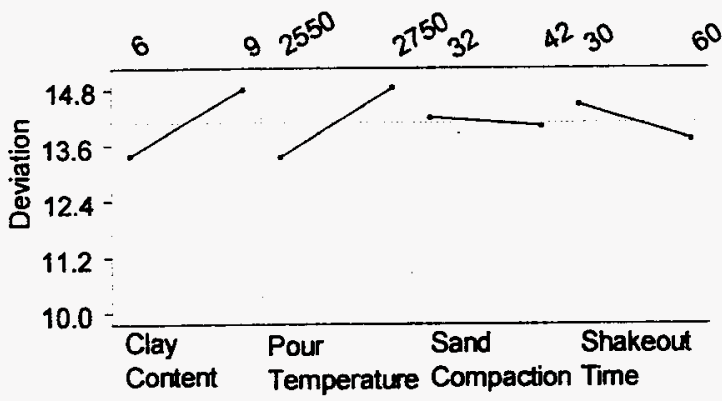

(b) Drag Side Fins

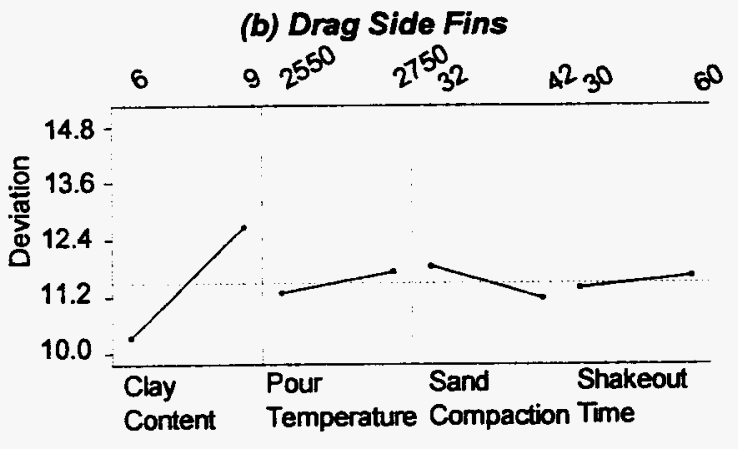

(d) All Fins

(c) Horizontal Fins

Fig. 7: Main Effects Plot for dimensional variation

Table 5: Comparison Table of Main Effects Plot for dimensional variation

\begin{tabular}{|l|c|c|c|c|c|c|}
\hline Process Parameters & Symbol & $\begin{array}{c}\text { Cope } \\
(\mu \mathrm{m})\end{array}$ & $\begin{array}{c}\text { Drag } \\
(\mu \mathrm{m})\end{array}$ & $\begin{array}{c}\text { Parting } \\
(\mu \mathrm{m})\end{array}$ & All $(\mu \mathrm{m})$ & $\begin{array}{c}\text { Average of Cope, } \\
\text { Drag, Hor Fins } \\
(\mu \mathrm{m})\end{array}$ \\
\hline Clay Content & $\mathrm{A}$ & 4.8 & 1.4 & 0.4 & 3.3 & 2.2 \\
\hline Pour Temp. & $\mathrm{B}$ & 0.4 & 1.5 & 1.4 & 0.8 & 1.4 \\
\hline Sand Compactability & $\mathrm{C}$ & 0.6 & 0.1 & 0.6 & 1.3 & 0.4 \\
\hline Shakeout Time & $\mathrm{D}$ & 1.2 & 0.6 & 0.6 & 0.2 & 0.8 \\
\hline
\end{tabular}

Fig. 8 gives a visual understanding of the interactions of the parameters. The interaction between two parameters is shown in the graphs located at the intersection of the two parameters. For example, the three plots in row one represent interactions between clay content (A) (with values of $6 \%$ and $9 \%$ ) and the remaining three parameters. The second column contains the values for the pour temperature (B) parameter $\left(2550^{\circ} \mathrm{F}\right.$ and $\left.2750^{\circ} \mathrm{F}\right)$, and so on. The intersection between pour temperature (B) and sand compactability $(C)$ is illustrated in column 3 , row 2 . To illustrate, the dotted line shows the change in standard deviation as the parameters are changed from $32 \%$ sand compactability $(\mathrm{C}), 2550^{\circ} \mathrm{F}$ pouring temperature (B), to $42 \%$ sand compactability. Similarly, the solid line shows the standard deviation as the parameters are changed from $32 \%, 2550^{\circ} \mathrm{F}$ to $42 \%$. Large differences in slope between the two lines indicates that the effects of the interactions between the two parameters on standard deviation are strong. This figure reinforces the conclusions drawn from Fig. 5.

Fig. 9 illustrates a trend between the average dimensional variation and the nominal dimension of the feature being measured. Here, the horizontal axis represents the nominal dimension of the casting feature in millimeters. For each fin, the standard deviation for the 10 castings in one of the 16 cases was calculated. Four such values were found for the cope ( 4 cope fins) and for each of the 16 parameter runs, totaling 64 values. These were averaged to yield a measure of the typical standard deviation in the cope, and similar values were found for the drag and parting line surfaces. These values are represented by the vertical axis in Fig. 9. The average dimensional variation increases nonlinearly as the nominal dimension increases. The dimensional variation for the cope fins was $80 \mu \mathrm{m}$, while the average dimension was $5.5 \mathrm{~mm}$. The dimensional variation of the drag side fins was $89 \mu \mathrm{m}$, and the average dimension was $6.5 \mathrm{~mm}$. The dimensional variation of the horizontal parting line fins was $96 \mu \mathrm{m}$ and the average dimension was $12.5 \mu \mathrm{m}$. 


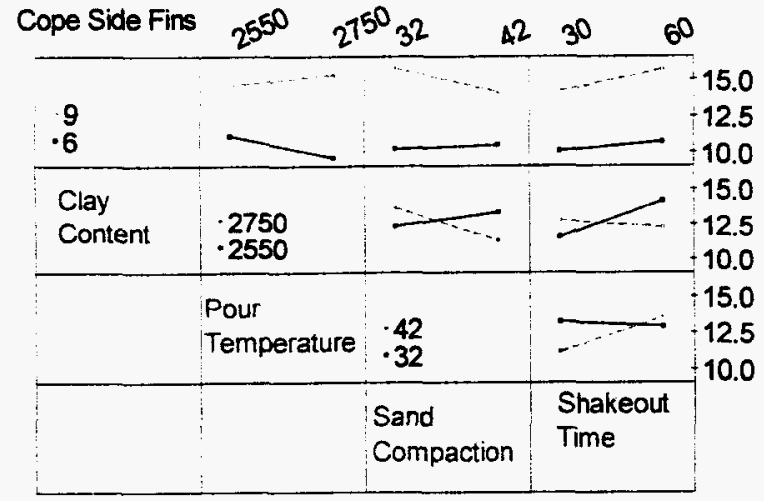

(a) Cope Side Fins

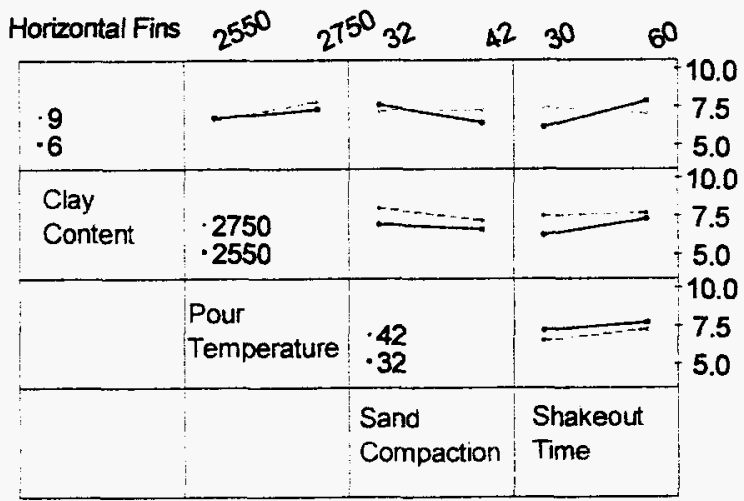

(c) Horizontal Fins

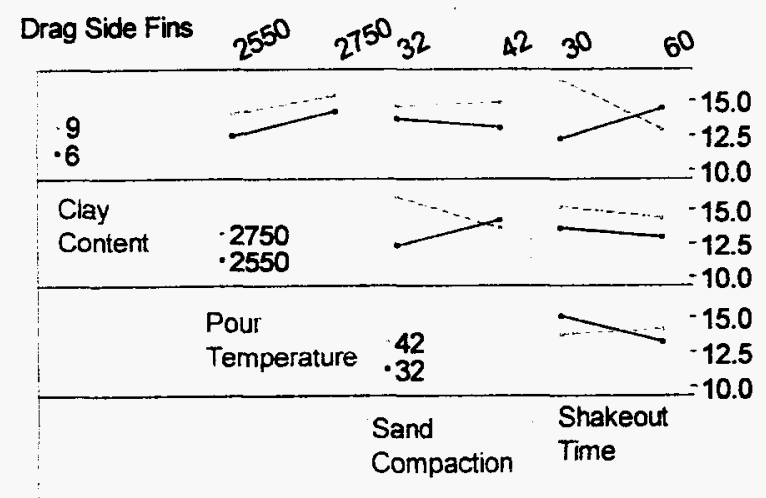

(b) Drag Side Fins

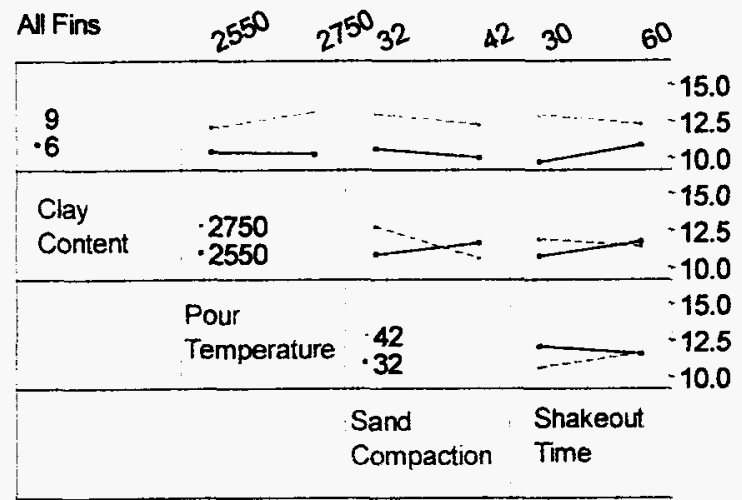

(d) All Fins

Fig. 8: Interaction Plots for dimensional variation

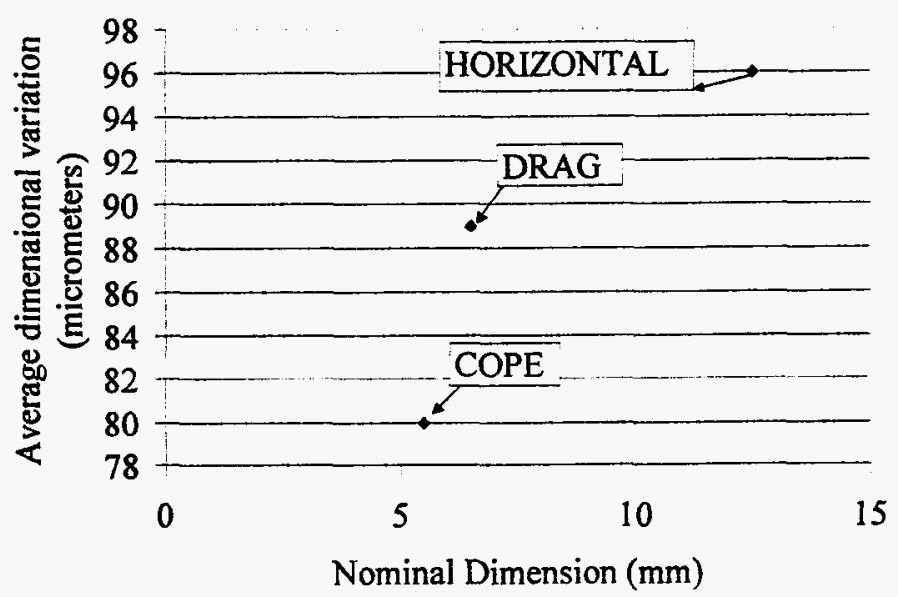

Fig. 9: Average dimensional variation vs. nominal dimension

\section{NOMINAL DIMENSION STUDY}

This effort involved the study of the effects of changing process parameters on the nominal dimensions of the castings. Extensive ANOVA analyses at $95 \%$ confidence interval (extended pair wise t-tests) were performed to check if the data was coming from the same population and if the data means were statistically similar. These tests were performed to determine if the effects were similar throughout the castings (meaning the data from all 12 fins could be combined, yielding statistically stronger analyses) or if they varied from one fin to another. The results of the data showed that the data from the various fins were not statistically similar to each other for the purpose of combining them into one population. Normalizing the data did seem to improve the similarity of some of the fins but not to the extent that the fins could be grouped together. Results are therefore presented for each fin independently in Fig. 11 through Fig. 16. The layout of the stars is shown in Fig. 10. The 
gating of the casting in the mold is attached to parting line fin number 2 and the numbering of the fins is as shown. The circled numbers on the diagonal lines in star casting 1 are the numbers of the vertical drag fins.

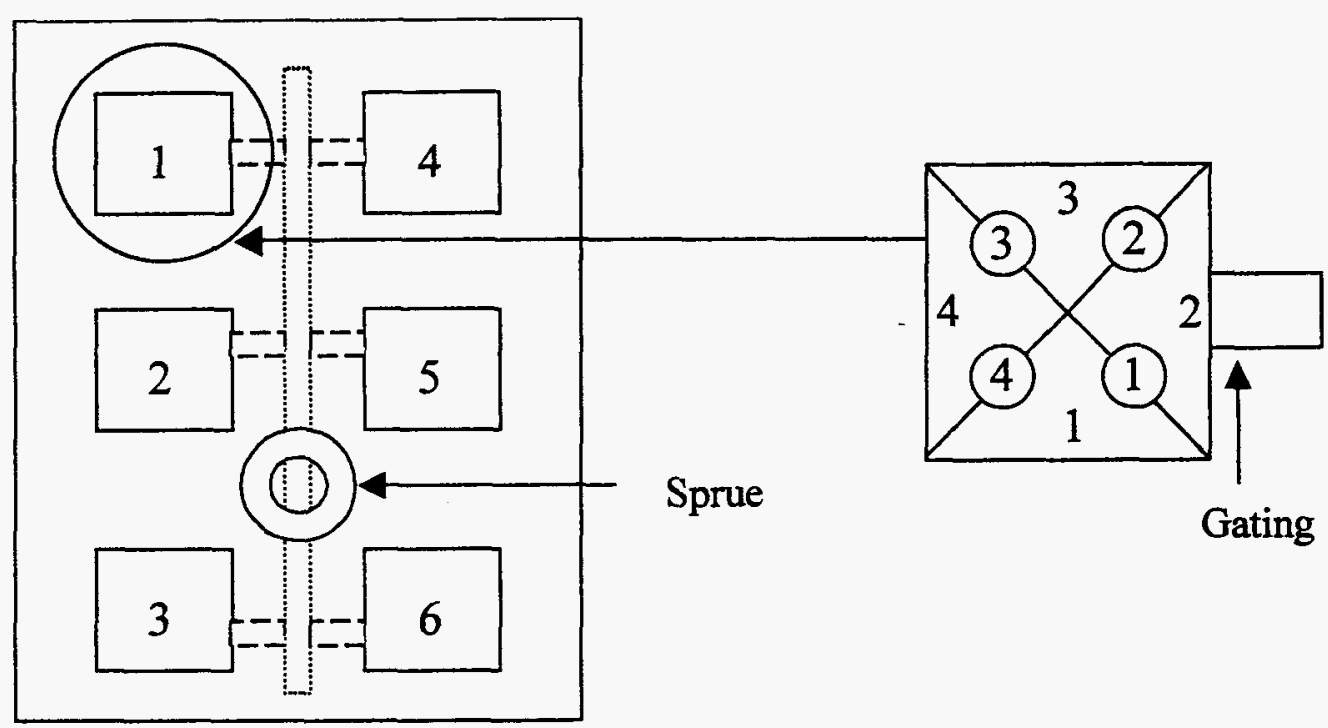

Fig. 10: Layout of the stars and numbering of the fins

Fig. 11 shows the Pareto's Chart for the four horizontal fins. As before, any effect that extends beyond the reference line parallel to the vertical axis is considered significant The significant effects have been listed in Table 6. Note that sand compactability (C) was not significant at all in controlling the nominal dimension of the horizontal fins. Shakeout (D) was the most dominant effect in horizontal fin 1 and fin 3. Pouring temperature (B) and the interaction between clay, sand and shakeout (ACD) were the most dominant effects in horizontal fins 2 and 4, respectively. Note that fin number 2 had the gating attached to it, so the metal is the hottest when it fills this cavity. Pouring temperature was also a significant process parameter in horizontal fins 1, 3 and 4. Clay (A) was a significant factor in fins 2 and 3 . The interaction between clay and pour temperature was significant in fins 2 and 4 , and the interaction between clay and shakeout was significant in 1,3 and 4 . The three-way interaction between clay, pouring temperature, and shakeout (ABD) was significant in fins 1 and 4 . There were no four-way interactions of all the process parameters, indicating that sand compactability was not significant in controlling the nominal dimension of the castings. The only other significant interaction between pouring temperature and shakeout was in horizontal fin 1. 


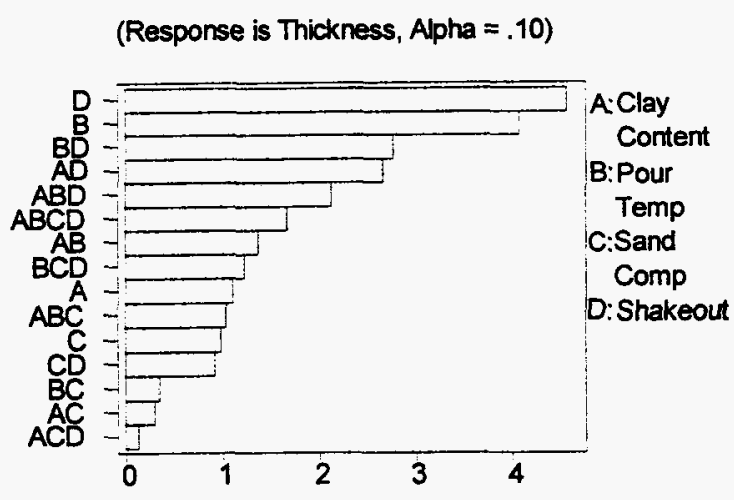

(a) Horizontal Fin-1

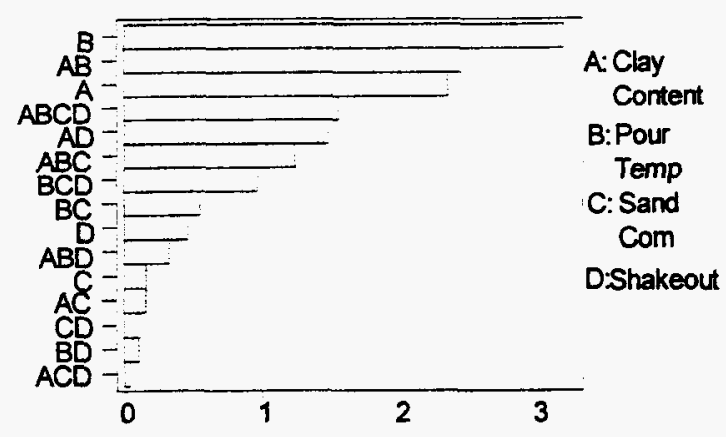

(b) Horizontal Fin-2

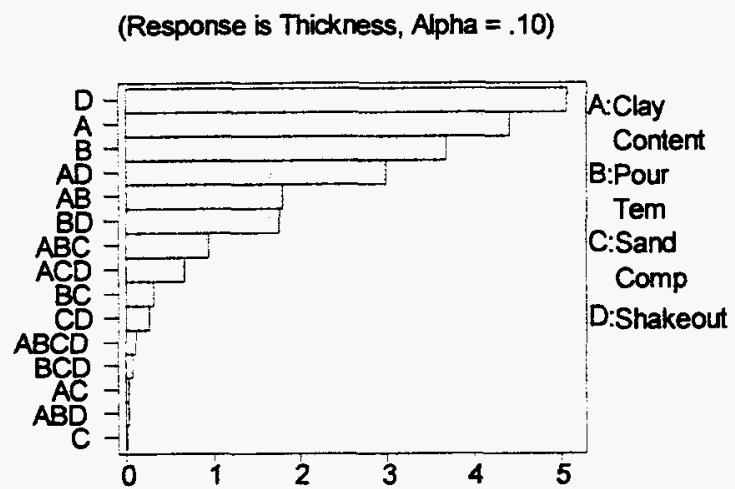

(c) Horizontal Fin-3

Fig. 11: Pareto's Chart for Horizontal fins

(Response is Thickness, Apha $=.10$ )

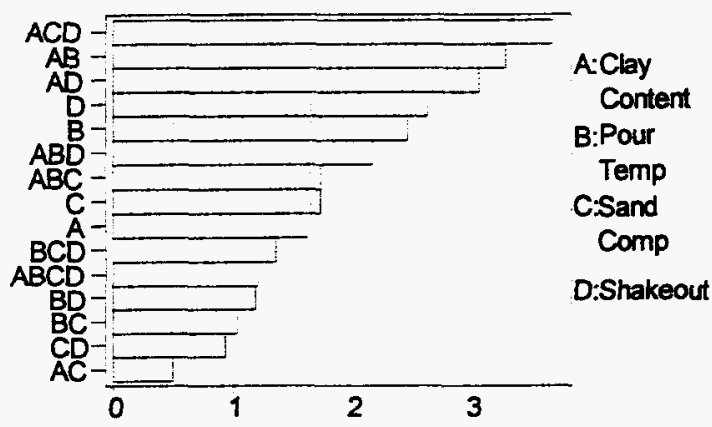

(d) Horizontal Fin-4

Table 6: Comparison Table of Pareto's Effects Plot for Horizontal fins

\begin{tabular}{|l|c|c|c|c|c|c|}
\hline Fin & \multicolumn{6}{|c|}{ Dominant Process Parameters or Interactions } \\
\hline & Highest & \multicolumn{1}{|c|}{ Lowest } \\
\hline Horizontal-1 & $\mathrm{D}$ & $\mathrm{B}$ & $\mathrm{BD}$ & $\mathrm{AD}$ & $\mathrm{ABD}$ & None \\
\hline Horizontal-2 & $\mathrm{B}$ & $\mathrm{AB}$ & $\mathrm{A}$ & None & None & None \\
\hline Horizontal-3 & $\mathrm{D}$ & $\mathrm{A}$ & $\mathrm{B}$ & $\mathrm{AD}$ & None & None \\
\hline Horizontal-4 & $\mathrm{ACD}$ & $\mathrm{AB}$ & $\mathrm{AD}$ & $\mathrm{D}$ & $\mathrm{B}$ & $\mathrm{ABD}$ \\
\hline
\end{tabular}$\quad \begin{aligned} & \text { A: Clay Content } \\
& \text { B: Pour Temperature } \\
& \text { C: Sand Compactability } \\
& \text { D: Shakeout Time } \\
& \\
& \end{aligned}$

The Main Effects plots for horizontal parting line fins are presented in Fig. 12 and summarized in Table 7. Pouring temperature was the most dominant process parameter and accounted for $65 \mu \mathrm{m}$ of change in the nominal dimension. Shakeout followed with $58 \mu \mathrm{m}$, followed by clay with $50 \mu \mathrm{m}$. Sand compactability again had the least effect at $17 \mu \mathrm{m}$. An increase in shakeout time increased the measured dimension of the casting, as did clay content. Increasing pouring temperature decreased the dimension. An increase in sand compactability increased the dimension slightly in horizontal fin-1 and decreased it in fin-4. It had no effect in fins 2 and 3.

Table 7: Comparison Table for Main Effects Plot of Horizontal Fins

\begin{tabular}{|l|c|c|c|c|c|c|}
\hline Process Parameters & Symbol & $\begin{array}{c}\text { Hor Fin- } \\
1(\mu \mathrm{m})\end{array}$ & $\begin{array}{c}\text { Hor } \\
\text { Fin-2 } \\
(\mu \mathrm{m})\end{array}$ & $\begin{array}{c}\text { Hor } \\
\text { Fin-3 } \\
(\mu \mathrm{m})\end{array}$ & $\begin{array}{c}\text { Hor } \\
\text { Fin-4 } \\
(\mu \mathrm{m})\end{array}$ & Average $(\mu \mathrm{m})$ \\
\hline Clay Content & $\mathrm{A}$ & 30 & 50 & 80 & 40 & 50 \\
\hline Pour Temp. & $\mathrm{B}$ & 80 & 70 & 70 & 40 & 65 \\
\hline Sand Compactability & $\mathrm{C}$ & 30 & 5 & 0 & 30 & 17 \\
\hline Shakeout Time & $\mathrm{D}$ & 90 & 10 & 90 & 40 & 58 \\
\hline
\end{tabular}


1st Horizontal Fin

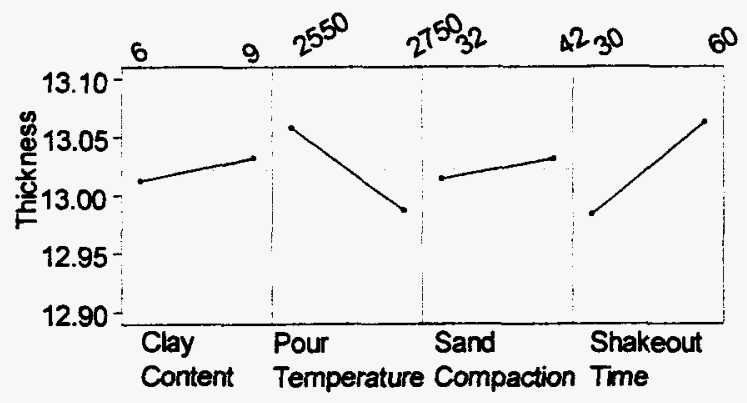

(A) Horizontal Fin-1

3rd Horizontal Fin

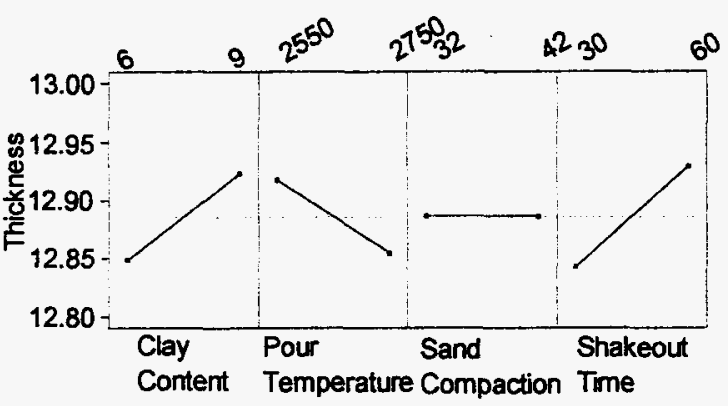

(C) Horizontal Fin-3 2nd Horizontal Fin

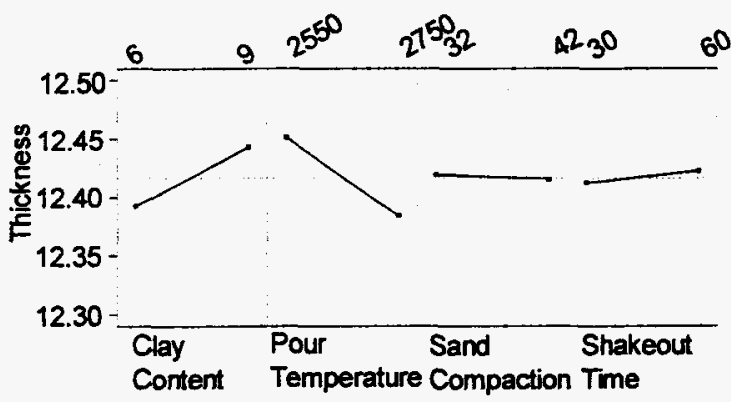

(B) Horizontal Fin-2

4th Horizontal Fin

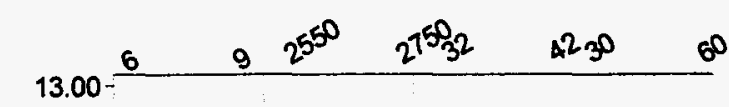

: 12.95
兽 12.90

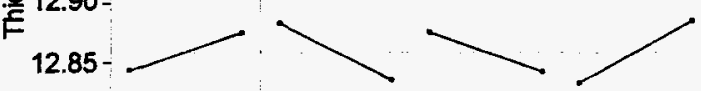

12.80 -

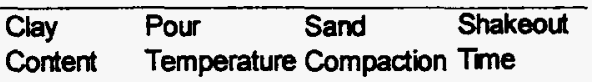

Fig. 12: Main Effects Plot for Horizontal Fins

The Pareto's Chart for the cope fins are shown in Fig. 13 and summarized in Table 8. Note that sand compactability and shakeout time had negligible effects on the cope fins, and that clay was dominant in three of the four fins. The only exception was in fin 3 (located near the gating), where the pouring temperature was the dominant factor.

Table 8: Comparison Table of Pareto's Effects Plot for Cope Fins

\begin{tabular}{|l|c|c|c|c|c|}
\hline Fin & \multicolumn{4}{|c|}{ Dominant Process Parameters or Interactions } \\
\hline Cope Fin-1 & A & B & AB & None & None \\
\hline Cope Fin-2 & A & AB & B & C & ACD \\
\hline Cope Fin-3 & B & AB & A & None & None \\
\hline Cope Fin-4 & A & BD & B & None & None \\
\hline
\end{tabular}

A: Clay Content

B: Pour Temperature

C: Sand Compactability

D: Shakeout Time

The Main Effects plots for cope fins are presented in Fig. 14 and Table 9. Clay was again the most dominant process parameter and accounted for 83 microns of change in the dimension. Pouring temperature followed with 42 microns. Increasing clay content increased the dimension of the casting whereas increasing pouring temperature decreased the nominal dimension. Shakeout had little effect.

The Pareto's Charts for the drag are shown in Fig. 15, and the significant effects have been listed in Table 10. Clay is again the dominant process parameter in drag fins 1 and 2 and pouring temperature is dominant in 3 and 4 . Again, fin 3 is near the gating where the metal is the hottest. Clay was also a significant parameter in drag fin- 4 . Shakeout time was significant in all four fins as opposed to the cope fins where its effect was negligible. Sand compactability alone was not a significant parameter in the drag as in the cope. 


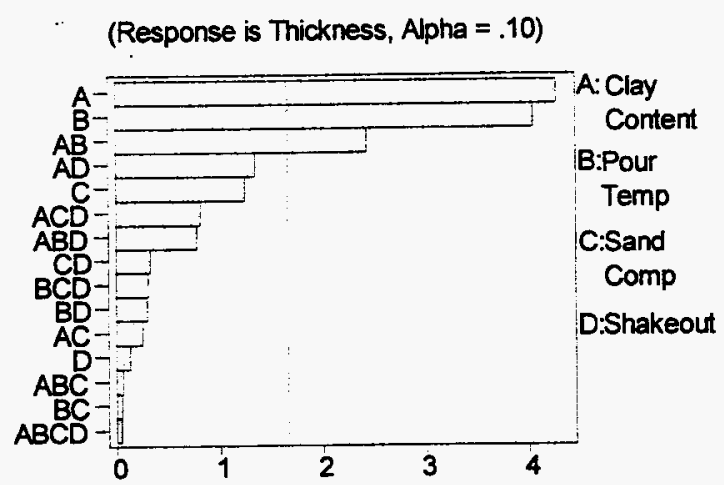

(A) Cope Fin-1

(Response is Thickness, Alpha $=.10$ )

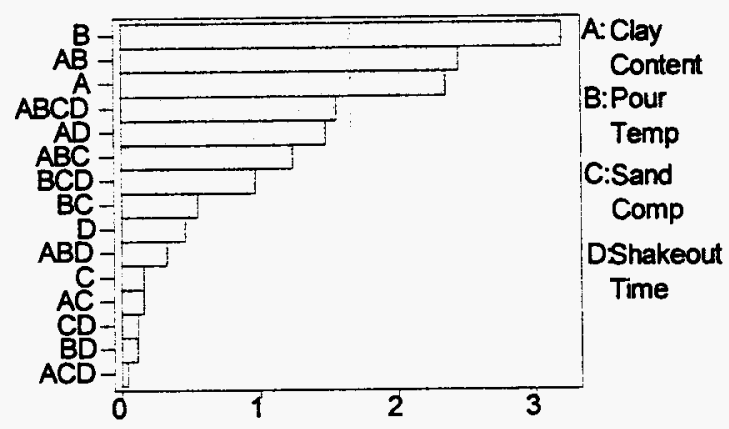

(C) Cope Fin-3

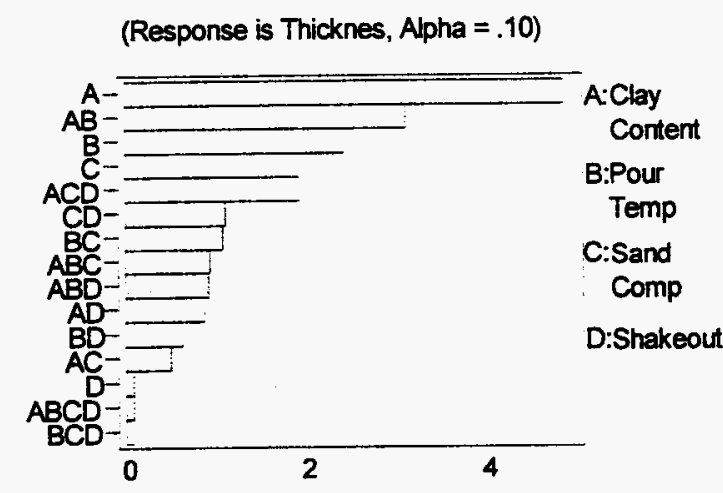

(B) Cope Fin-2

(Response is Thickness, Apha $=.10$ )

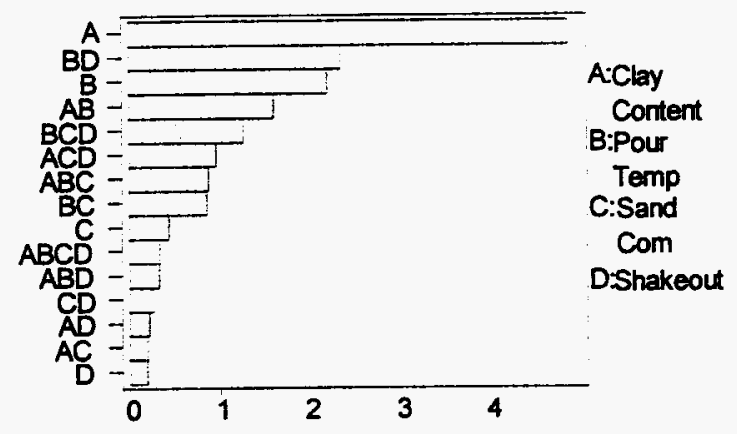

(D) Cope Fin-4

Fig. 13: Pareto's Chart for Cope Fins

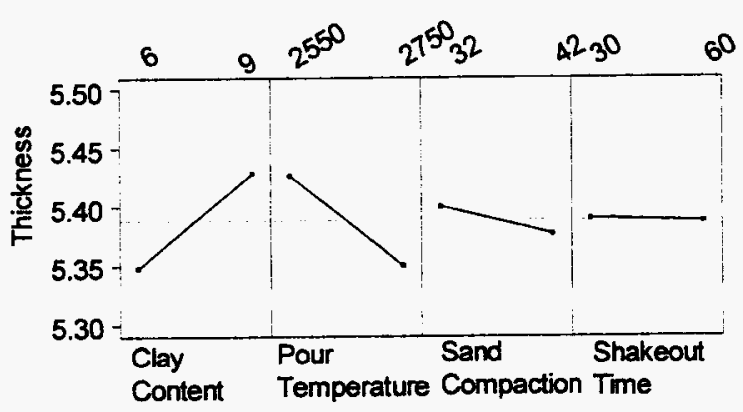

(A) Cope Fin-1

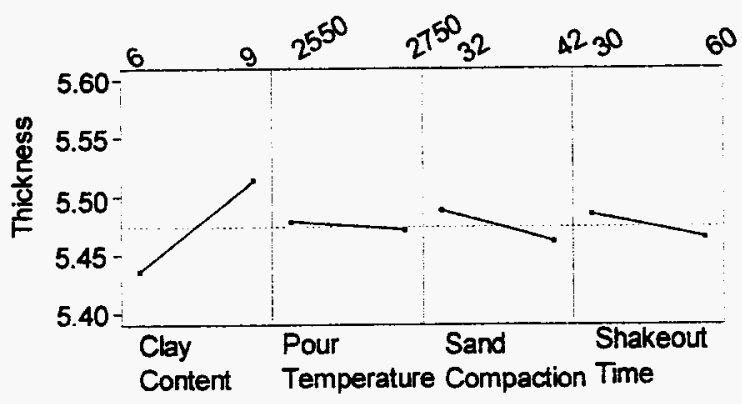

(C) Cope Fin-3

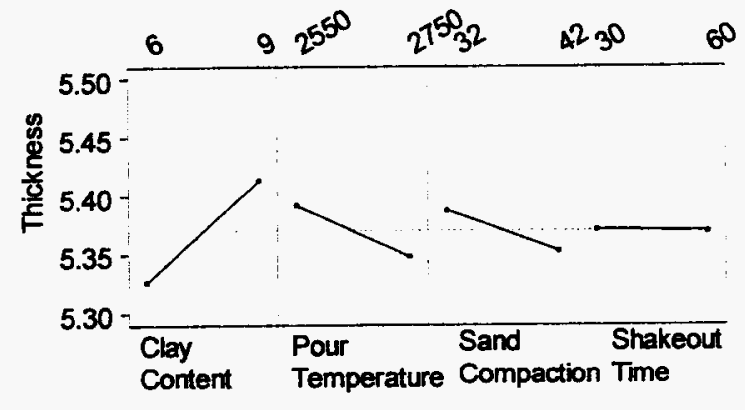

(B) Cope Fin-2

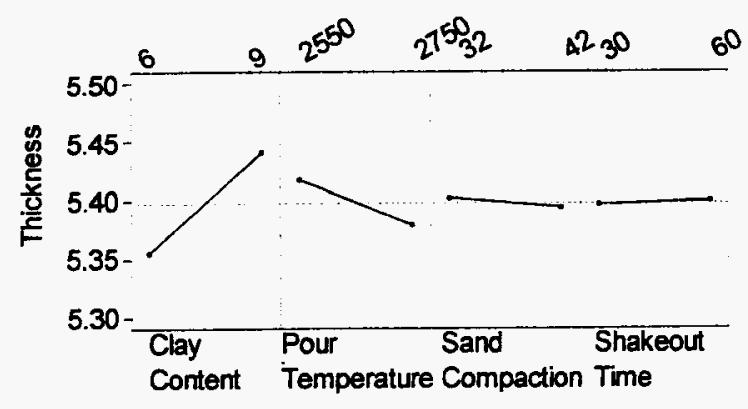

(D) Cope Fin-4

Fig. 14: Main Effect Plot for Cope Side Fins 
Table 9: Comparison Table of Main Effects Plot for Cope Fins

\begin{tabular}{|l|c|c|c|c|c|c|}
\hline Process Parameters & Symbol & $\begin{array}{c}\text { Cope } \\
\text { Fin-1 } \\
(\mu \mathrm{m})\end{array}$ & $\begin{array}{c}\text { Cope } \\
\text { Fin-2 } \\
(\mu \mathrm{m})\end{array}$ & $\begin{array}{c}\text { Cope } \\
\text { Fin-3 } \\
(\mu \mathrm{m})\end{array}$ & $\begin{array}{c}\text { Cope } \\
\text { Fin-4 } \\
(\mu \mathrm{m})\end{array}$ & Average $(\mu \mathrm{m})$ \\
\hline Clay Content & A & 85 & 85 & 70 & 90 & 83 \\
\hline Pour Temp. & B & 75 & 48 & 8 & 35 & 42 \\
\hline Sand Compactability & C & 20 & 40 & 30 & 8 & 25 \\
\hline Shakeout Time & D & 1 & 1 & 25 & 4 & 8 \\
\hline
\end{tabular}

Figure 16 presents the Main Effects plots for the drag fins which are summarized in Table 11. Once again, clay dominated as in the cope fins and is responsible for 61 micrometers of change in dimension. Pouring temperature and shakeout follow with equal effects of $50 \mathrm{~mm}$ in the drag. Sand compactability had negligible effect.

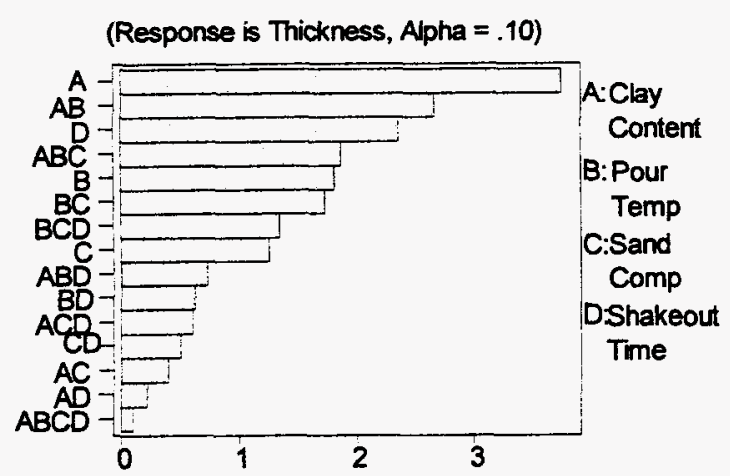

(A) Drag Fin-1

(Response is Thickness, Alpha $=.10$ )

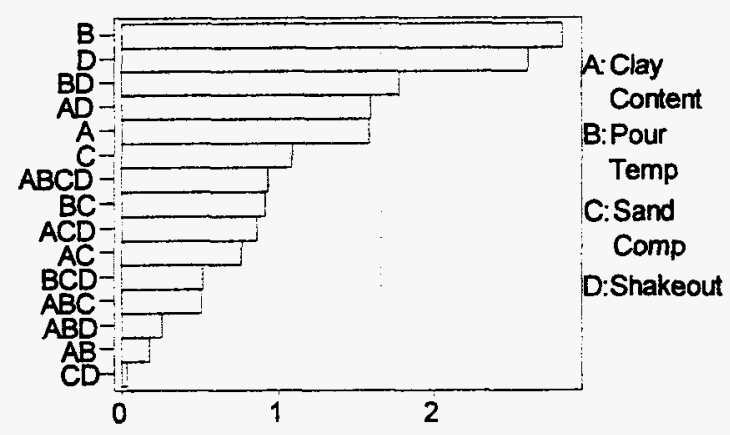

(C) Drag Fin-3

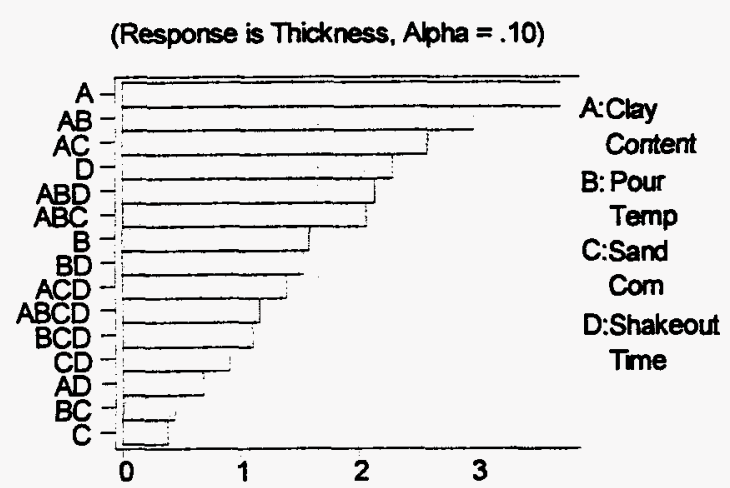

(B) Drag Fin-2

(Response is Thickness, Alpha $=.10$ )

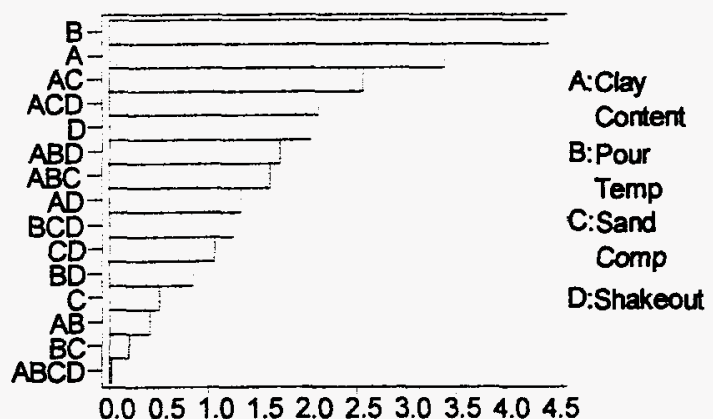

(D) Drag Fin-4

Fig. 15: Pareto's Chart for Drag Side Fins

Table 10: Comparison Table of Pareto's Effects Plot for Drag Side Fins

\begin{tabular}{|l|c|c|c|c|c|c|}
\hline Fin & \multicolumn{6}{|c|}{ Dominant Process Parameters or Interactions } \\
\hline Drag Fin-1 & $\mathrm{A}$ & $\mathrm{AB}$ & $\mathrm{D}$ & $\mathrm{ABC}$ & None & None \\
\hline Drag Fin-2 & $\mathrm{A}$ & $\mathrm{AB}$ & $\mathrm{AC}$ & $\mathrm{D}$ & $\mathrm{ABD}$ & ABC \\
\hline Drag Fin-3 & $\mathrm{B}$ & $\mathrm{D}$ & $\mathrm{BD}$ & None & None & None \\
\hline Drag Fin-4 & $\mathrm{B}$ & $\mathrm{A}$ & $\mathrm{AC}$ & $\mathrm{ACD}$ & $\mathrm{D}$ & None \\
\hline
\end{tabular}

A: Clay Content

B: Pour Temperature

C: Sand Compactability

D: Shakeout Time

\section{Summarized Results From Pareto's Charts}

In order to understand the effects of the process combinations on the whole casting better, the two most dominant parameters or interactions affecting the nominal dimension of each fin are plotted in Fig. 17. This figure represents a top view of the casting looking down on the surface of the horizontal fins. The diagonal lines represent the cope and drag fins, numbered 1 through 4 . The two most dominant parameters or interactions affecting the nominal dimension at the respective locations are shown in parentheses. For example, in the case of Horizontal Fin 1, shakeout time and pouring 
temperature were the two most sensitive effects from the Pareto's Chart. For Cope Fin 1, clay content and pouring temperature were the two most dominant effects.

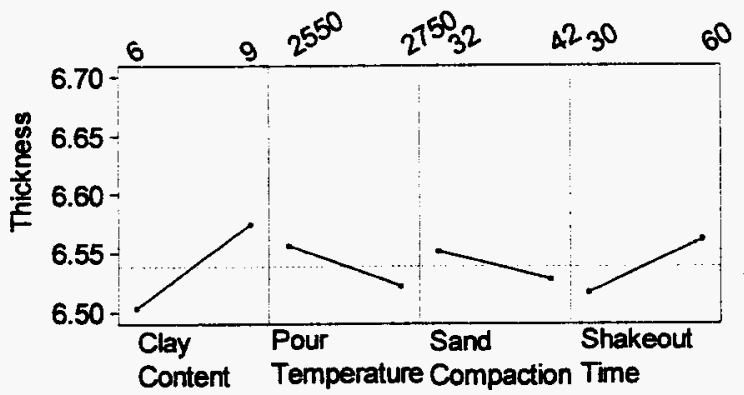

(a) Drag Fin-1

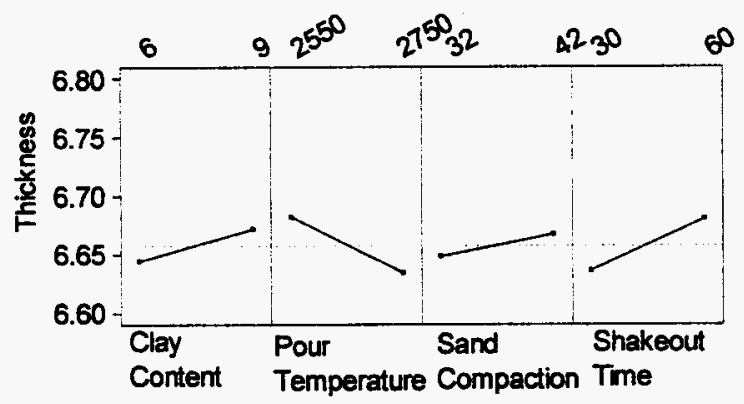

(c) Drag Fin-3

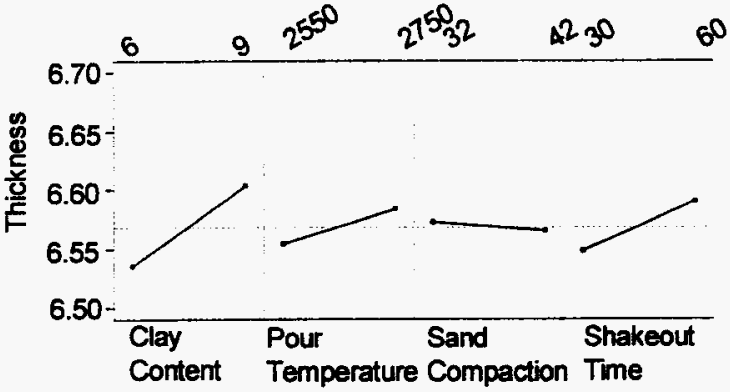

(b) Drag Fin-3

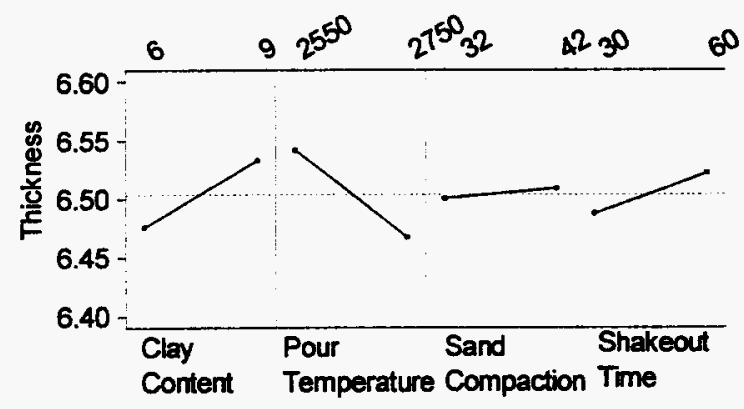

(d) Drag Fin-4

Fig. 16: Main Effect plot for Drag Side Fins

Table 11: Comparison Table of Main Effects Plot for Drag Side Fins

\begin{tabular}{|l|c|c|c|c|c|c|}
\hline Process Parameters & Symbol & $\begin{array}{c}\text { Drag } \\
\text { Fin-1 } \\
(\mu \mathrm{m})\end{array}$ & $\begin{array}{c}\text { Drag } \\
\text { Fin-2 } \\
(\mu \mathrm{m})\end{array}$ & $\begin{array}{c}\text { Drag } \\
\text { Fin-3 } \\
(\mu \mathrm{m})\end{array}$ & $\begin{array}{c}\text { Drag } \\
\text { Fin-4 } \\
(\mu \mathrm{m})\end{array}$ & Average $(\mu \mathrm{m})$ \\
\hline Clay Content & $\mathrm{A}$ & 75 & 70 & 35 & 65 & 61 \\
\hline Pour Temp. & $\mathrm{B}$ & 35 & 30 & 55 & 80 & 50 \\
\hline Sand Compactability & $\mathrm{C}$ & 25 & 8 & 15 & 10 & 15 \\
\hline Shakeout Time & $\mathrm{D}$ & 50 & 50 & 50 & 45 & 49 \\
\hline
\end{tabular}

Clay content was dominant for vertical fins 1 and 2 in both the cope and the drag, and the clay / pour temperature interaction followed for three of those four fins. The pouring temperature was dominant on vertical fins 3 and 4 in the drag and 3 in the cope. These locations represent the furthest points from the gate, where pouring temperature may have its largest impact. The horizontal fins do not show as strong of a pattern, although fins 1 and 3 were dominated by shakeout time. 


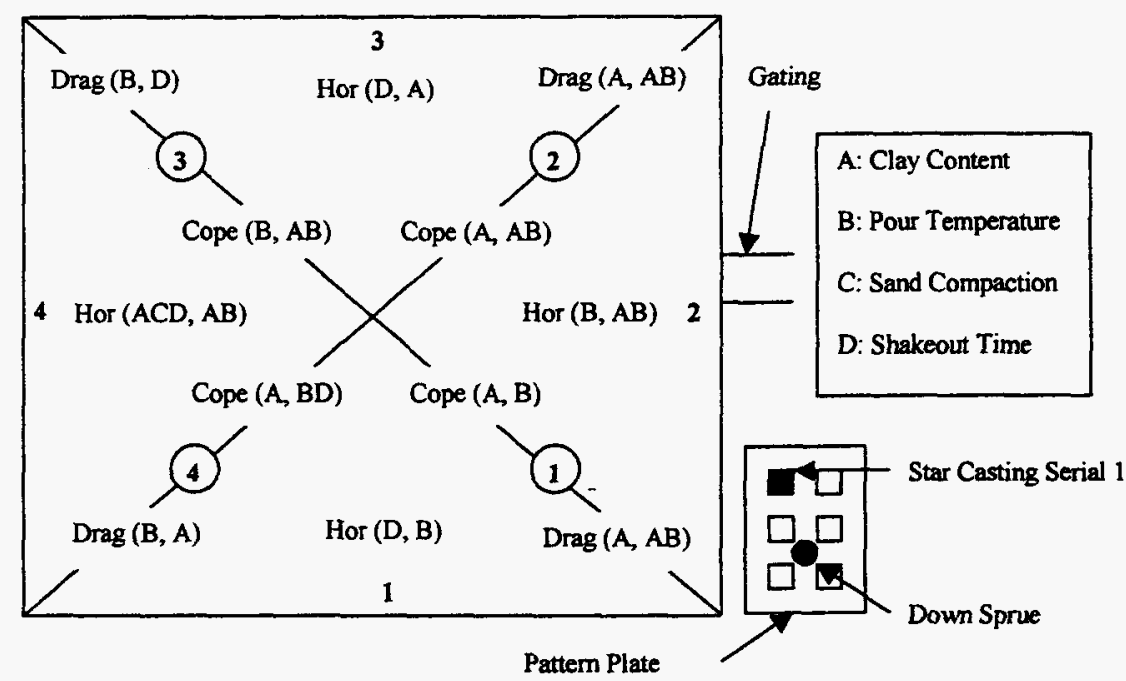

Fig. 17: Summarized Effects from Pareto's Chart for Nominal Dimension

\section{CONCLUSIONS}

A study has been conducted to examine the effects of four foundry parameters on the dimensional variation and the dimensions of thin wall iron features. The parameters studied included clay content, pouring temperature, sand compactability, and shakeout time. A design of experiments was created for execution at a research foundry and the resulting castings were measured at the Center for Precision Metrology at UNC Charlotte. Statistical analyses were conducted and are presented in this work.

\section{DIMENSIONAL VARIATION}

The study shows that the dimensional variation and dimension were affected by varying the process parameters. In terms of the dimensional variation, clay content had the highest effect in the cope, whereas pouring temperature had the highest effect across the parting line and in the drag (although to a lesser degree). An increase in clay content always increased the dimensional variation, but the effect of pouring temperature depended on the elevation of the feature in the casting. As the pouring temperature was increased, the standard deviation in the cope decreased while that in the drag increased, and that across the parting line fell in-between the two extremes. This effect, however, is less pronounced in the cope than in the drag and may be due to the dynamics of fluid motion during fill. An opposite trend was seen for shakeout, where an increase in shakeout time increased the dimensional variation in the cope, decreased variation slightly across the parting line, and decreased it more in the drag. An increase in sand compactability resulted in a slight increase in the dimensional variation for most cases. The dimensional variation was dependent on the nominal dimension and increased as the nominal dimension increased.

\section{GROSS DIMENSIONS}

In terms of the gross dimensions, clay content had the highest effect in the cope and drag, while pouring temperature was dominant across the horizontal parting line. Increases in clay always increased the dimensions, but increases in pouring temperature decreased the dimension. Shakeout time had a negligible effect in the cope but had a relatively high effect across the parting line and in the drag. An increase in shakeout increased the nominal dimension across the parting line and in the drag. Sand compactability had a very small and varying effect in the drag and across the parting line, but it had a stronger effect in the cope, where higher sand compactability decreased the nominal dimension. Pouring temperature seemed to have a dominating affect near the gating of the casting where the metal was the hottest.

The findings presented here will contribute to future efforts to reduce variations in cast iron components fabricated using green sand molds. The results indicate that control of clay content and pouring temperature are of utmost importance for reducing feature variations.

\section{ACKNOWLEDGMENTS}

This project was funded partially by Cooperative Agreement DE-FC07-98ID13612 with the United States Department of Energy. The opinions expressed in this paper are those of the authors and not necessarily those of the Department of Energy. The authors would like to thank the US DOE, the Thin Wall Iron Group of the American Foundry Society, and particularly 
the Molding Capability Steering Committee. In addition, special thanks are due to Technikon, LLC (formerly the Cast Emissions Reduction Program, CERP) for providing the castings for the study.

\section{REFERENCES}

Binichi, D., "Vacuum Process Produces Thin-Wall Iron Castings," Modern Casting, pp. 70-71, 1999.

Chandley, G.D., "Automatic Counter Gravity Casting of Shell Molds," Transactions of the American Foundrymen's Society, v 91, Paper 83-23, pp. 199-204, 1983.

Cuttino, J.F., J. Andrews, and T. Piwonka, "Developments In Thin Wall Iron Casting Technology," Transactions of the American Foundrymen's Society, v 107, Paper 99-189, pp. 363 - 372, 1999.

Davis, J.L., and J. Begg, "Dimensional accuracy and mechanical properties of thin section grey iron castings," BCIRA Technology, pp. 10-12, 1992.

Dobbener, R. and K. J. Best, "Foundry Experiences In The Use Of Late Mould_Inoculation for Production of Thin Walled S.G. and C.G. Iron Castings," presented at The Next 40 years - BCIRA Conference, University of Warwick, Apr 7 - 9, 1987.

El-Ashram, A., "Expansion Pressure of Gray Iron Castings," AFS Cast Metals Research Journal, pp.27-32, 1971.

Engler, S., D. Boenisch, and B. Kohler, "Metal and Mold Wall Movement During Solidification of Cast Iron," AFS Cast Metals Research Journal, pp. 20-30, 1973.

Gedeonova, Z., S. Bodi, J. Dul, G. Nandori and L. Vigh, "Displacement on the Surface Mould and Metal during the Solidification of Nodular Graphite Iron Castings," Materials Science Forum, vol. 215-216, pp. 391-398, 1996.

Gedeonova, Z., J. Dul, J. Koren and S. Bodi, "Effect of Mould Rigidity on the Casting-Mould Interface Movement During Solidification of Spheroidal Graphite Cast Iron," Slevarenstvi, vol. 40, no. 4, p. 145-148, 1992.

Hornung, K., "Thin Section Ductile Iron Castings," 61st World Foundry Congress, pp. 75-83, 1995.

Hummer, R., "A Study of the Shrinkage and Dilation during Solidification of Nodular Cast Iron - Its Relation to the Morphology of Crystallization," Physical Metallurgy of Cast Iron, Proc. of the 3rd International Symposium, pp. 213222, Stockholm, Sweden, Aug 29-31, 1984.

Katz, S., "Thin Wall Iron Castings - Planning the Future," Foundry Management \& Technology, pp. 34-36, 1997.

Kachru, A., Molding Capability Study for Thin Wall Iron Castings, Master's Thesis, University of North Carolina at Charlotte, 2001.

Measurement Systems Analysis - Reference Manual, Published and Copyright by the A.I.A.G., 1990.

Moore, C.M., K. Rouhrig, and R. Deike, "Auto Aluminum, is it really cost effective?," Foundry International, pp. 37-42, 1999.

Okamura, T., T. Sato, M. Naito, and T. Ohno, "An Innovative Foundry for the 21st Century," Transactions of the American Foundrymen's Society, v 107, Paper 99-46, pp. 19-24, 1999.

Peters, F.E., R. Velaga, and R.C. Voigt, “Assessing Dimensional Repeatability of Metalcasting Processes," Transactions of the American Foundrymen's Society, v 104, Paper 96-224, pp. 181-190, 1996.

Stefanescu, D., L. Dinescu, S. Cracium, and M. Popescu, "Production of vermicular graphite cast-irons by operative control and correction of graphite shape," 46th International Foundry Congress, CIATF Madrid, Spain, pp. 37-3 to 37-15, 1979.

Stroebel, G., "Complex Thin Wall Castings - A specialty of GEC Foundries Company," Foundry Trade Journal International 5 (20), pp. 227-228, 1983.

Winter, B.P., T.R. Ostrom, D.J. Hartman, P.K. Trojan and R.D. Phelke, "Mold Dilation and Volumetric Shrinkage of White, Gray, and Ductile Cast Irons," Transactions of the American Foundrymen's Society, v 92, Paper 84-69, pp. 551-560, 1984.

Yang, Y. and J. Alhainen, "Quantitative Study on the Shrinkage Behavior of SG Iron with Derivative Dilatation Analysis," Transactions of the American Foundrymen's Society, v 100, Paper 92-97, pp. 129-133, 1992.

Viets, R., M. Breuer, H. Haferkamp, and T. Kruessel, "Solidification Process and Infrared Image Characteristics of Permanent Mold Castings," Proceedings - SPIE, The International Society for Optical Engineering 0277-786X 1999, Issue 3700, pp. 132-140, 1999. 


\title{
The Effects of Shot Blasting on Dimensional Variation of Castings
}

\author{
J. F. Cuttino \\ The University of North Carolina at Charlotte, Charlotte, NC \\ A. Kachru \\ Cummins, Inc., Columbus, IN \\ E. Morse \\ The University of North Carolina at Charlotte, Charlotte, NC \\ T. Piwonka \\ The University of Alabama, Tuscaloosa, AL
}

Copyright 02001 American Foundry Society

\begin{abstract}
The effects of shotblasting on the dimensional variation and metrology of thin features of iron castings are presented. The study was conducted as part of the efforts of the Thin Wall Iron Group (TWIG) of the American Foundry Society. In the study, iron castings with thin features (thicknesses of $13 \mathrm{~mm}$ and less) were fabricated and subjected to successive shotblasting treatments. The casting features were measured between each treatment, and variables such as dimensional variation of the sampling and nominal dimension were analyzed.
\end{abstract}

Both the dimensional variations and the nominal dimensions of the casting features are shown to decrease with additional shotblasting. This result raises questions as to the measurement of the actual bulk material. For example, the dimensional variation is considered to be a measure of the quality of the structural part. However, if this is the case, the surface asperities could be considered random and should not affect the dimensional variation. Therefore, the study concludes that if the variation decreases because the surface finish is improved, the measurement of the variation in the "bulk" dimension is flawed because the variation is partly due to surface asperities that provide little structural contribution. The point is also made that shotblasting may provide an economical solution to reducing variation and subsequently the design dimension, casting weights, and dimensional scrap rates as long as warping and other effects are not detrimental.

\section{INTRODUCTION}

Recent efforts in the metal casting industry are addressing the need to become more energy efficient and cost effective by providing better dimensional control of castings and reducing casting weight. The anticipated energy savings are found in numerous areas, including the reduction in the total amount of metal melted and poured for a given number of castings, the reduction in scrap materials generated, and the design of thinner and more accurate features in near-net shape castings. The premise is that more accurate castings will provide energy and cost savings while improving the market for iron castings by making them a more viable alternative in non-traditional areas such as the aerospace industry.

In attempting to meet this goal, the University of North Carolina at Charlotte and the University of Alabama have conducted collaborative research that focuses on the improvement of the green sand molding process and subsequent cleanup techniques, particularly as applied to thin wall castings. The motivation is that castings are often oversized to allow for variations in production. For example, many features in the automotive industry such as engine manifolds and water jackets require wall thicknesses of less than $4 \mathrm{~mm}$ to be structurally sound, but dimensional variations of $\pm 1 \mathrm{~mm}$ require that design specifications be as much as $25 \%$ larger, thus adding weight. The work presented here describes the effect that shot blasting has on the measured dimensional variation in castings and its potential in the fabrication of thin wall iron castings.

This work was originally initiated as a parametric study of the effects of changing process parameters on the dimensional variation of thin wall castings. In conducting that research, it became apparent that the metrology of the castings being studied was strongly affected by the amount of shot blasting they had received. This being the case, the authors began a parallel experiment to quantify the affects of shot blasting on the castings. The results are presented in this paper. The results apply to the single test casting used in the study, which contained "thin" features, but none less than $5 \mathrm{~mm}$ thick. The results therefore apply for more traditional castings, but not extra-thin features of $3 \mathrm{~mm}$ and less, where warping and tearing may take place. 
A literature search was conducted to identify works directly studying the interaction of surface finish and tolerancing. References that are remotely pertinent are varied in scope, ranging from studies on mold-wall movement to shot blasting processes. Emphasis of the search was placed on metrology techniques and the development of thin wall iron castings.

Production of thin wall gray iron castings in the United States was reported as early as 1981 (Bailey, 1981). Unfortunately, the production of thin wall iron castings in ductile iron or compacted graphite iron is apparently limited to simple geometries such as exhaust manifolds. Numerous automotive manufacturers have investigated the production of more complicated castings such as engine blocks in an effort to reduce weight and improve gas mileage. The complexity of these products has, for the most part, prevented the overall success of such efforts.

Several factors affect the dimensional metrology of castings in a foundry. One study (Davis and Begg, 1992) has shown that different sand binders and thermally insulating materials play an important role in reducing variation. Peters, et al. (1996) claim that dimensional variation shows a dependence on feature length and casting weight. The authors also point out that the current dimensional standards for production castings do not provide an accurate picture of the dimensional capabilities of different casting industry segments. Kaul (1995) suggests that dimensional variation is an important parameter to consider in ensuring customer satisfaction.

Numerous works have been published on the effects of shot peening on castings. Shot peening is a mechanical method of imposing a residual compressive stress at the surface of a metal part. It is accomplished by pelting the surface of a metal part with round metallic shot thrown at relatively high velocity (Anderson, 1953). An article that appeared in Foundry

Management \& Technology (author unknown, 1997) describes the shotpeening process. As pellets strike a casting surface, they make slight indentations that cause plastic flow and stretching of the surface layers of the metal, imposing a residual compressive layer of stress at the surface. There are numerous factors that need to be taken into account when selecting shot, including the type, size, geometric configuration, length, width, height, diameter, and weight of the part. Numerous works document the use of shot peening to improve fatigue strength (Simonin and Flavenot, 1987; Welsch, 1990; DeLitizia, 1984), reduce porosity, and improve casting surface quality (DeLitizia, 1982). Several studies have shown that shot peening also improves the surface of the castings and reduces dimensional variability. However, few were found that directly addressed the finishing of thin walled sections.

\section{EXPERIMENTAL APPROACH}

The study was conducted using castings that were fabricated at Technikon, LLC (formerly the Cast Emissions Reduction Program, or CERP), a research foundry in Sacramento, California. The castings consist of 12 thin webs arranged in a star-like pattern as illustrated in Fig. 1. The nominal dimension of the horizontal surfaces across the parting line is $12.5 \mathrm{~mm}$. The vertical fins are drafted at $3^{\circ}$ and have a nominal dimension at the edge of $5.5 \mathrm{~mm}$ in the cope and $6.5 \mathrm{~mm}$ in the drag. These star castings are of intricate design given that the metal has to flow in every direction in order to reach the cavity of the part. Six castings, or serials, are cast in a single mold. For the purpose of this study, a single serial (serial 5) was chosen for measurement in order to remove variations due to placement in the mold. A total of 28 star castings were used in the study at each level of shot blasting.
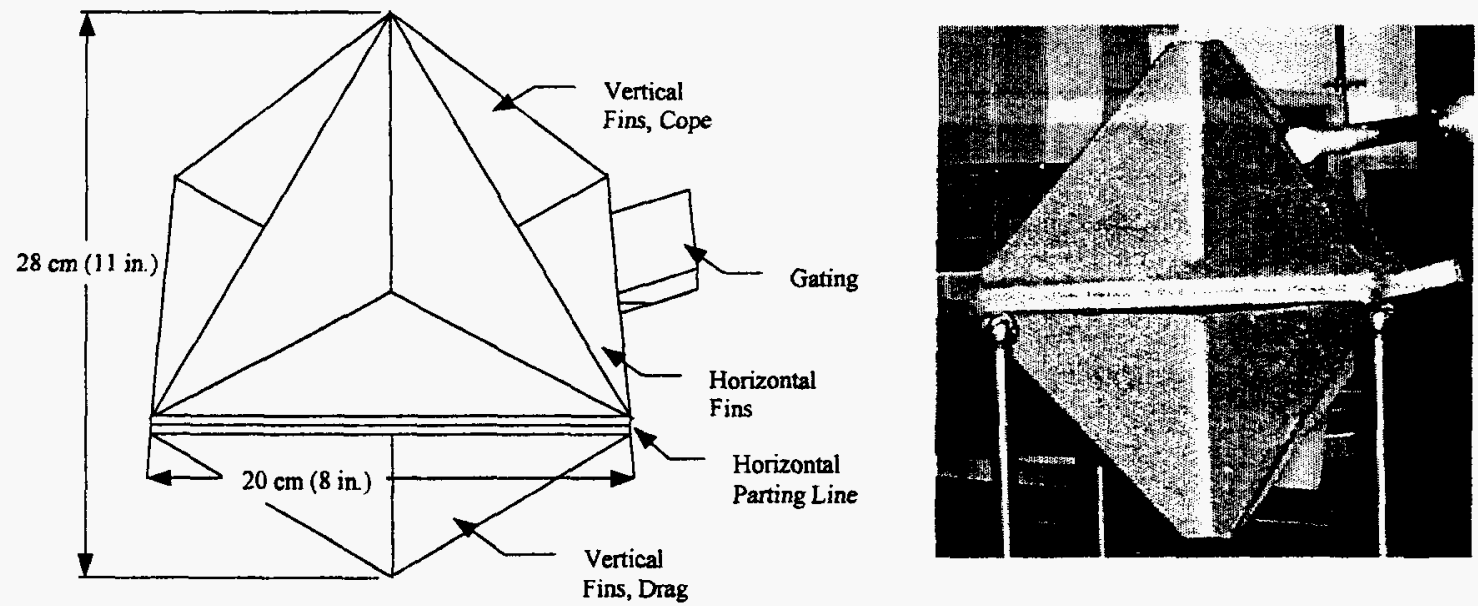

Fig. 1: "Star" casting 
A Brown and Sharpe Xcel $765 \mathrm{CMM}$ was used to measure the thicknesses of the fins at specified locations on the star castings using a program created in Quindos software.The program measures 108 thickness values at different points on the test part and writes them to a file which can be downloaded and opened in a database package for analysis. The metrology sequence included four procedures that were performed for each case, the measurement of the castings using the CMM, verification of CMM performance, measurement of the intensity of the shotblast, and measurement of the resulting surface finish. Each procedure is discussed below.

Nine points were measured on each fin as shown in Fig. 2. Out of these nine points, five were measured towards the outer most edge in a nominally straight line. The selection of 5 points along the free plane ensured that third order and lower deformations could be measured. This scheme is illustrated in Fig. 3, where the measurement of less than 5 points would not capture the warping effect shown. Higher order deformations were assumed to be negligible in amplitude.

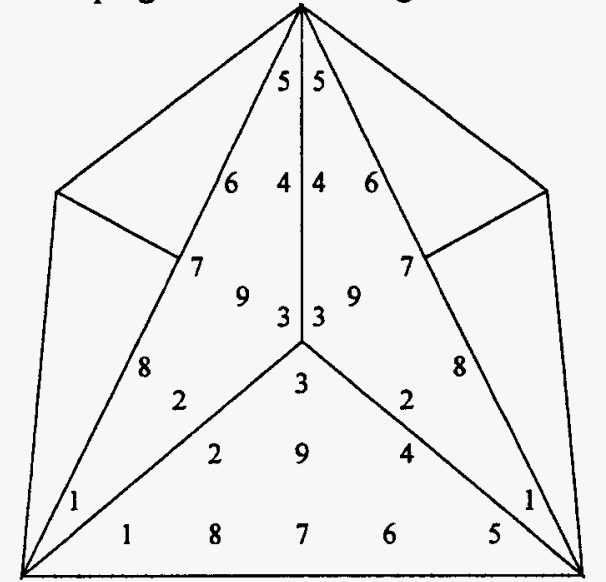

Fig. 2: Locations of the measured points on the triangular webs of the test casting

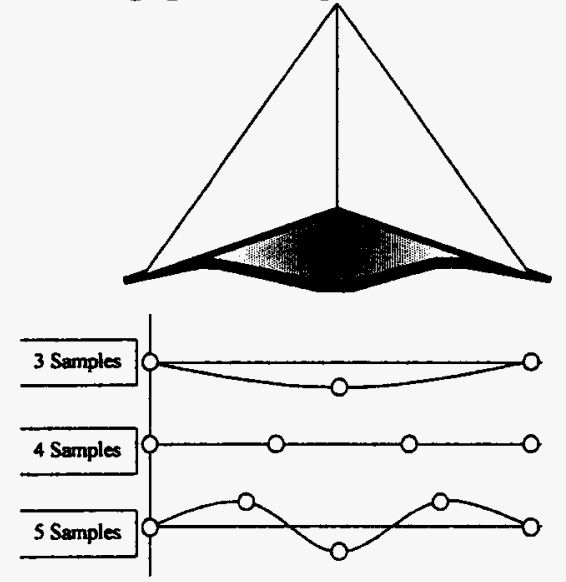

Fig. 3: Effects of sampling on warpage analysis

Because of the complex shape of the star casting, several probe orientations were required in order to avoid collisions and to eliminate the need to reorient the casting during measurement. An indexable Renishaw PH9 probe head was used to provide the fifteen different probe orientations required by the program. A kinematic fixture was used to restrain the casting in six degrees of freedom on the CMM. The fixture is shown in Fig. 4. It consists of three precision balls mounted on posts. Each ball contacted the casting at two points on two orthogonal sides of the casting, constraining motion in all six degrees of freedom.

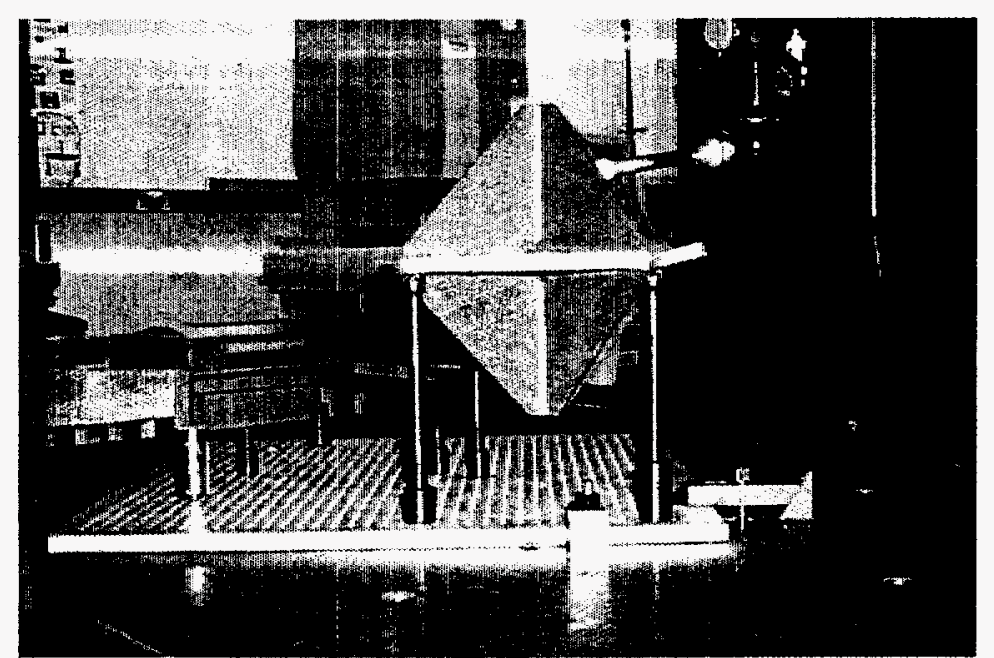

Fig. 4: Setup for the measurement of Star Casting on the CMM

Experiments were conducted to optimize the sampling strategy of the CMM. Because of the high surface roughness values of the castings (as high as 300 micrometers peak to valley), experiments were conducted to compare various probe tip sizes and sampling techniques. Samples were taken with $3 \mathrm{~mm}$ ruby probes and an $18 \mathrm{~mm}$ ceramic probe to compare variation. A star 
casting was measured five times with each of the probes to compare the variation of the features from one run to another. The $18 \mathrm{~mm}$ probe appears to provide an averaging effect to the sample, thereby reducing the average variations in the metrology of the castings from $18 \mu \mathrm{m}$ for the $3 \mathrm{~mm}$ probe to $8 \mu \mathrm{m}$ for the $18 \mathrm{~mm}$ probe. Three-point sampling was also examined to see if it provided any benefits compared to one-point sampling. The study was conducted using the $18 \mathrm{~mm}$ probe. Three-point sampling proved to be of little benefit, because the large diameter ball tended to provide the same filtering. The repeatability of both strategies was $5 \mu \mathrm{m}$ for one point sampling and $4 \mu \mathrm{m}$ for a three point sampling. The one-point sampling strategy was therefore adopted since a $1 \mu \mathrm{m}$ gain in repeatability would double the measuring time for the star casting.

Definition of the part coordinate systems was also found to be a critical step in the metrology of the castings. Manually defining the coordinate system in a single step directly off of the part resulted in errors that often exceeded $100 \mu \mathrm{m}$. A fourstep procedure was therefore used to define the coordinate system. In this procedure, an initial coordinate system was identified by operating the CMM in manual mode and touching-off of the three balls on the fixture. This initial coordinate system was then verified and modified by repeating the procedure using direct computer control (DCC). The part was then placed on the fixture and a new part coordinate system was defined relative to the modified fixture coordinate system under DCC. The final coordinate system was established by re-sampling the part using the part coordinate system, thereby providing for iterative improvements in the definition of the coordinate system.

\section{CMM PERFORMANCE VERIFICATION}

In order to test the machine's ability to report a consistant value of the measurand, a Gage Repeatability and Reproducibility (Gage R\&R) Study was conducted prior to measuring the 28 castings after each shot blasting procedure. The repeatability determined by the Gage R\&R analysis yields information concerning the ability of the CMM to repeat a measurement accurately without any changes to the system or object being measured. The reproducibility, or appraiser variation, measures the influence that changing conditions (different operators) have on the measurements. The repeatability and reproducibility value is a combination of the machine and operator errors and is useful for distinguishing the variation in the part from the variation in the measuring process.

The purpose of conducting the Gage R\&R study between each shot blasting treatment was twofold. The first purpose was to determine if the Gage $R \& R$ varied with additional finishing. The second purpose was to determine whether there was a direct correlation between the Gage $R \& R$ and the part variation in the case that Gage $R \& R$ did vary.

The stars were originally shot blasted at Technikon using a Jet Wheel Blast model PT-12A with two (2) 15 HP shot motors on one side of the cabinet located 45 degrees above and below centerline of the feed stock. The shot was originally composed of $75 \% 460$ steel shot and $25 \% 390$ steel shot. The relative intensity of the original shot blasting were not measured due to the logistics of the manufacturing process; however, the 28 castings were all processed together so that the treatment was similar and could be considered as a benchmark. Once the castings arrived at UNC Charlotte, they were measured in an asreceived condition for benchmarking. They then received additional shot blasting at Charlotte Pipe and Foundry with 360 steel shot on a US Filter Wheelabrator A142462 with eight 20-HP wheels, four above the feed stock and four below, and a continuous mesh belt conveyor running at $3 \mathrm{ft} / \mathrm{min}$. They were then returned to UNC Charlotte for measurement. The process was repeated a total of four times, so that 5 states of finishing were analyzed.

The Gage $R \& R$ analysis was conducted using three locations on the star that were assumed to be representative of the various feature orientations on the part. One of the points was selected on the horizontal surface and the other two were selected on two perpendicular vertical surfaces in order to capture variations due to six degree-of-freedom movement. The relationship between Gage R\&R and dimensional variation was then examined, the results of which are included below.

\section{MEASUREMENT OF SHOT BLASTING INTENSITY}

In order to measure the effects of the shot blasting process, a test star was instrumented with six Almen strip indicators, which are used to measure the intensity of incident shot blast on the casting, as shown in Fig. 5. An Almen strip is a thin metallic strip which is mounted to a holder with a single face exposed to the shot. As the outer surface is peened, it deforms, causing the top layer to elongate. This causes the strip to curve when removed from the fixture, and the amount of curvature is a nonlinear function of the intensity of the shot blast process. While the actual correlation between the deflection of the strip and the shot blasting intensity is very much a topic for continued research (Davis and Begg, 1992, and Peters, Valaga, and Voigt, 1996) it is still a valid measure of the relative intensity. Since each of the additional treatments was nominally equal to the previous (with the exception of the last treatment), the measure of intensity was considered to be linear for comparison purposes. 
The instrumented test casting is shown in Fig. 5. Only four of the six Almen strip mounting blocks are visible, while two more are located on the side not visible in the figure. The strips were distributed around the casting so as to provide directional information. The test casting was run through the shot-blasting machine with the 28 castings to measure the actual intensity. The results were used to correlate shot blasting intensity with dimensional variation.

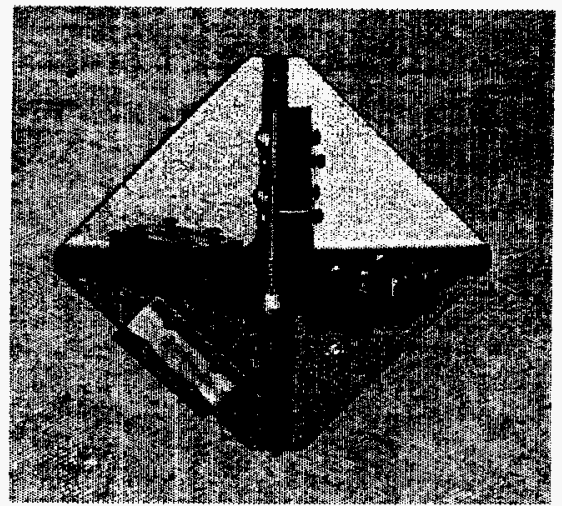

Fig. 5: Instrumented star part with fixtures for holding the Almen strip

\section{MEASUREMENT OF SURFACE FINISH}

As a final check for the finish study, resulting values for surface finish were measured using a Federal Surfanalyzer 5000 stylus profilometer. A single trace was taken on each of the four horizontal surfaces for each of the 10 stars used in the study. The results were used to determine if correlations could be drawn between the surface roughness and dimensional variation.

\section{RESULTS}

The results of the four measurement areas described above are presented in the following sections. The results are presented individually and then several correlations are drawn relating the areas.

\section{DIMENSIONAL MEASUREMENTS}

A total of 108 thickness values were collected on each casting, representing nine points on each of the 12 fins of the star. For this analysis, the fins were grouped into one of the three categories, horizontal fins, vertical cope fins, or vertical drag fins. The sampled thicknesses were then grouped accordingly; for example, the 28 measured values for point number 1 on horizontal surface number 1 were combined with the values for point number 1 on horizontal surfaces 2 through 4 , for a total of 112 values. The standard deviation of these 112 points was then calculated, yielding a single value of standard deviation for point number 1 on any horizontal surface. Similar groupings were conducted for the remaining 8 positions as well as for the vertical cope and drag surfaces.

Fig. 6a shows the standard deviation values of the four vertical surfaces in the cope portion of the star casting. Note that there is a relatively large value for standard deviation at point 3 because of excessive burn-in that occurred near the center of the casting, which was present even after the cleanup process. The standard deviation values follow a similar pattern for the drag surfaces, as shown in Fig. 6b, except that burn-in was even more excessive. Fig. 6c shows the standard deviation values of the nine points on the four horizontal surfaces of the star part over the 28 measured castings. Again point 3 has a higher value for the standard deviation because of the burn-in material present. If point 3 is neglected, the cope and drag appear similar, with low values of standard deviation of $<0.1 \mathrm{~mm}$ at point number 8 and high values of $<0.15 \mathrm{~mm}$ at point number 5 . Horizontal surfaces had a slightly higher but a similar dimensional variation even though the nominal dimension of the horizontal surfaces is higher. The surface roughness of the castings in an unfinished state was very high and probably contributed strongly to the measured variations shown in Fig. 6. 


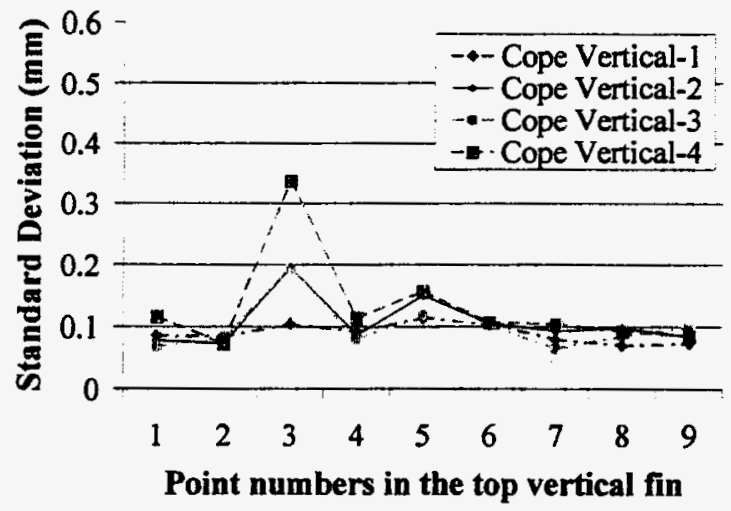

a) Cope Vertical Surface

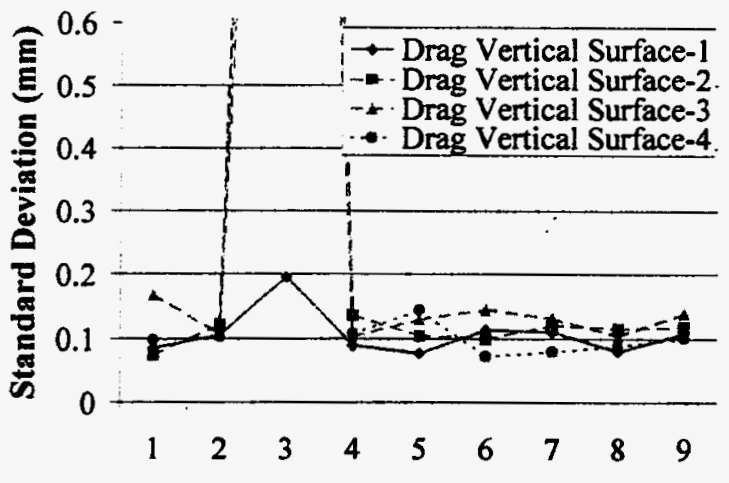

Point Number on the bottom vertical fin

b) Drag Vertical Surface

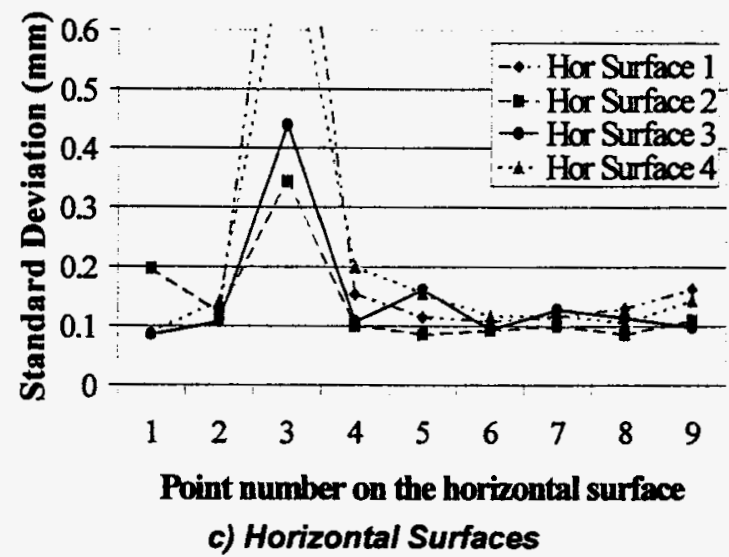

Fig. 6: Benchmark Measurements of Standard Deviation at Measurement Points

In order to determine the effects of shot blasting on the castings, they were shot blasted four additional times and measured for each iteration. For illustration, the measurements of standard deviation following four rounds of shot blasting are shown in Fig. 7. It is clear that there is a significant change in the dimensional variability of the 28 castings after the shot blasting process. Values for the cope fins decreased from $125 \mu \mathrm{m}$ to $50 \mu \mathrm{m}$, representing a $60 \%$ reduction. Variation in the drag fins decreased from $125 \mu \mathrm{m}$ to $60 \mu \mathrm{m}$, or $55 \%$. The horizontal surfaces showed similar trends, dropping from $1.6 \mathrm{~mm}$ to $0.8 \mathrm{~mm}(50 \%)$.

Fig. 8 shows the effect of the shot blasting process over the five stages of the finish process (including the state as delivered from Technikon) and the additional shot blast treatments conducted at Charlotte Pipe and Foundry. Note that point 3 was neglected since it had a much higher value for the standard deviation due to burn-in. The five lines represent the standard deviation of the remaining eight points over the five stages of shot blasting. The change between treatments was significant. For example, the standard deviation for point 1 dropped from 0.105 to $0.055 \mathrm{~mm}$, representing a $48 \%$ decrease. Similar trends followed for the other points.

These results are presented in different formats in Fig. 9 and Fig. 10. In Fig. 9, the 8 lines represent the standard deviation of points 1,2 , and 4 through 9 over the five steps of the finish process. The slope of the lines represents the decrease in the standard deviation of the dimensions after each step of shot blasting. 


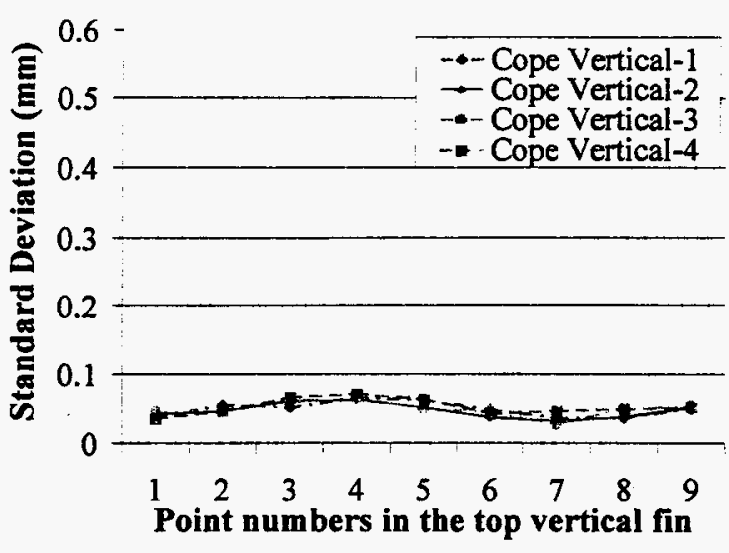

a) Cope Vertical Surface

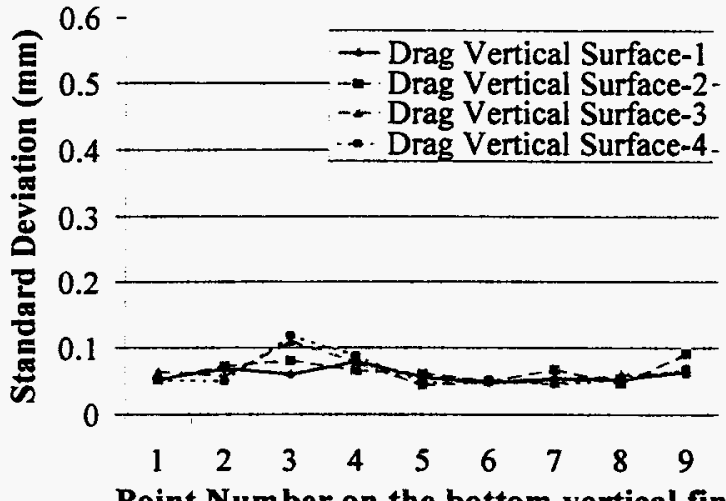

b) Drag Vertical Surface

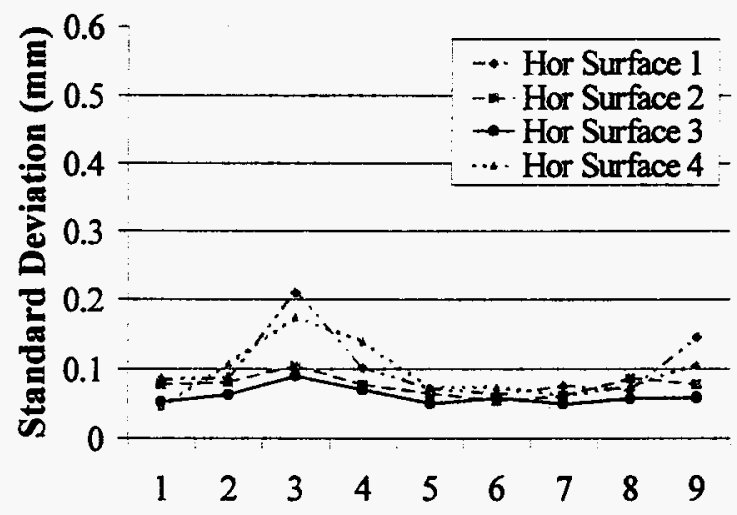

Point number on the horizontal surface

c) Horizontal Surfaces

Fig. 7: Measurements of Standard Deviation after Four Shot Blast Runs

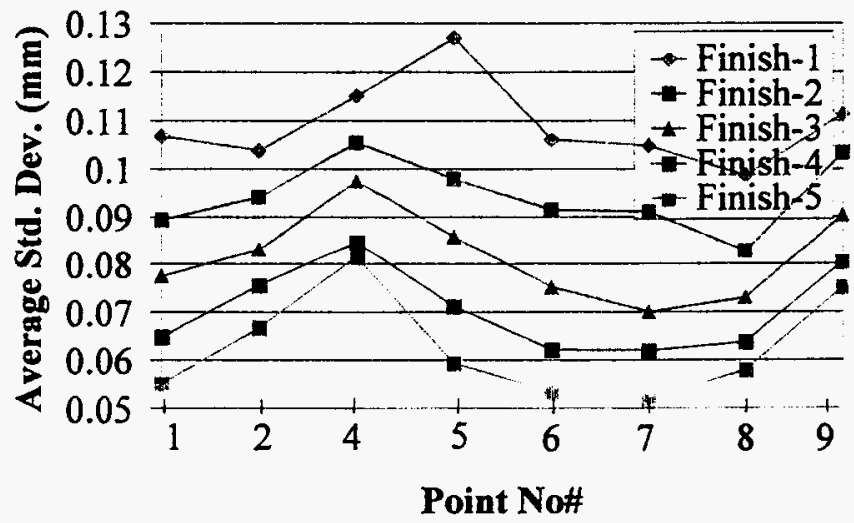

Fig. 8: Average Standard Deviation after Finish Steps 1, 2, 3, 4 and 5 


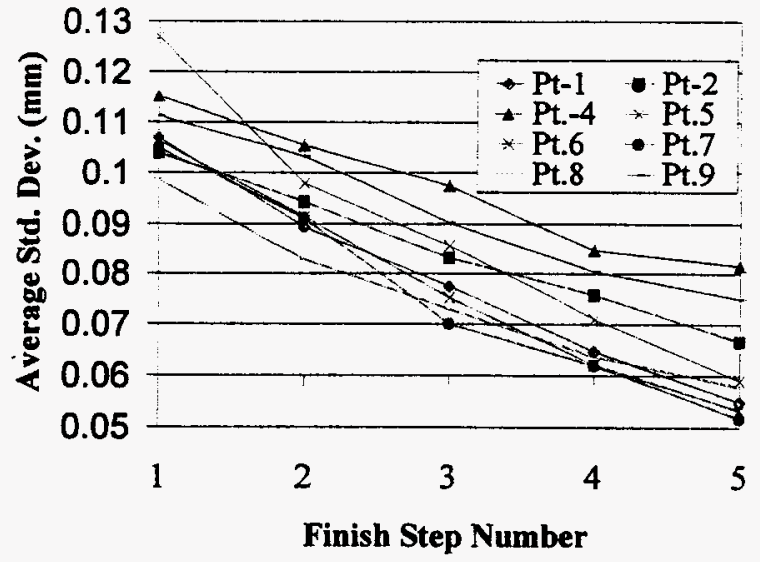

Fig. 9: Average Standard Deviation after Finish Steps-1, 2, 3, 4 and 5

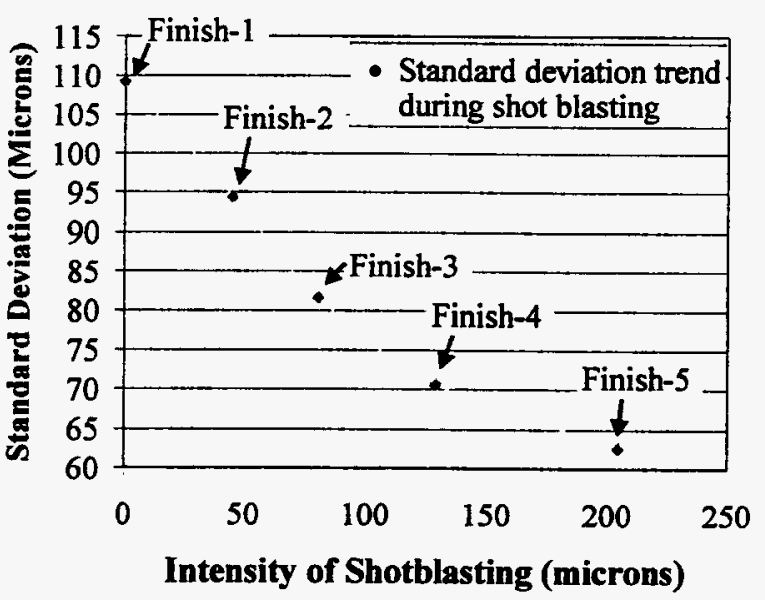

Fig. 10: Effect of shot blasting on the Average Standard Deviation

Fig. 10 summarizes the effect of shot blasting over the five steps. The Y-axis represents the value of the standard deviation in microns and the horizontal axis represents the cumulative deflection of the Almen strips in micrometers. The five points on the line represent the average standard deviation of all of the features over each step. The average standard deviation decreases from 109 to 63 microns after the shot blasting process.

During the shot blasting process, the nominal dimension of all of the 108 features decreased by $0.2 \mathrm{~mm}$. This result raises questions as to the measurement of the actual bulk material. For example, was the benchmark measurement artificially large due to surface asperities, or is the bulk material compressed through the shot blasting process? If the variation decreases because the surface finish is improved, the measurement of the variation in the "bulk" dimension is flawed and the variation is simply due to surface asperities that provide no structural contribution (although it plays a significant role through the introduction of stress risers). If, however, variation is being decreased by the shot blast process, it may provide a very economical solution to reducing variation and subsequently the design dimension, casting weights, and scrap rates. It should be noted, however, that the detrimental effects of shot blasting must also be considered such as the extreme warping of very thin features and work hardening. These issues are beyond the scope of this work but are included in the references sited in the background.

\section{CMM PERFORMANCE}

Results from the Gage R\&R analyses are presented in Table 1 and Table 2. Table 1 is a representative report of the Gage $R \& R$ analysis and was generated for the "as-received" condition of the castings. The figure breaks the measurement variation into several components in order to separate the effects of the machine's ability to make the measurement from the effects of using different operators. For example, repeatability refers to the ability of the CMM to repeat a measurement accurately, and the values measured reached as high as $21 \mu \mathrm{m}$. This variation is likely due to the large asperities on the part and the fact that positioning of the probe is not exact (a CMM can measure a position accurately, but it cannot go to a position accurately, therefore the probe was not placed in exactly the same position each time). It is interesting to note that the repeatability is better for the horizontal surface than for the vertical surfaces by around $5 \mu \mathrm{m}$. The important point is that the repeatability values constitute less than $7 \%$ of the total variation measured on the part for any of the three points. 
Table 1: Gage R\&R Results for Three Locations

\begin{tabular}{|l|c|c|c|}
\hline $\begin{array}{l}\text { Measurement Unit Analysis and } \\
\% \text { Process Variation }\end{array}$ & Horizontal Surface & $\begin{array}{c}\text { First Vertical } \\
\text { Surface }\end{array}$ & $\begin{array}{c}\text { Second Vertical } \\
\text { Surface }\end{array}$ \\
\hline $\begin{array}{l}\text { Repeatability - Equipment } \\
\text { Variation (EV) }\end{array}$ & $14.7 \mu \mathrm{m}$ & $19.5 \mu \mathrm{m}$ & $21.1 \mu \mathrm{m}$ \\
\hline \% Equipment Variation & $2.64 \%$ & $6.64 \%$ & $4.75 \%$ \\
\hline $\begin{array}{l}\text { Reproducibility-Appraiser } \\
\text { Variation (AV) }\end{array}$ & $6.81 \mu \mathrm{m}$ & $5.8 \mu \mathrm{m}$ & $4.0 \mu \mathrm{m}$ \\
\hline$\%$ Appraiser Variation & $1.22 \%$ & $1.98 \%$ & $0.91 \%$ \\
\hline $\begin{array}{l}\text { Repeatability and Reproducibility } \\
\text { (R \& R) }\end{array}$ & $16.2 \mu \mathrm{m}$ & $20.3 \mu \mathrm{m}$ & $21.5 \mu \mathrm{m}$ \\
\hline \% R\&R & $2.91 \%$ & $6.93 \%$ & $4.84 \%$ \\
\hline Part Variation (PV) & $556.7 \mu \mathrm{m}$ & $293.4 \mu \mathrm{m}$ & $444.7 \mu \mathrm{m}$ \\
\hline$\%$ Part Variation & $99.96 \%$ & $99.76 \%$ & $99.8 \%$ \\
\hline Total Variation (TV) & $556.949 \mu \mathrm{m}$ & $294 \mu \mathrm{m}$ & $445.2 \mu \mathrm{m}$ \\
\hline
\end{tabular}

Appraiser variation is a measure of the influence different operators have on the measurement. For example, if one operator is more aggressive than another, the measurement can be affected by differences in approach speed or measuring force. The fact that the Xcel CMM is numerically controlled removes a great deal of appraiser variation. Originally, the appraiser variation values were significant because of the errors in placing the stars on the fixture. The inclusion of redundant checking and definition of the part coordinate systems compensated for inexact placement of the stars on the fixture and reduced those errors. Subsequently, the appraiser variations were less than $2 \%$ of the total variation for each of the three cases.

The repeatability and the reproducibility (Gage $R \& R$ ) is a combination of the machine, environmental, and operator errors, and is useful for distinguishing from the variation in the part and the variation in the measuring process. The maximum Gage $R \& R$ is $7 \%$ of the total variation, but it is interesting to note that the Gage R\&R is higher for both vertical surfaces (20 $\mu \mathrm{m}$ and $22 \mu \mathrm{m})$ than for the horizontal surface $(16 \mu \mathrm{m})$. The small percentages, however, are due to the large values for total variation, and serve only to justify neglect of measurement errors.

Part variation was significant for the castings measured, with $557 \mu \mathrm{m}$ for the horizontal surface and $294 \mu \mathrm{m}$ and $445 \mu \mathrm{m}$ for the two vertical surfaces. These represented over $99.7 \%$ of the total variation. Note that the variations from the appraisers, machine, and part are not additive because of overlap in the measurements; they are simply indications of the total effects. Because these effects are assumed to be independent, the root-sum-square of these values gives the total variation.

Table 2 and Fig. 11 compare the Gage R\&R values for each shot blasting treatment. The Gage R\&R shows no obvious trend as a function of shot blasting treatment, an expected result since it is really a measure of operator and machine capabilities.

Table 2: Gage R\&R Values vs. Location and Finish

\begin{tabular}{|l|c|c|c|c|c|}
\hline $\begin{array}{l}\text { Point } \\
\text { location }\end{array}$ & $\begin{array}{c}\text { Finish 1 } \\
(\mu \mathrm{m})\end{array}$ & $\begin{array}{c}\text { Finish 2 } \\
(\mu \mathrm{m})\end{array}$ & $\begin{array}{c}\text { Finish 3 } \\
(\mu \mathrm{m})\end{array}$ & $\begin{array}{c}\text { Finish 4 } \\
(\mu \mathrm{m})\end{array}$ & $\begin{array}{c}\text { Finish 5 } \\
(\mu \mathrm{m})\end{array}$ \\
\hline $\begin{array}{l}\text { Horizontal } \\
\text { Point }\end{array}$ & 16.2 & 6.5 & 12.4 & 6.5 & 6.5 \\
\hline $\begin{array}{l}\text { Vertical } \\
\text { Point-1 }\end{array}$ & 20.3 & 13.5 & 10.4 & 20.1 & 25.3 \\
\hline $\begin{array}{l}\text { Vertical } \\
\text { Point-2 }\end{array}$ & 21.5 & 11.9 & 43 & 33.3 & 33.3 \\
\hline
\end{tabular}




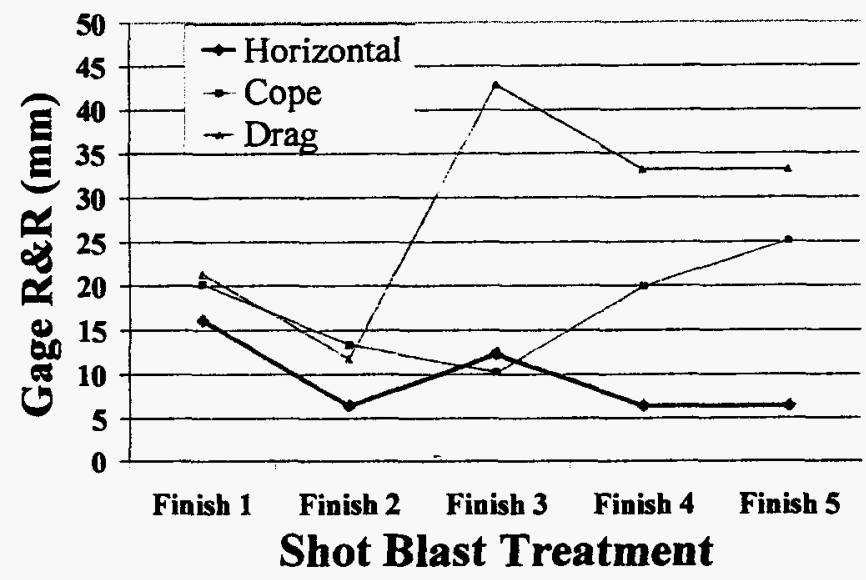

Fig. 11: Gage R\&R as a Function of Finish Treatment

The deflections of each of the Almen strips at the six different locations and for the four times the test casting was run through the shot blasting machine are documented in Table 3. The results are shown in Fig. 12a and Fig. 12b. Fig. 12a plots the mean values of the surface roughnesses of the 4 horizontal surfaces for a particular finish run, while Fig. $12 \mathrm{~b}$ plots the average of the four values of the standard deviations obtained for each of the horizontal fins. Each of the two plots verify that surface finish is improving, an obvious and expected conclusion. The interesting point is that the standard deviation did not improve from the benchmark run (run 1) to run 2, but instead increased by $0.17 \mu \mathrm{m}$. The reason for these results could be the quality of shot blasting. At times shot blasting could have hit some areas of the surface while skipping other areas on the same surface, leaving an uneven pattern that was detected by the Federal Gage probe as a rough surface. The possibility of this occurring is increased since the castings were sent through the Wheelabrator a single time for each treatment rather than multiple times. This conclusion does not necessarily mean that shot blasting was not effective; again when looking at the overall result, the surface roughness was better after shotblasting.

Table 3: Almen strip deflections at six different locations on the test casting

\begin{tabular}{|c|c|c|c|c|}
\hline Location & $\begin{array}{c}\text { Shot blast-1 } \\
\text { Deflection (in) }\end{array}$ & $\begin{array}{c}\text { Shot blast-2 } \\
\text { Deflection (in) }\end{array}$ & $\begin{array}{c}\text { Shot blast-3 } \\
\text { Deflection (in) }\end{array}$ & $\begin{array}{c}\text { Shot blast-4 } \\
\text { Deflection (in) }\end{array}$ \\
\hline Position-1 & 0.0069 & 0.0039 & 0.0047 & 0.0059 \\
\hline Position-2 & 0.0102 & 0.0112 & 0.0024 & 0.0099 \\
\hline Position-3 & 0.0061 & 0.0080 & 0.0085 & 0.0108 \\
\hline Position-4 & 0.0094 & 0.0043 & 0.0048 & 0.0068 \\
\hline Position-5 & 0.0062 & 0.0108 & 0.0085 & 0.0087 \\
\hline Position-6 & 0.0077 & 0.0065 & 0.0066 & 0.0069 \\
\hline Average & 0.0078 & 0.0075 & 0.0059 & 0.0081 \\
\hline
\end{tabular}

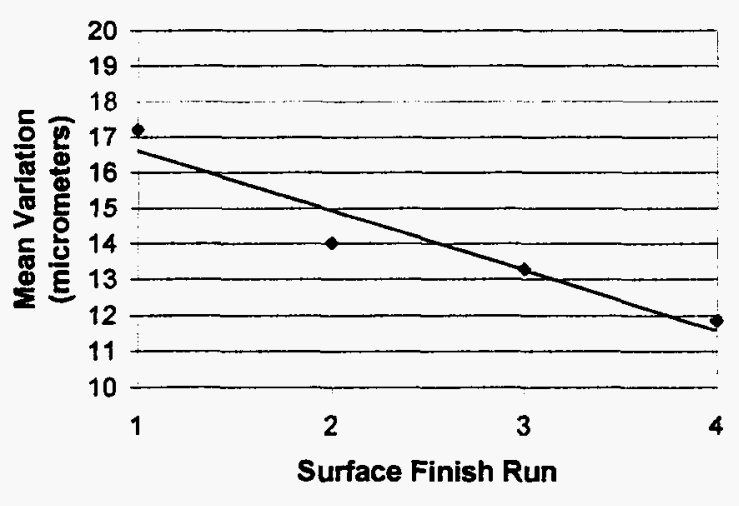

a) Mean Variation

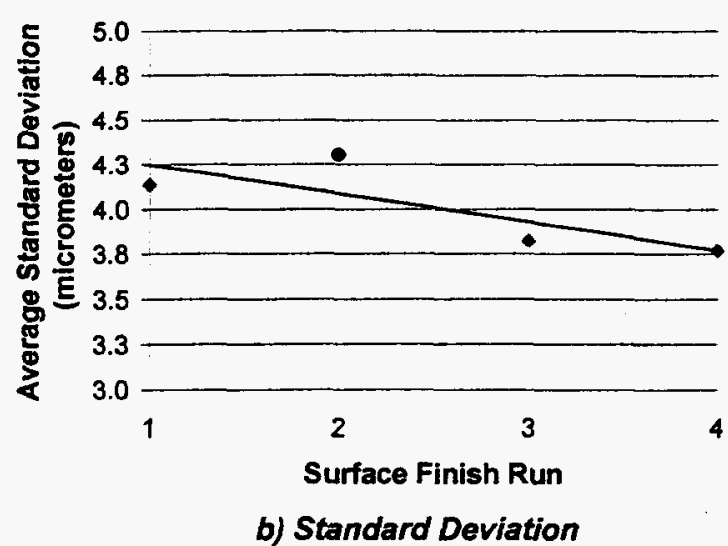

b) Standard Deviation

Fig. 12: Effects of Shot Blasting on Measured Surface Roughness 


\section{CONCLUSION}

Shot blasting decreases the dimensional variability significantly. If the variation decreases because the surface finish is improved, the measurement of the variation in the "bulk" dimension is flawed and the variation is simply due to surface asperities that provide no structural contribution. If the variation is being decreased by the shot blasting process, it may provide a very economical solution to reducing variation and subsequently the design dimensions, casting weight, and scrap rates. It is intuitive that the reduction in dimensional variability may reach a limit that can be achieved through shot blasting. Also the nominal dimension appears to decrease with additional shot blasting. The surface finish of the castings improves after shot blasting, and the average standard deviation of the batch can be predicted from the average part variation from the Gage R\&R test, as these values are proportional.

\section{ACKNOWLEDGMENTS}

This project was funded partially by Cooperative Agreement DE-FC07-98ID13612 with the United States Department of Energy. The opinions expressed in this paper are those of the authors and not necessarily those of the Department of Energy. The authors would like to thank the US DOE, the Thin Wall Iron Group of the American Foundry Society, and particularly the Molding Capability Steering Committee. In addition, special thanks are due to Charlotte Pipe and Foundry for shot blasting the castings used in the study.

\section{REFERENCES}

Anderson, E.F., "Shot peening...to reduce porosity in die castings," Modern Metals, 9, 1957.

Davis J.L., and J. Begg, "Dimensional accuracy and mechanical properties of thin section gray iron castings," BCIRA Technology, pp. 10-12, 1992.

Delitizia, A.T., "Improved Fatigue Life through Advanced Shot Peening Techniques," Manufacturing Engineering (05), pp. 85-87, 1984.

DeLitizia, A.T., "Shot Peening For Improved Castings," Modern Castings 72 (10), pp. 26-28, 1982.

Kachru, A., Molding Capability Study for Thin Wall Iron Castings, Master's Thesis, University of North Carolina at Charlotte, 2001.

Kaul, S., "Dimensional Tolerance Key to Customer Satisfaction," presented at the 43rd Indian Foundry Congress, Madras, pp. 3-5, Feb 1995.

Measurement Systems Analysis - Reference Manual, Published and Copyright by the A.I.A.G., 1990.

Peters, F.E., R. Velaga, and R.C. Voigt, “Assessing Dimensional Repeatability of Metalcasting Processes," AFS Transactions 224, pp. 181-190, 1996.

Simonin, P., and J Flavenot, "Shot Peening of Nodular Cast Iron," presented at the International Conference on Shot Peening, 1987.

Unknown, "Shakeout/ Cleaning/ Finishing," Foundry Management \& Technology 125 (01), pp. G3-G10, 1997.

Welsch, W., "Peening Improves Fatigue Life," Welding Design \& Fabrication 63 (09), 38-40, 1990. 


\title{
Current Thin Wall Iron Molding Capability - A Round Robin Study
}

\author{
J. F. Cuttino \\ The University of North Carolina at Charlotte, Charlotte, NC \\ E. Morse \\ The University of North Carolina at Charlotte, Charlotte, NC \\ T.S. Piwonka \\ The University of Alabama, Tuscaloosa, AL
}

Copyright 02001 American Foundry Society

\begin{abstract}
This paper presents the last of four studies conducted to investigate the current capabilities of foundries to produce green sand molds capable of producing thin wall iron castings with reduced dimensional variations. The paper presents data obtained in a round robin study where participating foundries were asked to produce castings from a common pattern on vertical parting (Disamatic) molding machines using their existing practices.
\end{abstract}

Trends are reported and compared to the results from three studies conducted earlier in the project in a research foundry. Results are presented showing the degree of dependence of variation on four molding parameters, melt composition, location in the mold, and proximity to adjoining features.

\section{INTRODUCTION}

Great efforts have been made in the last 20 years to reduce weight in automobiles in an effort to improve fuel economy and to reduce emissions. A plethora of automobile components have traditionally been poured in cast iron using green sand molds due to the low cost, well-established practices, and many desirable properties of cast iron. However, a significant drawback is the large dimensional variability obtained in cast iron products. The result of this variability is that components must often be oversized to ensure a minimal dimension and subsequent strength of the component, thereby leading to increases in weight.

Aluminum has become a popular alternative because of its significant weight benefits, but its high cost and reduced fatigue properties represent formidable disadvantages. Numerous alternative iron casting procedures have been developed that are capable of reducing variation and improving finish, but these also result in higher production costs. Recent efforts by the authors have therefore been directed towards assessing the capabilities of production foundries to produce thin castings with low variability and determining the sensitivity of the casting process to various casting parameters.

\section{EXPERIMENTAL PROCEDURE}

\section{TEST ARTIFACT}

The pattern is shown in Fig. 1, and a representative casting is shown in Fig. 2. The test casting was designed to compliment previous studies (Cuttino et al., 2001a, 2001b, 2001c) conducted in collaboration with the Cast Emissions Reduction Program (CERP) at Technikon LLC in Sacramento, CA. The Parametric study was a designed experiment used to identify the sensitivity of dimensional variation to four foundry parameters, pouring temperature, clay content, shakeout time, and sand compactability. The study was conducted using an existing casting shown in Fig. 3 and was conducted on a horizontally parted Georg Fischer machine.

The new pattern was designed to fit on the smallest of the DISA machines, the 2013 , so that it could be run on virtually any DISA vertically parting machine using a bolster if necessary. Recalling that the CERP castings were run on a horizontal parting machine using a 6-on pattern and gated through the horizontal webs, significant modifications were required for the Round Robin castings. First, in order to fit on the 2013 plate, the overall casting size was reduced to $75 \%$ that of the CERP castings. In order to bracket the dimensions of interest, the fin thicknesses were reduced to 1.3 $\mathrm{mm}$ to $6 \mathrm{~mm}$ rather than the $6 \mathrm{~mm}$ fin thicknesses on the CERP castings. The reduced thicknesses were designed to provide experimental identification of the threshold for the fabrication of sound thin-walled castings. The gating was 
designed to come up through the center of the casting in a 1.25 " cylinder rather than to enter the casting cavity through one of the fins. These changes in geometry are illustrated in Fig. 2 and Fig. 3.

The castings showed very interesting casting problems, including chill.on the thinner fins and evidence of white iron. The pattern proved to be a good design, bracketing thickness values between 1.3 and $6 \mathrm{~mm}$. The dimensions of the test casting were specified such that the fins would bracket desirable and undesirable properties; for example, the authors suspected that there would be a minimal thickness somewhere around 2 and $2.5 \mathrm{~mm}$ where desirable properties would be obtained, and that below that the resulting casting would include white iron and excessively brittle properties.
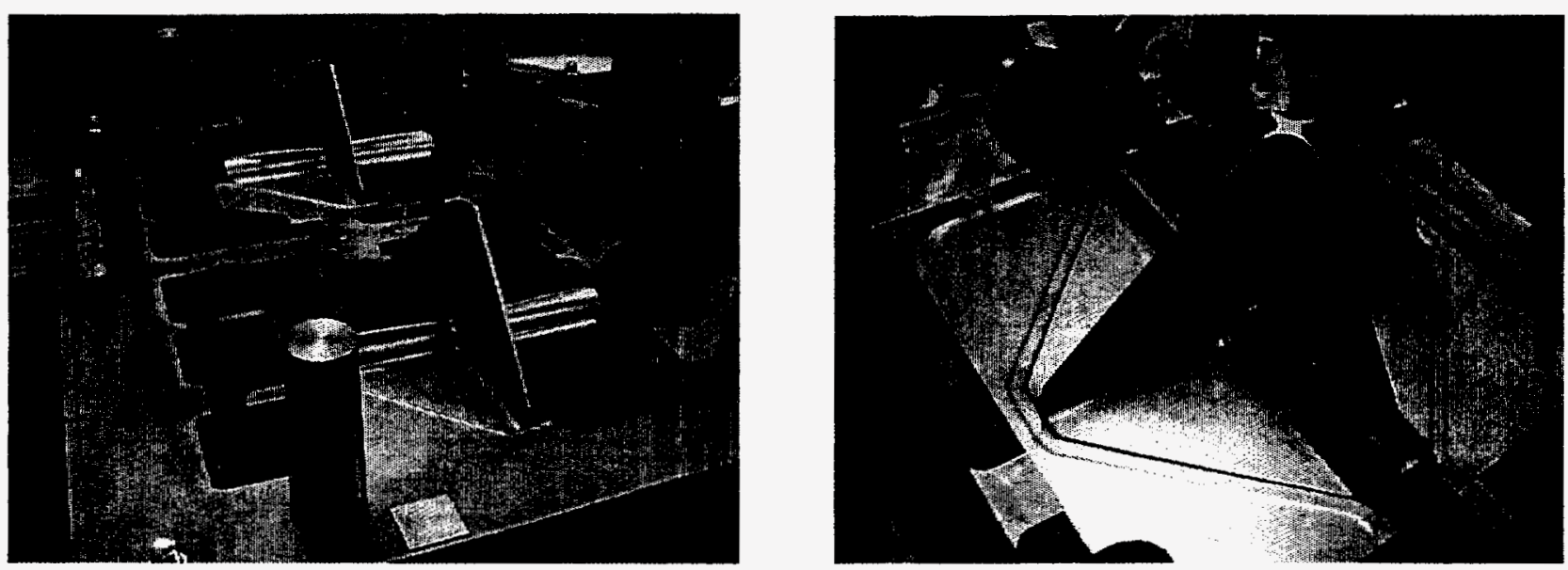

Fig. 1: 2-on Pattern

Fig. 4 shows close up views of representative imperfections in the castings. The castings were shot blasted minimally to remove the mold sand, but even that amount of blasting caused damage to the thinner fins. Shot blasting was conducted only long enough to knock off the green sand, without attempting to "smoothen" the surface finish. A casting instrumented with Almen strips was included in the process for later comparisons with other foundry runs.

The orientation of the stars in the mold also played an important role. The pattern was designed to be non-symmetric, with serial 1 having its thinnest fins adjacent to the downsprue and serial 2 having its away from the sprue, near the exterior surface of the mold. In nearly every case, the $1.3 \mathrm{~mm}$ fins in serial 2 were extremely warped and torn following shot blasting, whereas they were only slightly warped and intact in the serial 1 castings. This indicates strongly that the different heat transfer rates in the various locations in the mold play a significant role in the ability to produce thin castings. Apparently, the heat of the downsprue slowed cooling in the serial 1 fins and resulted in a tougher casting. 

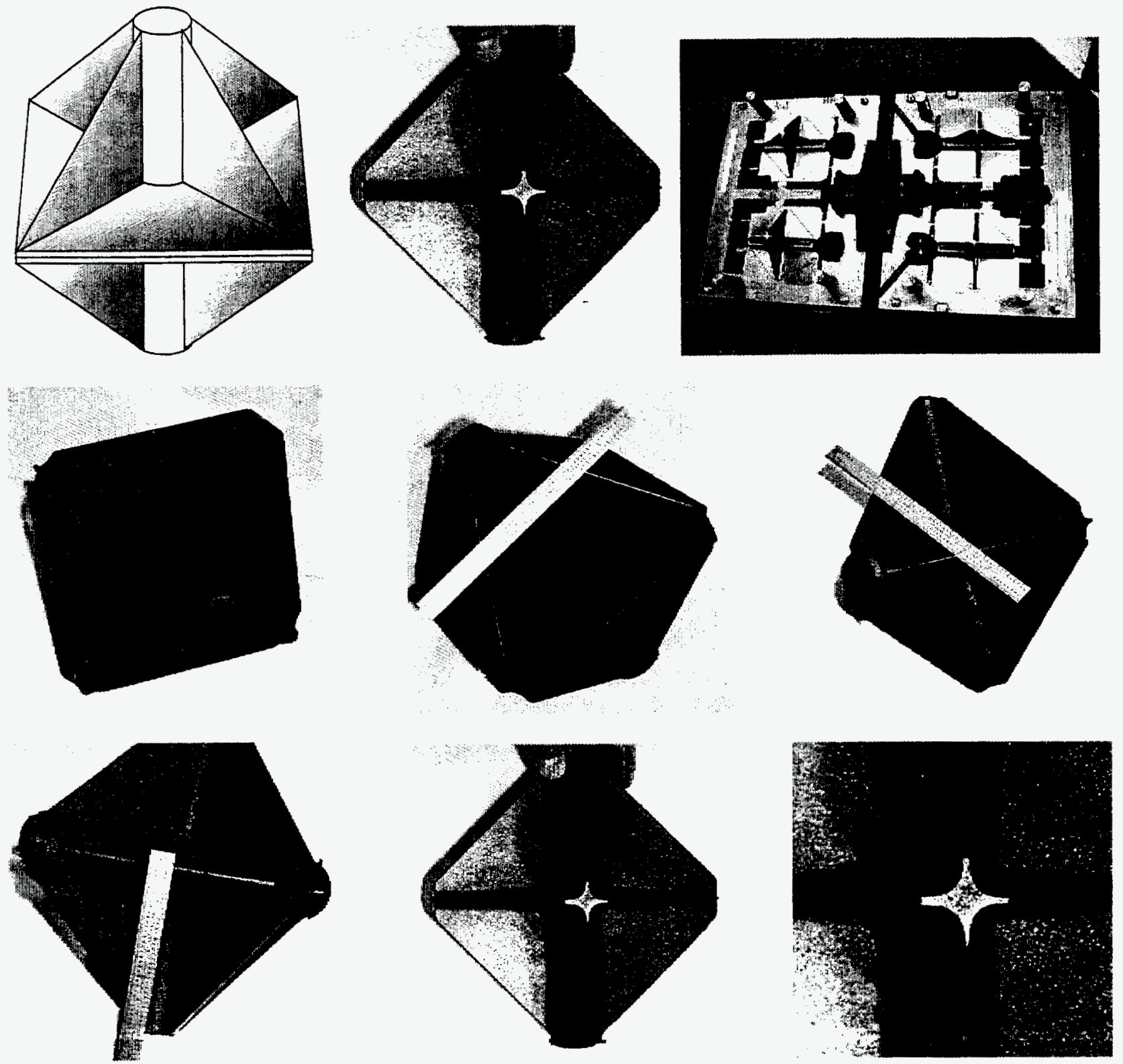

Fig. 2: Representative casting
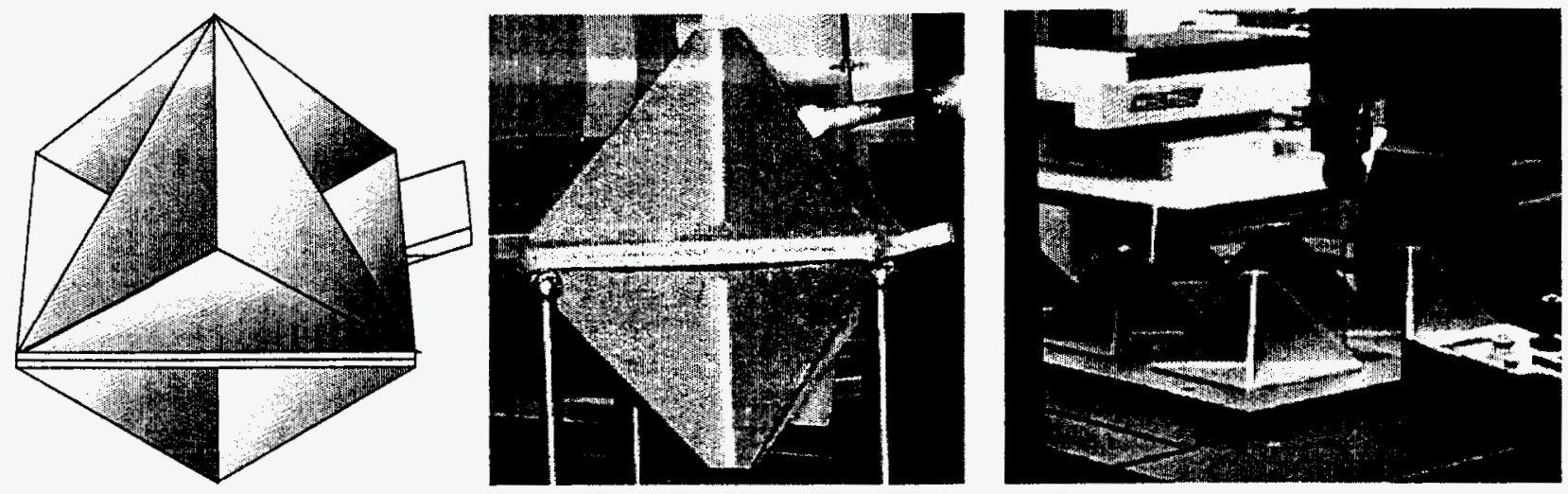

Fig. 3: Original CERP Casting and Pattern 

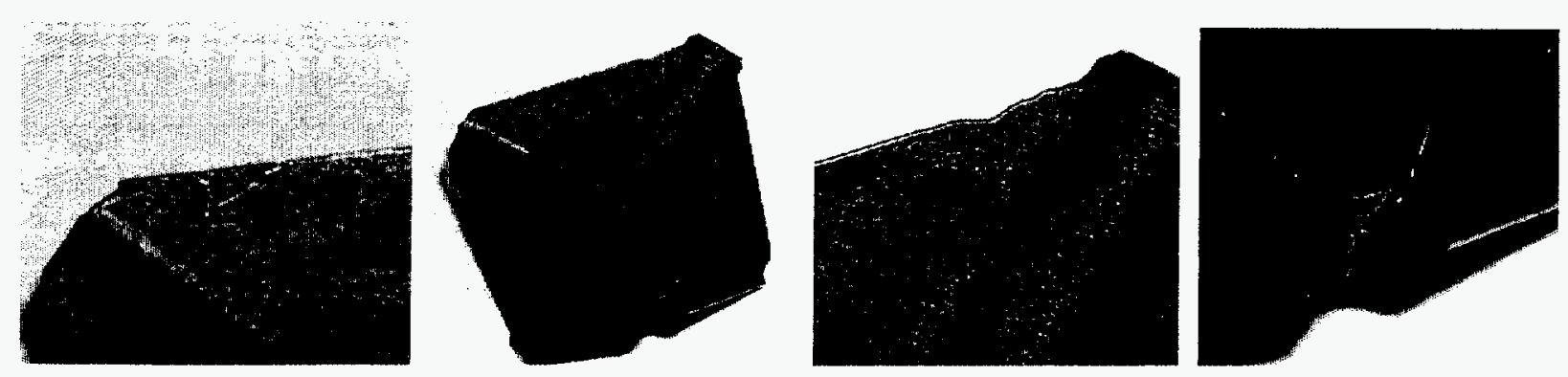

Fig. 4: Imperfections in Casting

\section{METROLOGY OF THE STAR CASTING}

The geometry of the castings posed many metrology challenges. The probe of the CMM had to be oriented for each sampling such that it avoided all fixturing and interference with the gating. In addition, the thinnest thin wall castings posed new difficulties due to the excessive deformation (bowing) and cracking of the fins that resulted from the shot blasting process. These defects had detrimental effects on the determination of fin thickness, since the probing direction would no longer be perpendicular to the feature.

The metrology of the castings was divided into two components, data collection and analysis. The division of tasks served multiple purposes. First, the data collection process could be conducted for numerous castings more quickly if the analysis was conducted "off-line." Second, the analysis was decoupled from the data collection, so that new analyses deemed necessary by the researchers would not require additional sampling on the CMM. Finally, shifts in data would be traceable directly back to the raw data so that troubleshooting analyses could be conducted.

A Brown and Sharpe 765 Coordinate Measuring Machine (CMM) was used to measure the castings. A CNC program was written to conduct the measurements using QUINDOS software. A kinematic fixture was used to restrain the casting in six degrees of freedom on the CMM. The fixture is shown in Fig. 6. It consists of three precision balls mounted on posts, each ball contacting the casting on two orthogonal sides to constrain motion in all degrees of freedom.

The program differed in a number of ways from that used for the previous Parametric study conducted in collaboration with CERP. To begin with, the castings are $25 \%$ smaller than the CERP castings and offer less room for manipulating the probe. In addition, the castings are of different geometry, bringing the gating up through the middle of the casting rather than into a fin, as illustrated in Fig. 2. The smaller fins made it harder to manipulate the probe around the fixture, so that the hit pattern had to be modified on certain fins. Finally, significant warping in the castings required larger standoffs in the CMM program to ensure that the probe did not crash into the casting surface.

The program redundantly samples specified features on the casting in order to establish a metrology coordinate system. It then samples either ten or eleven points per fin surface depending on the location of the fins. The sampling patterns are shown in Fig. 5. The modified pattern shown in the figure allows for the fixture while still maintaining alignment of the pins for analyzing warp in the castings. 

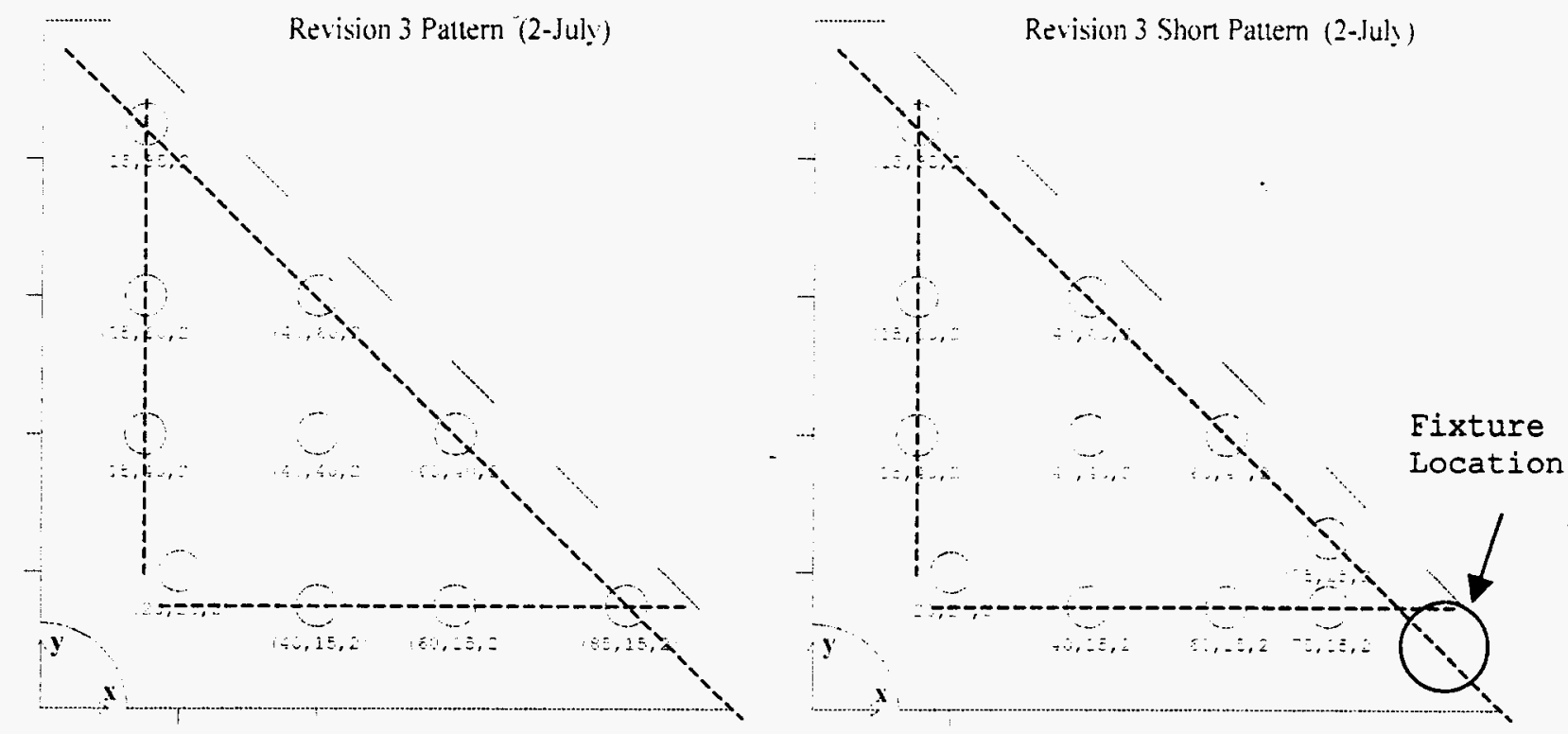

Fig. 5: Sampling Patterns
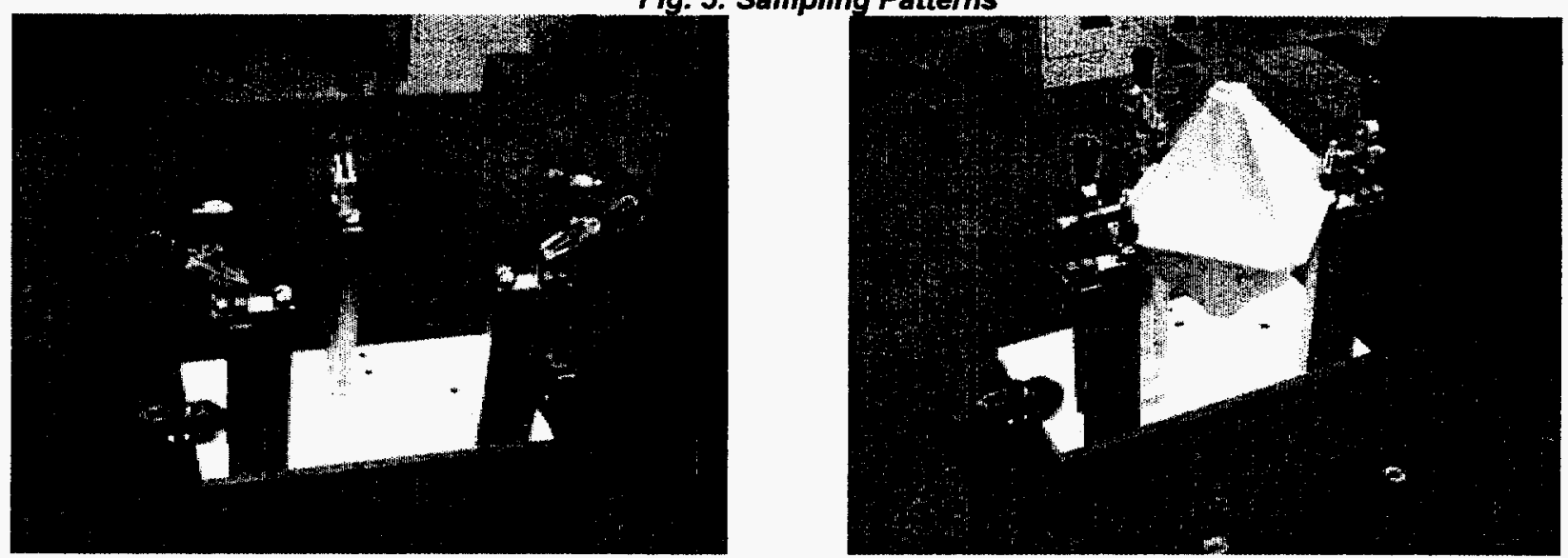

Fig. 6: Locating Fixture

\section{SUMMARY OF CERP FINDINGS FOR COMPARISON WITH ROUND ROBIN RESULTS}

In the original Parametric study conducted with CERP, sixteen different process parameter combinations were identified (Kachru, 2001). Four factors were selected for the study based on preliminary results, extensive feedback from the steering committee, and the ability to control and monitor the process. The four factors chosen for the study were clay content, pouring temperature, sand compactability, and shakeout time. Two levels for each factor were chosen, a "low level" and a "high level," as shown in Table 1.

Table 1: Low and High Levels of the Four Factors

\begin{tabular}{|c|c|c|}
\hline Process Parameters & Low Level & High Level \\
\hline Clay Content (\%) & 6 & 9 \\
\hline Pour Temperature $\left({ }^{\circ} \mathrm{F}\right)$ & 2550 & 2750 \\
\hline Sand Compactability (\%) & 32 & 42 \\
\hline Shakeout Time (min.) & 30 & 60 \\
\hline
\end{tabular}

The results are given in detail in (Kachru, 2000), and are summarized in Table 2. Clay (A) had by far the highest effect on the dimensional variation of the castings as can be seen by its presence in all but two significant process parameter interactions in Table 2. Pouring temperature (B) also had a significant effect. The interaction between shakeout time and clay content $(\mathrm{AD})$ showed some effectiveness in controlling the dimensional variation of the castings and occurred randomly in some interactions. This combination was dominant for the drag and horizontal fins. The interaction of all four process parameters, $A B C D$, was also significant in the cope and drag fins. 
Table 2: Comparison Table for Pareto's Effects Plot

\begin{tabular}{|l|c|c|c|}
\hline Grouped Fins & Dominant Process Parameters or Interactions \\
\hline & Highest & Second & Third \\
\hline Cope & $\mathrm{A}$ & $\mathrm{ABC}$ & $\mathrm{ABCD}$ \\
\hline Drag & $\mathrm{AD}$ & $\mathrm{BC}$ & $\mathrm{ABCD}$ \\
\hline Horizontal & $\mathrm{AD}$ & None & None \\
\hline All & $\mathrm{A}$ & $\mathrm{ABCD}$ & $\mathrm{BC}$ \\
\hline
\end{tabular}
A: Clay Content
B: Pour Temperature
C: Sand Compactability
D: Shakeout Time

Fig. 7 provides a breakout of the effects of the individual parameters. Note that the vertical axes in the plots show the standard deviation in micrometers and that the ranges are constant for all of the plots. For example, Fig. 7a shows the standard deviation changing from 10.4 to $14.9 \mu \mathrm{m}$ due to a change in clay content (A) from 6 to $9 \%$. Clay content (A) was also the dominant factor in all fins combined. The results from the Main Effects Plots are summarized in Table 3. Columns 3, 4, 5 and 6 in Table 3 show the effect of each process parameter on the dimensional variation of the Cope, Drag, Parting line and "All fins" combined. Column 7 averages the effect of each process parameter on the Cope, Drag and the horizontal parting line fins.

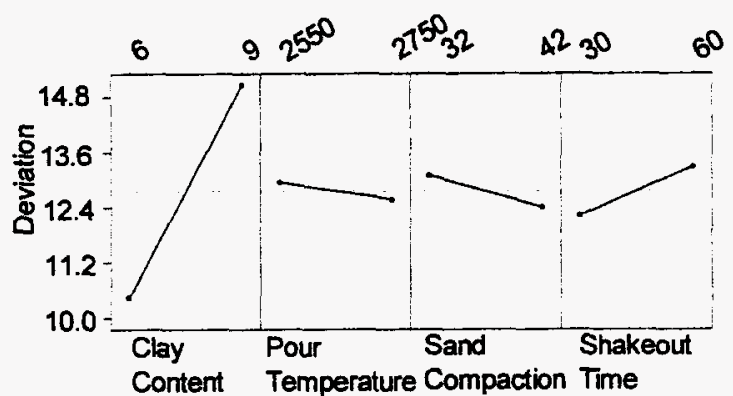

(a) Cope Side Fins

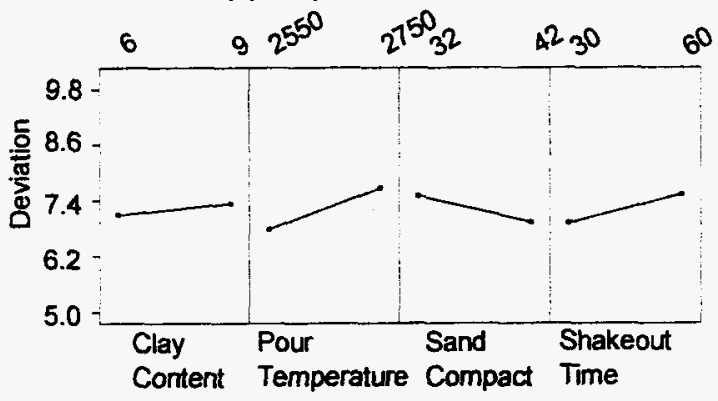

(c) Horizontal Fins

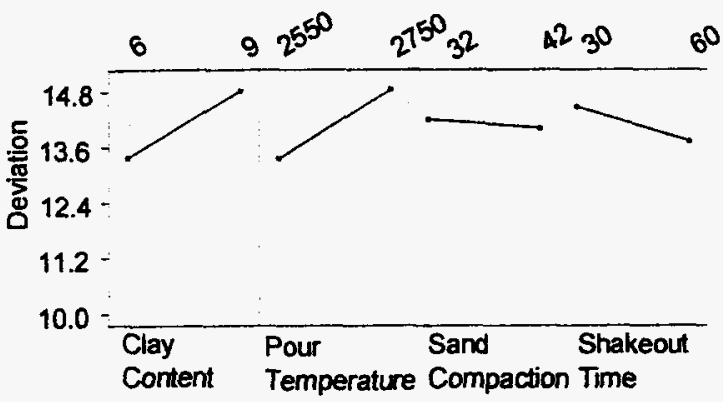

(b) Drag Side Fins

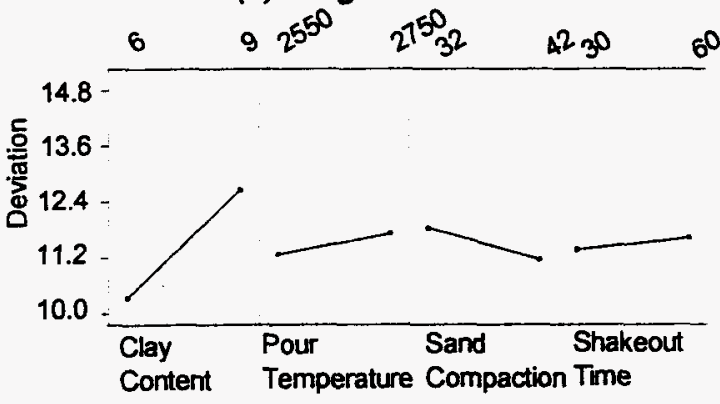

(d) All Fins

Fig. 7: Main Effects Plot for dimensional variation

Table 3: Comparison Table of Main Effects Plot for Dimensional Variation

\begin{tabular}{|c|c|c|c|c|c|c|}
\hline Process Parameters & Symbol & $\begin{array}{l}\text { Cope } \\
(\mu \mathrm{m})\end{array}$ & $\begin{array}{l}\text { Drag } \\
(\mu \mathrm{m})\end{array}$ & $\begin{array}{c}\text { Parting } \\
\text { ( } \mu \mathrm{m})\end{array}$ & All $(\mu \mathrm{m})$ & $\begin{array}{c}\text { Average of Cope, } \\
\text { Drag, Hor Fins } \\
(\mu \mathrm{m})\end{array}$ \\
\hline Clay Content & A & 4.8 & 1.4 & 0.4 & 3.3 & 2.2 \\
\hline Pour Temp. & $\mathrm{B}$ & 0.4 & 1.5 & 1.4 & 0.8 & 1.4 \\
\hline Sand Compactability & C & 0.6 & 0.1 & 0.6 & 1.3 & 0.4 \\
\hline Shakeout Time & $\mathrm{D}$ & 1.2 & 0.6 & 0.6 & 0.2 & 0.8 \\
\hline
\end{tabular}

\section{ROUND ROBIN RESULTS}

Results from the round robin are presented in the following paragraphs. The results are taken from 10 different test cases representing variations in metal compositions, mold positions, and foundry facilities. Only those results showing significant changes are presented unless direct comparisons with the CERP data dictate otherwise. 
The most surprising conclusion was that, contrary to the results from the CERP study, the clay content showed little effect on the dimensional variation, as shown in Fig. 8. In this figure, it appears that the correlation between clay content and dimensional variation is very low, whereas sensitivity was determined to be very high in the CERP study. This may be explained however by a number of factors. First, green sand used on Disamatic machines typically contains a much higher percentage of clay. In the round robin study, clay content ranged from $10 \%$ to $12.3 \%$, whereas the clay content for the CERP study (on a horizontally parting molding machine) ranged from $6 \%$ to $9 \%$. The conclusion is therefore that the sensitivity to clay content may drop off as one exceeds $9 \%$, and that a "threshold" may exist above which additional clay does not significantly affect the variability. Obviously, a refined sampling would be necessary to determine the exact relationship and is beyond the scope of this study.

Pouring temperature varied from $2450 \mathrm{~F}$ to $2580 \mathrm{~F}$ for the round robin study, as opposed to $2550 \mathrm{~F}$ to $2750 \mathrm{~F}$ for the CERP study. The trends here compliment those seen in the CERP study, where increasing temperature increased the dimensional variation. Similar to the CERP study, sand compaction and shakeout time for the round robin did not show appreciable results, and are therefore not presented.

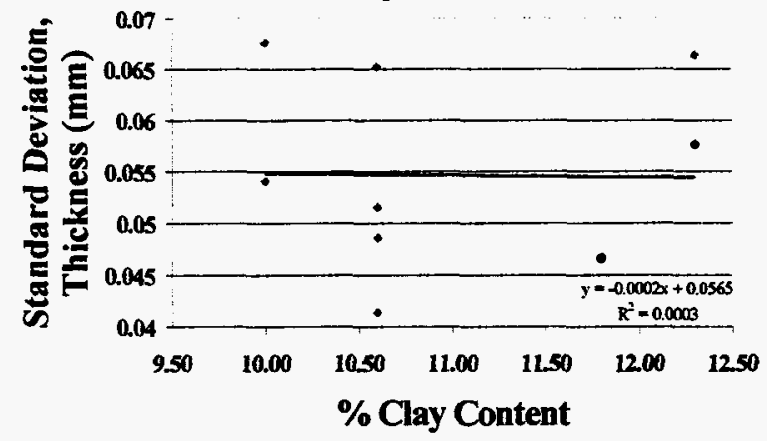

Fig. 8: Clay Content

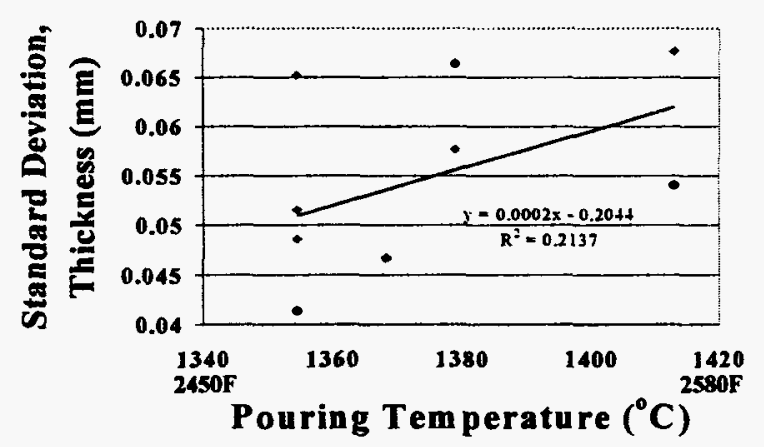

Fig. 9: Pouring Temperature

The round robin study did allow examination of the effects of metal composition on the dimensional variation. Of significance were the carbon, silicon, and manganese content, which are shown in Fig. 10. Although the plots contain significant scatter of the data (represented by the low $R^{2}$ values), the trends do appear to be significant. Dimensional variation is found to increase with increasing carbon and manganese, and to decrease with increasing silicon.
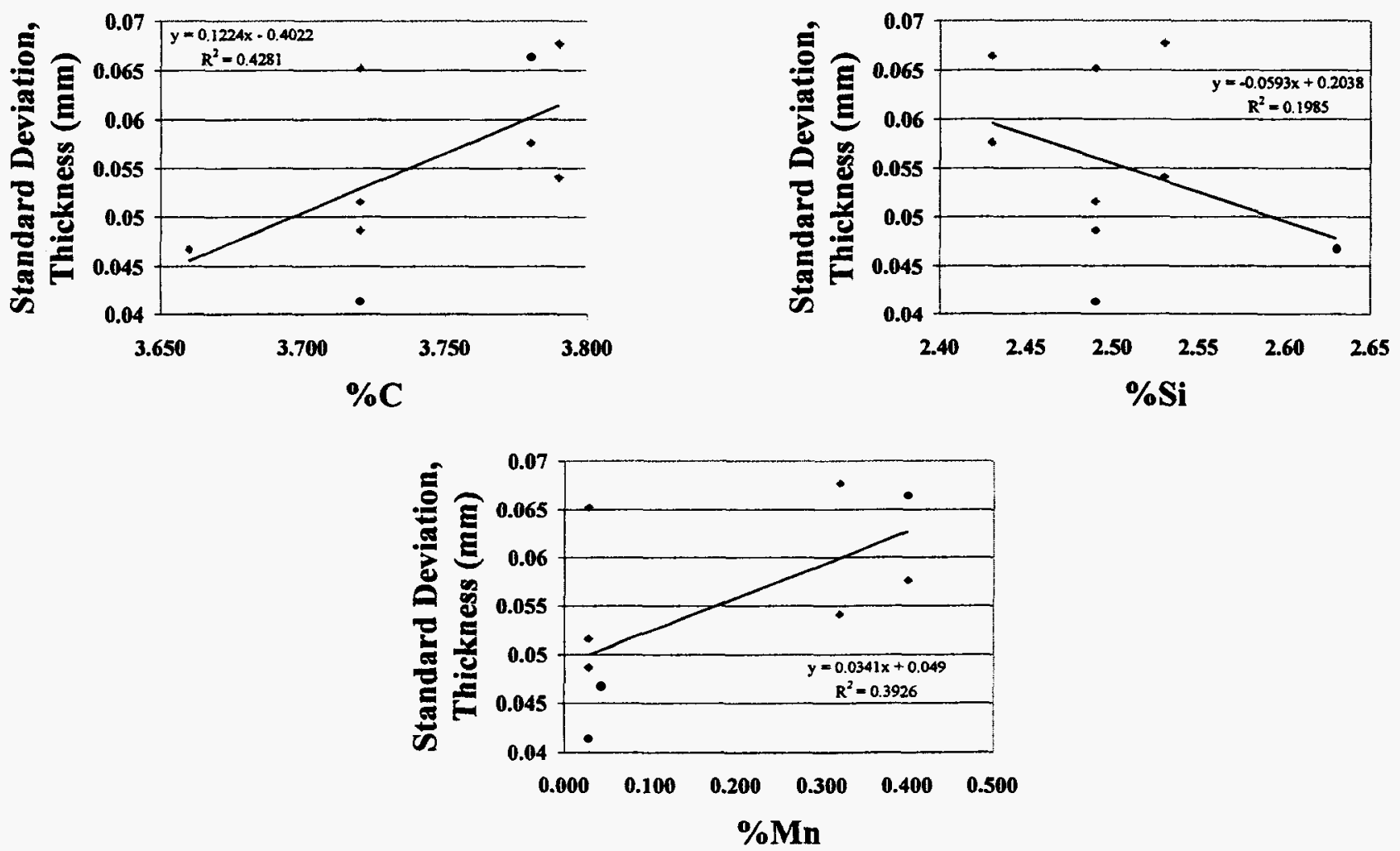

Fig. 10: Metal Composition 
Variation as a function of position in the mold was also examined and compared to previous studies conducted at CERP (Cuttino et al., 2001a, 2001b, 2001c). Fig. 11 shows the dimensional variation as a function of the distance from the center of the casting, as illustrated at the top of the figure. The assumption here is that the largest "bulk" concentration of molten metal is located at the center, and would therefore have an effect on the dimensional stability of the casting. The CERP results shown in Fig. 1la show a decaying effect as the distance from the center increases. However, the CERP castings were subject to severe burn-in near the center. Fig. $11 \mathrm{~b}$ shows similar results for all of the samples taken, with the exception of the point nearest the center where burn-in was not as significant. Note that with the exception of the first point on the CERP results, the variations remain within $150 \mu \mathrm{m}$ and are comparable, although the slope does drop off more rapidly for the Round Robin case indicating that less variation may be obtainable for the vertically-parting molding machines.

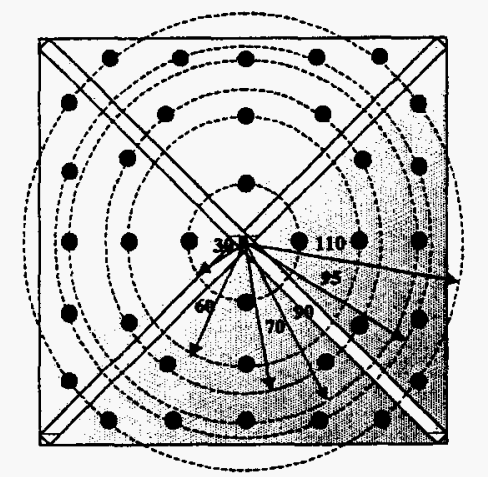

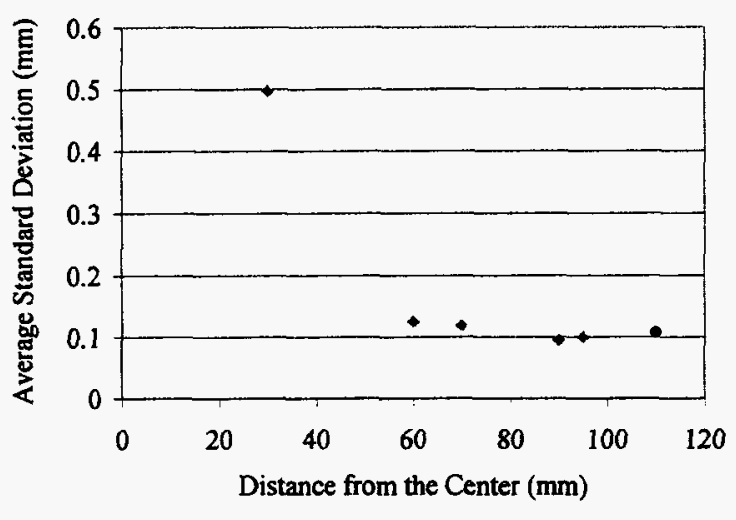

a) CERP results

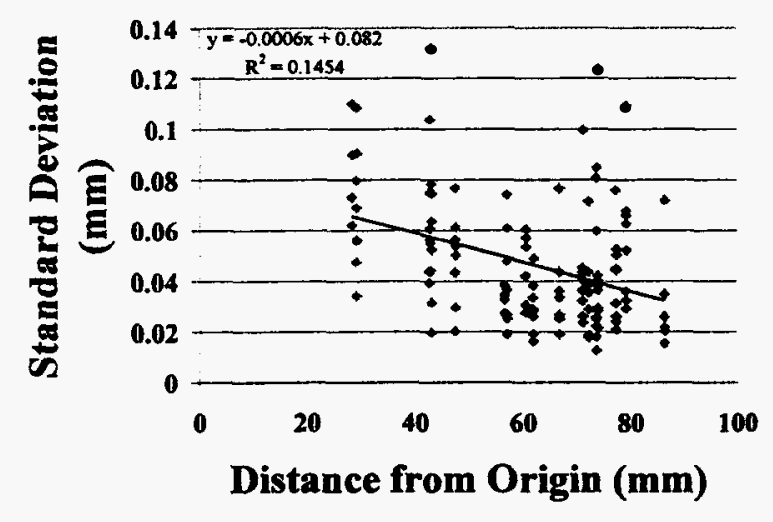

b) Round Robin Results

Fig. 11: Relationship to Distance from Origin

Similar results were obtained when variation was compared to proximity to adjoining features. In this case, the CERP castings were again subject to severe burn-in for the first point. Neglecting that point, however, similar trends were again noted. The further a point was from any adjacent features, the smaller the deviation in the measured thickness. The data were again scattered, but the best fit line for the round robin indicated a $50 \%$ reduction in the average deviation over that of the horizontal molding machine. It is important to remember, however, that the two patterns were significantly different in nominal thicknesses.

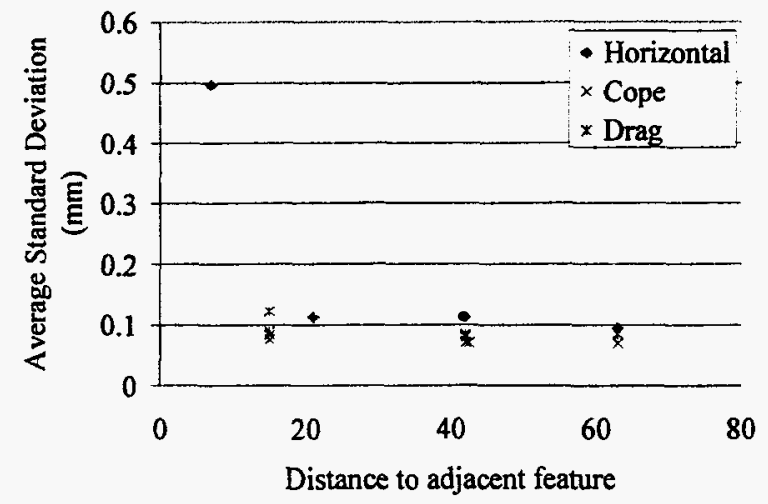

a) CERP results

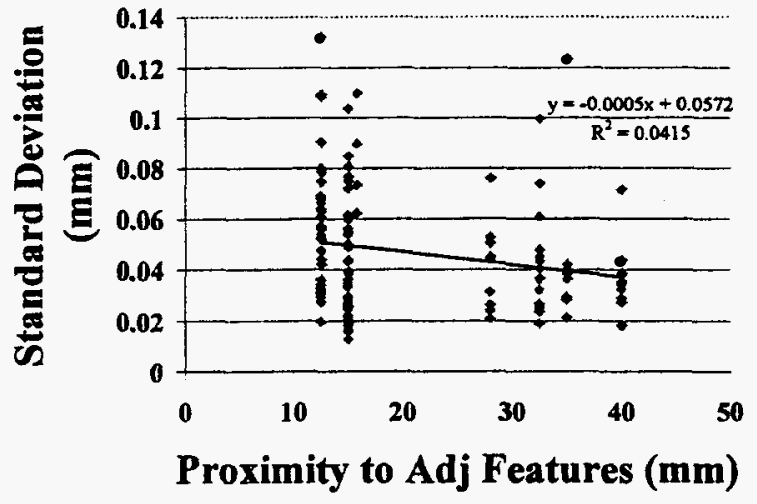

b) Round Robin Results

Fig. 12: Relationship to Proximity to Adjoining Features 
The CERP results indicated that there was a strong dependence of dimensional variation on position in the mold with regard to placement across the parting line, in the cope, and in the drag, as indicated in Fig. 13. The data obtained in the round robin study were therefore examined to determine if this effect was also present there.

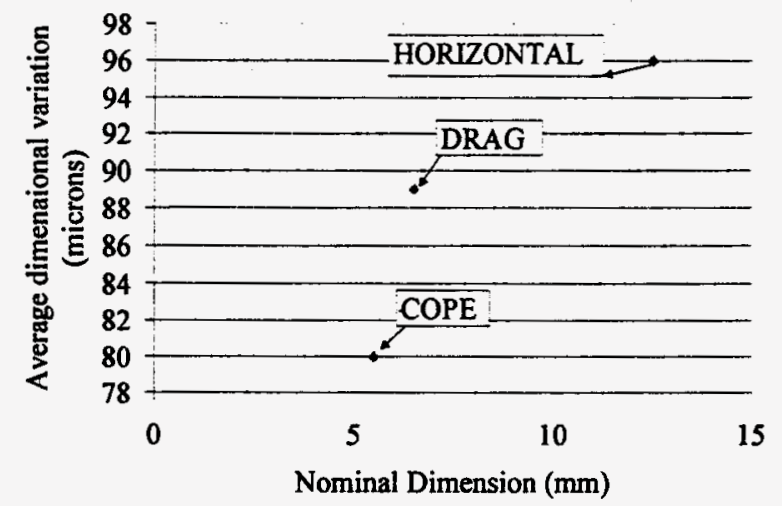

Fig. 13: CERP results showing variation vs. nominal dimension

Initial results from the round robin study indicated that similar results did indeed verify those found in the CERP study, and that variation was reduced in the upper vertical fins (equivalent to the cope fins in the CERP study) and increased in the lower vertical fins (equivalent to the drag fins in the CERP study). The horizontal fins did not have the highest variation, as they did in the CERP study, however. This is probably because the gate in the CERP study came in at the horizontal fins, where the gate for the round robin study came up from the bottom of the casting in a more optimized arrangement.

As more data were analyzed, it became apparent that the trend of increasing variation as height increased did not hold true for all samples. A number of representative plots are therefore included in Fig. 14 to illustrate the position of the fins (or webs) and the resulting variation. Each plot represents a different test condition. It is clear in the first two plots that variation appears to increase with height; however, this trend is less clear in some of the remaining plots, and is actually reversed in the last two. The authors believe that variation is dependent on vertical height in the mold, but the inability to control the parameters in the round robin study make it difficult to prove or disprove this presumption.

Plots were created to examine the effects of thickness on variation and are shown in Fig. 15. The variation does show a dependency on the thickness of the casting at the point where the sample was taken as shown in Fig. 15a. In addition, the average of all the points on a particular web was calculated and the variation plotted as a function of the resulting number, as shown in Fig. 15b. Both figures show an increase in variation with nominal dimension with a slope of 0.01 .

The final parameter studied in the round robin was the flatness of each web, which was plotted as a function of web thickness and is shown in Fig. 16. The flatness is calculated as the maximum deviation of the fin from a best fit plane. The flatness is fit with a power curve, indicating a very nonlinear relationship which was easily visible in the resulting castings. The "threshold" for achieving reasonably flat castings appears to be around $3 \mathrm{~mm}$, above which the flatness did not exceed 0.2 $\mathrm{mm}$. As the flatness deviations were caused by residual stresses and the carbidic structure of the metal in the thin webs, the importance of controlling cast structure by controlling the cooling rate in the thin walls is seen to be important not only from the standpoint of cast structure control, but also to control dimensional variation. The actual relationships between adjacent section sizes and their effect on warpage has yet to be determined. 

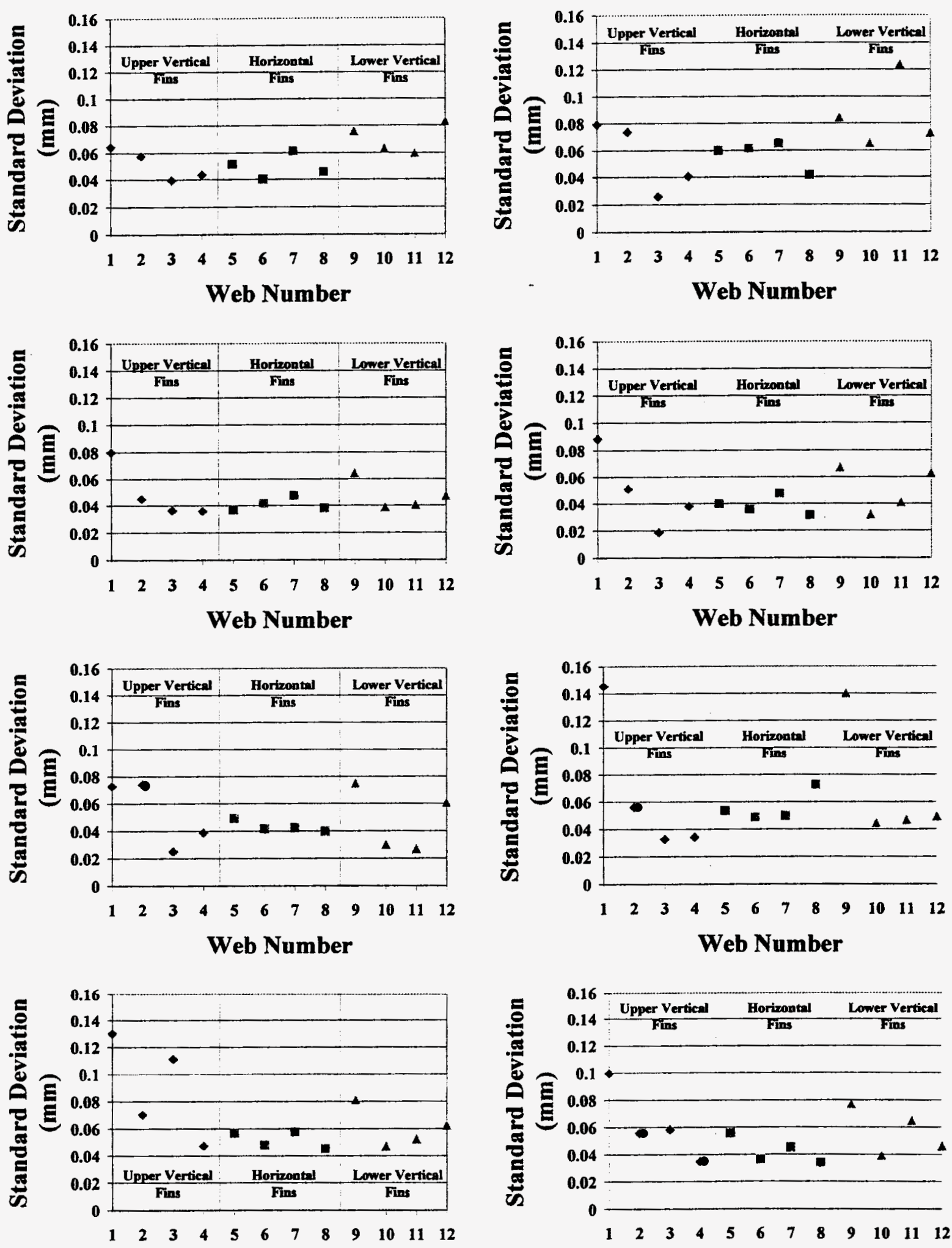

Web Number

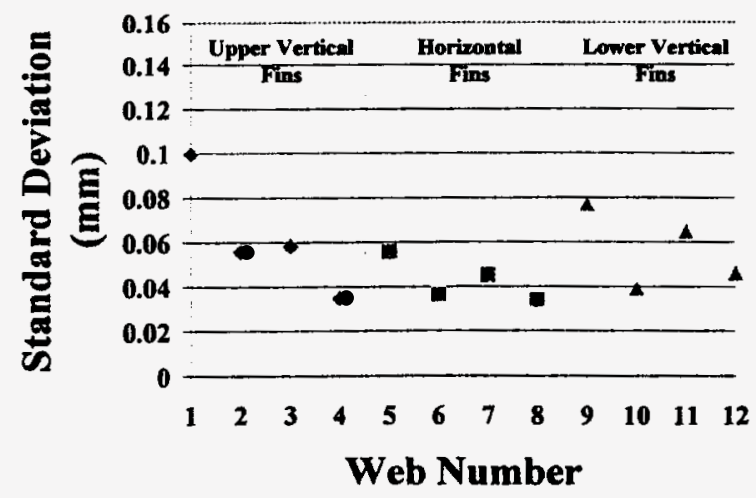

Fig. 14: Plots showing variation as a function of web (fin) number 

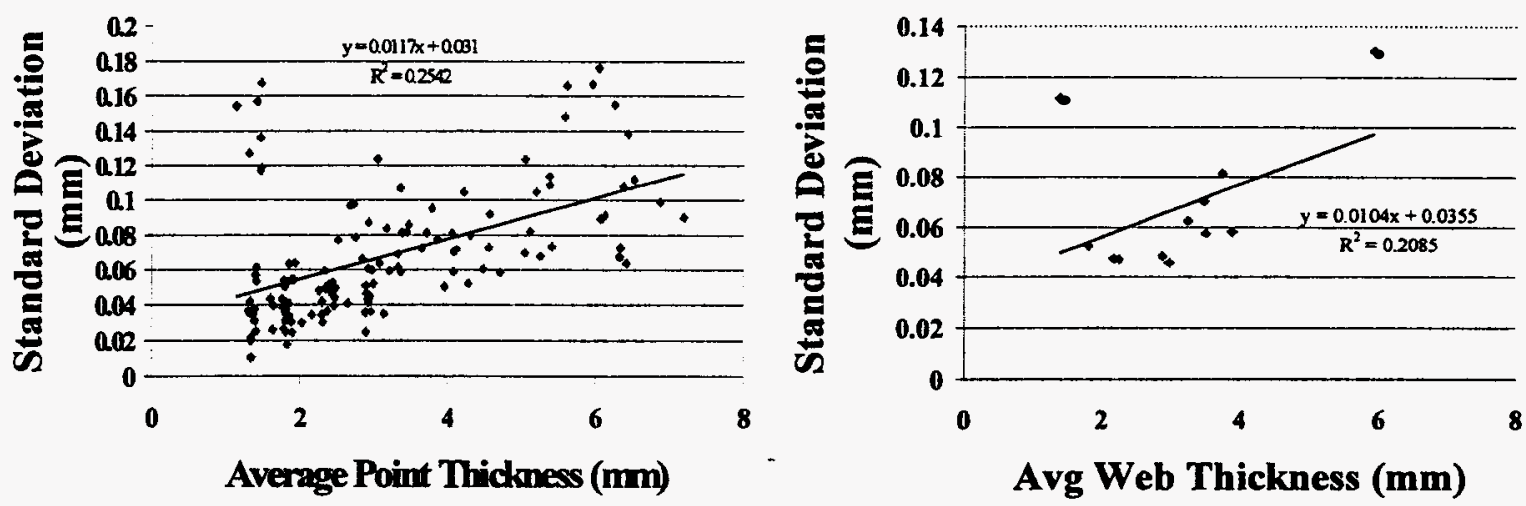

Fig. 15: Variation as a function of thickness

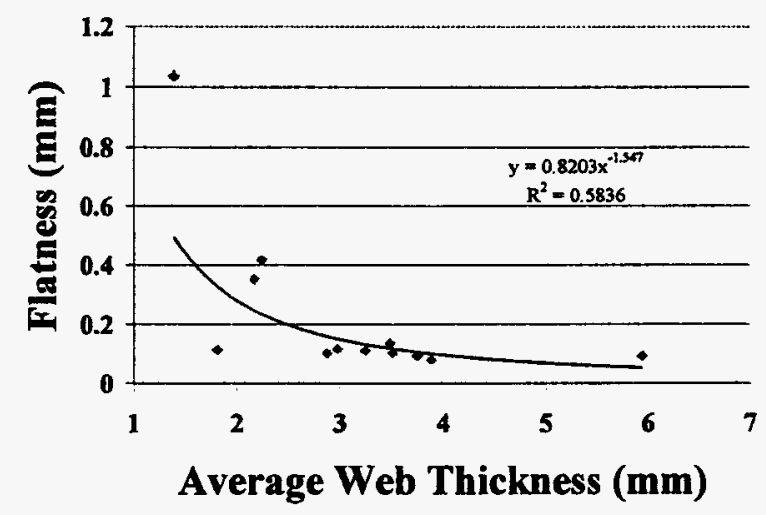

\section{CONCLUSIONS}

Fig. 16: Flatness vs. Thickness

The round robin study verified, for the most part, the results seen in the Parametric study conducted at CERP. The round robin study did indicate that the vertically parted molding machines are more successful at reducing variations, as indicated by the fact that the variations in the round robin castings fell between 40 and 60 micrometers while the CERP castings were between 80 and 96 micrometers.

Clay content proved to have less of an impact on variation for the round robin than for the CERP study, but this is likely due to the much higher percentages of clay used in the Disamatic machines than in horizontally parted molding machines. The pouring temperature trends shown in the CERP study were verified in the round robin, and the insensitivity to shakeout time and compactability were also verified.

Proximity to adjacent bulk molten metal was shown to be in concert with the CERP study in having a significant impact on variation. Some of the mold placement data backed the conclusion that variation is lower in the cope than in the drag, although the horizontal fins showed less variation than those in the CERP study (probably because the gate in the CERP study came in at the horizontal fins, where the gate for the round robin study came up from the bottom of the casting in a more optimized arrangement).

The round robin allowed examination of the effects of metal composition on dimensional variation. In this case, the variation was shown to increase with carbon, phosphorus, and manganese, but decreased with silicon. The variation was also verified to be strongly dependent on point thickness and average web thickness. Flatness was significantly affected by thickness for features less than $3 \mathrm{~mm}$ thick.

\section{ACKNOWLEDGMENTS}

This project was funded partially by Cooperative Agreement DE-FC07-98ID13612 with the United States Department of Energy. The opinions expressed in this paper are those of the authors and not necessarily those of the Department of Energy. The authors would like to thank the US DOE, the Thin Wall Iron Group of the American Foundry Society, and particularly the Molding Capability Steering Committee. In addition, special thanks are due to Technikon, LLC (formerly the Cast Emissions Reduction Program, CERP) for providing the castings for the study. 


\section{REFERENCES}

Cuttino, J.F., A. Kachru, E. Morse, S. Patterson, T.S. Piwonka, 2001a, "A Parametric Study of the Effects of Casting Parameters on Dimensional Variation in Thin Wall Iron Castings," submitted for publication in the 2001 American Foundry Society Transactions.

Cuttino, J.F., A. Kachru, E. Morse, T.S. Piwonka, 2001b, "The Effects of Shot Blasting on Dimensional Variation of Castings," submitted for publication in the 2001 American Foundry Society Transactions.

Cuttino, J.F., A. Kachru, E. Morse, S. Patterson, T.S. Piwonka, 2001c, "A Study of the Effects of Mold Placement on Dimensional Variation in Thin Wall Iron Castings," submitted for publication in the 2001 American Foundry Society Transactions.

Kachru, A., 2001, Molding Capability Study for Thin Wall Iron Castings, Master's Thesis, University of North Carolina at Charlotte. 


\section{Microstructure Control and Modeling Executive Summary}

The Thin Wall Iron Casting research project was successful in developing significant aspects of the technology for thin wall ductile and compacted graphite (CG) iron castings. Phase I of the project developed market opportunities for iron foundries by demonstrating that ductile and compacted iron castings that weigh only $10 \%$ more than "lightweight" materials, can be produced at far lower costs, and far more reliable performance. Also documented was the fact that ductile and compacted iron castings can compete successfully on the basis of weight, performance, and cost with lightweight materials as well as other competing manufacturing methods, which opens markets in light rail, transportation systems and other markets where minimum weight, low cost, and maximum reliability are essential.

Some of the major technical accomplishments are summarized in the following paragraphs. Recommended practices for metallographic characterization were established for thin-wall nodularity. Reference photographs for nodule counts from 800 to 2000 nodules $/ \mathrm{mm}^{2}$ have been produced. Regression equations that allow calculation of equivalent visual nodularity from shape factors obtained through image analysis have been generated for ductile and CG iron. Once again, compactness and compactness nodularity $(C N)$ were shown to be less than ideal descriptors for graphite shape in either ductile or CG iron. While $C N$ is considered by many the industry standard, it has the major disadvantage that it cannot tell the difference between imperfect graphite spheroids and good spheroids (e.g., exploded graphite and spheroidal graphite). It is true that the numbers given by $C N$ are conveniently similar to those established through visual observation of standards (visual nodularity $V N$ ). However, $C N$ is just as insensitive to the details of the graphite shape as the human eye is. This becomes a major problem when evaluating thin castings where the small size of the graphite decreases the discriminating ability of the eye. Based on three years of research sphericity is recommended for use as the shape factor of choice for ductile and CG thin iron castings.

Extensive work with instrumented castings generated relationships between the thickness of the plates used in this research and casting cooling rate. Depending on the feeding and the amount of metal flowing through the plate, the cooling rate could change by a factor of three. For example, in a $2.5 \mathrm{~mm}$ plate the cooling rate can vary between 8.2 and $32.5 \mathrm{~K} / \mathrm{s}$. This implies that through intelligent design, castings having sections as thin as $1.5 \mathrm{~mm}$ could be cast in ductile iron free of carbides. Using the technology developed during this research, carbide-free microstructures were obtained at cooling rates of up to $30 \mathrm{~K} / \mathrm{s}$, and as-cast ferritic microstructures at cooling rates of $10 \mathrm{~K} / \mathrm{s}$ and above. Thus, carbide-free sections can be produced at cooling rates four to five times higher than currently used in iron casting. This leaves the door open for the control of the matrix microstructure to give a variety of properties, as desired by designers.

Solidification modeling technology has been successfully used to design molds for the casting of sound thin plates in ductile iron. We have demonstrated that thin-wall $(2.5 \mathrm{~mm})$ sections of ductile iron can be consistently produced free from carbides and microporosity. The test samples machined from the sandblasted plates exhibited excellent 
static mechanical properties. For example, tensile strength higher than $60 \mathrm{ksi}$, yield strength higher than $40 \mathrm{ksi}$ and elongation higher than $12 \%$ could be obtained at cooling rates of $10 \mathrm{~K} / \mathrm{s}$ ( $3.5 \mathrm{~mm}$ plates). These properties were rather sensitive to surface quality and graphite shape. Lower properties were associated with rougher surfaces and lower sphericity, although both visual nodularity and $C N$ were acceptable (above $80 \%$ ).

Carbide-free CG iron with nodularity less than $20 \%$ were produced through $\mathrm{Mg}$ Ti ladle treatment and aluminum postinoculation at cooling rates of up to $19 \mathrm{~K} / \mathrm{s}$. It was also demonstrated that carbide-free CG iron could be produced with a titanium-free inmold process at cooling rates in the same range. The in-mold treatment allowed precise control of the residual magnesium, enough to overcome the problem of narrow process window for treatment of $C G$ iron with magnesium alone.

Extensive work on cooling curve analysis (CCA) has proven that CCA can provide useful on-line information on graphite shape when a specific liquid treatment process is used. Specific parameters of the cooling curve to be used for this goal have been identified and proven reliable through statistical analysis. However, it cannot be used to predict graphite shape of irons produced with different processes. This is because CCA is as sensitive to the nucleation potential of the melt as it is to graphite shape. Consequently, to predict graphite shape it is necessary to compare melts with similar nucleation potential. This means that a particular foundry will have to collect and interpret their own process-specific data if reliable graphite shape predictions are desired.

Simulation software was developed to predict microstructure in thin-wall ductile iron castings. A semi-empirical mechanical properties model has been developed for CG iron. It allows prediction of tensile strength and hardness from either microstructure data or computer modeled microstructure information. While at this time the prediction accuracy is only reasonable, it is expected to increase substantially when sound CG iron plates are used for the evaluation of mechanical properties.

Finally, two benchmark experiments were preformed to be used for validation of commercial mold filling and solidification models. The first one consisted in positioning open thermocouples in the plate-mold cavity to determine the exact time when the liquid metal reaches that particular position. The second experiment consisted in performing 580 metallographic evaluations on the plates to develop a microstructural map for thin ductile iron plates.

The results of this research have been summarized in three research papers submitted for publication to the American Foundry Society. These papers are attached. 


\title{
Thin Wall Compacted Graphite Iron Castings
}

\author{
S. Charoenvilaisiri ${ }^{1}$, D.M. Stefanescu ${ }^{2}$, R. Ruxanda ${ }^{2}$, T.S. Piwonka ${ }^{2}$ \\ ${ }^{1}$ King Mongkut's University of Technology Thonburi, Thailand, ${ }^{2}$ University of Alabama, Tuscaloosa, AL \\ Copyright@2002 American Foundry Society
}

\begin{abstract}
Extensive research has been conducted to evaluate technologies for manufacturing of compacted graphite iron (CGI) as applied to thin wall castings. For CGI "thin" was defined as less than $4 \mathrm{~mm}$. The first part of the program addressed metallographic techniques applicable to thin wall CGI, and in particular quantitative image analysis. It was found that sphericity is the best descriptor for graphite shape. Sphericity is basically the ratio between graphite area and graphite perimeter on the metallographic image. Sphericity was correlated with visual nodularity based on SinterCast ${ }^{\circ}$ wall charts.

Twelve $200 \mathrm{lb}$ heats were produced to evaluate different ladle and in-mold treatments for CGI poured into horizontal and vertical plate castings of thickness varying from 2.5 to $8 \mathrm{~mm}$. The best results with ladle treatment were obtained with a combination of $0.024 \% \mathrm{Mg}$ and $0.13 \%$ Ti residuals in relatively high sulfur $(0.04 \%)$ base iron. Carbide-free structures with maximum nodularity of $40 \%$ were obtained in plates as thin as $4 \mathrm{~mm}$. Postinoculation with $0.2 \%$ Al proved very effective in eliminating carbides while maintaining a low nodularity $(<2 \%)$ in irons having $0.09 \% \mathrm{Mg}$ and $0.14 \% \mathrm{Ti}$.
\end{abstract}

In-mold experiments demonstrated that the residual magnesium could be controlled accurately within narrow limits. Within the experimental range of 0.008 to $0.009 \% \mathrm{Mg}$, the difference in graphite shape was minimal. CG iron free of carbides and with less than $20 \%$ nodularity was produced at cooling rates as high as $18 \mathrm{~K} / \mathrm{s}$.

Cooling curve analysis can provide useful information on graphite shape as long as a specific liquid treatment process is used. The most significant cooling curve parameters are the maximum cooling rate after the eutectic plateau (the minimum of the first derivative) and the time interval at the end of eutectic solidification.

\section{INTRODUCTION}

The current market trend toward diesel engines, combined with the high peak firing pressures required to satisfy emission regulations, is driving the need for stronger engine materials and lower weight engine parts. Neither gray iron, the traditional material used in engine applications, nor aluminum that has unseated gray iron in many applications because of its lower density, can satisfy the demands of diesel engines. Compacted graphite iron (CGI) provides a cost effective solution to this challenge.

In 1998 the AFS, the Department of Energy, and 30 industrial sponsors initiated a program at The University of Alabama to research thin wall iron casting technology. The goal of the program was to develop the enabling technology to manufacture sound parts having section sizes as small as $2.5 \mathrm{~mm}$ and a carbide-free microstructure. The emphasis was on ductile and CG iron. This paper reports some of the findings on thin wall CG iron.

There were three main research directions, as follows:

- Establish procedures for microstructure evaluation and for testing of mechanical properties of thin wall CGI

- Evaluate CGI processes for thin wall castings and establish optimum process parameters

- Evaluate cooling curve analysis as a tool for process control

\section{PROCEDURES FOR MICROSTRUCTURE EVALUATION OF THIN WALL CG IRON}

As the main microstructure feature in CGI is graphite shape, the evaluation of graphite shape will be discussed in some detail.

\section{SOME BASIC DEFINITIONS FOR SHAPE PARAMETERS}

The standard procedure for evaluating graphite shape in the foundry is visual estimation of nodularity (Visual Nodularity, $V N)$. It consists in comparing the microstructure of interest with metallographic charts. The most accepted is the equation that uses object area:

$\%$ Nodularity $($ area $)=\frac{\text { Area of acceptable particles }}{\text { Area of acceptable }+ \text { unacceptable particles }} \cdot 100$

Equation 1

This definition is based on ASTM A247. However, the definition of "acceptable" may differ from company to company. Therefore, smaller companies that have not developed their own standards use published wall charts, as for example the AFS 


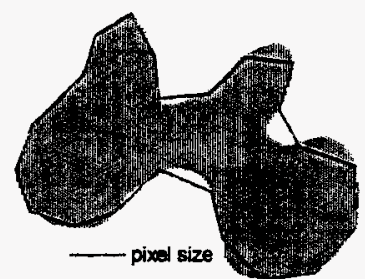

a) measurement of perimeter

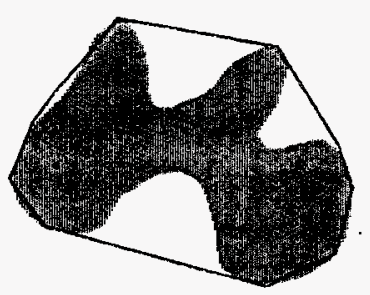

b) measurement of convex perimeter

Fig. 1. Difference between perimeter and convex perimeter measurement (schematic representation).

(Ductile Iron Microstructures Rating Chart 1993) or SinterCast ${ }^{\Phi}$ (Compacted Graphite-Iron Nodularity Rating Chart 1999, Compacted Graphite Iron-Nodularity Evaluation 2001) charts. -

To increase measurement objectivity, image analysis may be used to evaluate graphite shape. Again, there is no uniform standard throughout the industry. Different companies are using different image analysis measurements, including:
Sphericity $=\frac{4 \cdot \pi \cdot \text { Area }}{(\text { perimeter })^{2}}$
Compactness $=\frac{4 \cdot \pi \cdot \text { Area }}{(\text { convex } \text { perimeter })^{2}}$
Equation 2
Roundness $=\frac{4 \cdot \text { Area }}{\pi \cdot(\text { Max Axis Length })^{2}}$
(Compacted Graphite Iron Nodularity Rating Chart 1999)
Equation 3
Equation 4

The criterion of considering a particle as nodule, according to each shape factor, is:

$S>0.65 \quad C>0.70 \quad R>0.65+1.7 \exp (-$ Max Axis Length/3.5)

Equation 5

The limit on roundness was taken from the reference (Compacted Graphite Iron-Nodularity Rating Chart 1999). Sphericity is based on area and perimeter measurements. Roundness is based on area and maximum axis length measurements.

Compactness is based on area and convex perimeter measurements. The difference between perimeter and convex perimeter is illustrated in Fig. 1. It is seen that perimeter is, in principle, a more detailed description of the shape of the object.

However, perimeter measurement is more sensitive to the magnification under which it is measured (pixel size) than convex perimeter. The least sensitive to pixel size is roundness, since it is only using the maximum axis length (the largest distance between two parallel tangents of the object).

Any of these shape descriptors can be used to calculate a quantitative nodularity based on Equation 1 . Thus, one can use sphericity nodularity $(S N)$, compactness nodularity $(C N)$, or roundness nodularity $(R N)$.

\section{CORRELATION BETWEEN THE VARIOUS SHAPE DESCRIPTORS}

To establish a correlation between visually estimated nodularity $(V N)$ and the three main quantitative descriptors, sphericity $(S)$, compactness $(C)$, and roundness $(R)$, the SinterCast ${ }^{\star}$ wall chart for the highest nodule count was used (Compacted Graphite Iron-Nodularity Rating Chart 1999). The various shape factors were evaluated on each micrograph. The correlation between visual nodularity and the shape factors is presented in Fig. 2. Using linear regression, an equivalent SinterCast ${ }^{\circ}$ nodularity $\left(E N_{S C}\right)$ can be correlated to the quantitative measurements described by the shape factors $(S F)$ through the relationship:

$$
E N_{S C}=a S F-b
$$

Equation 6

The regression and correlation coefficients are given in Table 1. Because of limited microscopy data, there is limited validity for each shape factor. If $S F$ is below the lower limit indicated in Table 1, VN must be taken as zero.

Assuming an acceptable $V N$ of $20 \%$ or less, the following upper limits are derived for the three shape factors:

$S<0.53 \quad C<0.65 \quad R<0.47 \quad$ Equation 7

Table 1. Regression coefficients for $V N-S F$ correlation on SinterCast ${ }^{\circledR}$ chart (high particle count).

\begin{tabular}{ccccc}
\hline$S F$ & $a$ & $b$ & $R^{2}$ & Range of validity \\
\hline$S$ & 500.00 & 247.80 & 0.86 & $0.50-0.59$ \\
$C$ & 416.67 & 257.38 & 0.81 & $0.62-0.73$ \\
$R$ & 322.58 & 134.19 & 0.86 & $0.42-0.57$ \\
\hline
\end{tabular}




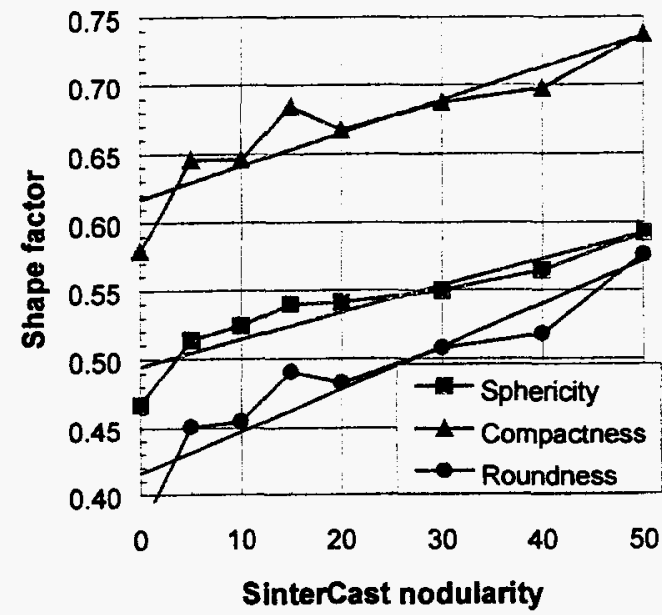

Fig. 2. Measured shape factors vs. visual nodularity on SinterCast chart.

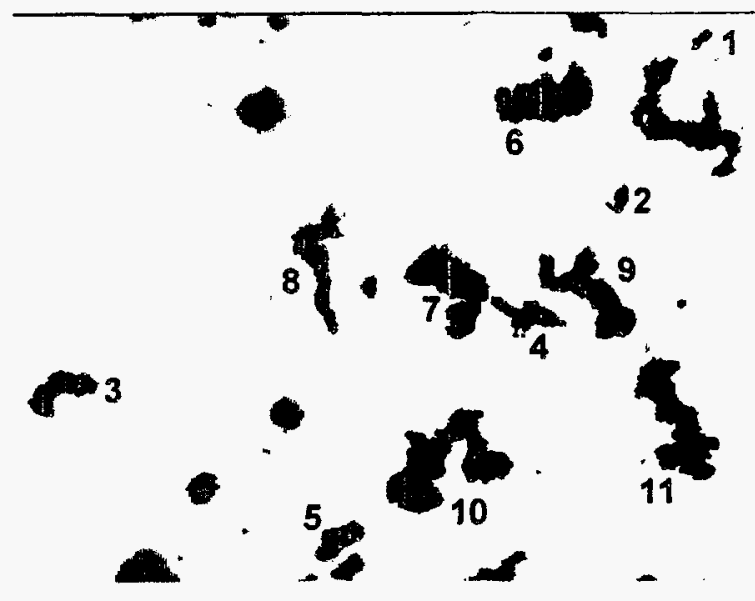

Fig. 3 Graphite particles used for the evaluation of shape factors.

Table 2. Measurements on the compacted graphite particle in Figure 3.

\begin{tabular}{cccccccccccc}
\hline & 1 & 2 & 3 & 4 & 5 & 6 & 7 & 8 & 9 & 10 & 11 \\
\hline$C$ & 0.62 & 0.64 & 0.62 & 0.46 & $\mathbf{0 . 7 0}$ & 0.58 & $\mathbf{0 . 6 6}$ & 0.37 & 0.50 & 0.57 & 0.53 \\
$S$ & 0.51 & 0.39 & 0.42 & 0.26 & 0.53 & 0.39 & 0.53 & 0.23 & 0.23 & 0.18 & 0.21 \\
$R$ & 0.36 & 0.46 & 0.38 & 0.26 & 0.43 & 0.48 & 0.50 & 0.19 & 0.32 & 0.44 & 0.32 \\
\hline
\end{tabular}

These limits were obtained using a minimum graphite size of $5 \mu \mathrm{m}$ on microstructures obtained from castings with regular thickness as given in the SinterCast ${ }^{\mathscr{D}}$ wall chart for the highest nodule count (Compacted Graphite Iron-Nodularity Rating Chart 1999) and equations 1 to 5 . However, new wall charts recently developed by SinterCast ${ }^{\circledR}$ (Compacted Graphite IronNodularity Evaluation 2001) where the minimum acceptable graphite size was taken as $10 \mu \mathrm{m}$ suggest that the upper limit for roundness should be increased to $R=0.525$.

Based on the correlation coefficients it is apparent that all shape factors are acceptable, although sphericity and roundness seem to be slightly better in terms of reliability. The question is then which one to use? To answer this question, a typical CG iron microstructure was selected (Fig. 3). All CG particles were identified visually and marked with numbers from 1 to 11 . The shape factor of each particle was measured and tabulated in Table 2.

From these data, it is seen that sphericity varies from 0.18 to 0.53 , while compactness varies from 0.37 to 0.70 , and roundness varies from 0.19 to 0.50 . Thus, all particles are acceptable for sphericity and roundness (when using the new upper limit of 0.525 suggested by Compacted Graphite Iron-Nodularity Evaluation 2001) but not for compactness. Since visual examination concludes that all the particles are CG, it is apparent that, for the case of compacted graphite iron in thin wall castings, sphericity and roundness are better descriptors of graphite shape than compactness.

$S N$ and $R N$ represent the nodularity calculated using sphericity and roundness as a criterion for acceptable shape. A correlation between $E N_{S C}$ and $S N$ or $R N$ (by area) from SinterCast ${ }^{\circledR}$ chart (Compacted Graphite Iron, Nodularity Rating Chart 1999 ) were developed following the same approach as for $E N_{S C}-S F$ :

$E N_{S C}=1.163 S N-6.527$

Equation 8

$E N_{S C}=1.044 R N-0.515$

Equation 9

From these equations it is derived that a $20 \% E N_{S C}$ corresponds to $22.8 \% S N$ or $19.65 \% R N$ (see Table 3 ). Although sphericity $(S)$ and sphericity nodularity $(S N)$ are used in this research, similar results are expected if roundness $(R)$ and roundness nodularity $(R N)$ are used.
Table 3. Corresponding critical visual nodularity for sphericity nodularity and roundness nodularity.

\begin{tabular}{lll}
\hline$V N, \%$ & 20 & 50 \\
\hline$S N, \%$ & 23 & 49 \\
$R N, \%$ & 20 & 48 \\
\hline
\end{tabular}




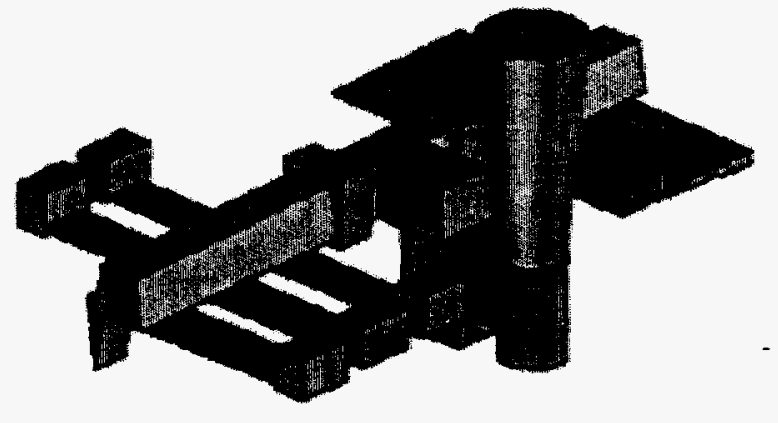

a) horizontal plates pattem

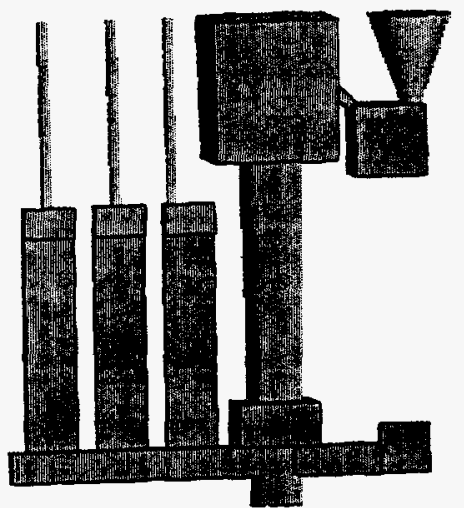

b) vertical plates pattern

Fig. 4. Patterns used for CG iron tests.

\section{EVALUATION OF CGI PROCESSES FOR THIN WALL CASTINGS}

The experimental work involved the use of two main liquid metal treatment procedures: ladle treatment and in-mold treatment. The ladle treatment process was used to study the effects of $\mathrm{Si}, \mathrm{Ti}, \mathrm{S}$, and $\mathrm{O}$, as well as of aluminum postinoculation, on producing CGI through the sandwich process. The in-mold treatment was also used because it gives a better composition control. The variables controlled were carbon equivalent and the amount of liquid treatment alloys.

\section{EXPERIMENTAL PROCEDURE}

\section{Pattern design}

Two types of patterns were used for this research:

- A pattern with horizontal plates and with an in-mold reaction chamber (Fig. 4a). The pattern has five independent plates of thickness $2.5,3.5,5,6$, and $8 \mathrm{~mm}$, and eight connected plates of thickness $2.5,3,3.5,4,5,6,7$, and $8 \mathrm{~mm}$.

- A pattern with vertical plates (Fig. 4b). It has three plates of thickness 3, 4, and $7 \mathrm{~mm}$.

In the molds produced with the vertical plate pattern the molten metal is poured into the reaction chamber, then flows to an open reservoir on top of the sprue. The connection from the reservoir to the sprue is initially closed by a steel disc to allow time for metal homogenization. When the steel disc melts the modified liquid flows into the sprue through the filter located above the runner. The pattern includes a small square disc ( $2 \mathrm{~mm}$ thick) for spectral evaluation of chemistry. In the mold, a chill block is placed against this disc.

Experiments were conducted with the CG iron patterns to determine the correlation between plate thickness and cooling rate. Castings instrumented with thermocouples were produced with both the vertical and horizontal plate patterns. The castings were poured in resin-bonded molds at a temperature of $1400^{\circ} \mathrm{C}(2550 \mathrm{~F})$ for the horizontal mold and $1450^{\circ} \mathrm{C}(2640 \mathrm{~F})$ for the vertical mold. All resin-bonded molds were poured with Pep-Set ${ }^{\mathrm{TM}}$ binder. The cooling curves were recorded and their first derivatives calculated and plotted. The cooling rate at $1170^{\circ} \mathrm{C}(2140 \mathrm{~F})$ for each plate was obtained from these graphs. The relationships between plate thickness and the cooling rate for the horizontal and vertical patterns are plotted in Fig. 5. Linear interpolation of the data in the figures results in the following correlation between cooling rate, $\dot{T}(\mathrm{~K} / \mathrm{s})$, and thickness $(\mathrm{mm})$ :

- For horizontal plates pattern

$$
\begin{array}{ll}
\multicolumn{1}{c}{\text { connected plates }} & \dot{T}=27.59-2.385 \cdot t \\
\text { independent plates } & \dot{T}=24.67-1.702 \cdot t \\
\text { For vertical plates pattern } & \dot{T}=39.90-4.24 \cdot t
\end{array}
$$

As expected, the cooling rate in the independent plates is higher than in the connected plates. Using the above equations the calculated cooling rate of $4 \mathrm{~mm}$ independent plate is about $18^{\circ} \mathrm{C} / \mathrm{s}$ for horizontal plates as compared with $22.9^{\circ} \mathrm{C} / \mathrm{s}$ for the vertical plates. 


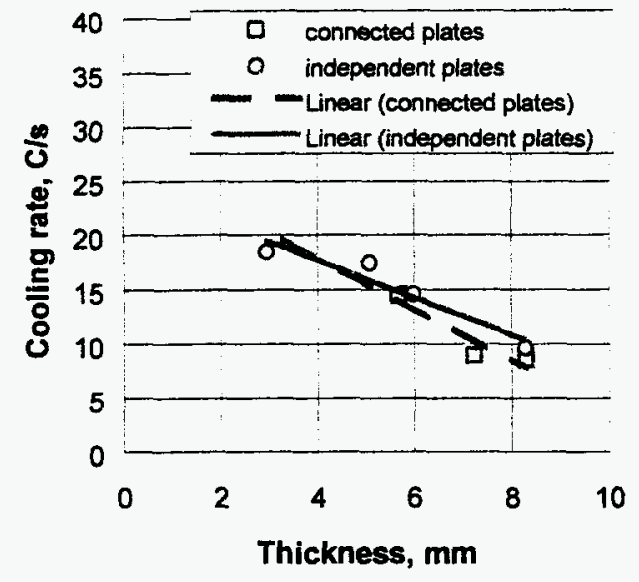

a) horizontal plates

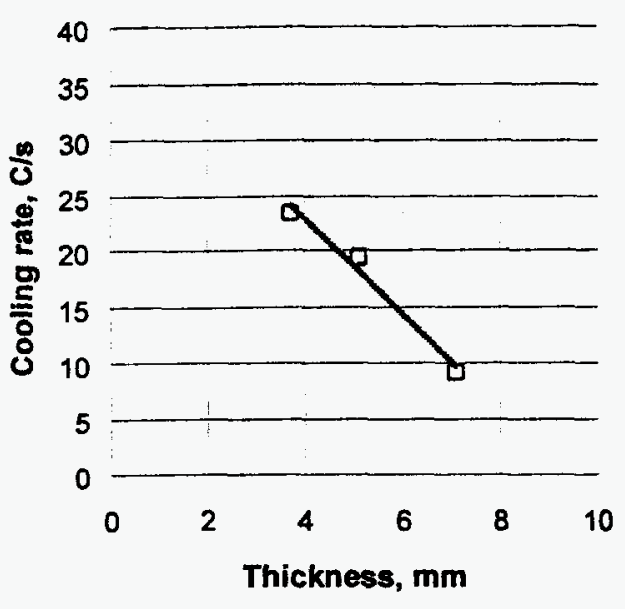

b) vertical plates

Fig. 5. Correlation between plate thickness and cooling rate at $1170^{\circ} \mathrm{C}(2140 \mathrm{~F})$.

Molding

When the horizontal plate pattern was used a green sand and a resin-bonded sand mold was poured from each heat. Only resin-bonded molds were used with the vertical plate pattern. Pin tests of various diameters were also poured for preliminary microstructure evaluation.

\section{LADLE TREATMENT OF CG IRON}

Methods and materials

The original target chemical composition of the castings was: $-3.7 \% \mathrm{C}, 2.3-2.4 \% \mathrm{Si}, 0.02 \% \mathrm{~S}, \max 0.1 \% \mathrm{Cr}, \max 0.4 \% \mathrm{Mn}$. However, this composition was changed during the course of the experiments.

A total of 12 heats were produced to evaluate the ladle treatment method. The experimental sequence was as follows:

- charge $20 \%$ Sorel pig, $40 \%$ ductile iron returns, $40 \%$ steel scrap

- add alloying elements after melt down: sulfur as FeS (pyrite), titanium as Fe70Ti

- superheat to $1550^{\circ} \mathrm{C}(2820 \mathrm{~F})$

- pour cooling curves at the end of superheating

- liquid treatment:

materials: $\mathrm{FeSi} 3.5 \mathrm{Mg}$

method: sandwich (from top to bottom: steel scrap, FeSiMg)

- postinoculation: aluminum

- pour cooling curve and pin test (cylindrical rods having diameters between 1.6 and $14 \mathrm{~mm}$ )

- target pouring temperature: $1425^{\circ} \mathrm{C}(2600 \mathrm{~F})$ for green sand and $1400^{\circ} \mathrm{C}(2550 \mathrm{~F})$ for resin-bonded

The furnace and ladle additions for the heats produced are given in Table 4. The main differences between the first 10 heats consist in the levels of sulfur, magnesium and titanium.

The last two heats were produced using $\mathrm{Ti}$ alloying in the furnace, ladle treatment with FeSiMg, and post-inoculation with aluminum. The purpose of heat 00501 was to establish the optimum amount of Al post-inoculation. Seven resin-bonded sand molds with three vertical plates each were poured from this heat. For the first six molds, increased amounts of $\mathrm{Al}$ were added in the ladle before pouring. No aluminum was used for the last mold. Based on the results of the first heat, a second heat, 00704, was produced to confirm results and poured in a resin-bonded mold with horizontal plates.
Table 4. Furnace and ladle additions used for ladle treatment $\mathrm{CG}$ iron heats (wt\%).

\begin{tabular}{ccccc}
\hline Heat No. & \multicolumn{2}{c}{ furnace addition } & \multicolumn{2}{c}{ ladle addition } \\
\cline { 2 - 5 } & FeTi & FeS & FeSi3.5Mg & Al \\
\hline 90302 & - & - & $0.51^{*}$ & - \\
90304 & - & - & 0.72 & - \\
90402 & - & - & 0.72 & - \\
90403 & - & - & 0.57 & - \\
\hline 90802 & 0.352 & 0.067 & 2.69 & - \\
90804 & 0.365 & 0.067 & 2.10 & - \\
\hline 90805 & 0.315 & - & 0.71 & - \\
90807 & 0.409 & - & 0.57 & - \\
91206 & 0.330 & - & 0.57 & - \\
00203 & 0.330 & - & 0.43 & - \\
\hline 00501 & 0.330 & - & 0.50 & $0.1-0.6$ \\
00704 & 0.330 & - & 0.50 & 0.3 \\
\hline
\end{tabular}


Results and discussions

The chemical compositions of the ladle treated CG iron melts is given in Table 5. Note that the table contains more heats than listed in Table 4 . This is because all these heats were used for cooling curve analysis, and will be discussed in that section. For the first 10 heats, pins were poured together with the horizontal plates. The results of the metallographic analysis on these pins are presented in Table 6. The accepted visual nodularity $(V N)$ for these heats was taken as 20 to $45 \%$ on pin no.3, of equivalent thickness $\sim 4 \mathrm{~mm}$ (diameter/2).

Magnesium treated iron

For the first four heats, it is apparent that the target microstructure was achieved only for the 14 mm diameter pins. Thus, when only magnesium was used for liquid treatment nodularity was too high in all cases. It was concluded that to obtain CG in thin walls it is necessary to use some graphite anti-compactizers like $\mathrm{Ti}, \mathrm{S}$, or oxygen. Alternatively, a treatment alloy that contains rare earths could be used.

Carbide free microstructures were obtained in most pins from heats having carbon content higher than $4 \%$. However, such high carbon levels create the risk of exploded graphite. Accordingly, for the following heats the target carbon content was chosen to be $3.9 \%$.

Magnesium + Sulfur + Titanium treated iron In the second group of experiments, heats 90802 and 90804 , higher levels of $\mathrm{Mg}$ and $\mathrm{S}$ were used. Titanium was also added to the melt. The ratio between compactizing and anti-compactizing elements was $\mathrm{Mg} /(\mathrm{S}+\mathrm{Ti})=0.15-0.16$. The metallographic data are summarized in Fig. 6. Heat 90804 had good graphite shape and pearlite-ferrite structure free of carbides.

Table 5. Chemical composition of CG iron produced by ladle treatment.

\begin{tabular}{|c|c|c|c|c|c|c|c|c|c|}
\hline eat & C & Si & $M n$ & $P$ & $S_{\text {initial }}$ & $S_{\text {final }}$ & $M g$ & $T i$ & $M g / S$ \\
\hline \multicolumn{10}{|c|}{ treatment elements: $\mathrm{Mg}$} \\
\hline 90302 & 4.03 & 2.47 & 0.24 & 0.018 & - & 0.011 & 0.018 & - & 1.63 \\
\hline & 3.64 & & 0.22 & 0.017 & - & & & . & 0.82 \\
\hline 02 & 4.28 & & & 0.017 & - & 13 & & & \\
\hline 90403 & 4.07 & & & 0.016 & - & 0.009 & & - & \\
\hline & 3.70 & & & 0.0 & - & 0.009 & & - & \\
\hline & 3.8 & & & 0.0 & - & 10 & & - & \\
\hline & & & & & - & & & - & \\
\hline & 3. & & & 0.0 & - & 99 & & - & \\
\hline & 3.8 & 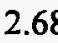 & & & - & & & - & .00 \\
\hline & & & 20 & 0.0 & - & & & & .10 \\
\hline \multicolumn{10}{|c|}{ treatment elements: $\mathrm{Mg}, \mathrm{S}, \mathrm{Ti}$} \\
\hline & & & & 0.0 & 0.050 & & 0.028 & & 0.78 \\
\hline & & & & & 0.040 & & & & 0.77 \\
\hline & & & 0.16 & 0.017 & - & 0.034 & 0.023 & & 0.68 \\
\hline \multicolumn{10}{|c|}{ treatment elements: $\mathrm{Mg}, \mathrm{Ti}$} \\
\hline & 3.80 & & 0.17 & 0.017 & 0.011 & 0.008 & 0.0 & & .62 \\
\hline & 3.8 & & & 0.0 & 0.012 & .008 & & & 0.05 \\
\hline & 3.4 & & & 0.0 & 0.012 & 0.008 & 0.0 & & 1.50 \\
\hline & & & .17 & 0.019 & 0.011 & 0.008 & 0.008 & & 1.00 \\
\hline & 3.81 & & 0.18 & 0.018 & - & 0.011 & & & 0.09 \\
\hline & & 2. & 0.17 & 0.01 & - & 0.011 & & & 0.73 \\
\hline & 3.78 & 2.2 & 0.16 & 0.0 & & 0.012 & & & 1.00 \\
\hline & & 2.58 & 0.15 & 0.017 & - & 0.009 & 0.010 & & 1.11 \\
\hline \multicolumn{10}{|c|}{ treatment elements: $\mathrm{Mg}, \mathrm{Ti}, \mathrm{Al}$} \\
\hline & & & 0.19 & 0.018 & & 0.009 & 0.008 & & 0.89 \\
\hline & 3 & & 0.15 & 0.017 & - & 0.009 & 0.009 & .14 & 1.00 \\
\hline \multicolumn{10}{|c|}{ treatment elements: $\mathrm{Mg}, \mathrm{Ti}, \mathrm{O}$} \\
\hline & & & & & - & 0.007 & & & 0.43 \\
\hline & & & 0.19 & 0.013 & & 0.008 & 0.008 & 0.13 & 1.00 \\
\hline
\end{tabular}



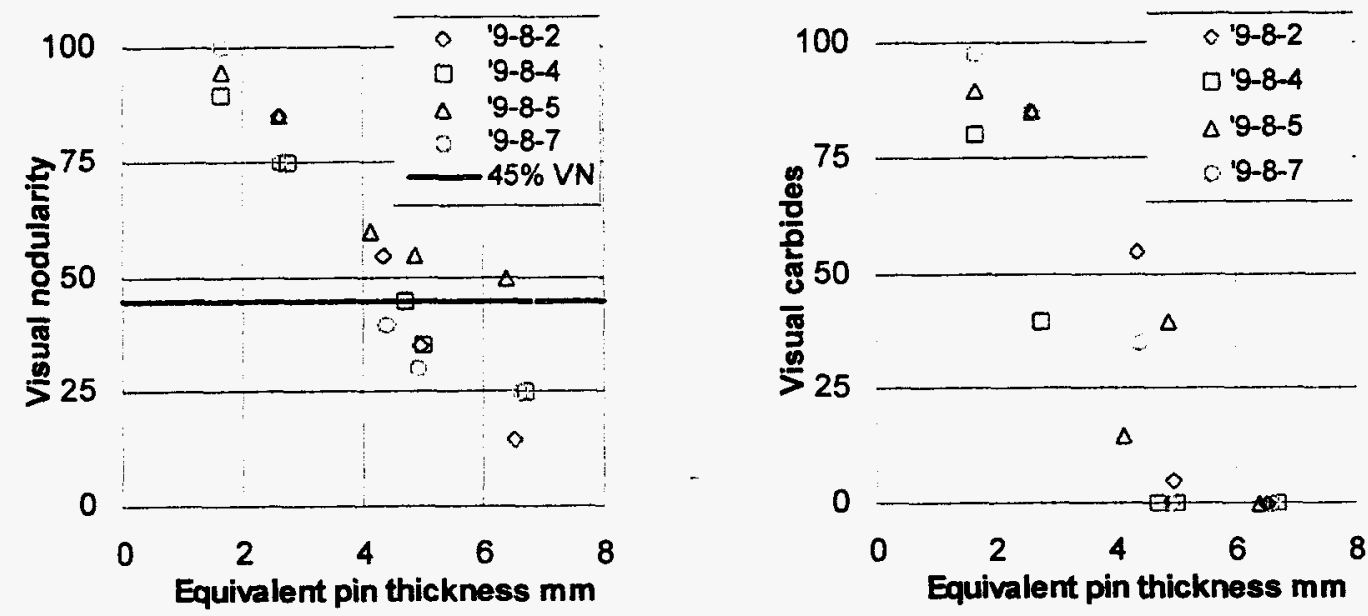

Fig. 6. Influence of equivalent pin thickness on visual estimates of nodularity and carbides.

Table 6. Metallographic data (visual estimates) on pin tests for CG iron produced with the ladle treatment process.

\begin{tabular}{|c|c|c|c|c|c|c|c|c|c|c|}
\hline $\begin{array}{l}\text { Pin } \\
\text { no. }\end{array}$ & $\begin{array}{l}\text { Dia., } \\
\text { mm }\end{array}$ & $\begin{array}{c}\text { Equivalent } \\
\text { thickness, } \mathrm{mm}\end{array}$ & $\begin{array}{l}V N, \\
\%\end{array}$ & $\begin{array}{c}\text { Carbide, } \\
\%\end{array}$ & $\begin{array}{l}V N, \\
\%\end{array}$ & $\begin{array}{c}\text { Carbide, } \\
\%\end{array}$ & $\begin{array}{l}V N, \\
\%\end{array}$ & $\begin{array}{c}\text { Carbide, } \\
\% \\
\end{array}$ & $\begin{array}{l}V N, \\
\%\end{array}$ & $\begin{array}{c}\text { Carbide, } \\
\%\end{array}$ \\
\hline \multicolumn{3}{|c|}{ treatment elements: $\mathrm{Mg}$} & \multicolumn{2}{|c|}{ Heat 90302} & \multicolumn{2}{|c|}{ Heat 90304} & \multicolumn{2}{|c|}{ Heat 90402} & \multicolumn{2}{|c|}{ Heat 90403} \\
\hline 1 & 14.6 & 7.3 & 25 & 0 & 40 & 0.13 & 45 & 0 & 45 & 0 \\
\hline 2 & 11.0 & 5.5 & 40 & 0 & 55 & 0.1 & 50 & 0 & 65 & 0 \\
\hline 3 & 8.6 & 4.3 & 55 & 0 & 55 & 0.1 & 60 & 0 & 60 & 0 \\
\hline 4 & 5.6 & 2.8 & 70 & 0 & 80 & 18.1 & 75 & 0 & 80 & 0 \\
\hline 5 & 4.0 & 2.0 & 90 & 1.3 & 80 & 23.8 & 80 & 1.8 & 90 & 1.1 \\
\hline \multicolumn{3}{|c|}{ treatment elements: $\mathrm{Mg}, \mathrm{S}, \mathrm{Ti}$} & \multicolumn{2}{|c|}{ Heat 90802} & \multicolumn{2}{|c|}{ Heat 90804} & & & & \\
\hline 1 & 14.6 & 7.3 & 15 & 0 & 25 & 0 & & & & \\
\hline 2 & 11.0 & 5.5 & 35 & $5^{*}$ & 35 & 0 & & & & \\
\hline 3 & 8.6 & 4.3 & 55 & 55 & 45 & 0 & & & & \\
\hline 4 & 5.6 & 2.8 & 85 & 85 & 75 & 40 & & & & \\
\hline 5 & 4.0 & 2.0 & - & - & 90 & 80 & & & & \\
\hline \multicolumn{3}{|c|}{ treatment elements: $\mathrm{Mg}, \mathrm{Ti}$} & \multicolumn{2}{|c|}{ Heat 90805} & \multicolumn{2}{|c|}{ Heat 90807} & \multicolumn{2}{|c|}{ Heat 91206} & \multicolumn{2}{|c|}{ Heat 00203} \\
\hline 1 & 14.6 & 7.3 & 50 & 0 & 25 & 0 & 35 & 0 & 20 & 0 \\
\hline 2 & 11.0 & 5.5 & 55 & 15 & 30 & 0 & 40 & 0 & 35 & 0 \\
\hline 3 & 8.6 & 4.3 & 60 & 40 & 40 & 35 & 50 & 0 & 40 & 0 \\
\hline 4 & 5.6 & 2.8 & 85 & 85 & 75 & 85 & - & - & - & - \\
\hline 5 & 4.0 & 2.0 & 95 & 90 & 100 & 98 & - & - & - & - \\
\hline
\end{tabular}

Based on the analysis of the pins and using the acceptability criteria for pins ( $\leq 45 \% V N$ and $0 \%$ carbides on pin 3$)$, it was concluded that only heat 90804 is acceptable. Accordingly, this heat was further analyzed. The microstructure and mechanical properties of the plates poured in resin-bonded and green sand are given in Table 7. The relationship between graphite shape and plate thickness is summarized in Fig. 7. It is seen that $V N$ is smaller than $45 \%$ in all plates. All plates thicker than $5 \mathrm{~mm}$ were free of carbides. Some of the thinner plates were also free of carbides.

\section{Magnesium + Titanium treated iron}

The third group of heats was designed to evaluate the effect of $\mathrm{Mg}+\mathrm{Ti}$ additions at regular sulfur levels, as well as the effect of increased silicon content. The chemical analysis and the microstructural results on the pins from these heats are given in Table 5 and Table 6, respectively. The $\mathrm{Mg} /(\mathrm{S}+\mathrm{Ti})$ ratio for these heats ranged from 0.02 to 0.08 , i.e., it was much smaller than that in the previous two heats. The regular silicon heats exhibited high carbide content and relatively high nodularity. Increasing the silicon content from 2.5 to $3.6 \%$ eliminated the carbides in all pins having equivalent thickness higher than 4 $\mathrm{mm}$ with acceptable nodularity. 


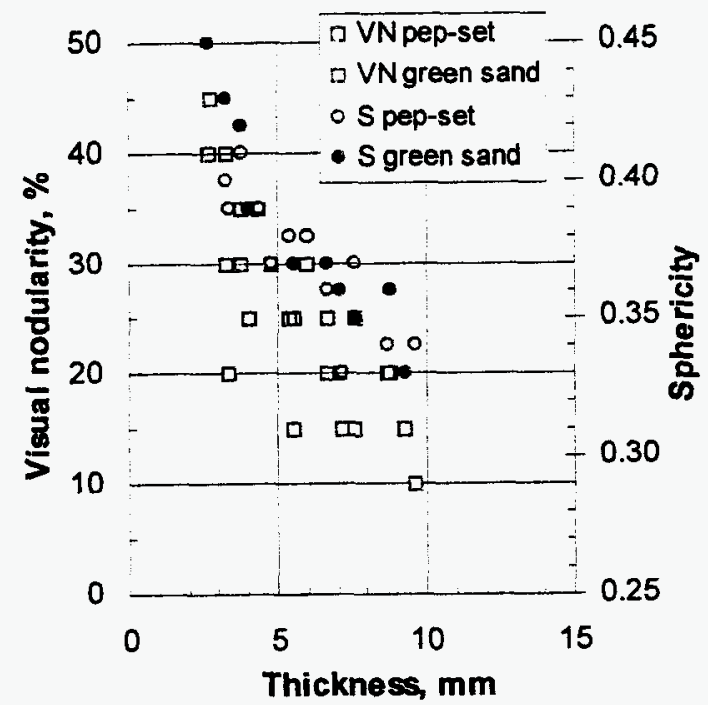

Fig. 7. Relationship between graphite shape and plate thickness for heat 90804.

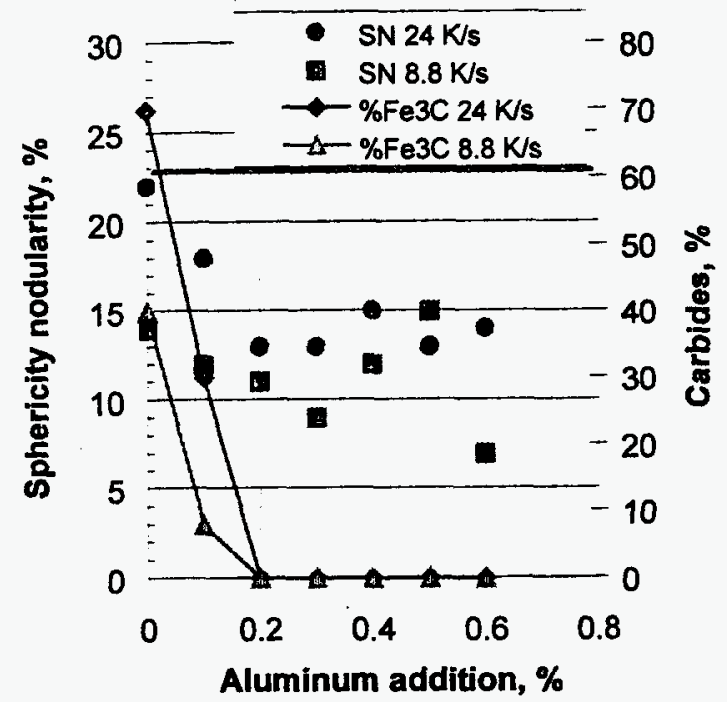

Fig. 8. Influence of Al addition and of cooling rate on the SN and amount of carbides in Mg-Ti ladle treated CGI.

Table 7. Microstructure and mechanical properties of $\mathrm{CG}$ iron produced by ladle treatment with $\mathrm{Mg}, \mathrm{S}$, and $\mathrm{Ti}$.

\begin{tabular}{|c|c|c|c|c|c|c|c|c|c|c|c|}
\hline \multirow{2}{*}{$\begin{array}{c}\text { Heat } \\
\text { no. }\end{array}$} & \multicolumn{2}{|r|}{ Plate } & \multicolumn{3}{|c|}{ Graphite } & \multicolumn{2}{|c|}{ Matrix } & \multicolumn{3}{|c|}{ Mechanical prop. } & \multirow[t]{2}{*}{ Notes } \\
\hline & no. & $\begin{array}{c}\text { Thickness, } \\
\text { mm }\end{array}$ & Nods $/ \mathrm{mm}^{2}$ & $S$ & $\begin{array}{l}V N, \\
\%\end{array}$ & $\begin{array}{c}\mathrm{Fe}_{3} \mathrm{C}, \\
\% \\
\end{array}$ & $\begin{array}{c}\text { Ferrite, } \\
\%\end{array}$ & $\begin{array}{l}\text { UTS, } \\
\mathrm{MPa}\end{array}$ & $H R B$ & $\begin{array}{l}E l ., \\
\%\end{array}$ & \\
\hline 9-08-04 & 1 & 7.2 & 654 & 0.33 & 15 & 0 & 67 & 386 & 87.2 & 2.5 & \\
\hline resin- & 2 & 5.4 & 687 & 0.38 & 25 & 0 & 67 & - & 86.3 & - & Surface defect \\
\hline bonded & 3 & 3.8 & 872 & 0.41 & 35 & 0 & 68 & - & 90 & - & Surface defect \\
\hline & 4 & - & - & - & - & - & - & - & - & - & Cold shut \\
\hline & 5 & 8.7 & 605 & 0.34 & 20 & 0 & 69 & 354 & 87.2 & 3.2 & \\
\hline & 6 & 6.7 & 614 & 0.36 & 25 & 0 & 72 & 362 & 82.8 & 3 & \\
\hline & 7 & 4.4 & 874 & 0.39 & 35 & 5.5 & 50 & 419 & 86.8 & 4.4 & \\
\hline & 8 & 3.4 & 816 & 0.39 & 20 & 0 & 75 & 547 & 89 & 1.1 & \\
\hline & 9 & 3.3 & 888 & 0.4 & 30 & 0 & 31 & 574 & 82 & 1.6 & \\
\hline & 10 & 4.8 & 789 & 0.37 & 30 & 7.6 & 49 & 415 & 84 & 2.1 & Inverse chill \\
\hline & 11 & 6.0 & 695 & 0.38 & 30 & 1 & 57 & 400 & 85.3 & 2.4 & \\
\hline & 12 & 7.6 & 686 & 0.37 & 25 & 0 & 78 & 327 & 76.1 & 2.2 & \\
\hline & 13 & 9.7 & 641 & 0.34 & 10 & 0 & 75 & 336 & 80.7 & 1.2 & \\
\hline 9-08-04 & 1 & 7.6 & 589 & 0.35 & 15 & 1.2 & 67 & 397 & 89 & 2.4 & \\
\hline green & 2 & 5.6 & 716 & 0.37 & 25 & 0 & 68 & 408 & 91.8 & 2.2 & \\
\hline sand & 3 & 3.3 & 977 & 0.43 & 40 & 0.2 & 59 & 515 & 92.7 & 2.9 & Cold shut \\
\hline & 4 & 2.7 & 991 & 0.45 & 40 & 0.8 & 26 & 518 & 83.5 & 1.1 & Cold shut \\
\hline & 5 & 9.3 & 562 & 0.33 & 15 & 0 & 71 & 371 & 86.1 & 2.1 & \\
\hline & 6 & 7.1 & 622 & 0.36 & 20 & 0 & 71 & 441 & 86.3 & 1 & \\
\hline & 7 & 4.1 & 872 & 0.39 & 25 & 0.7 & 43 & 410 & 87.6 & 1.5 & \\
\hline & 8 & - & - & - & - & - & - & - & - & - & Cold shut \\
\hline & 9 & 2.8 & 929 & 0.46 & 45 & 1.5 & 25 & 517 & 86.2 & 1.4 & \\
\hline & 10 & 3.8 & 912 & 0.42 & 30 & 8 & 66 & 466 & 86.4 & 1.5 & \\
\hline & 11 & 5.6 & 778 & 0.37 & 15 & 0 & 65 & 377 & 85.1 & 1.7 & \\
\hline & 12 & 6.7 & 738 & 0.37 & 20 & 0 & 74 & 319 & 83.5 & 2.3 & \\
\hline & 13 & 8.8 & 635 & 0.36 & 20 & 0 & 76 & 335 & 83.3 & 4.7 & \\
\hline
\end{tabular}

Magnesium + Titanium + Aluminum treated irons

The metallographic data on the plates from melt 00501 are presented in Table 8. Using these data, the influence of aluminum addition on sphericity nodularity and on the amount of carbides was plotted in Fig. 8. It is seen that at aluminum additions of higher than $0.2 \%$ the plates are carbide-free at all cooling rates, up to $24 \mathrm{~K} / \mathrm{s}$. The addition of aluminum also decreased 
nodularity, which was under the $22 \% S N(20 \% V N)$ limit for all the plates. It is apparent that the optimum aluminum addition is $0.3 \%$.

Table 8. Experimental results on plates from heat 00501 .

\begin{tabular}{ccccccc}
\hline Mold & \%Al added & Thickness, $\mathrm{mm}$ & Cooling rate, $\mathrm{K} / \mathrm{s}$ & $\mathrm{S}$ & $\mathrm{SN} \%$ & $\% \mathrm{Fe}_{3} \mathrm{C}$ \\
\hline 1 & 0.1 & 3.7 & 24.2 & 0.50 & 18 & 30 \\
& & 4.9 & 19.1 & 0.46 & 17 & 25 \\
& & 7.4 & 8.5 & 0.46 & 12 & 8 \\
\hline 2 & 0.2 & 3.6 & 24.6 & 0.48 & 13 & 0 \\
& & 4.7 & 20.0 & 0.45 & 11 & 0 \\
& & 7.2 & 9.4 & 0.45 & 11 & 0 \\
\hline 3 & 0.3 & 3.6 & 24.6 & 0.51 & 13 & 0 \\
& & 4.7 & 20.0 & 0.50 & 11 & 0 \\
& & 7.3 & 8.9 & 0.46 & 9 & 0 \\
\hline 4 & 0.4 & 3.6 & 24.6 & 0.49 & 15 & 0 \\
& & 4.7 & 20.0 & 0.46 & 13 & 0 \\
& & 7.4 & 8.5 & 0.44 & 12 & 0 \\
\hline 5 & 0.5 & 3.7 & 24.2 & 0.47 & 13 & 0 \\
& & 4.7 & 20.0 & 0.47 & 11 & 0 \\
& & 7.3 & 8.9 & 0.46 & 15 & 0 \\
\hline 6 & 0.6 & 3.8 & 23.8 & 0.49 & 14 & 0 \\
& & 5.1 & 18.3 & 0.45 & 11 & 0 \\
& & 7.5 & 8.1 & 0.45 & 7 & 0 \\
\hline 7 & 0 & 3.6 & 24.6 & 0.52 & 22 & 70 \\
& & 4.7 & 20.0 & 0.46 & 18 & 50 \\
& & 7.3 & 8.9 & 0.48 & 14 & 40 \\
\hline
\end{tabular}

Table 9. Metallographic data of the plates from heat 00704.

\begin{tabular}{cccccccccc}
\hline $\begin{array}{c}\text { Plate } \\
\text { no. }\end{array}$ & $\begin{array}{c}\text { Thickness } \\
\mathrm{mm}\end{array}$ & $\begin{array}{c}\text { Cooling } \\
\text { rate, } \mathrm{K} / \mathrm{s}\end{array}$ & $S$ & $\begin{array}{c}S N \\
\%\end{array}$ & $\begin{array}{c}V N \\
\%\end{array}$ & $\begin{array}{c}f_{\mathrm{Gr}} \\
\%\end{array}$ & $\begin{array}{c}\mathrm{Fe}_{3} \mathrm{C} \\
\%\end{array}$ & $\begin{array}{c}\text { Ferrite } \\
\%\end{array}$ & Notes \\
\hline 1 & 7.4 & 9.9 & 0.34 & 4 & 5 & 4.7 & 0 & 77 & \\
2 & 5.4 & 14.7 & 0.37 & 11 & 15 & 5.5 & 0 & 81 & \\
3 & 3.9 & 18.3 & 0.40 & 11 & 20 & 6.2 & 0 & 78 & \\
4 & 3.1 & 20.2 & 0.41 & 69 & 70 & 5.9 & 22.5 & 21 & \\
5 & 8.8 & 6.6 & 0.32 & 3 & 5 & 4.5 & 0 & 74 & \\
6 & 6.7 & 11.6 & 0.35 & 5 & 10 & 5.4 & 0 & 74 & \\
7 & 4.5 & 16.9 & 0.38 & 8 & 15 & 5.9 & 0 & 81 & \\
8 & 3.6 & 19.0 & 0.40 & 12 & 20 & 6.4 & 0 & 68 & \\
\hline 9 & 3.2 & 19.2 & 0.41 & 12 & 80 & 6.2 & 0 & 44 & \\
10 & 4.6 & 16.8 & 0.37 & 9 & 15 & 7.1 & 9.8 & 66 & Inv. Chill \\
11 & 6.1 & 14.3 & 0.36 & 7 & 5 & 6.0 & 0 & 75 & \\
12 & 7.7 & 11.6 & 0.37 & 3 & 5 & 5.9 & 0 & 87 & \\
13 & 10.0 & 7.7 & 0.35 & 2 & 5 & 6.3 & 9.2 & 72 & Inv. Chill \\
\hline
\end{tabular}

The metallographic data on the plates from melt 00704 are presented in Table 9 . It is seen that all plates, with the exception of plate 4 , had acceptable nodularity, which is $S N<22$. Plate 4 also had high carbide content of $22.5 \%$. This plate has the highest cooling rate from all plates poured $(20.2 \mathrm{~K} / \mathrm{s})$. An interesting anomaly was observed for plate 9 : the visual nodularity is much higher than sphericity nodularity $(V N=80, S N=12)$. Finally, inverse chill occurred in the independent plates 10 and 13. In general, it was confirmed that CG iron with nodularity less than $20 \%$ could be obtained through $\mathrm{Mg}$ - $\mathrm{Ti}$ ladle treatment and aluminum postinoculation at cooling rates of up to $19 \mathrm{~K} / \mathrm{s}$. 

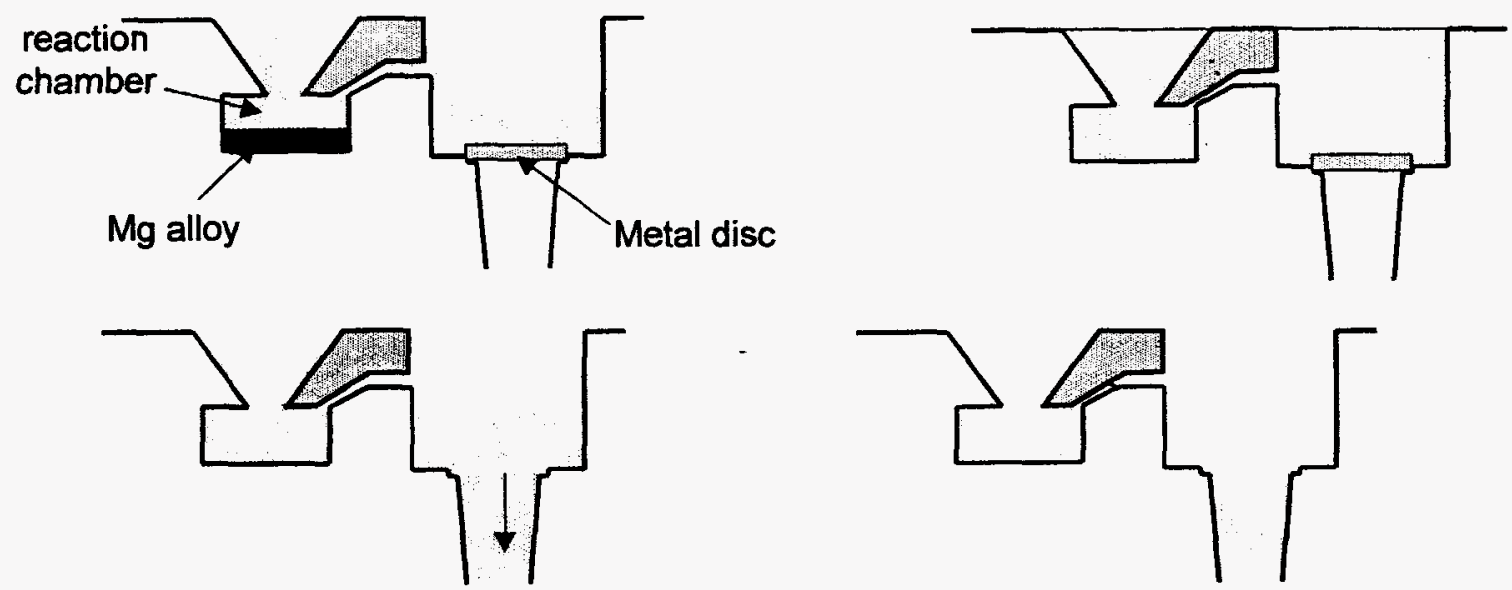

Fig. 9. Principle of the delayed in-mold system.

\section{IN-MOLD TREATMENT OF CG IRON}

The motivation for the attempt to produce thin CG iron castings by in-mold stems from previous successful experiments performed in 1984 in the Metal Casting Laboratory at the University of Alabama (Fowler et al., 1984). It was demonstrated that CG iron with less than $20 \%$ nodularity could be produced in $1 \mathrm{in}$. bars using a regular MgFeSi alloy with no Ti. The present experiments were conducted to assess the possibility of extending this technology to thinner sections.

\section{Methods and materials}

The same patterns as presented in Fig. 4 were used. Note that the pattern for horizontal plates had a chamber for in-mold treatment. The details of the design of the in-mold chamber are given in the TWIG Annual Report Year 1 (Stefanescu et al., 1999). The second one uses a special in-mold technique (Sillen, 1979) called delayed in-mold. Its principle is described schematically through the sequence of four drawings in Fig. 9.

Two heats were produced with the delayed in-mold process. Heat no. 00102 had no Ti addition, whereas $0.15 \%$ Ti was added to heat no 00306 after charge melting. The target composition of the base metal was as follow: $3.85 \% \mathrm{C}, 2.5 \% \mathrm{Si}, 0.17 \% \mathrm{Mn}$, $0.018 \% \mathrm{P}$, and $0.014 \% \mathrm{~S}$. The experimental method involved the following steps:

- charge $20 \%$ Sorel pig, $40 \%$ SG iron returns, $40 \%$ steel scrap

- add alloying elements (FeTi) after melt down, if necessary.

- target pouring temperature: $1460^{\circ} \mathrm{C}(2660 \mathrm{~F})$

- pour six molds with increasing amounts of $\mathrm{Mg}$ (see Table 10).

A third heat, no. 00606, was produced based on the results from these initial heats. The horizontal plate pattern was used. The $\mathrm{Mg}$ addition of this last heat was narrowed down to two levels that were found to promote CG. Ti was also added. The alloying additions are presented in Table 11.

\section{Results and discussion}

Samples for chemical analysis were cut from the runners of each mold from the first two heats and the $\mathrm{Mg}$ level was analyzed by wet chemical analysis at the Climax Research Center. The results, including calculated $\mathrm{Mg}$ recoveries, are presented in Table 12. It is seen that the $\mathrm{Mg}$ recovery rate of the delayed in-mold treatment process is about $70 \%$ compared to $40 \%$ for the ladle treatment process.

Table $10 . \mathrm{Mg}$ addition and target for in-mold treatment of $\mathrm{CG}$ iron heats.

\begin{tabular}{ccccc}
\hline \multirow{2}{*}{ Mold no. } & \multicolumn{2}{c}{ Heat no. 00102 (Ti-free) } & \multicolumn{2}{c}{ Heat no. 00306 (Ti alloyed) } \\
\cline { 2 - 5 } & FeSi4.46Mg, \% & \%Mg addition & FeSi4.46Mg, \% & \%Mg addition \\
\hline 1 & 0.22 & 0.0098 & 0.28 & 0.0120 \\
2 & 0.28 & 0.0125 & 0.34 & 0.0150 \\
3 & 0.33 & 0.0149 & 0.39 & 0.0175 \\
4 & 0.39 & 0.0174 & 0.45 & 0.0199 \\
5 & 0.45 & 0.0199 & 0.50 & 0.0224 \\
6 & 0.50 & 0.0224 & 0.56 & 0.0250 \\
\hline
\end{tabular}


Table 11. Alloying additions for CG iron in-mold treatment heat no. 00606.

\begin{tabular}{ccc}
\hline Mold no. & \%Mg addition & \%Ti addition \\
\hline 1 & 0.0125 & 0.23 \\
2 & 0.0149 & 0.23 \\
\hline
\end{tabular}

Table 12. $\mathrm{Mg}$ addition and residual $\mathrm{Mg}$ for the initial heats of in-mold treatment process.

\begin{tabular}{ccccccccccc}
\hline $\begin{array}{c}\text { Mold } \\
\text { no. }\end{array}$ & $\begin{array}{c}\text { Mg, \% } \\
\text { Addition }\end{array}$ & $\begin{array}{c}\text { Resid. } \\
\text { Mg, \% }\end{array}$ & $\begin{array}{c}\text { Recovery } \\
\%\end{array}$ & $S$ & $\begin{array}{c}S N \\
\%\end{array}$ & $\begin{array}{c}\text { Mg, \% } \\
\text { Addition }\end{array}$ & $\begin{array}{c}\text { Resid. } \\
\text { Mg, \% }\end{array}$ & $\begin{array}{c}\text { Recovery } \\
\%\end{array}$ & $S$ & $\begin{array}{c}S N \\
\%\end{array}$ \\
\hline 1 & 0.0098 & 0.006 & 61 & flake & flake & 0.0120 & 0.008 & 67 & 0.43 & 13 \\
2 & 0.0125 & 0.008 & 64 & 0.47 & 21 & 0.0150 & 0.009 & 60 & 0.44 & 17 \\
3 & 0.0149 & 0.009 & 63 & 0.46 & 22 & 0.0175 & 0.012 & 69 & 0.49 & 20 \\
4 & 0.0174 & 0.011 & 63 & - & - & 0.0199 & 0.014 & 70 & 0.48 & 22 \\
5 & 0.0199 & 0.014 & 85 & 0.48 & 24 & 0.0224 & 0.016 & 71 & 0.56 & 44 \\
6 & 0.0224 & 0.017 & 75 & 0.62 & 56 & 0.0250 & 0.017 & 68 & 0.68 & 53 \\
\hline
\end{tabular}

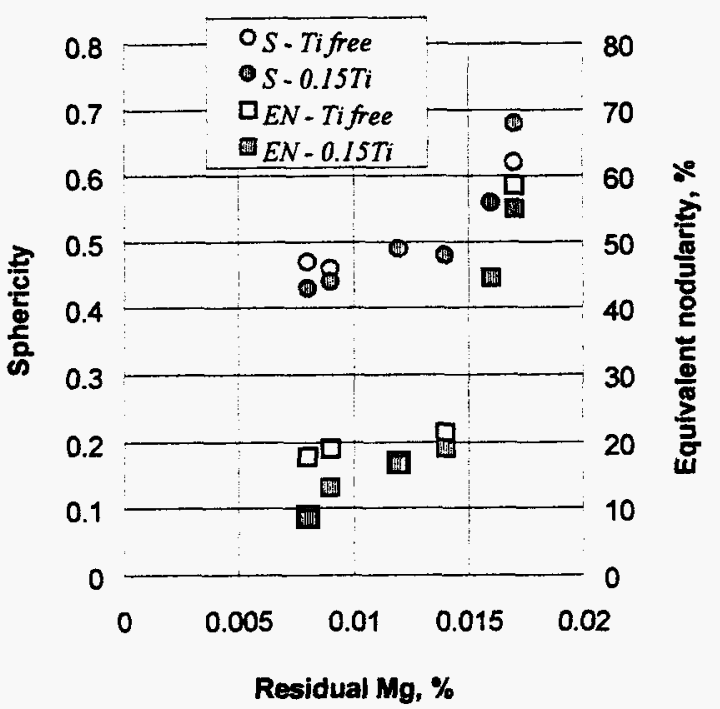

Fig. 10. Influence of residual Mg on graphite shape at $18.7 \mathrm{~K} / \mathrm{s}$ cooling rate.
A preliminary microstructure analysis was performed on the runner $(10 \times 5 \mathrm{~mm})$ of each mold from both heats. The $S$ and $S N$ values for each mold are presented in Table 12 . The calculated cooling rate of the $5 \mathrm{~mm}$ thick runner is $18.7^{\circ} \mathrm{C}$. Graphite shape versus residual $\mathrm{Mg}$ data is plotted in Fig. 10. The runner microstructures of molds 1 to 6 are given in Fig. 11 for heat no. 00102 and in Fig. 12 for heat 00306. It is seen that for both Ti-free and Ti-alloyed irons, CG microstructures with less or about $20 \% V N$ can be obtained for $0.008-0.015 \% \mathrm{Mg}$. Above the $0.015 \% \mathrm{Mg}$ limit nodularity increases rapidly. The benefits of $\mathrm{Ti}$ addition are minor and, somewhat surprisingly, mostly in the lower range of residual $\mathrm{Mg}$.

The last heat, no. 00606, was produced by a standard in-mold treatment technique. Two horizontal plate resin bonded sand molds were cast with $0.008 \%$ and $0.009 \%$ target residual $\mathrm{Mg}$, respectively. The microstructures of the plates are given in Table 13. With the exception of three plates, no carbides were present in the microstructure.

The data from this table were used to plot visual and sphericity nodularity as a function of cooling rate for the two heats (Fig. 13). Within the narrow experimental range of 0.008 to $0.009 \% \mathrm{Mg}$ the difference in graphite shape is minimal. In addition, note that CG iron free of carbides and with less than $20 \%$ nodularity can be produced at cooling rates as high as $18 \mathrm{~K} / \mathrm{s}$. This confirms the findings in the two preliminary heats (see Fig. 10).

\section{EVALUATION OF COOLING CURVE ANALYSIS AS A TOOL FOR PROCESS CONTROL}

\section{EXPERIMENTAL PROCEDURE}

From the ladle treatment CG iron heats, nineteen were selected for cooling curve analysis. The cooling curve data were collected from Electro-Nite plain Quik-Cups (chromel-alumel thermocouple) through a data acquisition system at a rate of two data points per second. The data were transferred to an EXCEL\& spreadsheet program to calculate the first and second derivative of the cooling curve using numerical differentiation.

The cups were transversely cut and metallographic samples were machined from material close to the thermocouple tip. The microstructure was observed with an optical microscope, and the graphite morphology was characterized with the Buehler $\mathbb{B}$ Omnimet image analyzer. An area of $20 \mathrm{~mm}$ in diameter was chosen at the center of each sample, from which five fields were taken to cover an equivalent total area of $0.6 \mathrm{~mm}^{2}$. The fraction of graphite was measured, and for each graphite particle on the field, the area and the shape factor were also measured. Only the particles with an area diameter $>5 \mu \mathrm{m}$ were selected for the metallographic analysis. Particles located on the border of the metallographic field were considered only for graphite fraction analysis. 

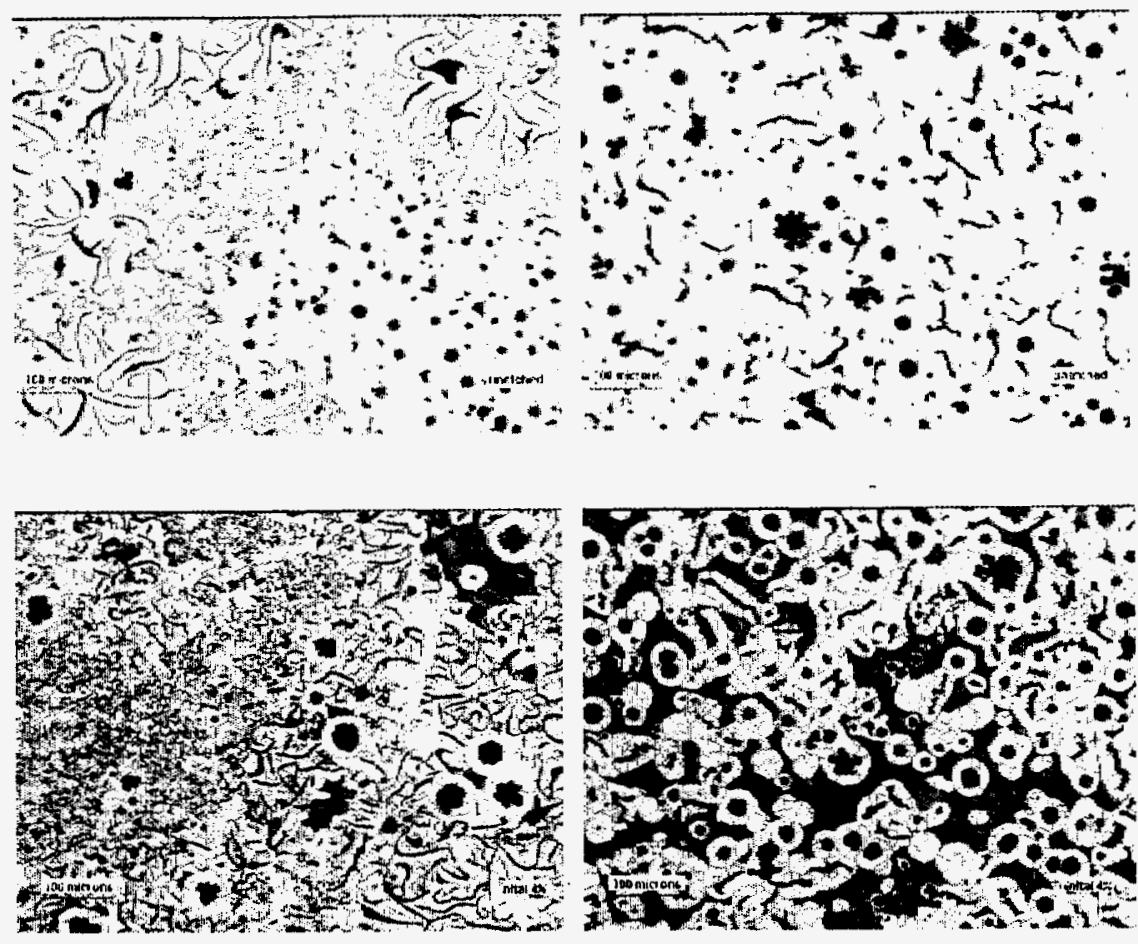

Mold 1 heat 00102: 0.006\% Mg

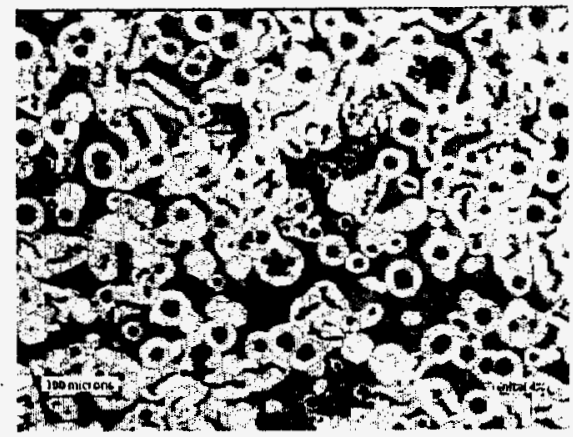

Mold 2 heat 00102: $0.008 \% \mathrm{Mg}$
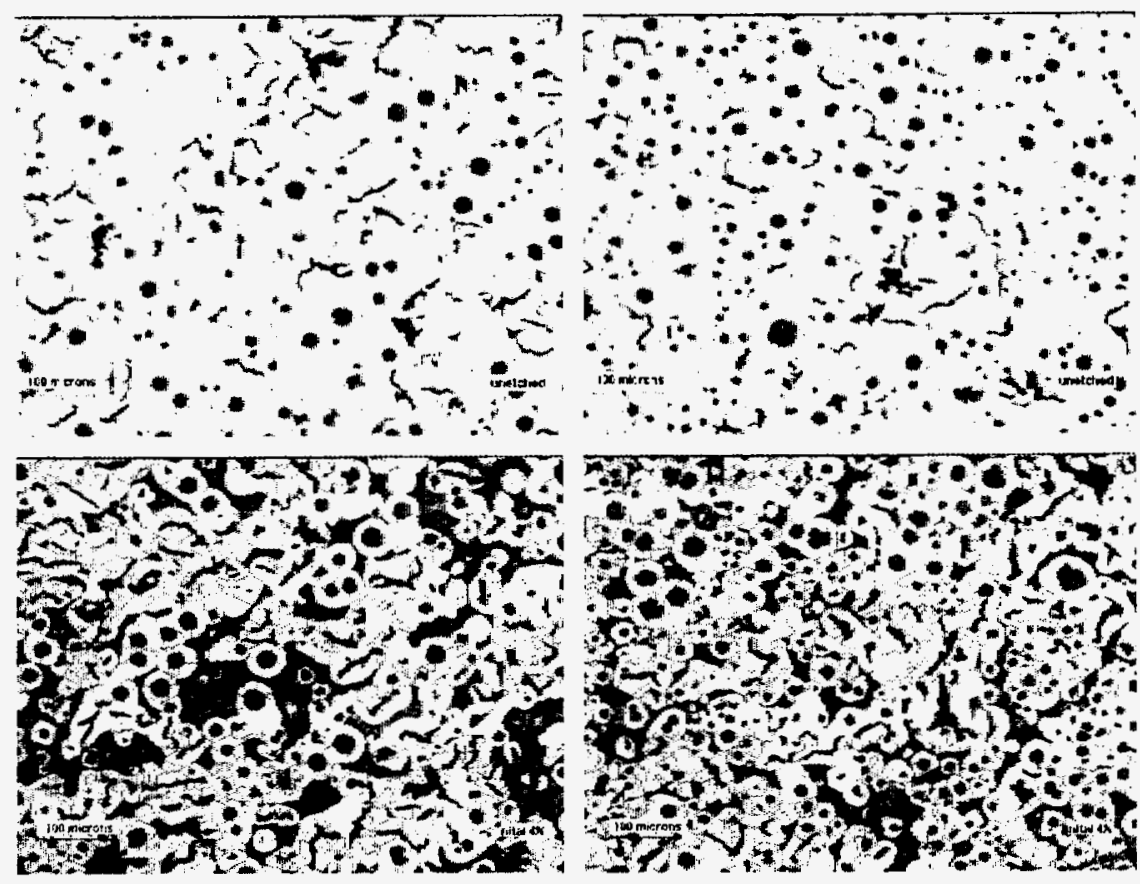

Mold 5 heat 00102: 0.014\% Mg
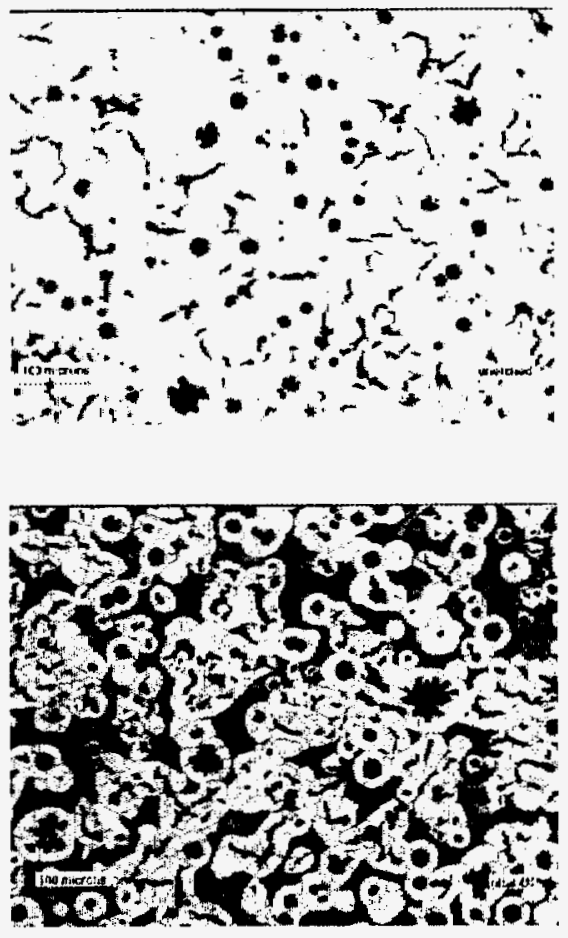

Mold 3 heat 00102: $0.009 \% \mathrm{Mg}$

Fig. 11. Microstructure of the $5 \mathrm{~mm}$ thick $\left(18.7^{\circ} \mathrm{C} / \mathrm{s}\right)$ runners for heat no. 00102. 

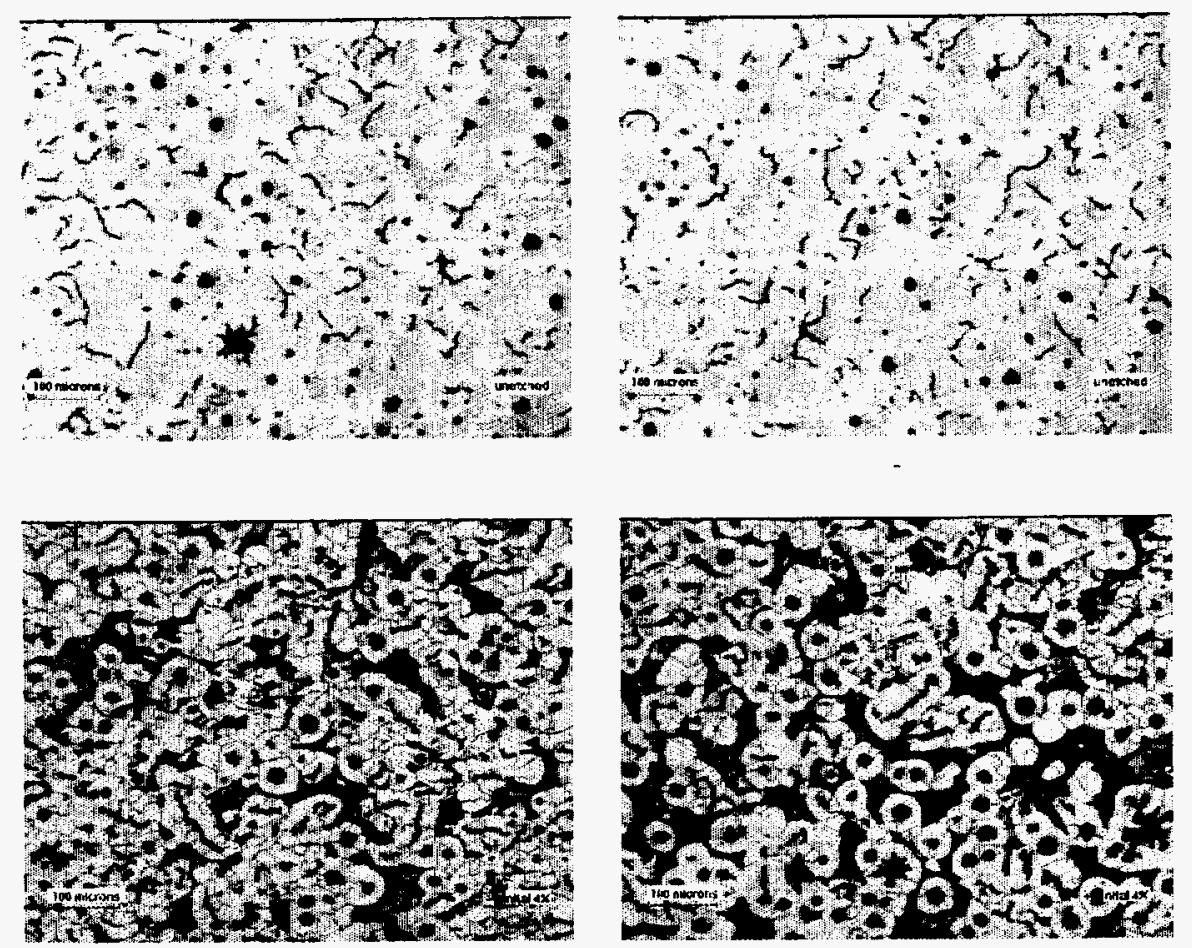

Mold 1 heat 00306: 0.008\% Mg
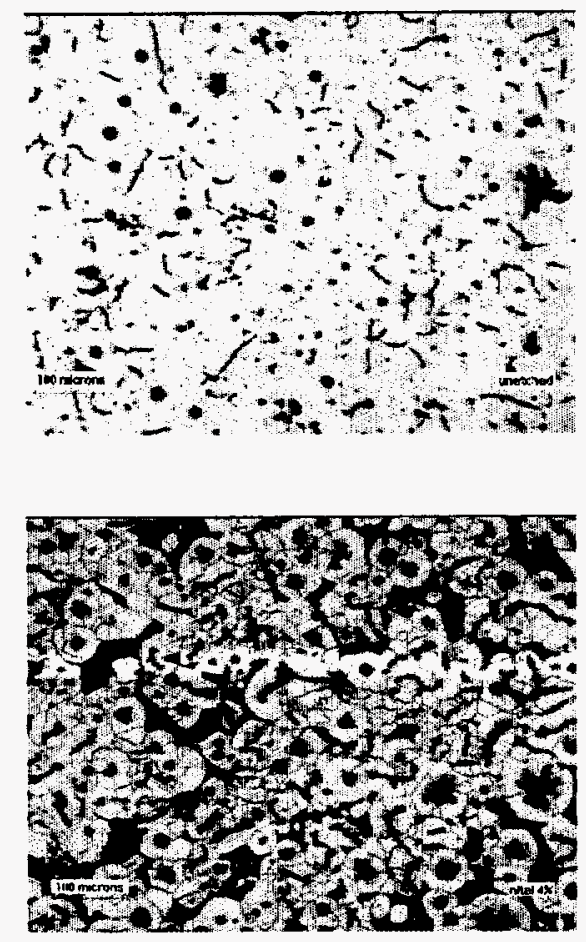

Mold 4 heat 00306: $0.014 \% \mathrm{Mg}$

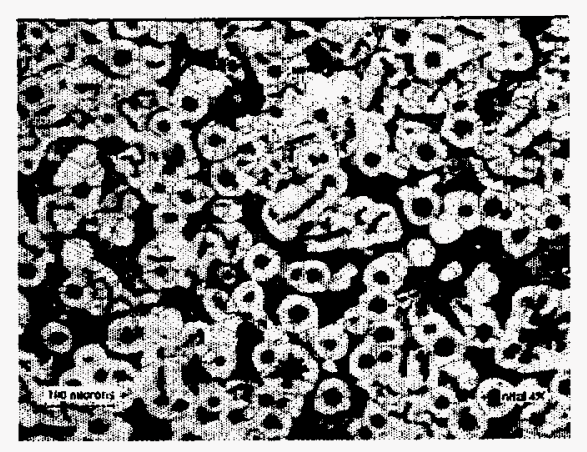

Mold 2 heat 00306: 0.009\% Mg

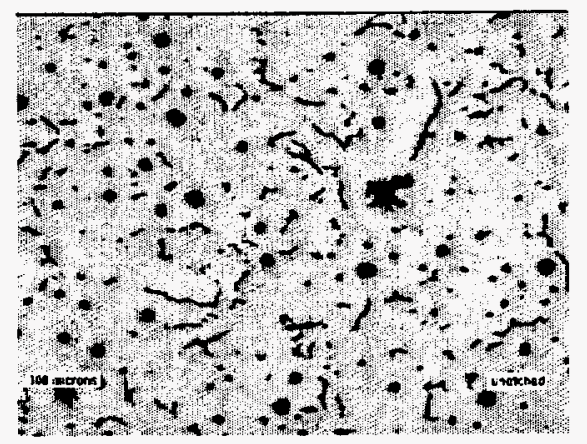

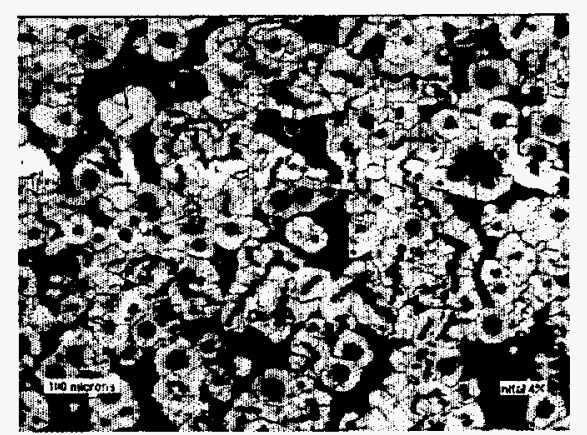

Mold 5 heat 00306: 0.016\% Mg
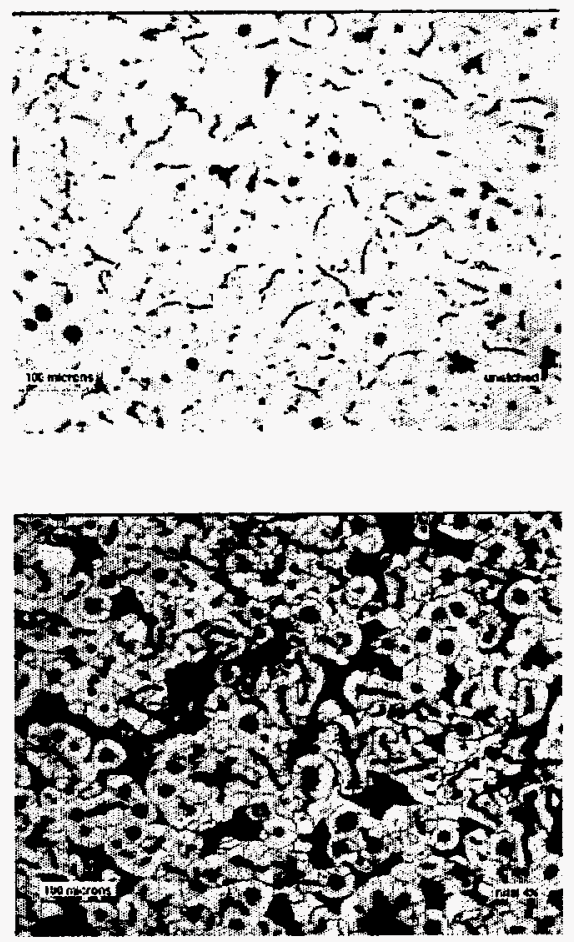

Mold 3 heat 00306: $0.012 \% \mathrm{Mg}$

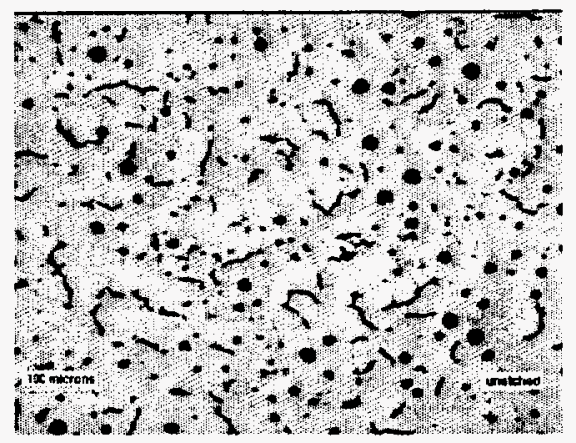

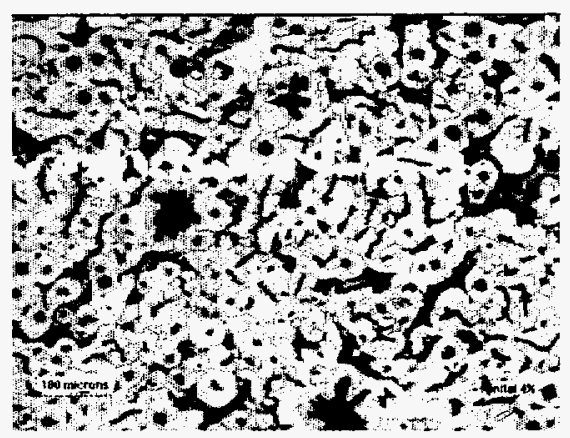

Mold 6 heat 00306: $0.017 \% \mathrm{Mg}$

Fig. 12. Microstructure of the $5 \mathrm{~mm}$ thick $\left(18.7^{\circ} \mathrm{C} / \mathrm{s}\right)$ runners for heat no. 00306 . 
Table 13. Microstructure of CG iron horizontal plates produced through in-mold treatment.

\begin{tabular}{cccccccccc}
\hline $\begin{array}{c}\text { Heat } \\
\text { no. }\end{array}$ & \multicolumn{3}{c}{ Plate } & \multicolumn{3}{c}{ Graphite } & \multicolumn{3}{c}{ Matrix } \\
\cline { 2 - 10 } & no. & $\begin{array}{c}\text { Thickness } \\
\text { mm }\end{array}$ & $\begin{array}{c}\text { Cooling rate, } \\
\text { K/s }\end{array}$ & $S$ & $S N \%$ & $\begin{array}{c}V N \\
\%\end{array}$ & $\begin{array}{c}f_{G r} \\
\%\end{array}$ & $\begin{array}{c}F e_{3} C \\
\%\end{array}$ & $\begin{array}{c}\text { Ferrite } \\
\%\end{array}$ \\
\hline & 1 & 7.0 & 10.9 & 0.37 & 7 & 5 & 7.0 & 0 & 63 \\
& 2 & 5.1 & 15.4 & 0.38 & 13 & 15 & 6.1 & 0 & 60 \\
& 3 & 3.7 & 18.8 & 0.44 & 26 & 40 & 6.2 & 0 & 55 \\
& 4 & 2.9 & 20.7 & 0.52 & 35 & 55 & 5.7 & 0 & 30 \\
00606 & 5 & 8.5 & 7.3 & 0.35 & 5 & 10 & 7.1 & 0 & 63 \\
Mold 1 & 6 & 6.1 & 13.0 & 0.38 & 15 & 15 & 6.9 & 0 & 66 \\
& 7 & 4.0 & 18.1 & 0.42 & 22 & 30 & 7.0 & 0 & 66 \\
& 11 & 3.2 & 20.0 & 0.57 & 42 & 80 & 7.6 & 0 & 44 \\
& 12 & 5.3 & 15.6 & 0.37 & 10 & 15 & 6.8 & 23.1 & 31 \\
& 13 & 8.4 & 13.8 & 0.38 & 7 & 15 & 6.1 & 25.5 & 39 \\
& 1 & 7.0 & 9.9 & 0.37 & 8 & 15 & 7.6 & 0 & 77 \\
\hline & 2 & 5.2 & 10.9 & 0.36 & 7 & 5 & 7.7 & 0 & 70 \\
& 3 & 3.5 & 19.2 & 0.37 & 11 & 15 & 7.5 & 0 & 74 \\
& 4 & 2.6 & 21.4 & 0.46 & 27 & 40 & 8.6 & 0 & 56 \\
& 5 & 8.1 & 8.3 & 0.36 & 8 & 5 & 6.5 & 0 & 70 \\
00606 & 6 & 6.1 & 13.0 & 0.38 & 12 & 10 & 7.4 & 0 & 72 \\
Mold 2 & 7 & 4.0 & 18.1 & 0.41 & 19 & 25 & 7.3 & 0 & 76 \\
& 8 & 3.1 & 20.2 & 0.55 & 36 & 55 & 7.5 & 8.5 & 24 \\
& 12 & 6.1 & 14.3 & 0.39 & 12 & 10 & 6.9 & 0 & 73 \\
& 13 & 8.1 & 10.9 & 0.40 & 12 & 15 & 7.5 & 0 & 79 \\
\hline
\end{tabular}

Note: the plates missing from the table did not fill completely
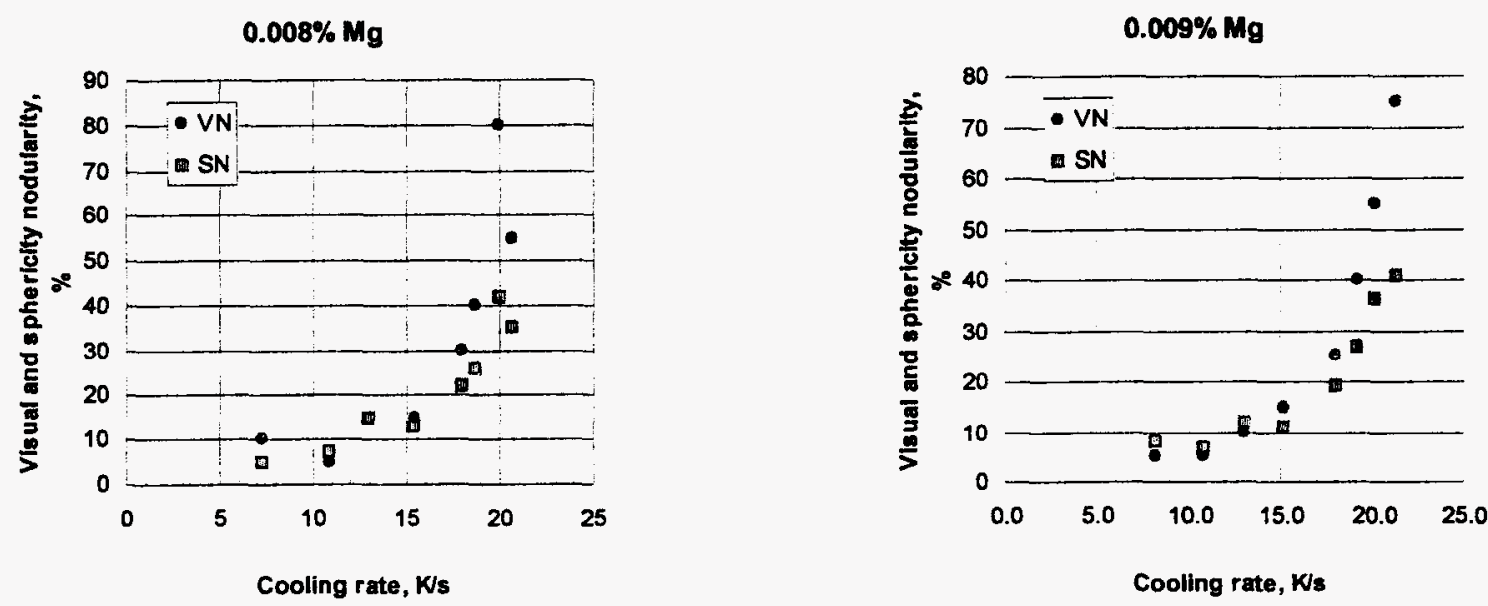

Fig. 13. Influence of residual $\mathrm{Mg}$ and of cooling rate on graphite shape of in-mold CG iron from heat 0-06-06 (horizontal plates).

\section{RESULTS AND DISCUSSION}

The definitions used in this paper for the different parameters of the cooling curve and its derivative are shown in Fig. 14.

They include:

$T_{\max }$ is the maximum temperature on the eutectic arrest

$T_{\min }$ is the minimum temperature before eutectic recalescence

$\Delta T=T_{\max }-T_{\min }$ is the recalescence

$\mathrm{HR}_{\max }$ is the maximum heating rate during eutectic reaction (maximum of $1^{\text {st }}$ derivative)

$\mathrm{CR}_{\max }$ is the maximum cooling rate after eutectic plateau (minimum of $1^{\text {st }}$ derivative)

$\Delta t_{\text {recal }}$ is the time interval of recalescence

$\Delta t_{\text {end }}$ is the time interval at the end of eutectic solidification 
The chemical composition of the CG iron melts used for cooling curve analysis are given in Table 5. The last group of data includes two heats where iron oxide was added in the furnace $(0.068$ and $0.022 \%$ respectively) before ladle treatment. The data from metallographic and cooling curves analysis are presented in Table 14. Some ductile and gray irons were included in the analysis. The microstructure of the cups from heats 90604 , 91102 , and 00304 exhibited flake graphite.

Therefore, $S$ and $S N$ of these samples were taken as 0.1 and 0 , respectively.

The experimental data was analyzed statistically. The independent (input) variables incorporated in the analysis are the cooling curve parameters listed previously. The dependent (output) variables are $S$ and $S N$. The statistical analysis included correlation analysis and regression analysis.

The correlation analysis measures the relationship between two data sets that are scaled to be independent of the unit of measure. A perfect correlation will return a value of 1 . Good correlation is considered to exist for values above 0.5 . The general multiple linear regression equation is:

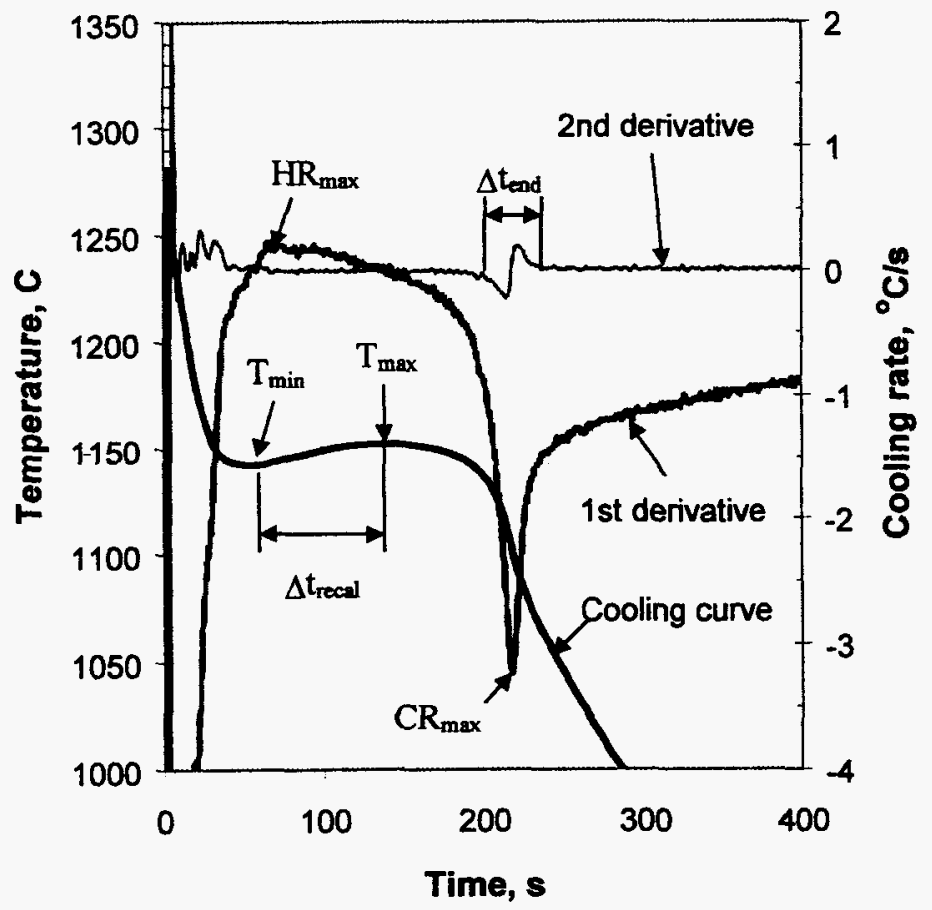

Fig. 14. Cooling curve and its derivative curve.

$$
y=a+\sum_{i} b_{i} x_{i}
$$

where $y$ is the dependent variable, $x_{i}$ are the independent variables, and $a$ and $b_{i}$ are the regression coefficients. The purpose of this analysis is to determine the coefficients $a$ and $b_{i}$ for the cooling curve variables of interest.

Table 14. Data from metallographic and cooling curve analysis.

\begin{tabular}{|c|c|c|c|c|c|c|c|c|c|c|}
\hline $\begin{array}{l}\text { Heat } \\
\text { No. }\end{array}$ & $\begin{array}{c}T_{\min } \\
{ }^{\circ} \mathrm{C}\end{array}$ & $\begin{array}{c}T_{\max }, \\
{ }^{\circ} \mathrm{C}\end{array}$ & $\begin{array}{l}\Delta T, \\
{ }^{\circ} \mathrm{C}\end{array}$ & $\begin{array}{c}\Delta t_{\text {recal }} \\
\mathrm{s}\end{array}$ & $\begin{array}{l}\mathrm{HR}_{\max } \\
{ }^{\circ} \mathrm{C} / \mathrm{s}\end{array}$ & $\begin{array}{c}\mathrm{CR}_{\max } \\
{ }^{\circ} \mathrm{C} / \mathrm{s}\end{array}$ & $\begin{array}{c}\Delta t_{\text {end }} \\
\mathrm{s}\end{array}$ & $S$ & $\begin{array}{l}S N \\
\% \\
\end{array}$ & Type \\
\hline 90302 & 1156.7 & 1160.3 & 3.6 & 59 & 0.17 & -2.6 & 70 & 0.47 & 19 & Ti-free \\
\hline 90403 & 1149.4 & 1150.5 & 0.1 & 45 & 0.1 & -2.8 & 64 & 0.44 & 17 & Ti-free \\
\hline 90601 & 1142.1 & 1152.4 & 10.3 & 84 & 0.23 & -3.1 & 64 & 0.45 & 14.3 & Ti-free \\
\hline 90602 & 1139.7 & 1150.0 & 10.3 & 66 & 0.33 & -3.2 & 58 & 0.44 & 11.9 & Ti-free \\
\hline 90603 & 1141.0 & 1149.4 & 8.4 & 49 & 0.3 & -3.4 & 55 & 0.42 & 7.6 & Ti-free \\
\hline 90604 & 1148.6 & 1159.4 & 10.8 & 54 & 0.4 & -4.3 & 42 & 0.10 & 0 & Ti-free \\
\hline 00703 & 1147.0 & 1150.6 & 3.6 & 31 & 0.07 & -2.5 & 79 & 0.70 & 47 & SG iron \\
\hline 00705 & 1134.0 & 1143.5 & 9.5 & 58 & 0.32 & -2.2 & 90 & 0.66 & 70 & SG iron \\
\hline 90807 & 1150.3 & 1151.2 & 0.9 & 27 & 0.13 & -2.5 & 74 & 0.36 & 8.4 & $\mathrm{Mg}-\mathrm{Ti}$ \\
\hline 00203 & 1148.4 & 1158.7 & 10.3 & 54 & 0.4 & -2.8 & 64 & 0.31 & 0.7 & $\mathrm{Mg}-\mathrm{Ti}$ \\
\hline 00304 & 1153.1 & 1161.2 & 8.1 & 61 & 0.26 & -3.4 & 55 & 0.1 & 0 & $\mathrm{Mg}-\mathrm{Ti}$ \\
\hline 00405 & 1160.2 & 1147.0 & 12.8 & 70 & 0.36 & -2.2 & 72 & 0.39 & 15.5 & Mg-Ti \\
\hline 00702 & 1153.7 & 1156.6 & 5.0 & 45 & 0.2 & -2.7 & 68 & 0.35 & 8.5 & Mg-Ti \\
\hline 00704 & 1148.2 & 1150.5 & 2.3 & 40 & 0.12 & -2.3 & 65 & 0.35 & 7.8 & $\mathrm{Mg}-\mathrm{Ti}$ \\
\hline 90802 & 1138.1 & 1149.0 & 10.9 & 39 & 0.53 & -2.2 & 81 & 0.49 & 17.6 & Mg-Ti-S \\
\hline 90804 & 1147.2 & 1150.5 & 3.3 & 35 & 0.27 & -2.4 & 72 & 0.36 & 2.5 & Mg-Ti-S \\
\hline 90902 & 1147.5 & 1149.0 & 1.5 & 16 & 0.2 & -2.3 & 68 & 0.34 & 1.6 & Mg-Ti-S \\
\hline 91102 & 1148.0 & 1153.4 & 5.4 & 78 & 0.15 & -3.4 & 41 & 0.1 & 0 & Mg-Ti-O \\
\hline 91202 & 1143.5 & 1149.0 & 5.5 & 57 & 0.33 & -2.7 & 77 & 0.35 & 3 & Mg-Ti-O \\
\hline
\end{tabular}



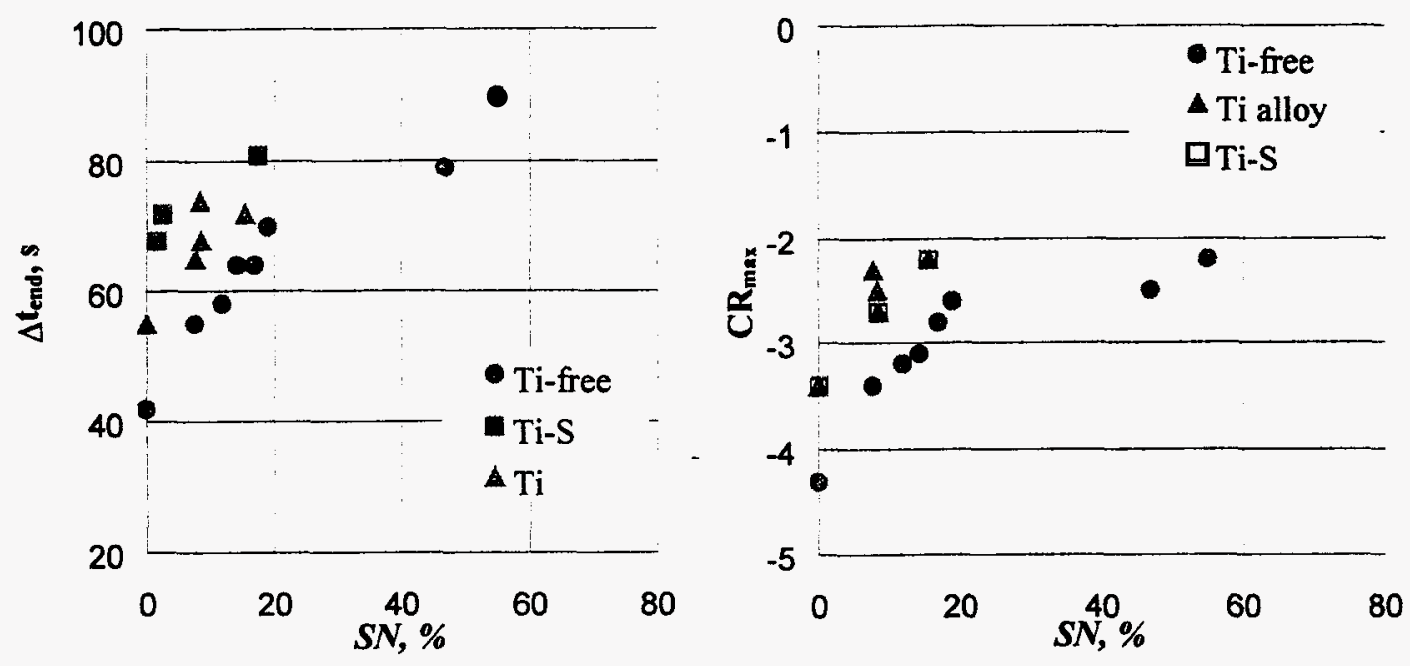

Fig. 15. Some relationship for all cooling cup analyses.

Statistical analysis of all the results from thermal analysis and metallographic data was carried out using an Excel(8) spreadsheet. The first approach was to look for any correlation between the seven variables studied. The result of the analysis of the 19 heats is given in Table 15 . The analysis showed that only a few pairs of parameters displayed a good linear correlation. Sphericity nodularity $(S N)$ correlated well with $\Delta t_{\text {end }}$. As shown in Fig. 15, $S N$ increases with higher $\Delta t_{\text {end }}$. A reasonable correlation was also obtained for $\mathrm{CR}_{\max }$. Even better correlation was obtained between these two cooling curve parameters and sphericity $(S)$. The other independent variables did not correlate well.

A complete multiple linear regression was run for $S N$ on all data in Table 14. The results are presented in Table 16 . The correlation coefficient was fairly good: $\mathbf{R}^{2}=$ 0.74 , and the standard error, SE (\%) was 9.07 . However, there is a problem related to the $\mathrm{P}$-values. The $\mathrm{P}$-values of the regression indicate whether the variables associated with them have a significant contribution or not. The $\mathrm{P}$-values must be smaller than 0.05 for a significant contribution. Thus, $\Delta T, \Delta t_{\text {recal }}, \mathrm{HR}_{\max }$, and $\mathrm{CR}_{\min }$ were Table 15. Correlation analysis for all cooling curves.

eliminated from the analysis. Once this is done (see columns 4 to 7 ), the correlation

\begin{tabular}{ccc}
\hline & $S$ & $S N$ \\
\hline$S$ & 1.00 & \\
$S N$ & 0.75 & 1.00 \\
$\Delta T$ & -0.06 & 0.05 \\
$\Delta t_{\text {recal }}$ & -0.21 & -0.04 \\
$\mathrm{HR}_{\max }$ & -0.07 & -0.14 \\
$\mathrm{CR}_{\max }$ & 0.64 & 0.42 \\
$\Delta t_{\text {end }}$ & 0.78 & 0.65 \\
\hline
\end{tabular}
coefficient became too small.

Fig. 15 shows that there is a good correlation between $\Delta t_{\text {end }}, \mathrm{CR}_{\max }$ and $S N$ when the melts are grouped by processing type, i.e., Ti-free, Ti, Ti-S. For this reason, the subsequent graphs and data were grouped based on the alloying elements, as shown in Table 5.

The correlation analysis on the Ti-free irons is given in Table 17. As expected, better correlations for both $S N-\mathrm{CR}_{\max }$ and $S N$ $\Delta t_{\text {end }}$ were obtained. A better correlation coefficient $\left(R^{2}=0.87\right)$ with good $P$-values was obtained from multiple linear regression data, as shown in Table 18.

Table 16. Regression analysis for $\% S N$.

\begin{tabular}{lllllll}
\hline \multicolumn{1}{c}{$S N$} & Coefficients & P-value & Coefficients & P-value & Coefficients & P-value \\
\hline Intercept & -100.866 & 0.041 & -111.196 & 0.049 & -39.814 & 0.017 \\
$\Delta T$ & 3.518 & 0.124 & & & & \\
$\Delta t_{\text {recal }}$ & -0.148 & 0.466 & & & & \\
$\mathrm{HR}_{\max }$ & -119.705 & 0.133 & & & & \\
$\mathrm{CR}_{\min }$ & -12.888 & 0.06 & -13.389 & 0.174 & & \\
$\Delta t_{\text {end }}$ & 1.403 & 0.002 & 1.303 & 0.007 & 0.789 & 0.003 \\
\hline & $\mathrm{R}^{2}=0.74$ & $\mathrm{SE}=9.07$ & $\mathrm{R}^{2}=0.48$ & $\mathrm{SE}=11.46$ & $\mathrm{R}^{2}=0.42$ & $\mathrm{SE}=11.80$ \\
\hline
\end{tabular}


Table 17. Correlation analysis for Ti-free irons.

\begin{tabular}{cll}
\hline & \multicolumn{1}{c}{$S$} & \multicolumn{1}{c}{$S N$} \\
\hline$S$ & 1.00 & \\
$S N$ & 0.76 & 1.00 \\
$\Delta T$ & -0.37 & -0.22 \\
$\Delta t_{\text {recal }}$ & -0.13 & -0.32 \\
$\mathrm{HR}_{\max }$ & -0.60 & -0.37 \\
$\mathrm{CR}_{\max }$ & 0.93 & 0.84 \\
$\Delta t_{\text {end }}$ & 0.87 & 0.95 \\
\hline
\end{tabular}

Table 18. Multiple linear regression analysis for Ti-free irons.

\begin{tabular}{ccc}
\hline$S N$ & Coefficients & P-value \\
\hline Intercept & -350.019 & 0.016 \\
$\mathrm{CR}_{\max }$ & -50.170 & 0.030 \\
$\Delta t_{\text {end }}$ & 3.310 & 0.007 \\
\hline & $\mathrm{R}^{2}=0.87$ & $\mathrm{SE}=8.90$ \\
\cline { 2 - 3 } & &
\end{tabular}

A similar analysis was conducted for the Ti-containing melts (Table 19). After eliminating from the analysis some of the independent variables that are not significantly correlated, the coefficients and P-values are presented in Table 20. This time only $\mathrm{CR}_{\max }$ showed a significant relationship with $S N\left(\mathrm{R}^{2}=0.8, \mathrm{SE}=2.87\right)$.

This research shows that there is a definite possibility of predicting the shape of the graphite using thermal analysis of typical cooling cups. The most important part of the cooling curve is its end, described by $C_{\max }$ and $\Delta t_{\text {end. }}$ The thermal conductivity of ductile iron is relatively low compared to CG iron or gray iron because of the spheroidal shape of graphite. The heat dissipation from the last to solidify regions is thus slower in ductile iron as compared with the other irons. This determines a smaller $\mathrm{CR}_{\max }$ and a larger $\Delta t_{\text {end }}$.

Table 19. Correlation analysis for Ti-containing irons.

\begin{tabular}{ccc}
\hline & $S$ & $S N$ \\
\hline$S$ & 1.00 & \\
$S N$ & 0.89 & 1.00 \\
$\Delta T$ & -0.15 & 0.31 \\
$\Delta t_{\text {recal }}$ & -0.30 & 0.14 \\
$\mathrm{HR}_{\max }$ & -0.14 & 0.32 \\
$\mathrm{CR}_{\max }$ & 0.94 & 0.89 \\
$\Delta t_{\text {end }}$ & 0.91 & 0.84 \\
\hline
\end{tabular}

Table 20. Multiple linear regression analysis for Ti-containing irons.

\begin{tabular}{ccc}
\hline$S N$ & Coefficients & P-value \\
\hline Intercept & 34.97 & 0.022 \\
$\mathrm{CR}_{\max }$ & 10.28 & 0.042 \\
\hline & $\mathrm{R}^{2}=0.80$ & $\mathrm{SE}=2.87$ \\
\hline
\end{tabular}

For compacted graphite and flake graphite, the graphite tips are in contact with the remaining liquid throughout solidification. This interconnected graphite network provides high thermal conductivity. At the end of solidification, when the recalescence of the alloy is completed, the heat dissipates very fast through the graphite network to the mold and the cooling rate increases fast. Thus $C R_{\max }$ is large and $\Delta t_{\text {end }}$ is small.

To better understand the effect of chemical composition on nodularity a correlation analysis was performed on the data in Table 5. The result of the analysis is given in Table 21 . It is seen that $S N$ is mainly dependent on $\mathrm{Mg}$ and $\mathrm{Mg} / \mathrm{S}$ ratio values. The higher the $\mathrm{Mg}$ content or $\mathrm{Mg} / \mathrm{S}$ ratio, the higher is the sphericity nodularity. Ti does not have as strong an affect as $\mathrm{Mg}$. This is because $\mathrm{Ti}$ only increases the $\mathrm{Mg}$ window for $\mathrm{CG}$. Even at $0.15 \% \mathrm{Ti}$, if the $\mathrm{Mg}$ content is too high or too low in the melt, the graphite will be spheroidal or flake, respectively. Therefore, for compacted graphite production the $\mathrm{Mg}$ level in the melt is more critical than the Ti level.

\section{CONCLUSIONS}

From the experiments directed at producing thin wall CGI through ladle treatment it was concluded that even at magnesium levels as low as $0.01 \%$ it is not possible to obtain acceptable CGI in cylindrical pins with equivalent thickness of $4 \mathrm{~mm}$ because of excessive nodularity. Note that the cooling rate in these pins is much higher than typical for engine applications. However, carbide-free structures were obtained when the carbon content was increased to $4 \%(C E>4.8)$.

Using titanium additions of $\sim 0.15 \%$ in combination with low $\mathrm{Mg}$ levels of $\sim 0.01 \%$ did not solve the nodularity problem. Carbides were present even at the higher levels of carbon equivalent of $4.7 \%$. When silicon was increased to $3.6 \%$ in these irons carbidefree structures were obtained in $4 \mathrm{~mm}$. Graphite shape was also improved. The best results were obtained for heats with high $\mathrm{Mg} /(\mathrm{S}+\mathrm{Ti})$ ratio. The optimum final content of added elements was $0.024 \% \mathrm{Mg}, 0.15 \% \mathrm{Ti}$, and $0.031 \% \mathrm{~S}$.
Table 21. Correlation analysis of dependency of SN on chemical composition.

\begin{tabular}{lr}
\hline & \multicolumn{1}{c}{$S N$} \\
\hline$S N$ & 1.00 \\
Sulfur & -0.10 \\
$\mathrm{Mg}$ & 0.69 \\
$\mathrm{Ti}$ & -0.44 \\
$\mathrm{Mg} / \mathrm{S}$ & 0.92 \\
$\mathrm{CE}$ & 0.45 \\
\hline
\end{tabular}


In-mold experiments demonstrated that the residual magnesium could be controlled accurately within narrow limits. At $0.006 \% \mathrm{Mg}$ flake graphite was obtained. Within the experimental range of 0.008 to $0.009 \% \mathrm{Mg}$ CG iron free of carbides and with less than $20 \%$ nodularity was produced at cooling rates as high as $18 \mathrm{~K} / \mathrm{s}$.

The results obtained in this work indicate that cooling curve analysis can provide useful information on graphite shape as long as a specific liquid treatment process is used. For a given process, the best parameters to use are $\mathrm{CR}_{\max }$ (the maximum cooling rate after the eutectic plateau, that is the minimum of first derivative) and $\Delta t_{\text {end }}$ (the time interval at the end of eutectic solidification). The graphite shape changes from $S G$, to $C G$, to type $D$ flake graphite, when the $C R_{\max }$ increases (higher negative numbers), and $\Delta t_{\text {end }}$ decreases. The correlation $S N-\mathrm{CR}_{\max }$ and $S N-\Delta t_{\text {end }}$ changes significantly from on process to a different process.

It is also noted that the maximum recalescence temperature $\left(T_{\text {max }}\right)$ is around $1160^{\circ} \mathrm{C}$ for all heats that showed type $\mathrm{D}$ graphite (undertreated iron) in microstructure. This temperature could be used to calculate the amount of compactizing alloy to be added after the initial ladle treatment to correct the problem. A larger database needs to be collected and analyzed in order to establish such a relationship quantitatively.

Finally, it was demonstrated that the sphericity nodularity of $C G$ iron is mainly dependent on the $\mathrm{Mg}$ and/or $\mathrm{Mg} / \mathrm{S}$ ratio level in the melt.

\section{ACKNOWLEDGMENTS}

This research has been funded by a consortium of foundries and foundry suppliers and by the Metal Casting Competitiveness Program of the U. S. Department of Energy (DOE Cooperative Agreement DE-FC07-94ID13324). However, any opinions, findings, conclusions, or recommendations expressed herein are those of the authors and do not necessarily reflect the views of DOE. The authors acknowledge the active support of the industrial sponsors, without which the program could not have succeeded, and in particular the constructive comments of Tom Schroder. Dr. S. Charoenvilaisiri wishes to acknowledge the partial financial support of the National Metal and Materials Technology Center (MTEC) Thailand. Dr. R. Ruxanda wishes to acknowledge the support of the National Science Foundation through NSF-NATO Fellowship Grant \#DGE-98-04536.

\section{REFERENCES}

Compacted Graphite Iron, Nodularity Rating Chart, wall chart SinterCast ${ }^{\circledR}$ (1999) Compacted Graphite Iron, Nodularity Evaluation, wall chart SinterCast ${ }^{\oplus}$ (2001)

Ductile Iron Microstructures Rating Chart, wall chart AFS Ductile Iron Quality Control Committee (12.E) (1993)

Fowler J., Stefanescu D.M., Prucha T., AFS Transactions vol 92 p 361 (1984)

Schroeder T. and Shao S., "Image Analysis of Compacted Graphite Iron", Private Communication (1999)

Sillen R., AFS Transactions, vol 87 p. 191-194 (1979)

Stefanescu D. M. et al., TWIG Annual Report Year 1, p 50, University of Alabama (1999) 


\title{
Microstructure Characterization of Ductile Thin Wall Iron Castings
}

\author{
R.E. Ruxanda, D.M. Stefanescu, T.S. Piwonka \\ The University of Alabama, Tuscaloosa, Alabama \\ Copyright@2002 American Foundry Society
}

\begin{abstract}
Detailed characterization of the microstructure of a large number of thin ductile iron castings was performed. Visual estimation as well as image analysis was used to evaluate nodule count, average area of the graphite particle, graphite diameter, sphericity, compactness, nodularity by sphericity area and compactness area, visual nodularity, percentage area of graphite, ferrite, pearlite and carbides. Quantification of ferrite and pearlite through image analysis was straightforward and consistent. However, when carbides are present, a special color etching should be applied. No significant dendritic orientation of the microstructure was found in the analyzed thin plates.

An upper limit of 2200 nodules $/ \mathrm{mm}^{2}$ with the average nodule size of $13.61: \mathrm{m}$ for 1.4 to $2 \mathrm{~mm}$ thickness plate was obtained. A set of photographs was developed as reference for thin wall ductile iron castings for nodule counts exceeding 600 nodules $/ \mathrm{mm}^{2}$. It was shown that the nodule count and particle size are related by interparticle spacing $\left(\lambda_{G}\right)$. The spacing decreases significantly with increasing nodule count and cooling rate. Image analysis was used to characterize graphite shape through a number of graphite shape factors: sphericity $(S)$, compactness and fractal dimension. It was concluded that the best descriptor for graphite shape in ductile iron is sphericity and that a population of graphite particles having a minimum sphericity of $S=0.55$ should be categorized as nodular. Best results were obtained when using a magnification of $200 \mathrm{X}$ (pixel size $p=0.53: \mathrm{m})$ for graphite characterization and of $100 \mathrm{X}(p=1.06 \mathrm{~m})$ for matrix quantification.
\end{abstract}

Internal defects were analyzed by optical microscopy, SEM and EDAX. The microporosity has been evaluated through image analysis on polished samples. SEM investigation in the inverse chill area certified the presence of clusters of small graphite particles embedded in ledeburite. It also showed the stripe-like, with jagged edges morphology of the cementite. Manganese was found in high concentration in this area. The fracture mode in the inverse chill area is cleavage with a stepped, partially even texture. The flake graphite rim anomaly (interdendritic graphite) was occasionally observed at the edges of the plates because of positive microsegregation of magnesium, which is responsible for the alteration of the graphite shape. Graphite alignment that plays a decisive role in crack propagation was observed in some thin ductile iron castings. Small endogenous inclusions were also found.

\section{INTRODUCTION}

Lately, a large number of studies have been aimed to the production of thin wall iron castings due to the expected economical impact emphasized by various authors (Hornung 1995, Katz 1997). The definition of "thin" section has evolved in time. In this paper it implies sections equal to or thinner than $3 \mathrm{~mm}$. The real challenges of producing such thin sections of ductile cast iron are carbide and microporosity formation during solidification, which adversely affect the mechanical properties and machinability. Several parameters are responsible for carbide formation:

- high solidification cooling rates and high superheat (e.g., Javaid 1998);

- carbide forming elements in the charge materials, low carbon equivalent and/or silicon content, excessive magnesium content. A minimum of $4.30 \% \mathrm{CE}$ (Loper 1965$)(\mathrm{CE}=\% \mathrm{C}+0.31 \% \mathrm{Si})$ is required to prevent carbides. As shown in (Evans 1981), manganese and carbon higher than $4.65 \%$ induce carbon flotation;

- low nodule count (poor inoculation) and poor nodularity increases the amount of carbides (Evans 1981, Stefanescu 1981).

In this study, the general microstructure characteristics of thin ductile cast irons plates are analyzed. This includes discussion of the matrix (ferrite, pearlite and carbides) and graphite (size, shape and count) that defines the cast iron microstructure, as well as of the defects found in such castings. In addition, a general methodology for quantitative image analysis of thin wall ductile iron is introduced.

\section{EXPERIMENTAL PROCEDURE}

Two patterns were used to produce either horizontal or vertical plates, as shown in Fig. 1 . The patterns included plates with thickness ranging from 1.5 to $6 \mathrm{~mm}$. A number of 16 heats (16 molds) were produced using the horizontal pattern and three heats $(27$ molds) using the vertical one, resulting in a total number of 529 plates that have been tested for mechanical 


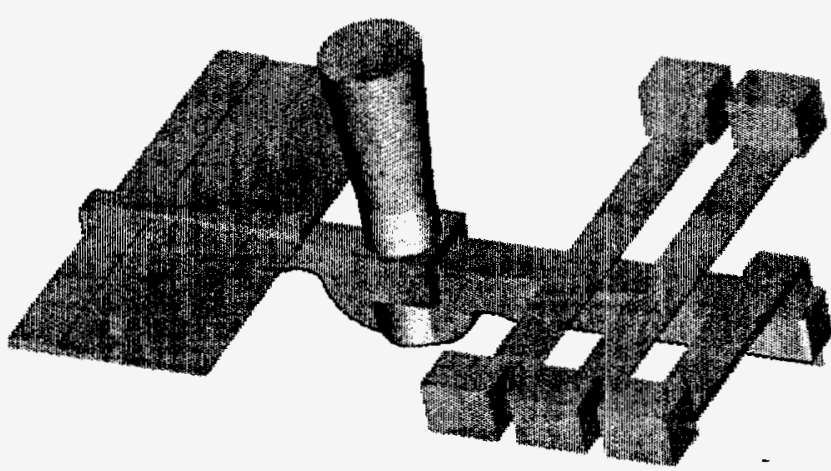

a)

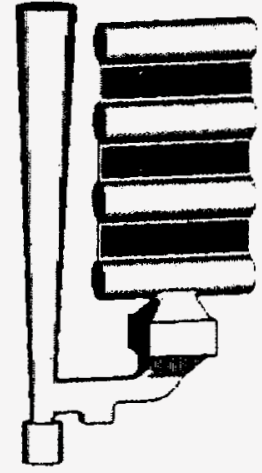

b)

Fig. 1. Pattern design to produce thin wall iron castings: a) horizontal plates; b) vertical plates.

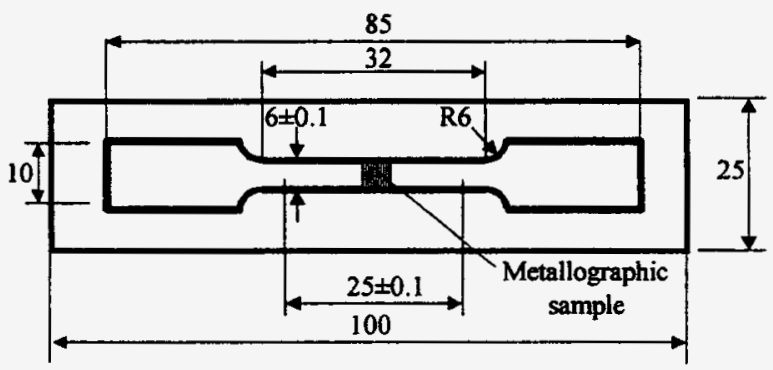

Fig. 2. Dimensions of the plate and mechanical properties testing test bar. The metallographic sample (dark area) is $5 \times 5 \mathrm{~mm}$. properties in as-cast condition and analyzed for microstructure (242 horizontal plates and 67 vertical plates). The liquid treatment consisted of a 2 -step method: a classic $200 \mathrm{lb}$. sandwich ladle was used for treatment with a Fe-Si-6Mg alloy. After the completion of the $\mathrm{Mg}$ reaction, half of the metal was transferred in a $100 \mathrm{lb}$. tea-pot pouring ladle and post-inoculated in the stream with $0.6 \% \mathrm{Fe}-75 \mathrm{Si}-1 \mathrm{Ca}$ during transfer. The pouring temperature range was $1314-1501^{\circ} \mathrm{C}(2397-2734 \mathrm{~F})$ for the horizontal plates and $1263-1402^{\circ} \mathrm{C}(2306-2556 \mathrm{~F})$ for the vertical ones. The cooling rate varied between 5.91 to $43.67^{\circ} \mathrm{C} / \mathrm{s}$ for the horizontal plates and 3.30 to $12.06^{\circ} \mathrm{C} / \mathrm{s}$ for the vertical ones. The chemical composition range is summarized in Table 1 . Note that the iron used for vertical plates included some copper addition.

Mechanical testing samples and metallographic samples were cut out of the cast plates as shown in Fig. 2, without further machining. The image analysis system used to quantitatively evaluate the microstructure consists of the Omnimet Enterprise 1.0 software (Omnimet Enterprise Handbook 1998) in conjunction with a Nikon Epiphot optical microscope and CCIR $765 \times 570 \mathrm{~B} 7 \mathrm{~W}$ video camera. The typical features used in image analysis measurements are listed in Table 2 . The measurements included nodule count, average area of the graphite particle, graphite diameter, sphericity, compactness, nodularity by sphericity area and compactness area, visual nodularity, percentage area of graphite, ferrite, pearlite and carbides. Each reported result represents the average of five fields. If not otherwise stated, sample preparation included grinding and polishing with oil base diamond suspension down to $1: \mathrm{m}$ diamond particle size, followed by etching with nital $4 \%(4 \mathrm{ml} \mathrm{HNO} 3+100 \mathrm{ml}$ alcohol) for several seconds until the microstructure was well delineated. Alumina suspension can be used to refine the mirror-look of the sample surface if inverse chill is not detected. However, in this case great care should be exercised, as the prolonged exposure of graphite particles to water facilitates their pullout from the matrix during

Table 1. Chemical Composition of the Samples

\begin{tabular}{lcccccccc}
\hline \multicolumn{1}{c}{ Pattern } & $\mathrm{C} \%$ & $\mathrm{Si} \%$ & $\mathrm{Mn} \%$ & $\mathrm{P} \%$ & $\mathrm{Mg} \%$ & $\mathrm{Cu} \%$ & $\mathrm{~S} \%$ & $\mathrm{CE}$ \\
\hline Horizontal plates & $2.91-4.73$ & $1.66-4.38$ & $0.19-0.22$ & $0.013-0.017$ & $0.0037-0.011$ & $0.026-0.048$ & $0.012-0.028$ & $3.76-5.33$ \\
Vertical plates & $3.29-3.77$ & $2.47-2.75$ & $0.17-0.20$ & $0.010-0.015$ & $0.0320-0.048$ & $0.088-0.211$ & $0.011-0.012$ & $4.04-4.68$ \\
\hline
\end{tabular}

Table 2. Typical Features Used in Image Analysis Measurements

\begin{tabular}{|c|c|}
\hline Feature & Description \\
\hline Length & Longest distance measured between two parallel tangents on each side of the object of interest*. \\
\hline Width & Shortest distance measured between two parallel tangents on each side of the object of interest. \\
\hline Diameter circular & Diameter of a circle having the same area with the object of interest. \\
\hline Perimeter & Length of the outside boundary of the object of interest. \\
\hline Convex perimeter & $\begin{array}{l}\text { Length of the convex outside boundary of the object of interest (a rubber band around all distances } \\
\text { between two tangents). }\end{array}$ \\
\hline Area & Area of the object of interest, minus the area of any holes. \\
\hline
\end{tabular}


polishing. A Philips XL 30 instrument was used to perform the scanning electron microscopy (SEM) analysis. Quantitative data on composition was obtained with the aid of an attached energy dispersive X-ray microanalysis (EDAX CDU LEAP Detector) unit. If not otherwise stated, the given EDAX data represent the average of three measurements.

\section{THIN WALL DUCTILE CAST IRONS MICROSTRUCTURE THE MATRIX}

The main constituents of the matrix of thin wall iron castings are ferrite, pearlite and carbides, if any. Their actual ratio, however, is highly dependent on the processing parameters that include cooling rate, liquid treatment, chemical composition, pouring temperature, etc. The thickness itself, although important, will not alone define the structure. Cooling rate may or may not be linearly dependant on thickness. For the same thickness of the sample, the matrix may range from fully ledeburitic to fully ferritic, depending on the processing parameters. The average carbides content is poorly related to cooling rate, but shows a slight increasing tendency. As for the inverse chill carbide content, it shows no correlation whatsoever with the cooling rate. It appears that some other effects as segregation of alloying and trace elements to intercellular regions of the nodular iron during solidification may become the predominant factor controlling matrix structure (Askeland, 1975).

To determine the percentage area of ferrite, pearlite and carbides on thin SG iron samples is not trivial. Modern metallography requires the use of quantitative image analysis to obtain precise values for further use in modeling and simulation. The ferrite and pearlite percentage area can be measured relatively quickly. However, when carbides are present, the measurement is complicated because both ferrite and carbides are white after the classical etching with nital $4 \%$. Therefore a subsequent color etching should be applied for several minutes: $1 \mathrm{~g} \mathrm{Na} \mathrm{S}_{2} \mathrm{O}_{5} / 100 \mathrm{ml}$ distilled water $+4 \mathrm{~g}$ picric $\mathrm{acid} / 100 \mathrm{ml}$ ethyl alcohol. The etching is completed when both ferrite and pearlite are dark and the carbide phase remains white (Fig. 3). Using this etching procedure, the image of the microstructure can be correctly processed to identify only the carbides.

To identify the objects of interest (in this case, carbides) through image analysis, the segmentation of the image into objects and background is required. Therefore, a threshold value to describe the level of contrast between the object and the surrounding matrix must be carefully set. Basically, all measurements in image analysis are very sensitive to thresholding. An

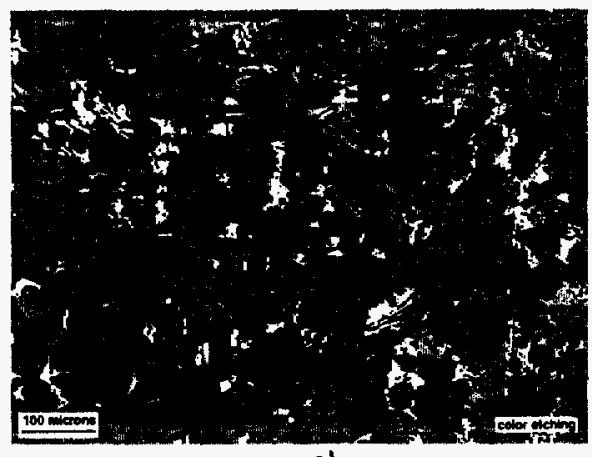

a)

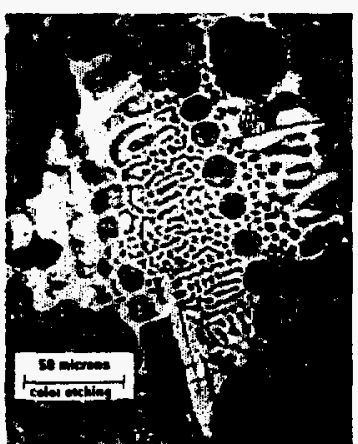

b)

Fig. 3. Example of final color etched microstructure used to measure percentage area of carbides on TWIC plates: a) ferrite and pearlite are dark, the carbide phase is white; b) higher magnification showing the effect of the color etching.

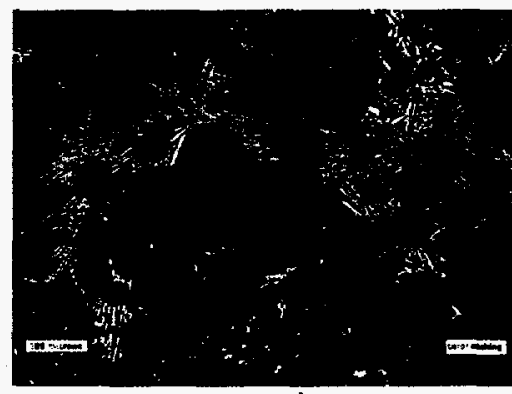

a)

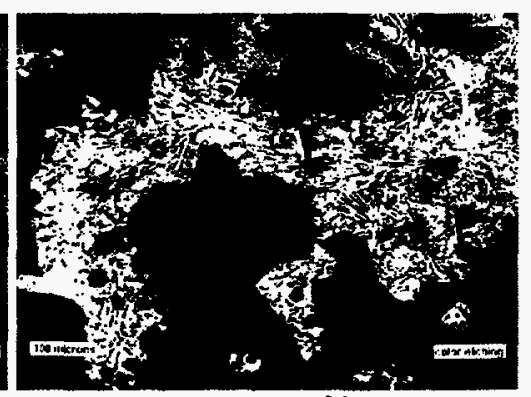

b)

Fig. 4. Cast iron microstructure processed by image analysis containing white eutectic: a) correct thresholding (measured area is $6,34 \%$ ); b) incorrect thresholding (measured area is $20.74 \%$ ).

example is shown in Fig. 4, where while thresholding the image to measure the whole eutectic, one may end up with a totally out of range value (compare Fig. 4a with Fig. 4b). The thresholded region in Fig. $4 \mathrm{~b}$ includes unavoidable wrong areas. The more appropriate procedure would be to measure the correct carbide percentage area $(6.34 \%)$ and calculate, if needed, the metastable eutectic percentage area $(9.70 \%$ in this case). To determine the actual percentage area of the ledeburitic eutectic, the equations presented in (Ruxanda et al., 2001b) may be applied.

Although some studies (Yeung 1998, Mampaey 1997) consistently indicated that a dendritic orientation of the microstructure from the mold surface toward the center was found in thin plates, in the investigated samples this tendency was weak. To reveal the dendritic orientation, a color etching technique sensitive to the segregation of silicon applied in ductile cast irons by Rivera (Rivera 1995) was used: $10 \mathrm{~g} \mathrm{NaOH}, 40 \mathrm{~g} \mathrm{KOH}$, $10 \mathrm{~g}$ picric acid and $50 \mathrm{ml}$ distilled water, used when boiling at $120^{\circ} \mathrm{C}$. As a result of the etching, a detailed picture of the Si microsegregation (Boeri 2001) can be identified. According to Yeung (Yeung 1998) the interdendritic segregation of Mn between the primary dendrites and $\mathrm{Si}$ segregation in their core occurs in thinsection ductile iron castings. However, only a few samples exhibited some oriented dendrites within 


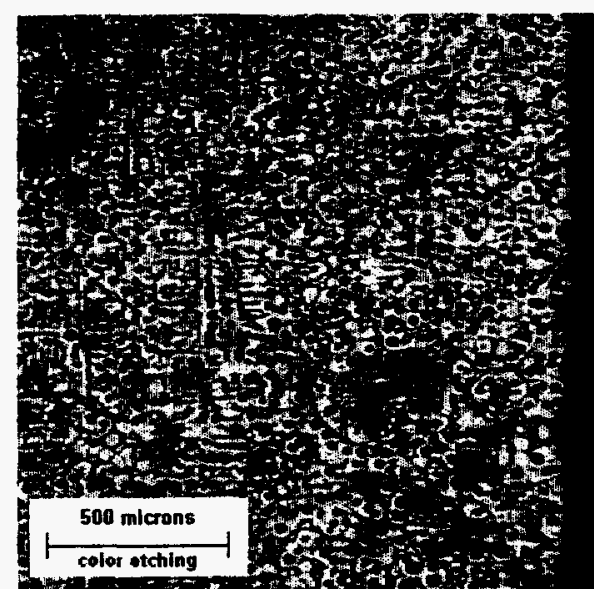

a)

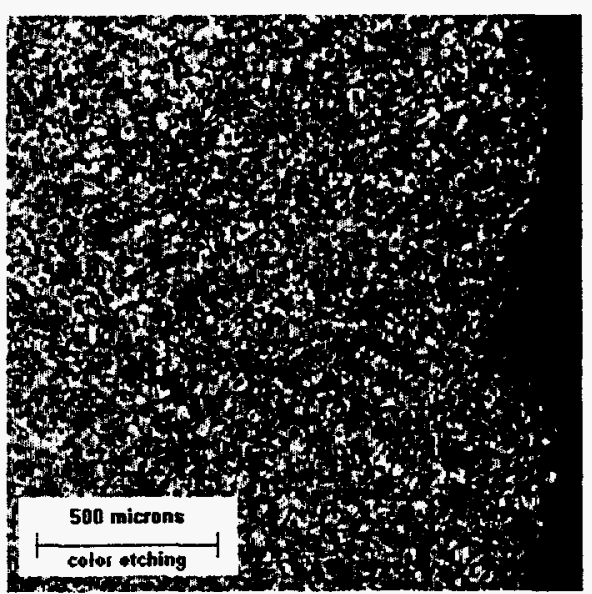

b)

Fig. 5. Black and white picture of the microstructure after color etching: a) some oriented dendrites within the bulk of the sample; b) no dendrite orientation was observed.

the bulk (Fig. 5a). Most showed no dendritic orientation (Fig. 5b). It was concluded that this tendency is not obvious throughout the present set of experiments.

\section{THE GRAPHITE}

The main issues on quantitative metallographic analysis of the graphite addressed in this paper include graphite nodule count evaluation and graphite shape evaluation.

\section{Graphite nodule count}

Extremely high nodule counts were reported in literature: 3500 to 4400 nodules $/ \mathrm{mm}^{2}$ (Mampaey 1997, Javaid 1998), for small section size $(3 \mathrm{~mm}$ to $1 \mathrm{~mm})$. However, these values depend heavily upon the chosen minimum diameter and the magnification at which the analysis is performed. Javaid (Javaid 1998) measured an average nodule size ranging from 3.9 to $5.9: \mathrm{m}$ in the $1 \mathrm{~mm}$ section. We obtained an upper limit of 2200 nodules $/ \mathrm{mm}^{2}$ with the average nodule size of $13.61 \mathrm{~m}$ for plates produced using the horizontal pattern for 1.4 to $2 \mathrm{~mm}$ plate thickness. A value of $5 \mathrm{~m}$ was used as minimum diameter in our measurements. The reason for this is explained in the following paragraphs.

For regular thickness ductile iron, the minimum nodule size accepted in measurements used to produce standard reference micrographs is typically $10 \mu \mathrm{m}$ diameter. However, this may not be a good lower limit for thin wall iron castings, where small graphite particles are always encountered (Fig. 6a). In Fig. 6b and Fig. $6 \mathrm{c}$ it is demonstrated that these small particles are indeed graphite nodules. In fact, almost all graphite particles in Fig. $6 \mathrm{~b}$ are smaller that $10 \mu \mathrm{m}$. Ignoring them will result in a significantly smaller nodule count.

An example of the influence of the minimum accepted diameter on the measured nodule count is illustrated in Fig. 7. A typical microstructure of a thin wall ductile iron is given in Fig. 7a. When all particles smaller than $10 \mu \mathrm{m}$ are eliminated (Fig. $7 \mathrm{~b}$ ), only one particle is found in the marked area. The overall nodule count is 720 nods $/ \mathrm{mm}^{2}$. When the minimum accepted
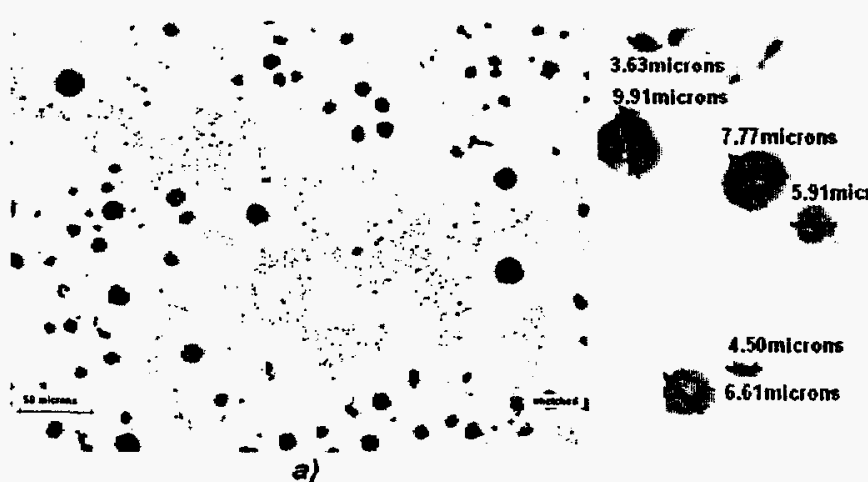

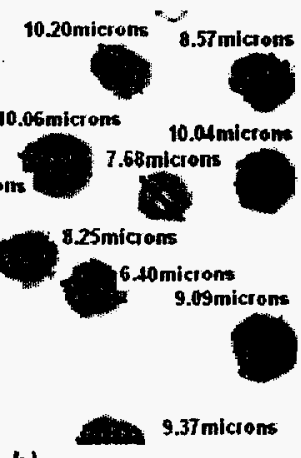

b)

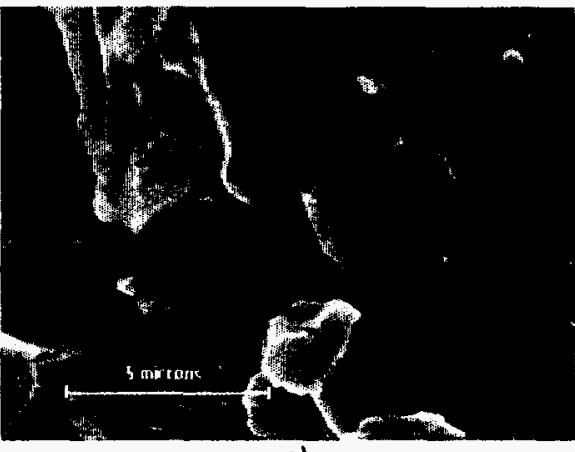

c)

Fig. 6. Case study of the dimensions of graphite nodules: a) different sizes of the graphite nodules; b) several graphite particles having the diameter less than $10 \mu \mathrm{m}$; c) SEM image of a very small graphite particle. 


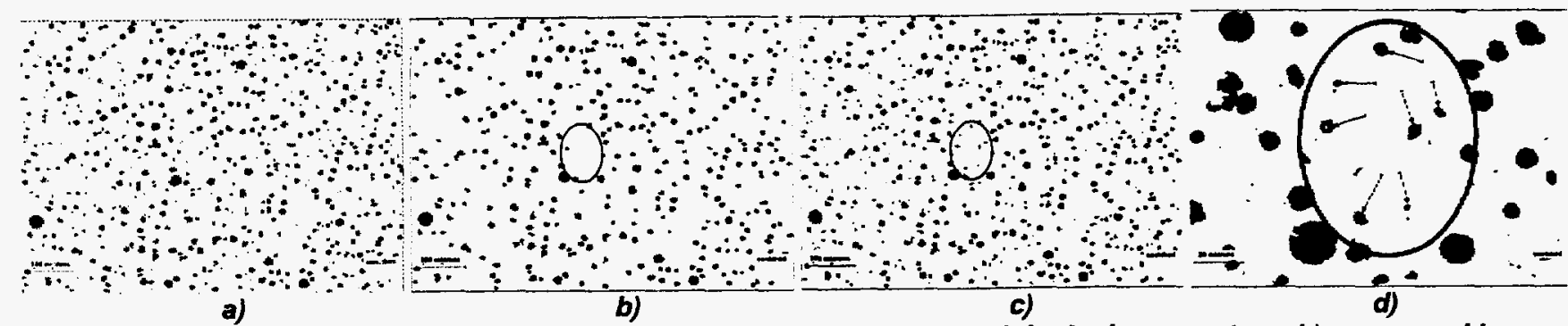

Fig. 7. Influence of the minimum accepted diameter on nodule count: a) original microstructure; b) processed image,

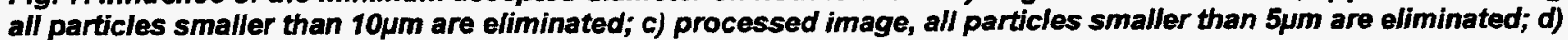
detail from (a) at higher magnification showing the same area as in (b) and (c).

diameter is decreased to $5 \mu \mathrm{m}$ (Fig. 7c), seven particles meet the criterion. The overall nodule count is 1173 nods $/ \mathrm{mm}^{2}$. The seven particles are shown in Fig. $7 \mathrm{~d}$ at a higher magnification.

An objective lower limit for graphite diameter cannot be established, since the size of the graphite nodule on the metallographic image depends on the height at which the nodule has been sectioned during polishing. This means that the size of any nodule on the metallographic image can theoretically vary between zero and the nominal diameter of the nodule. Thus, the selection of a lower limit is arbitrary by necessity.

To determine the optimum magnification for nodule count evaluation for thin wall iron castings, a number of plates were analyzed at $100 \mathrm{X}$ and $200 \mathrm{X}$. Nodule count was evaluated assuming a minimum size of $5 \mu \mathrm{m}$ and compared with results for a minimum size of $10 \mu \mathrm{m}$. The results of this exercise are summarized in Fig. 8. It is seen that when the minimum nodule size is taken as $5 \mu \mathrm{m}$, the nodule count decreases with higher thickness as expected. A slightly higher nodule count is observed for measurements made at $200 \mathrm{X}$. If the minimum nodule size was taken as $10 \mu \mathrm{m}$, the nodule count appears to increase with section thickness, both at 100 and $200 \mathrm{X}$ magnification. This is not correct. It is thus reasonable to conclude that the minimum nodule size should be taken as $5 \mu \mathrm{m}$. Note also the much higher regression coefficients for the $5 \mu \mathrm{m}$ diameter threshold $\left(\mathrm{R}^{2}=\right.$ 0.73 for $100 \mathrm{X}$ and $\mathrm{R}^{2}=0.66$ for $200 \mathrm{X}$ ). While the decision on the minimum acceptable graphite size is crucial, whether the examination is conducted at $100 \mathrm{X}$ or $200 \mathrm{X}$ seems to be less significant. However, slightly higher nodule count is obtained at $200 \mathrm{X}$ compared to $100 \mathrm{X}$. All our measurements of graphite particles were made at $200 \mathrm{X}$ magnification.

Based on this analysis, it was concluded that it is reasonable to take as a lower limit of particle size $5 \mu \mathrm{m}$ and to perform the measurement at $200 \mathrm{X}$ magnification. The reason why we did not decrease the acceptable limit under $5 \mu \mathrm{m}$ resides on the pixel size value. A discussion about of the importance of the pixel size is given the section on graphite shape. For the time being, it is enough to say that the particles having a diameter less than $5 \mu \mathrm{m}$ are not well enough described at $200 \mathrm{X}$ magnification. Because they are so small they look spherical anyway. On the other hand, the magnification cannot be increased indiscriminately, because then a much larger number (at a power of two) of metallographic fields should be measured to

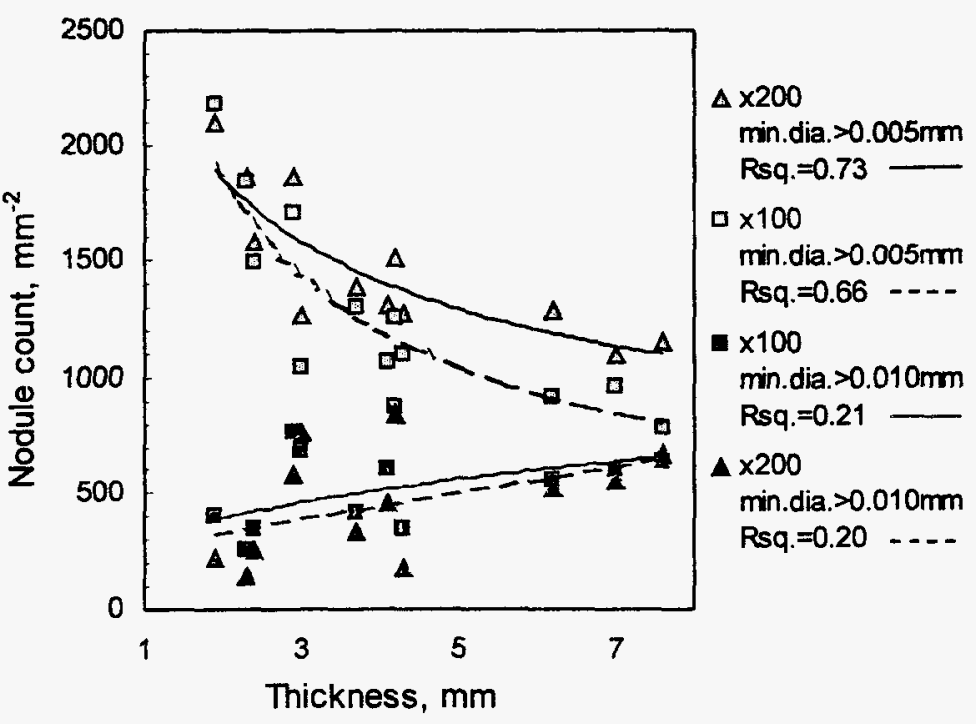

Fig. 8. Nodule count - plate thickness correlation. match the same surface area as measured at a lower magnification.

Finally, the nodule count indicated by both the American Foundry Society (Ductile Iron Microstructures Rating Chart 1993) and Ductile Iron Society (Graphite Rating in Ductile Iron Chart 1999) standards were compared with measurements on the same standards and a very good correlation was obtained. DIS (Ductile Iron Society) chart has a maximum of 600 nodules $/ \mathrm{mm}^{2}$. The alternative AFS (American Foundry Society) chart has a maximum of 300 nodules $/ \mathrm{mm}^{2}$. However, a significantly higher number of graphite particles do appear in thin ductile iron plates, sometimes as high as 2000 nodules $/ \mathrm{mm}^{2}$ or more.

A set of photographs (Fig. 9) was therefore developed as reference for thin wall ductile iron castings for nodule counts exceeding 


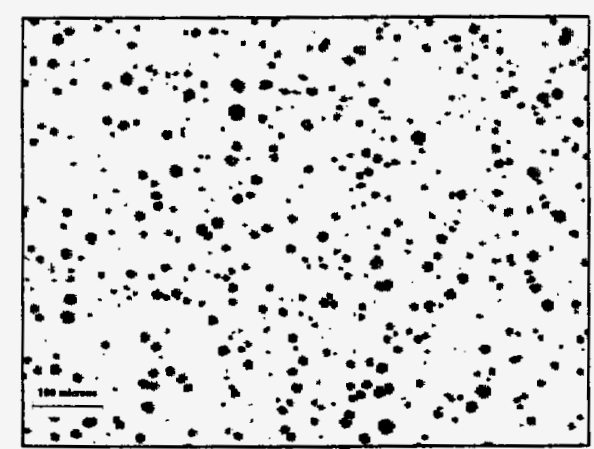

$800 \mathrm{nods} / \mathrm{mm}^{2}, \mathrm{~s}=0.75$

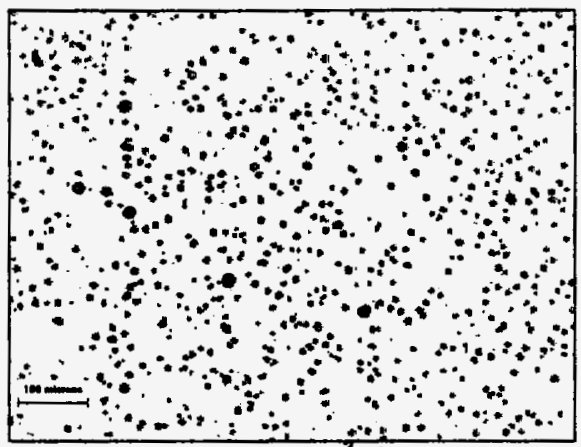

$1400 \mathrm{nods} / \mathrm{mm}^{2}, \mathrm{~s}=0.76$

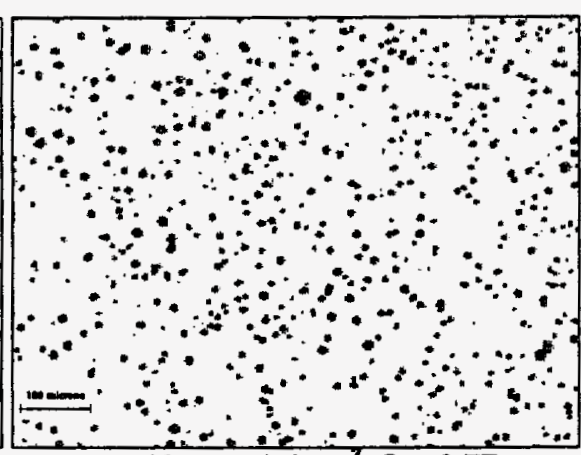

1000 nods $/ \mathrm{mm}^{2}, \mathrm{~s}=0.77$

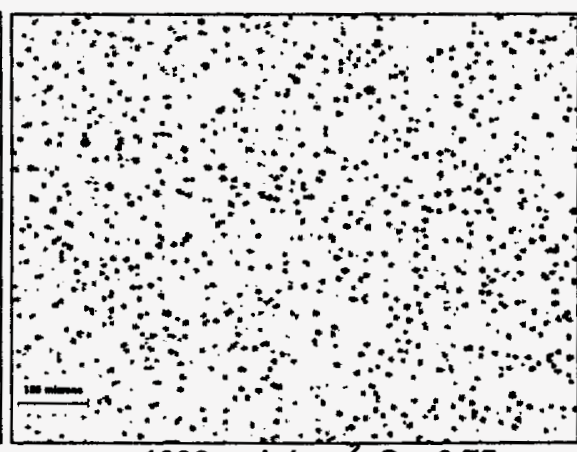

1600 nods $/ \mathrm{mm}^{2}, \mathrm{~S}=0.75$

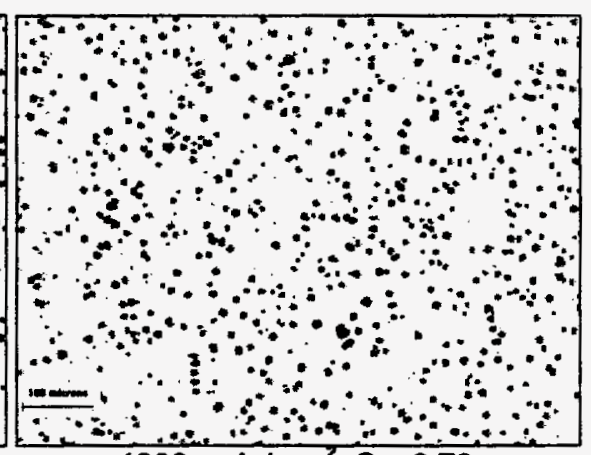

1200 nods $/ \mathrm{mm}^{2}, \mathrm{~s}=0.76$

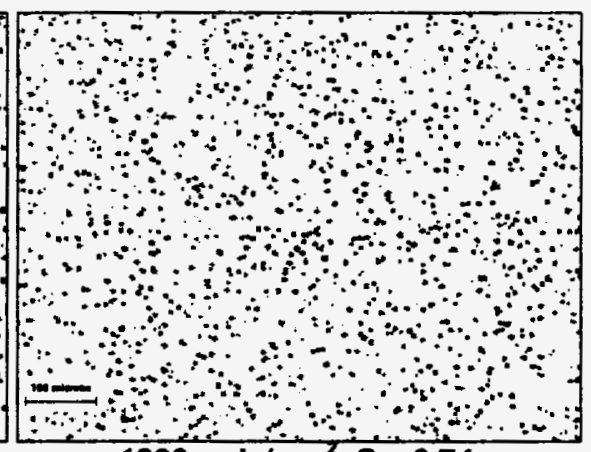

$1800 \mathrm{nods} / \mathrm{mm}^{2}, \mathrm{~s}=0.74$

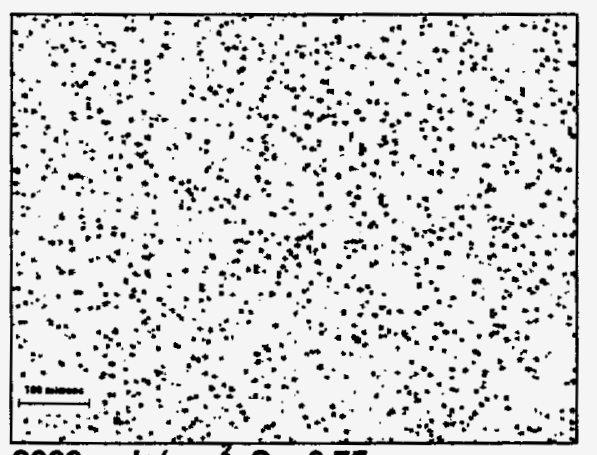

$2000 \mathrm{nods} / \mathrm{mm}^{2}, \mathrm{~s}=0.75$

Fig. 9. Reference photographs for nodule count in thin wall ductile iron.

600 nodules $/ \mathrm{mm}^{2}$. All pictures were taken at $100 \mathrm{x}$ to match DIS and AFS charts, from unetched microstructures from our experimental heats exhibiting the highest sphericity $(0.74$ to $0.77 \mathrm{~S})$. Explanation on sphericity measurement and its importance is given in the next section. The photographs show actual microstructures. They were better contrasted and slightly cleaned for any light unevenness, small scratches, etc., using Image Pro-Plus 4.0 software (Image-Pro Plus Reference Guide 1998). All particles having a diameter less than $5 \mu \mathrm{m}$ were disregarded in the nodule count. However, they are still shown on the pictures.

Nodule count and particle size are related by a parameter known as interparticle spacing $\left(\lambda_{G}\right)$. From a physical standpoint, the interparticle spacing represents the characteristic carbon diffusion distance. It can be calculated with the equation (Seher 1971):

$$
\lambda_{G}=55.4 \cdot\left(\frac{d_{\text {avg }}}{\text { Nodule count }}\right)^{\frac{1}{3}}
$$

where $d_{a v g}$ is the average graphite nodule diameter in $\mu \mathrm{m}$ and the nodule count is per $\mathrm{mm}^{2}$.

The noduie count and cooling rate for both horizontal plates and vertical plates were plotted against the interparticle spacing. As expected, the spacing decreases significantly with increasing nodule count for all plates (Fig. 10). Since the thin plates in 


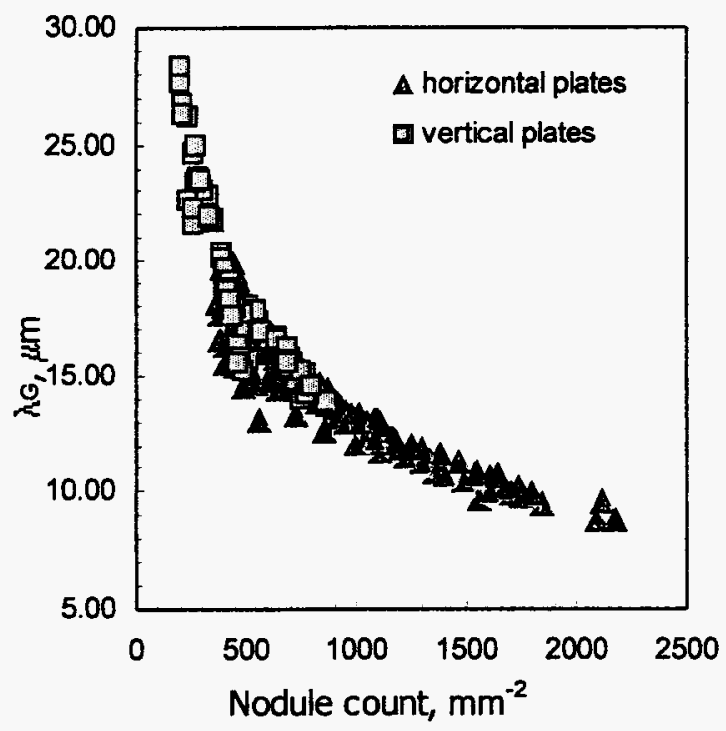

Fig. 10. Correlation between interparticle spacing and nodule count.

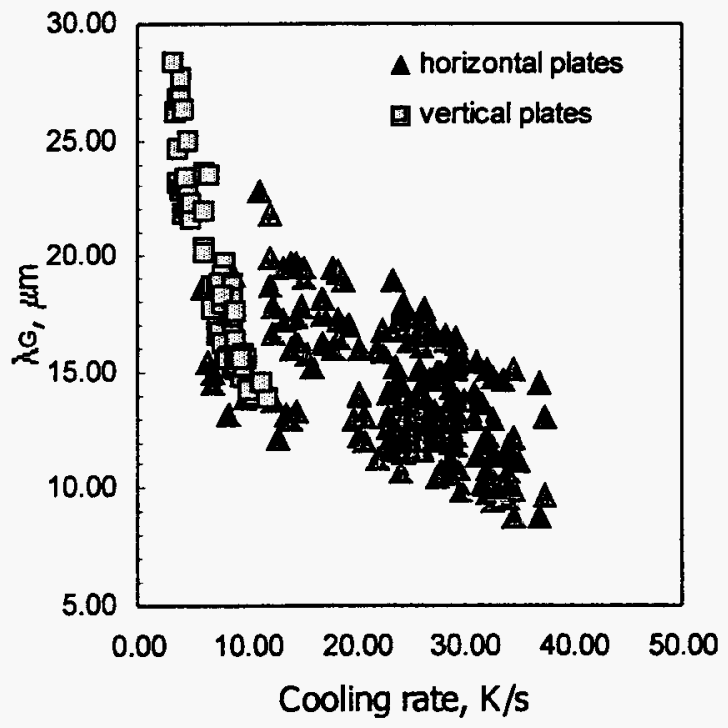

Fig. 11. Correlation between interparticle spacing and cooling rate.

this study have significantly higher nodule count than found in regular ductile iron castings it is reasonable to assume that the smaller carbon diffusion distance would promote a higher ferritization rate.

The influence of cooling rate on interparticle spacing is shown in Fig. 11. Two groups of data are shown. The cooling rate have been calculated based on the following equations for horizontal and vertical plates, respectively:

For horizontal plates (see Fig. 1a): $\frac{d T}{d t}=43.671-4.841 \cdot z \quad$ for connected plates $\quad$ (Equation 2)

$$
\frac{d T}{d t}=37.392-4.1551 \cdot z \quad \text { for independent plates } \quad \text { (Equation 3) }
$$

$\begin{array}{lll}\text { For vertical plates (Fig. 1b): } \quad \frac{d T}{d t}=41.070-0.02036 \cdot T_{\text {pour }}-1.374 \cdot z & \text { (Equation 4) }\end{array}$

where $z$ is the thickness of the plates.

A decreasing tendency of interparticle spacing with increasing cooling rate was observed in all plates. This tendency was much steeper for the vertical plates. Note that the influence of pouring temperature on cooling rate was ignored in the case of horizontal plates. The data scatter for the horizontal plates is because in some plates carbides are present. For the vertical plates the following correlation between $\lambda_{G}$ and cooling rate $d T / d t$ was found:

$\begin{array}{ll}\lambda_{G}=54.761 \cdot\left(\frac{d T}{d t}\right)^{-0.5526} & \text { (Equation 5) }\end{array}$

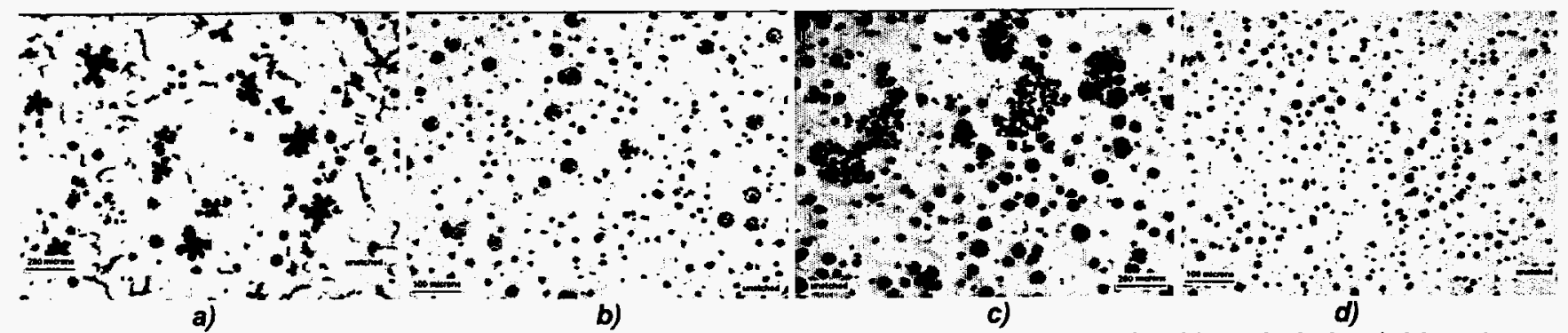

Fig. 12. Graphite particles that can be found in thin cast iron plates: a) chunky graphite; b) exploded graphite; c) clusters of graphite (graphite flotation); d) spheroidal graphite. 


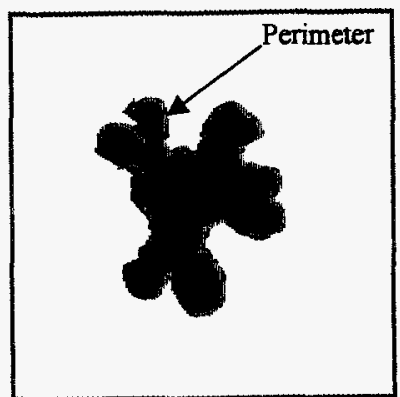

a)

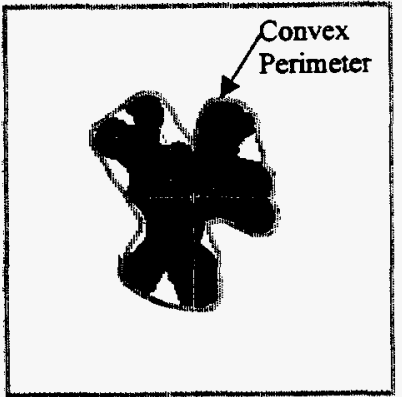

b)

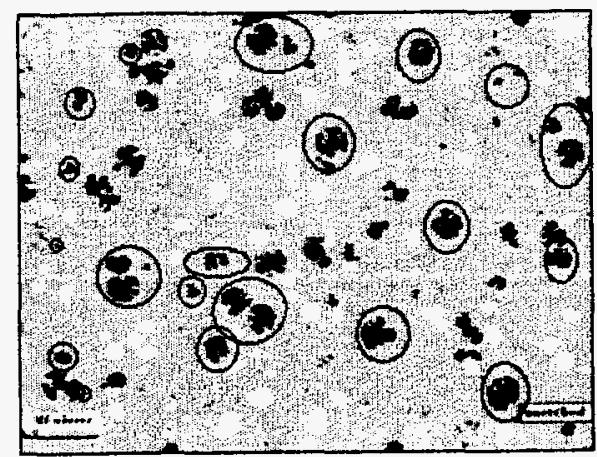

c)

Fig. 13. Difference between perimeter and convex perimeter (note that the actual values will depend on the pixel size): a) representation of perimeter; b) representation of convex perimeter; c) metallographic field showing good and poorly shaped graphite particles, where bright particles have acceptable S and C, while the circled ones have only acceptable $C$.

\section{Graphite shape}

The main problem concerning the nodularity in thin wall cast iron is poorly shaped graphite particles, which is not a rare event (Fig. 12). Since the particles are very small, the human eye cannot discern the irregularities of the graphite contour and as a consequence, visual nodularity gives typically very high values.

Considerable amount of effort was expended to develop an image analysis method that could correlate the visual nodularity evaluated from AFS or DIS standard micrographs to the quantitative nodularity evaluated through image analysis. The nodularity by using object area is defined in ASTM A247 as:

$\%$ Nodularity $=\frac{\text { Area of acceptable particles }}{\text { Area of acceptable }+ \text { unacceptable particles }} \cdot 100$

(Equation 6)

The acceptability criterion is based on the shape factor method. The most commonly used shape factors are the ones that relate the shape to a perfect sphere, like sphericity $S$ and compactness $C$ :

$$
S=\frac{4 \cdot \pi \cdot \text { Area }}{(\text { Perimeter })^{2}} \quad C=\frac{4 \cdot \pi \cdot \text { Area }}{(\text { Convex Perimeter })^{2}}
$$

For both, a perfect sphere will produce a value of one. If the shape deteriorates, the value decreases. According to a wide spread convention in industrial companies (Image pro-Plus Reference Guide, 1998, Omnimet Enterprise Handbook, 1998,

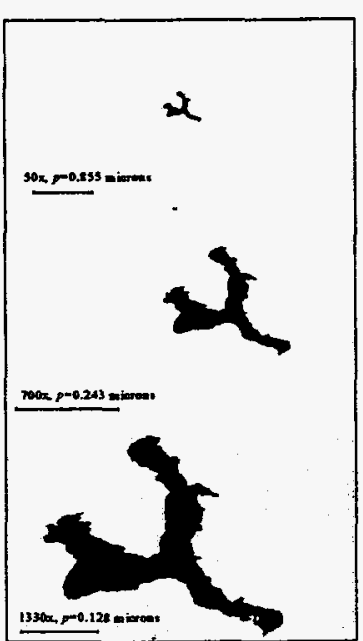

a)

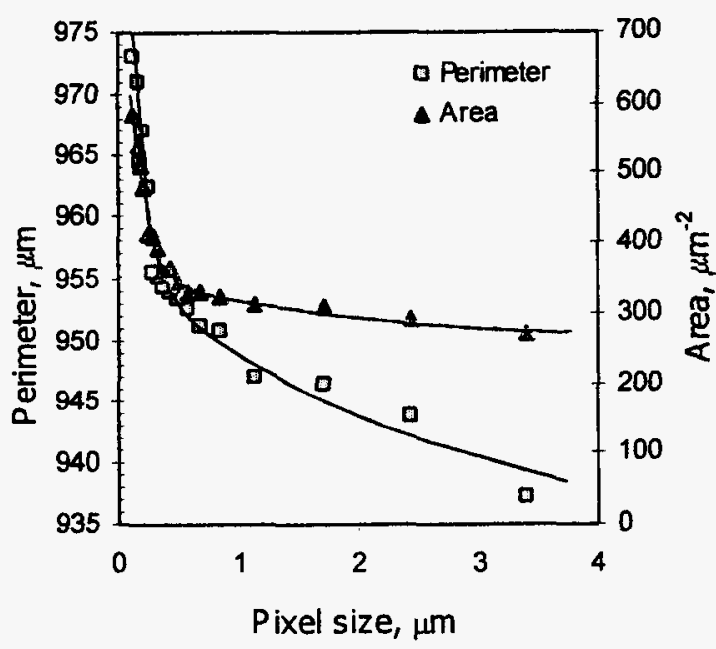

b)

Fig. 14, Influence of pixel size on quantitative measurements: a) graphite particle at different magnifications; b) dependency of measured perimeter and area on pixel size $p$ (magnification used from right to left along the curves: 50x, 70x, 100x, 150x, 200x, 250x, 300x, 350x, $400 x, 450 x, 500 x, 600 x$, $700 x, 800 x, 900 x, 1000 x, 1330 x)$.

UTHSCSA Image Tool Handbook, 1995 ), an acceptable nodule will have $S>$ 0.65 and $C>0.7$. The question is whether these values are also acceptable for thin wall cast iron.

Each of the two approaches ( $S$ versus $C$ ) seems to have their own merit. Sphericity is based on area and perimeter measurements. Compactness is based on area and convex perimeter measurements. The difference between perimeter and convex perimeter is illustrated in Fig. $13 \mathrm{a}, \mathrm{b}$. It is seen that perimeter is, in principle, a more detailed description of the shape of the object than the convex perimeter. This difference becomes crucial when poorly shaped graphite is involved, as shown in Fig. 13c. Here only the bright particles have acceptable sphericity $(S>0.65)$, while both bright colored and circled ones have acceptable 
compactness $(C>0.70)$. It is apparent that some exploded graphite particles are considered acceptable if compactness criterion is used.

These values are definitely sensitive to the magnification under which they were measured. Using current understanding of fractal dimensions and its applications in quantitative metallography it was shown (Lu 1994, Ruxanda et al., 2001) that any measurements (area, perimeter) depend on the pixel size $p$. The pixel size can be easily understood if seen like the yardstick length someone may use to outline a shape. An example of how the value of the pixel size may affect the results of a measurement made on a graphite particle is given in Fig. 14.

The fractal dimension, $D$, is a measure of the irregularity of the shape of an object, which is the case of the graphite as seen on a metallographic picture (the graphite particle/matrix interface is highly irregular). $D$, unlike the shape factors $S$ and $C$, is not pixel size dependent. If the fractal dimension method is used, one can clearly distinguish between poorly shaped and exploded graphite, which is exactly what $S$ predicts, as opposed to $C$ evaluation (Ruxanda et al., 2001). This shows the inadequacy of compactness as a descriptor for imperfect spheroidal graphite shapes. The fractal method is unlikely to be used for production purposes, because it is extremely laborious and it also has other limitations (Ruxanda et al., 2001), but it is a good research tool to evaluate simpler methods, as the shape factor method.

An agreement on the pixel size between laboratories is mandatory, since the achievable pixel size depends also on the image analysis system (i.e., software capabilities, image source, video camera, scanner, etc.). A reasonable value, high enough to accurately depict the graphite shape and low enough to satisfy the equipment capability restrictions is of approximately $0.5 \mu \mathrm{m}$, which is ten times smaller (considered as safe enough range) than the smallest nodule size to be included in the nodule count $(5 \mu \mathrm{m})$. On most equipment this requirement can be achieved with a magnification of $200 \mathrm{X}$. All our measurements were made at $200 \mathrm{X}$ (pixel size $p=0.53: \mathrm{m}$ ) for graphite characteriza tion and at $100 \mathrm{X}$ (pixel size $p=1.06: \mathrm{m}$ ) for matrix quantification.

The average sphericity $S$ or the nodularity using sphericity as shape factor $(S N)$ can be measured for any metallographic field. To relate these values with the visual nodularity from AFS or DIS standard micrographs, an Equivalent Nodularity ( $E N$ ) should be calculated. The regression equations derived from the actual charts, by applying the image analysis method on each set of pictures, are:
$E N_{A F S}=367.02 \cdot S-166.01$
and
$E N_{A F S}=0.8933 \cdot S N+21.029$
(Equation 8)
$E N_{D I S}=217.392 \cdot S-76.674$
and
$E N_{D I S}=1.0712 \cdot S N+0.0397$
(Equation 9)

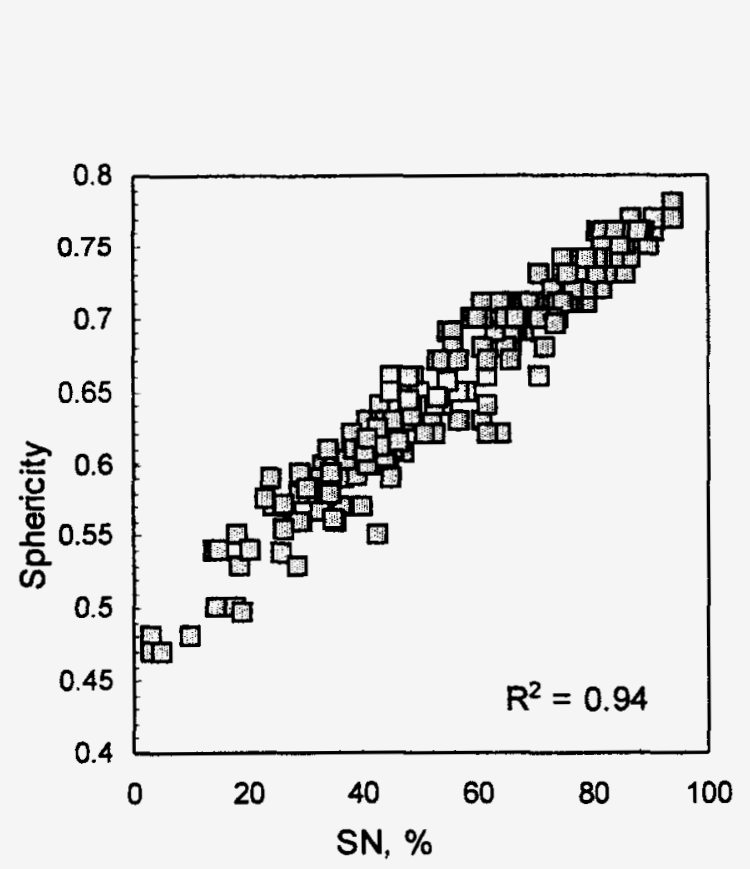

Fig. 15. Correlation between $S$ and $S N$ in thin wall iron castings.

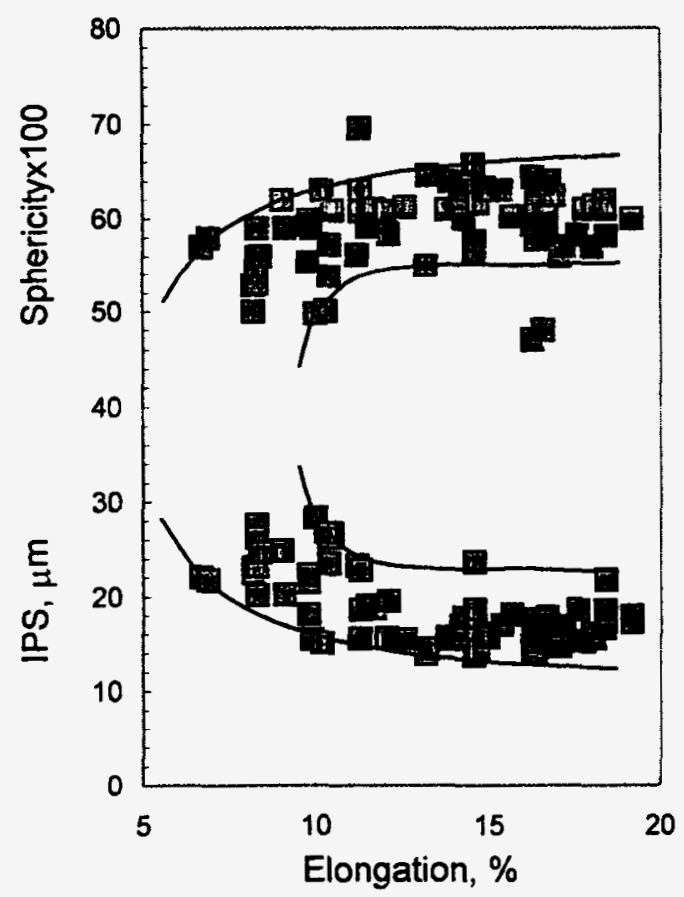

Fig. 16. Correlation between S, IPS and elongation in thin wall iron vertical castings. Note that $S$ values were multiplied by 100 . 
Using these equations, a microstructure should have $S=0.67-0.72$ or $S N=66 \%-88 \%$ to accept the population of graphite particles as nodular according to AFS charts. Similarly, a value of $S=0.72-0.81$ or $S N=75 \%-93 \%$ will indicate a nodular graphite shape for a DIS chart. However, in our study, that involved hundreds of measurements, other low limits are observed, as discussed in the following paragraph.

Contrary to the common belief that no relationship may exist between $S$ and $S N$ (which is conceptually true), a very good statistical correlation was found between the two with $R^{2}=0.94$ (Fig. 15). Note that data from all plates (horizontal plate pattern and vertical plate pattern) were plotted. However, no lower limits for $S$ or $S N$ could be establish from this figure. To set this limits, we have to relate $S$ or $S N$ to a sensitive mechanical property.

For this exercise, only the data from the vertical plates, free of carbides, were used. If $S$ and $\lambda_{G}$ are plotted against elongation at fracture on as-cast plates (Fig. 16) remarkable mirror symmetry is observed, which shows the consistency of the data. It can be easily seen from the figure that the elongation value of around $10.5 \%$ sets a limit: for higher values, $S$ values sit in a rather constant range whereas for lower values of elongation, a sudden drop occurs in the $S$ values. It follows from the graph that the lowest limit for sphericity would be $S=0.55$. To get the lower limit for $S N, S$ versus $S N$ for vertical plates was plotted. It was found that $S N=30 \%$.

From this analysis it is apparent that the population of graphite particles having a minimum sphericity of $S=0.55$ or $S N=$ $30 \%$ should be categorized as nodular. This relatively low limit compared to the initial acceptable shape factor $S=0.65$ is due in principal to the overly accuracy in the measurements. As for the relatively low limit for $S N$, it is a consequence of the use of the initial criterion in the nodularity formula (Equation 6). It was concluded that some of the charts presently used as industry standards might benefit from a revision of the criteria for shape acceptance based on modern quantitative techniques rather than visual estimates.

\section{DEFECTS OF THIN WALL DUCTILE CAST IRONS MACROSTRUCTURE \\ MICROPOROSITY}

The visual inspection of the fracture surface of the test plates indicated consistent differences between the plates produced with the two patterns. The fracture surfaces of the horizontal plates showed large blackened areas of various sizes and locations (Fig. 17a). This feature is missing in the vertical plates. These areas were revealed by SEM analysis to be

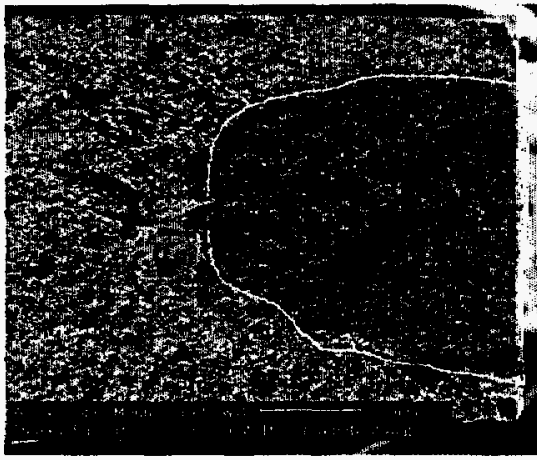

a)

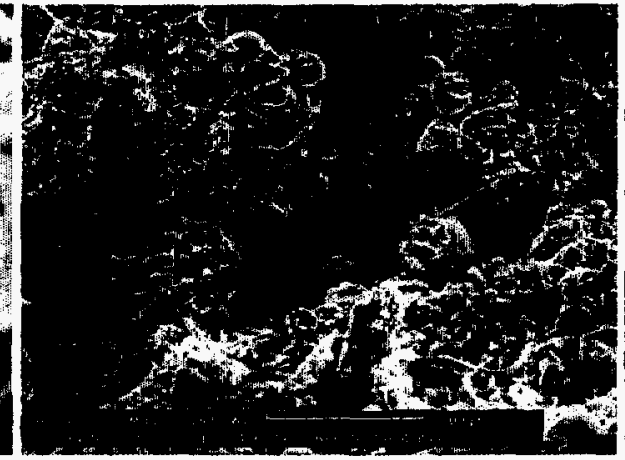

b)

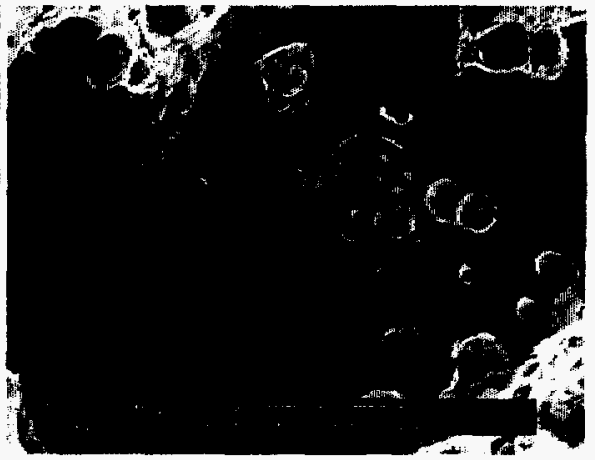

c)

Fig. 17. SEM analysis of a fracture: a) typical fracture surface of plated produced with the horizontal pattern; b) microporosity; c) dendritic phase found in the microshrinkage cavity.

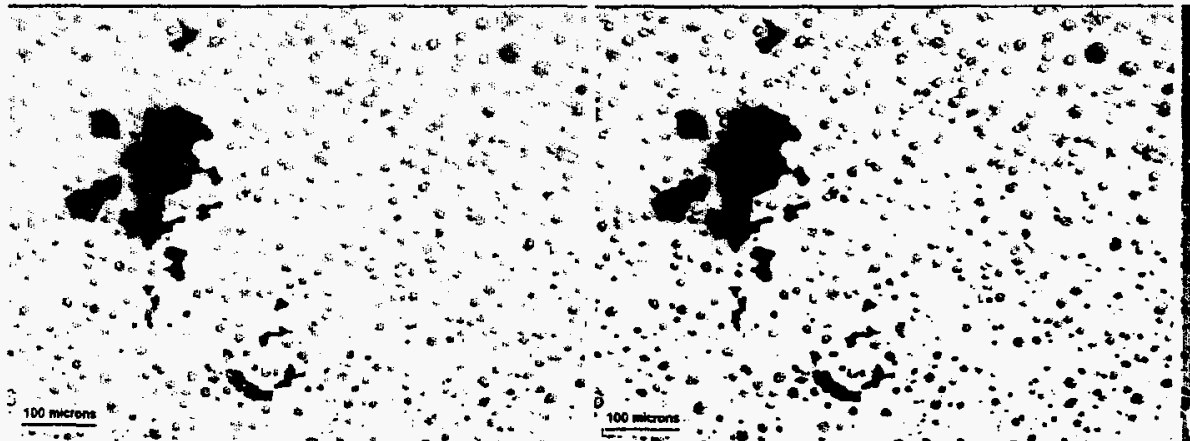

a) b)

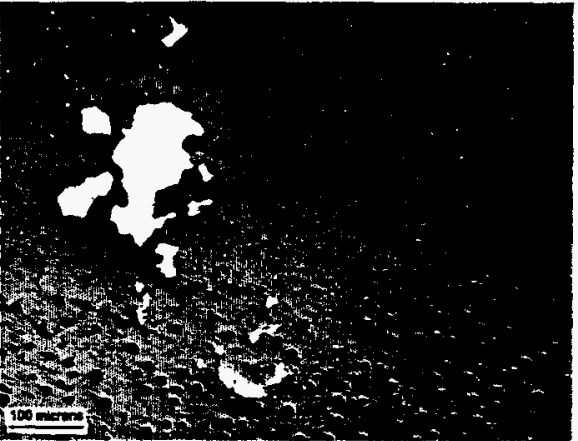

c)

Fig. 18. Porosity measurement in ductile iron: a) microstructure after carbon layer deposition; b) processed image after thresholding; c) identification of microporosity area after eliminating nodules $\left(0.025 \mathrm{~mm}^{2}\right)$. 


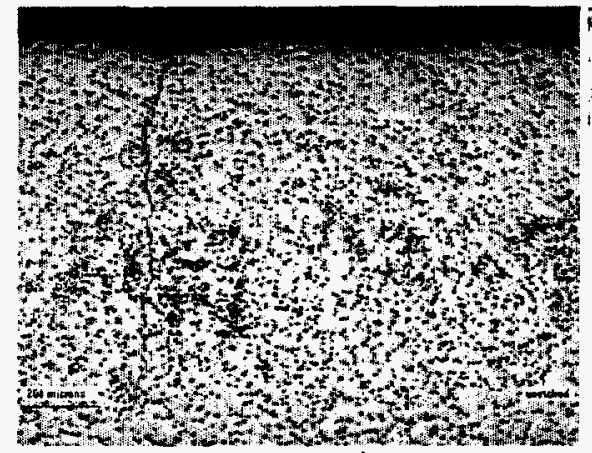

a)

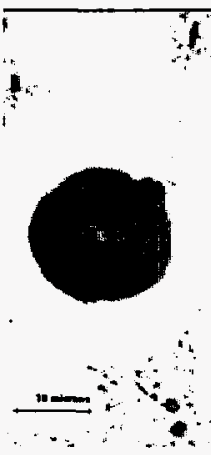

$\because$

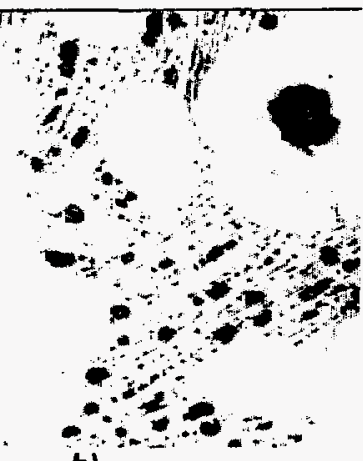

b)

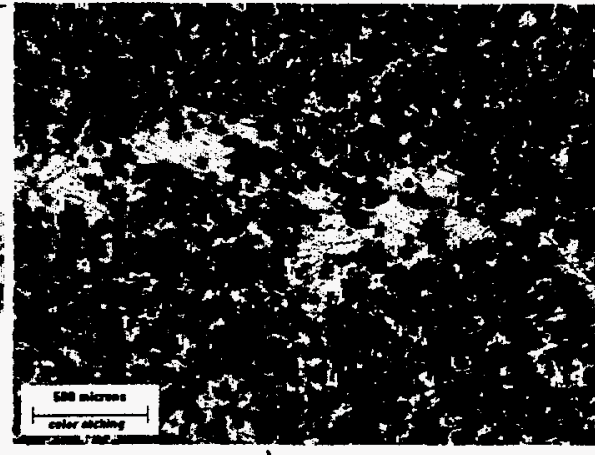

c)

Fig. 19. Optical micrographs showing indication of inverse chill a) clusters of small graphite in the centerline of the specimen; b) graphite particles aligned in a needle-like pattern; c) inverse chill in the centerline of the specimen.

microshrinkage (see Fig. 17b). Microporosity forms as a result of the inability of feed metal to reach the areas in the casting where the pores are forming. Even when micropores may not in themselves cause fracture (Gokhale 1999) they increase the plastic strain in the adjacent regions. Microporosity can also occur in the center of thin wall castings as a result of large eutectic grains and/or a weak mold (Chebotar 1993). The proper feeding and a lower cooling rate associated with the vertical pattern resulted in the elimination of microporosity. A more rigorous investigation on the morphology of the dendritic phase (Fig. 17c) found in the cavity is given in (Ruxanda et al., 2001a).

The immediate problem is the quantification of the microporosity. To this end, an attempt has been made to evaluate microporosity through quantitative metallography. The sequence of the procedure is illustrated in Fig. 18. It consists in first depositing a layer of carbon on the surface of the unetched sample. The graphite particles become bright gray while the porosity remains black. However, not all the graphite particles become bright enough to be eliminated when thresholding (Fig. 18b). Consequently some simple manual elimination of graphite particles must be done, after which the measurement of microporosity becomes possible (Fig. 18c). The size of the microporosity (white area) in the given sample was $0.025 \mathrm{~mm}^{2}$. This technique does not allow distinguishing between very small graphite nodules and voids of comparable size, or whether the voids are small porosity or graphite pulled out regions. An experienced operator could tell the difference. However, from the standpoint of mechanical properties this small porosity is not important.

\section{INVERSE CHILL}

The problem that really hinders the production of thin wall iron castings is the occurrence of the carbide phase (white eutectic), either in the entirety of the sample, dispersed/scattered, or as inverse chill (Fig. 19 to Fig. 22). In our castings, this defect was found only in the plates produced with the horizontal pattern. No carbides were found in plates produced using the vertical pattern. The issue of the presence of carbides in thin plates has been discussed (Karsay 1965, Yeung 1998, Fargues 1987, Javaid 1998, Evans 1981, Loper 1965, Begg 1993, Mampaey 1997, Mueller 1996, Stefanescu 1981), but few papers focused on inverse chill.

In optical metallography, inverse chill has an easily distinguishable aspect. The first indication is on the unetched sample, when clusters of small graphite occur in the centerline of the specimen (Fig. 19a). At higher magnification, these small graphite particles are aligned in a needle-like pattern (Fig. 19b). These areas become stained after polishing with alumina to

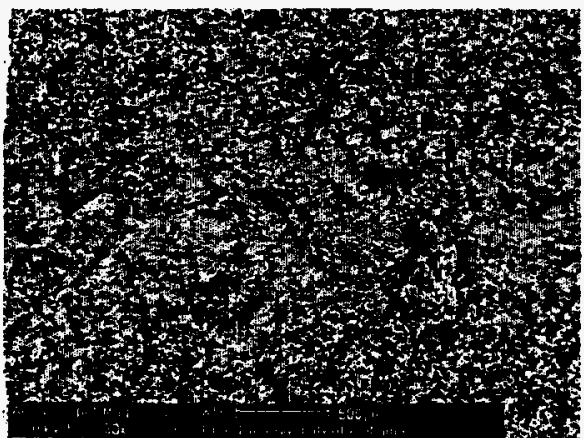

a)

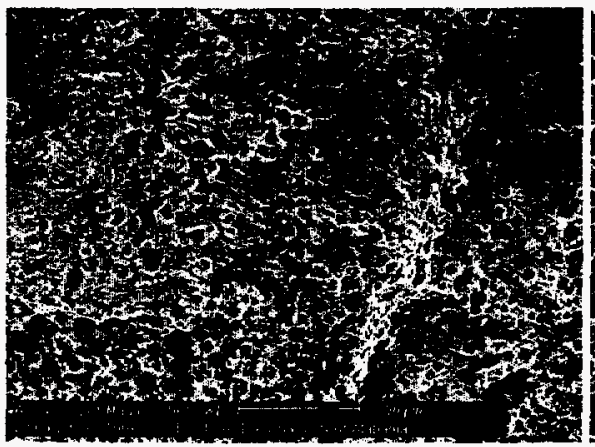

b)

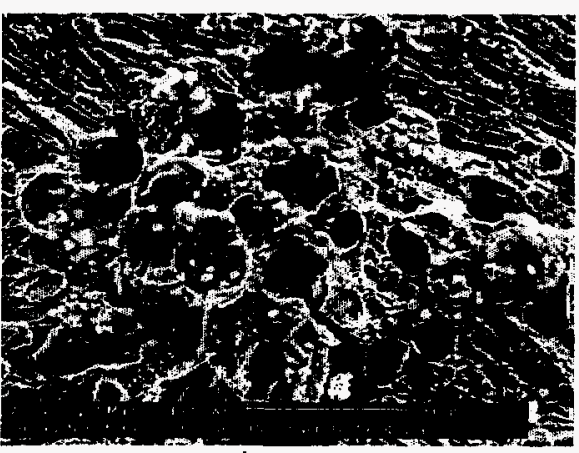

c)

Fig. 20. Fracture surface of a sample presenting inverse chill (SEM images): a) even texture along the axis; b) stepped (ledge) morphology; c) clusters of graphite particles. 


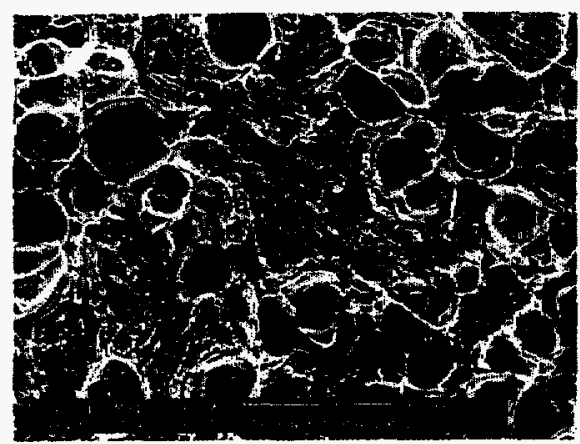

a)

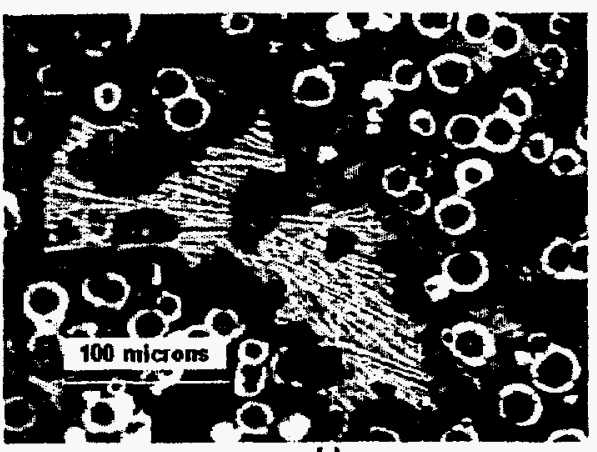

b)

Fig. 21. Area having inverse chill morphology confirmed by: a) SEM; b) optical microscopy.

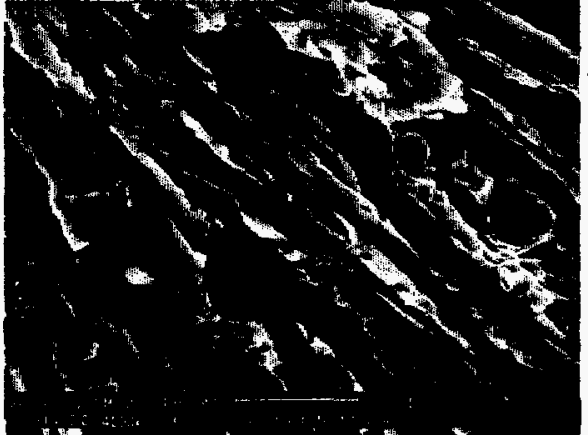

a)

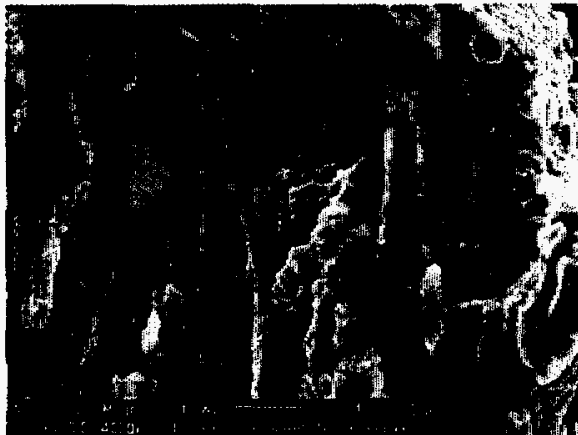

b)

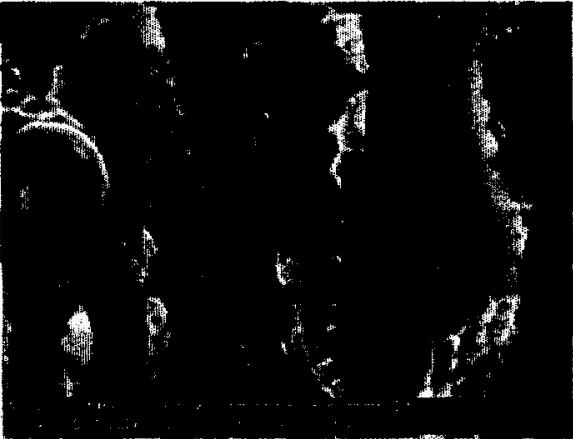

c)

Fig. 22. Higher magnification showing the inverse chill morphology in the fracture surface: a) small graphite particles embedded cementite; b) cementite appears as stripe-like, with jagged edges; c) detail from (b).

an extent where the characteristic inverse chill morphology becomes visible without etching. This is why it is recommended to use only oil based diamond suspension when the unetched samples are analyzed. After etching, this area is indeed shown to be inverse chill, where the cementite within the white eutectic usually exhibits the needle-like shape (Fig. 19c).

The inverse chill morphology was subsequently investigated on the fractured surface. The fracture mode in the centerline area (compare with Fig. 19a) is cleavage with a stepped, partially even texture in a narrow zone along the axis (Fig. 20a). At higher magnification (Fig. 20b), the steps are better seen as having a ledge appearance. Clusters of small graphite particles, similar to those observed in Fig. 19b, are embedded in ledeburite (Fig. 20c).

In-depth investigation was performed on an area confirmed by both SEM and optical microscopy (Fig. 21) as having inverse chill morphology. Observing this area at higher magnification, the true structure of the inverse chill was revealed (Fig. 22). Pearlite was practically absent in the eutectic, its place being taken by the small graphite particles embedded in cementite (Fig. 22a). The morphology of the cementite is not necessarily needle-like, as suggested by optical metallography, but more stripe-like, with jagged edges (Fig. 22b, c). It is believed that this might be an effect of tiny gas bubbles that might originate from vaporized magnesium being entrapped in the eutectic area during solidification.

EDX microanalysis on several inverse chill areas indicated high carbon content due to presence of the graphite particles (6.54-8.67-8.24C) and different quantities of $\mathrm{Si}(1.12-2.28-4.07 \% \mathrm{Si})$. Manganese was also found in high concentration $(1.01 \% \mathrm{Mn})$. These results are consistent with others, which associated inverse chill formation with depletion of $\mathrm{Si}$, segregation of Mn and high undercooling (Yeung 1998).

\section{FLAKE GRAPHITE RIM ANOMALY}

From the metallographic analysis of ductile iron plates it was found, both by optical or scanning electron microscopy, that under certain circumstances a thin rim (maximum $200: \mathrm{m}$ width) of flake interdendritic graphite is occasionally observed at the edges of the plates (Fig. 23). This was called the flake graphite rim anomaly. The EDX microanalysis was performed in order to quantify the composition in the bulk and at the surface. The areas of investigation were selected such as to include a random area of $10 \mu \mathrm{m}$ diameter from the bulk ferritic matrix of the sample and two areas of $5 \mu \mathrm{m}$ diameter from the interdendritic and dendritic ferritic areas (Fig. 23a). The EDAX composition is: $0.91 \% \mathrm{C}, 3.20 \% \mathrm{Si}, 0.62 \% \mathrm{Mg}$ in the bulk; $0.86 \% \mathrm{C}, 2.87 \% \mathrm{Si}, 0.21 \% \mathrm{Mg}$ in the interdendritic areas; $5.69 \% \mathrm{C}, 2.59 \% \mathrm{Si}, 0.53 \% \mathrm{Mg}$ in the dendritic areas. 


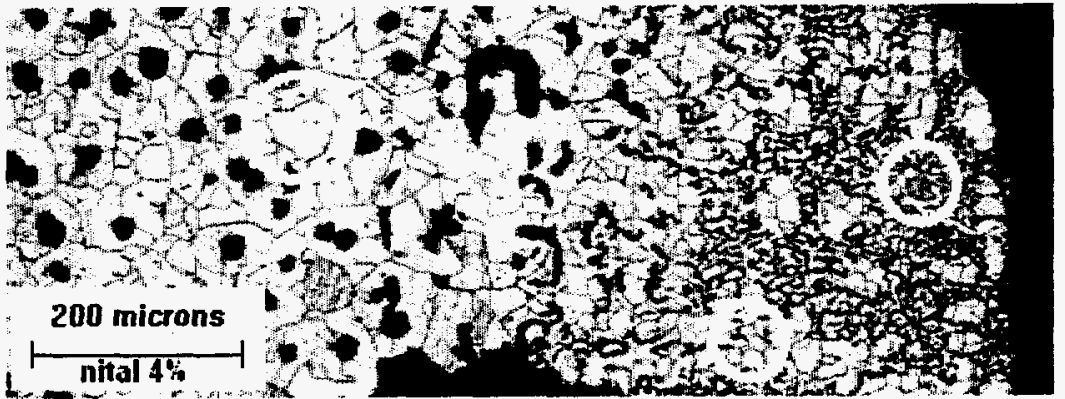

a)

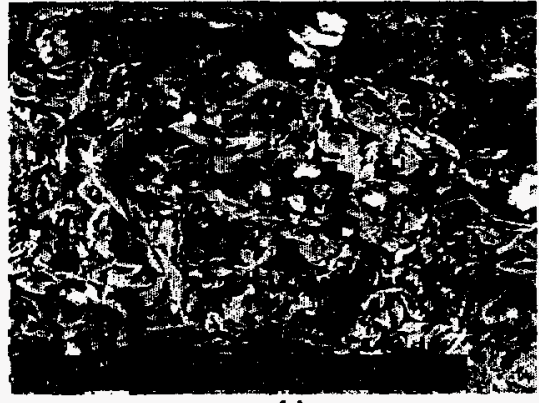

b)

Fig. 23. Rim of flake graphite at the free surface of a SG iron sample observed by: a) optical microscopy; b) SEM.

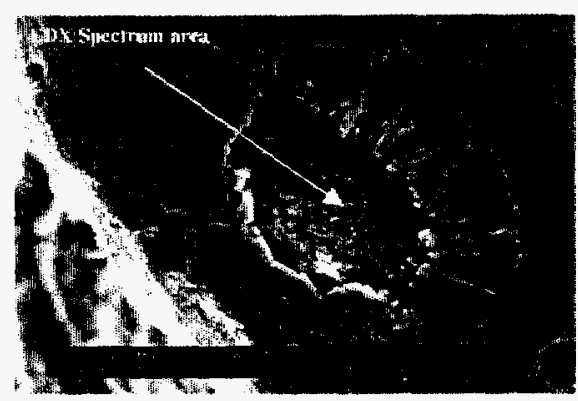

Fig. 24. Stem-type shape graphite particle.
The carbon values measured for the dendritic area indicate very high levels of carbon, as graphite particle agglomerations are a characteristic of the respective zone. In the bulk and in the interdendritic areas carbon values are typical for a ferrite-pearlite matrix. As can be seen, the $\mathrm{Mg}$ content in the bulk is higher than in the rim, and again higher in the dendritic area than in the interdendritic one. The explanation is that in the interdendritic areas positive microsegregation of $\mathrm{Mg}$ occurs. Thus, it is reasonable to conclude that the difference in magnesium content is responsible for the alteration of the graphite shape from spheroidal in the bulk to flake at the surface. It can be further assumed that the lower $\mathrm{Mg}$ content in the rim is a result of oxidation of $\mathrm{Mg}$ by gasses in the mold. However, the values for $\mathrm{Mg}$ content must be interpreted semi-quantitatively, as any elemental content below $1 \%$ is within the error level of the instrument.

An interesting feature which is relatively commonly observed at the free surface, and easily misinterpreted as exploded graphite, is presented in Fig. 24. Graphite particles exhibiting a particular steam- shape are attached to a void in a ring pattern. The EDAX composition collected from the void's wall (circular area in $\mathrm{Fig}$. 24 ) is $37.06 \% \mathrm{O}, 44.85 \% \mathrm{Al}, 5.31 \% \mathrm{Si}$, $2.2 \% \mathrm{Ca}, 10.57 \% \mathrm{Fe}$. The spectrum composition indicates the previous presence of a complex exogeneous inclusion (slag).

\section{GRAPHITE ALIGNMENT}

Although not quite as frequent, graphite alignment may occur in thin wall ductile iron castings (Fig. 25). This feature itself may not be extremely damaging, but again the geometry of the plates plays a greater role than in thicker sections. Under mechanical stress, this weak link inside the material may induce premature failure of the test sample. In the particular case shown in Fig. $25 \mathrm{a}$, the length of particle alignment $(0.6 \mathrm{~mm})$ represents $27 \%$ of the thickness of the plate $(2.2 \mathrm{~mm})$.

An investigation was carried out to determine the influence of the graphite alignment on the fracture mechanism. The test plate was polished and tensile tested, then the microstructure within the gauge length was analyzed (Fig. 26). As expected, the amount of surface deformation increases from the shoulder of the sample (Fig. 26a) to the fracture region (Fig. 26c). Crack initiation and propagation in ductile iron is considered as a link-up of microcracks in areas of high nodule count, with cracks propagating along paths of highest nodule density (Eldoky 1985, Adewara 1976a and b, Kuroda 1970, Gilbert 1964,

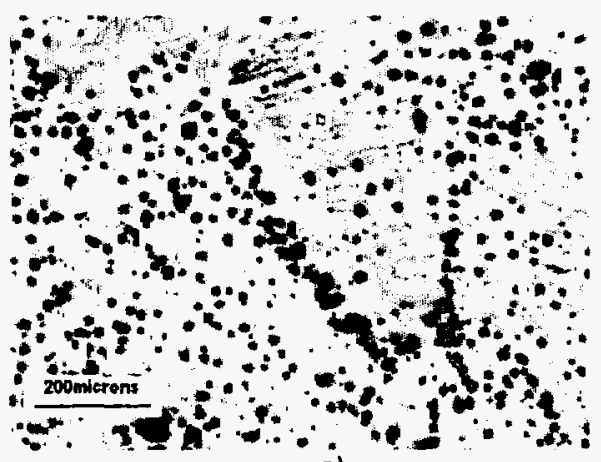

a)

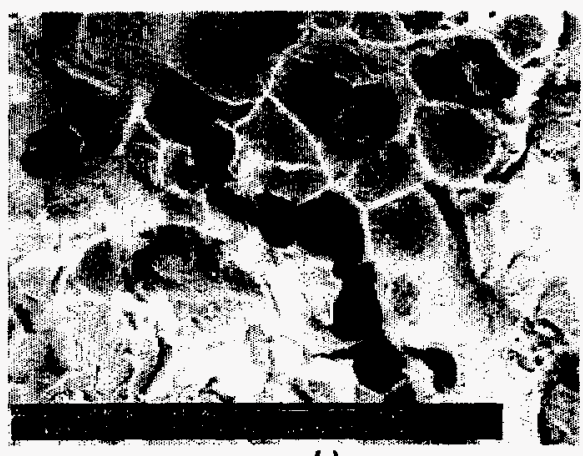

b)

Fig. 25. Graphite alignment: a) optical micrograph; b) SEM image from a fracture surface. 


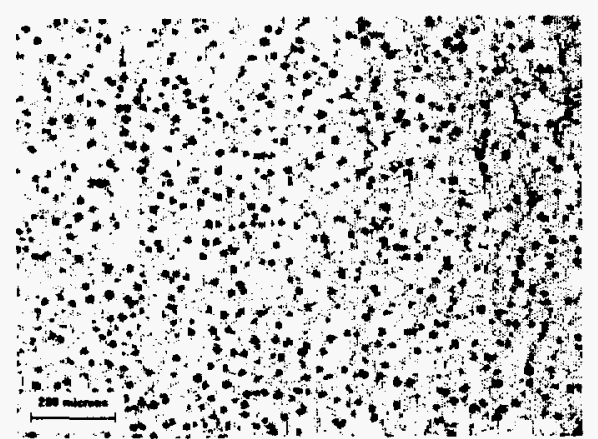

a)

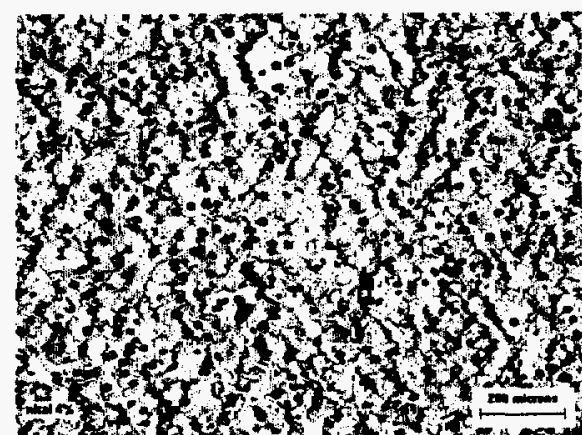

b)

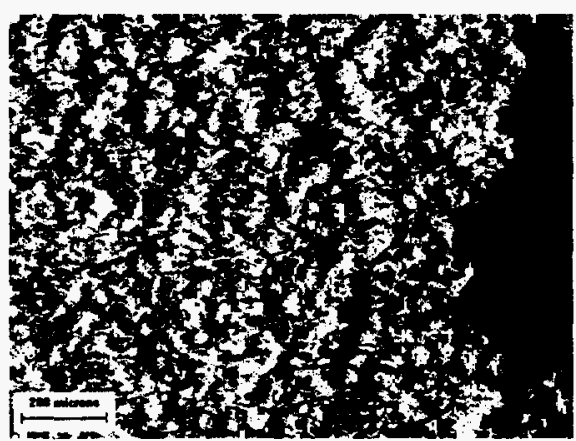

c)

Fig. 26. Microstructure in longitudinal section after testing: a) at the beginning of the deformation region; b) half way to the fracture; c) near the fracture.

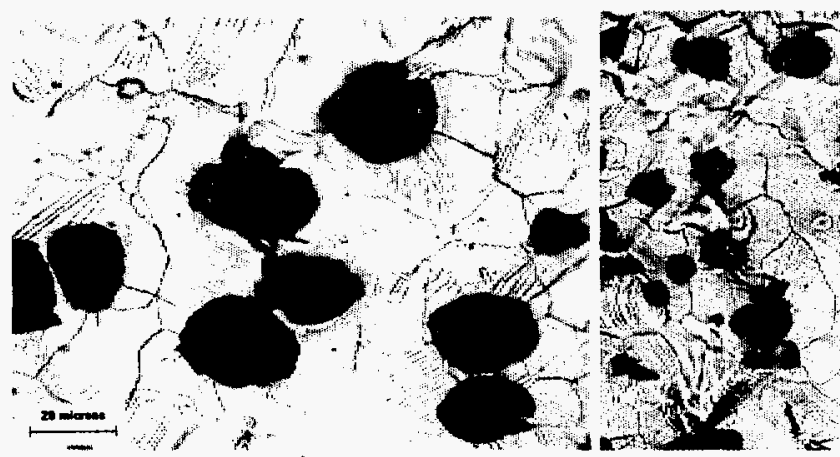

a)

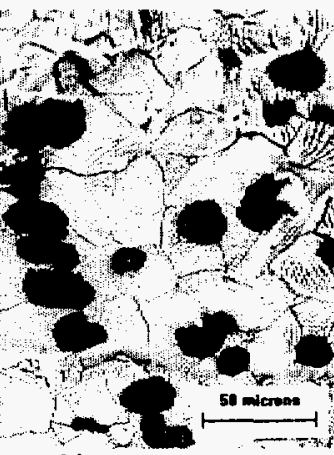

b)

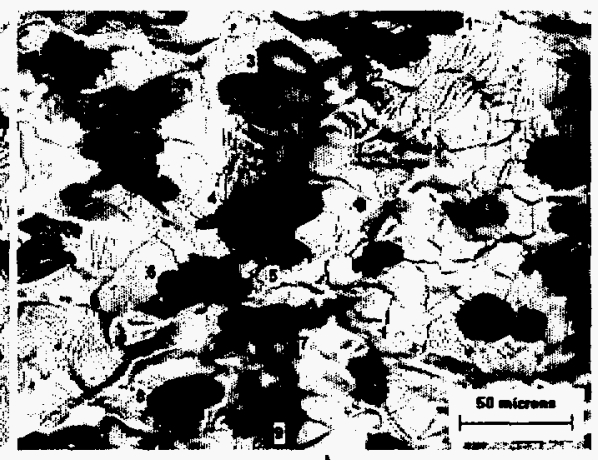

c)

Fig. 27. Crack formation: a) at the beginning of the deformation region; b) half way to the fracture; c) near the fracture (a chain of nine nodules is labeled to identify the crack path).

Jolley 1967, Rickards 1971, Veselyanskii 1970). Indeed, the plastic deformation starts with the development of slip lines on the surface of many ferrite grains and their subsequent deformation, followed by decohesion between the graphite particles and the matrix at low strain values, as it can be observed well ahead of the final fracture surface (Fig. 27a). Around the nodules voids are forming, that very soon become bigger and elongated as a result of necking of the ferrite grains. These elongated voids can be sometimes misinterpreted as elongated nodules, especially on poorly prepared samples. The deformation continues by the microtearing (Eldoky 1985) of ferrite and the appearance of microcracks between the nodules, which further propagate along the ferrite grain boundary (Fig. 27b). As the deformation increases, more linking-up of the internodular microcracks occurs and finally the primary crack front is joined. In the immediate vicinity of the fracture, the still undeformed graphite particles are barely retained in the matrix, some of them having been totally pulled out (Fig. 27c). Following this scenario, it is safe to conclude that graphite alignment plays a decisive role in crack propagation. The shorter the distance between the nodules and longer their alignment length, the faster the fracture will occur.

\section{INCLUSIONS}

From the standpoint of inclusions, thin wall castings are no different from conventional castings. If the filters are in place and the slag is thoroughly removed before tapping, exogenous inclusions should not be a problem. However, sand inclusions

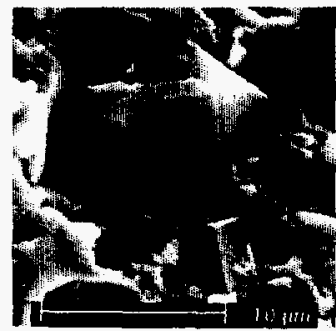

a)

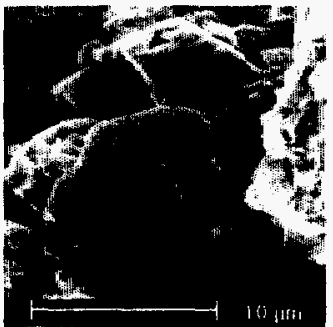

b)

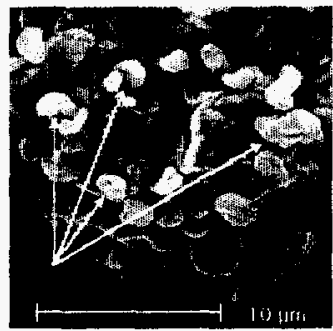

c)

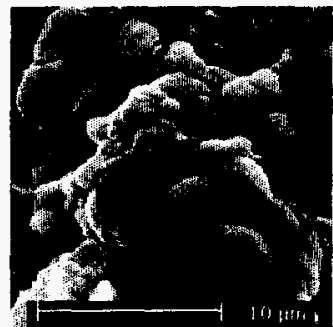

d)

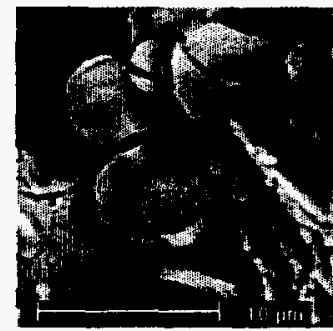

e)

Fig. 28. Endogenous inclusions: a) and b) silicon carbides (12.40\% C, $82.68 \%$ Si); c) tiny chromium carbides (15.59\%C, $71.60 \% \mathrm{Cr}$ ) shown by arrows); d) and e) conglomerate of complex Al, Si and Fe oxides (1.62\%Si, 11.66\%Al, 55.21\% Fe, $26.31 \% 0$ ). The difference to $100 \%$ is due to the averaging of the data for three measurements. 
from the mold were found, usually embedded into the plate surface. This is not a trivial defect, since the dimension of the sand inclusion (commonly hundreds of microns) may significantly reduce the actual thickness of a thin plate. Small endogenous inclusions, usually oxides and tiny carbides, may be found even for a well-controlled and maintained chemical composition before pouring (Fig. 28). These inclusions were identified both by optical microscopy and EDAX. Localized internal oxidation is another defect that may occur in the microshrinkage cavities.

\section{CONCLUSIONS}

An in-depth characterization of the microstructure on a large number of thin ductile iron plates was performed. Two patterns were used to produce either horizontal or vertical plates, ranging in thickness from 1.5 to $6 \mathrm{~mm}$.

For the same thickness of the sample, the matrix ranged from fully ledeburitic to fully ferritic, depending on the processing parameters. Image analysis was used to determine the percentage area of the constituents. The ferrite and pearlite percentage area can be measured relatively easy. However, when carbides are present, a special color etching should be applied. Using this etching procedure, the image of the microstructure can be correctly processed to identify only the carbides. Although some studies indicate that a dendritic orientation of the microstructure is expected in thin plates, in our study it was concluded that this tendency is not obvious.

The main issues on quantitative metallographic analysis of the graphite addressed in this paper include graphite nodule count evaluation and graphite shape evaluation. An upper limit of 2200 nodules $/ \mathrm{mm}^{2}$ with the average nodule size of $13.61: \mathrm{m}$ for 1.4 to $2 \mathrm{~mm}$ thickness plates was obtained when using the horizontal pattern. A set of photographs was developed as reference for thin wall ductile iron castings for nodule counts exceeding 600 nodules $/ \mathrm{mm}^{2}$. All pictures were taken from unetched microstructures from our experimental heats exhibiting the highest sphericity $(0.74$ to $0.77 \mathrm{~S})$.

It was shown that the nodule count and particle size are related by the interparticle spacing $\left(\lambda_{G}\right)$. As expected, the spacing decreases significantly with increasing nodule count for all plates. Since the thin plates in this study have significantly higher nodule count than found in regular ductile iron castings it is reasonable to assume that the smaller carbon diffusion distance would promote a higher ferritization rate. A decreasing tendency of interparticle spacing with increasing cooling rate was observed in all plates.

The main problem concerning the nodularity in thin wall cast iron is recognition of poorly shaped graphite particles. Since the particles are very small, the human eye cannot discern the irregularities of the graphite contour and consequently, visual evaluation of nodularity typically gives very high values. A method was developed to correlate the visual nodularity evaluated from AFS or DIS standard micrographs to the quantitative nodularity evaluated through image analysis. The acceptability criterion is based on the shape factor method. The most commonly used shape factors are sphericity $S$ and compactness $C$. However, it is apparent that some exploded graphite particles are considered acceptable if compactness criterion is used. These values are definitely sensitive to the magnification under which they were measured, and implicitly depend on the pixel size, $p$. Therefore the fractal method was also used, as the fractal dimension, $D$, is not pixel size dependent. When using the fractal dimension to characterize the graphite shape, one can clearly distinguish between poorly shaped and exploded graphite, which is exactly what $S$ predicts, as opposed to $C$. It was concluded that in our case the best descriptor for graphite shape is sphericity. A very good correlation between sphericity and nodularity based on sphericity criterion was found.

Regression equations were derived from the actual charts AFS or DIS standard micrographs to calculate an equivalent nodularity using average sphericity $S$ or the nodularity using sphericity as shape factor $(S N)$. To set the lower acceptable limit, we related $S$ or $S N$ to a sensitive mechanical property, which is elongation at fracture. From this analysis it is apparent that the population of graphite particles having a minimum sphericity of $S=0.55$ or $S N=30 \%$ should be categorized as nodular. Clearly, some of the charts presently used as industry standards may benefit from a revision of the criteria for shape acceptance based on modern quantitative techniques rather than visual estimates, when applied to thin wall iron castings.

To be able to compare results from different laboratories it is necessary to use a similar pixel size. However, the pixel size depends also on the image analysis system (i.e., software capabilities, image source, video camera, scanner, etc.). Based on our study, it was concluded that a magnification of $200 \mathrm{X}(p=0.53: \mathrm{m})$ for graphite characterization and of $100 \mathrm{X}(p=$ $1.06: \mathrm{m}$ ) for matrix quantification is a good choice.

The visual inspection of the fracture surface of the test plates indicated consistent differences between the plates produced with the two patterns. The fracture surfaces of the horizontal plates showed large areas of microporosity, formed because of the inability of feed metal to reach the areas in the casting where the pores are forming. The microporosity has been evaluated through quantitative metallography on metallographic prepared samples, using a special technique consisting in depositing a layer of carbon on the surface of the unetched sample and then processing the image through image analysis. 
Inverse chill is easy to observe through optical metallography. EDX microanalysis on several inverse chill areas indicated high carbon content due to presence of a large number of small graphite particles (6.54-8.67-8.24C) and different quantities of $\mathrm{Si}(1.12-4.07 \% \mathrm{Si})$. Manganese was also found in high concentration $(1.01 \% \mathrm{Mn})$.

A thin rim (maximum 200:m width) of flake interdendritic graphite is occasionally observed at the edges of the plates The EDAX composition showed a higher $\mathrm{Mg}$ content in the bulk than in the rim, and again higher in the dendritic area than in the interdendritic one. This is because positive microsegregation of $\mathrm{Mg}$ occurs in the interdendritic areas. Thus, it is reasonable to conclude that the difference in $\mathrm{Mg}$ content is responsible for the change of the graphite shape from spheroidal in the bulk to flake at the surface.

Graphite alignment may occur in thin walls ductile castings causing premature mechanical failure. Graphite alignment plays an important role in crack propagation. The shorter the distance between the nodules and the longer their alignment length, the faster the fracture will occur.

\section{ACKNOWLEDGEMENTS}

This research has been funded by a consortium of foundries and foundry suppliers and by the Metal Casting Competitiveness Program of the U. S. Department of Energy (DOE Cooperative Agreement DE-FC07-94ID13324). However, any opinions, findings, conclusions, or recommendations expressed herein are those of the authors and do not necessarily reflect the views of DOE. The authors acknowledge the active support of the industrial sponsors, without which the program could not have succeeded. One of the authors (RR) wants to acknowledge the support of the National Science Foundation through NSFNATO Fellowship Grant \#DGE-98-04536.

\section{REFERENCES}

Adewara J.O.T., Loper Jr. C.R., "Crack Initiation and Propagation in Fully Ferritic Ductile Iron", AFS Transactions, vol. 84, p. 527 (1976a)

Adewara J.O.T., Loper Jr. C.R., "Effect of Carbides in Crack Initiation and Propagation in Ductile Iron", AFS Transactions, vol. 84, p. 527 (1976b)

Askeland D.R., "Effect of Nodule Count and Cooling Rate on the Matrix of Nodular Cast Iron", AFS Transactions, vol. 83, pp. 313-320 (1975)

Begg J., "Research at BCIRA on Ductile Iron", Keith D. Millis World Symposium on Ductile Iron, Hilton Head Island, South Carolina, October 19-22 (1993)

Boeri R., Sikora J., "Solidification Macrostrcture of Spheroidal Graphite Cast IronI, Int. J. Cast Metals Res., vol. 13, pp. 307313 (2001)

Chebotar L.K., Lunev V.V., Pirozhkova V.P., "Pin Hole Porosity in Thin Wall Gray Iron Castings", Russian Metallurgy, pp. 64-68 (1994)

Ductile Iron Microstructures Rating Chart, wall chart AFS Ductile Iron Quality Control Committee (12.E) (1993)

Eldoky L., Voigt R.C., "Fracture of Ferritic Ductile Cast Iron", AFS Transactions, vol. 93, pp. 365-371 (1985)

Evans W.J., Carter Jr. J.F., Wallace J.F., "Factors Influencing the Occurrence of Carbides in Thin Sections of Ductile Iron", AFS Transactions, vol. 89, pp. 293-322 (1981)

Fargues J., Reynaud A., Parent-Simon S., "Extending the Production of S. G. Iron to Very Thin Sectioned Castings", BCIRA Int. Conf. For Cast Metals Technology, Birmingham, England, pp. 20-1-20-15, August 7-9 (1987)

Gilbert D.M.J., "The Stress-Strain Properties of Nodular Cast Irons in Tension and Compression", BCIRA Journal, p. 170, Mar (1964)

Gokhale A.M., Yang S, "Application of Image Processing for Simulation of Mechanical Response of Multi-Length Scale Microstructures of Engineering Alloys," Met. Mater. Trans. A, vol. 30A, p. 2369 (1999)

Graphite Rating in Ductile Iron Chart, wall chart prepared by Climax Research Services for the Ductile Iron Society (1999)

Hornung K., "Thin Section Ductile Iron Castings", in The $61^{s t}$ World Foundry Congress, Beijing, China, C.C. Liu ed., International Academic Publisher, P.R. China, pp. 5-01-05-09 (1995)

Image-Pro Plus Reference Guide, version 4.0, Media Cybernetics, L. P., Silver Spring, pp. 354-371 (1998)

Javaid A., Thomson J., Sahoo M., Davis K.G, "Factors Affecting the Formation of Carbides in Thin Wall Ductile Iron Castings", MTL 98-24 (OP-J), Report CNMET, September (1998)

Jolley G., Gilbert M.J., "Segregation in Nodular Irons and Its Influence on Mechanical Properties", The British Foundryman, vol. 60, p. 79 (1967)

Karsay S.I., "Production of Thin As-Cast Ductile Iron", Modern Castings, pp. 124-133 (1965)

Katz S., Warren A., "Thin Wall Iron Castings: Planning the Future", Foundry Management Technol. 125:34-36 (1997)

Kuroda Y., Takada H., "Study of Cast iron Fracture Using the Scanning Type Electron Microscope", AFS Cast Metal Research Journal, p. 63 (Jun 1970) 
Loper C.R., Heine R.W., "The Effect for Processing Variables on Ductile Iron Quality", AFS Transactions, pp. 488-496 (1965)

Lu S.Z., Hellawell A., "An Application of Fractal Geometry to Complex Microstructures: Numerical Characterization of Graphite in Cast Irons", Acta Metall. Mater., vol. 42, No. 12, pp. 4035-4047 (1994)

Mampaey F., Xu Z.A., "Mold Filling and Solidification of a Thin-Wall Ductile Iron Casting", AFS Transactions, vol. 105, pp. 95-103 (1997)

Mueller J., Wolf G., "Entwicklung von Verfahren zur reproduzierbaren Herstellung duennwandiger Gu2teile aus Gu2eisen mit Lamellengraphit und Gu2eisen mit Kugelgraphit", Giessereiforshung, vol. 48, part I pp. 20-27, part II pp. 49-60 (1996)

Omnimet Enterprise Handbook, version 1, pp. A1-A15 Buehler Ltd., Lake Bluff, IL (1998)

Rickards P.J., "Ductile and Brittle Fracture in Ferritic Nodular Graphite Irons", ISIJ,vol. 209, p. 190, Mar (1971)

Rivera G., Boeri R., Sikora J., "Revealing he Solidification Structure of Nodular Iron", Cast Metals, vol. 8, pp. 1-5, (1995)

Ruxanda R., Beltran-Sanchez L., Massone J., Stefanescu D.M., "On the Eutectic Solidification of Spheroidal Graphite Iron An Experimental and Mathematical Modeling Approach" Proceedings of Cast Iron Division AFS 105th Casting Congress, Dallas TX, April 28-May 1, 2001, pp. $37-48$ (2001a)

Ruxanda R., Stefanescu D.M., Piwonka Th., "Quantification of the Solidification Microstructure of Ductile iron Through Image Analysis", Proceedings of The International Conference on The Science of Casting and Solidification, Brasov Romania, 28-31 May 2001, D.M. Stefanescu et al. eds., pp. 361-368 (2001b)

Seher R.J., Jamers H.M., Maniar G.N., "Quantitative Metallography of the Age Hardening Precipitate in Superalloys by Replica Electron Microscopy", Stereology and Quantitative Metallography, ASTM STP 504, pp. 119-137 (1972)

Stefanescu D.M., "Production of As-Cast Ferritic and Ferritic-Pearlitic Ductile Iron in Green Sand Molds", AFS International Cast Metals Journal, vol. 6, pp. 23-31 (1981)

UTHSCSA Image Tool Handbook, version 1.10, pp. 31-35, University of Texas HSC San Antonio, TX (1995)

Veselyanskii T.S. et al., "Electron Fractographic Study of Nodular Cast Iron", Russian Casting Production, vol. 26, p. 520, Nov (1970)

Yeung C.F., Zhao H., Lee W.B., "The Morphology of Solidification of Thin-Section Ductile Iron Castings", Materials Characterization 40:201-208 (1998) 


\title{
Tensile Properties of Thin Wall Ductile Iron
}

\author{
D. M. Stefanescu ${ }^{1}$, L. P. Dix ${ }^{1}$, R.E. Ruxanda ${ }^{1}$, C. Corbitt-Coburn ${ }^{2}$, and T. S. Piwonka ${ }^{1}$ \\ ${ }^{1}$ University of Alabama, Tuscaloosa, AL ${ }^{2}$ U.S. Steel, Birmingham, AL \\ Copyright@2002 American Foundry Society
}

\begin{abstract}
Extensive experimental work was conducted to establish the tensile mechanical properties and hardness of thin wall ductile iron castings. Plates having dimensions of $100 \times 25 \mathrm{~mm}$ and thickness between 1.5 and $7 \mathrm{~mm}$ were cast in green and resinbonded sand molds. After preliminary experiments, a casting having plates of $2.5,3.5$ and $6 \mathrm{~mm}$ thickness was designed for soundness using mold filling and solidification simulation. The charge material consisted of $20 \%$ Sorel pig iron, $40 \%$ ductile iron returns, and $40 \%$ steel scrap. Cerium containing alloys were used for liquid treatment. The tensile properties and hardness were measured on as-cast plates as well as on machined plates to obtain bulk properties of the material.
\end{abstract}

Since the cooling rate is not only a function of thickness, extensive experiments were conducted with instrumented molds to establish the correlation between cooling rate and the parameters affecting it for the test castings used in this study. The cooling rates, measured at $1170^{\circ} \mathrm{C}$, ranged from $3.5^{\circ}$ to $12^{\circ} \mathrm{C} / \mathrm{s}$.

Once the experimental conditions to produce carbide-free sound plates were established, only plates free of carbides, with mostly ferritic matrix and with no internal defects were produced. The typical mechanical properties of machined plates were in the following range: $60-70 \mathrm{ksi}$ tensile strength, 43-46 ksi yield strength, 18-25\% elongation, and 133-167 HB. These properties exceed ASTM specifications for as-cast ductile iron, and compare favorably with the properties of regular section size ductile iron.

\section{INTRODUCTION}

Today's foundries are confronted with continuous demand to manufacture high-quality, cost-effective cast components. Those specializing in automotive castings have the added pressure of developing new processes and materials that reduce overall car weight to meet federally mandated fuel economy standards, without sacrificing performance. In order to meet these needs, automakers have increasingly turned to lighter weight materials, and castings continue to be a prime target. This is why some ferrous markets have been lost during the last 15 years to aluminum and other less dense materials in applications such as engine blocks and cylinder heads.

Is this market segment forever lost for the ferrous metal casters? A closer examination of the relative mechanical capabilities and cost of various materials shows that ferrous alloys are competitive with aluminum base alloys. Among these, ductile iron occupies a special position, as shown in Fig. 1 and Fig. 2, where forged steel has been normalized to 1 . Ductile iron is not only by far a cheaper material, but it is also comparable or superior to aluminum in most instances, based on the relative weight per unit of yield strength.

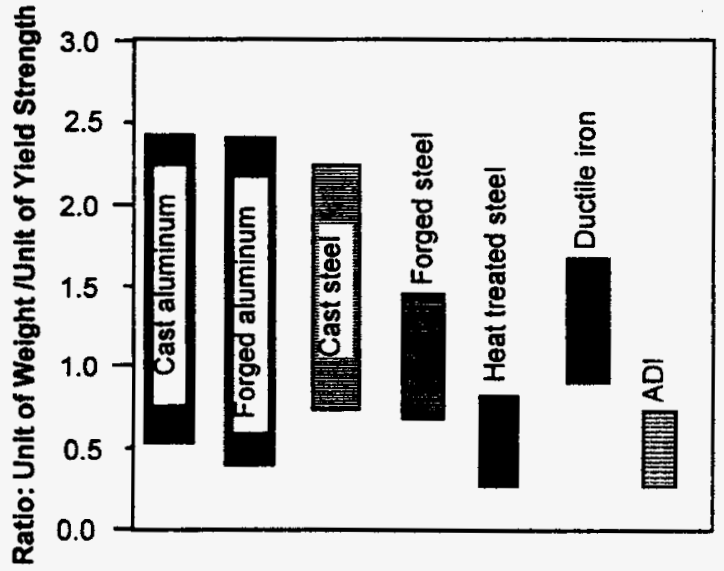

Fig. 1. Relative weight per unit of yield strength for different metallic materials (Hayrynen, 1985).

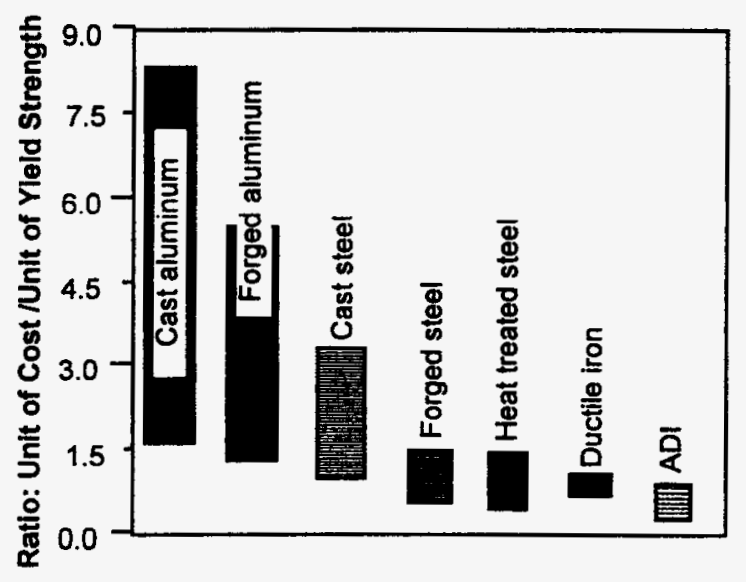

Fig. 2. Relative cost per unit of yield strength for different metallic materials (Hayrynen, 1985). 
European automakers have made significant progress replacing aluminum castings with iron castings. However, if cast iron is to regain the market lost to competition with aluminum, it must be better engineered to achieve in practice its potential. The objective is to develop technology to produce high quality thin wall castings (down to $2.5 \mathrm{~mm}$ wall thickness). The resulting reduction in casting weight, combined with superior yield strength, fatigue and wear resistance, high temperature properties, high damping capacity and lower cost will protect the demand for iron castings in the automotive industry.

In 1998 the AFS, the Department of Energy, and 30 industrial sponsors initiated a program at The University of Alabama to develop thin wall iron casting technology. The program's goal is to develop the enabling technology to manufacture sound parts having section sizes as small as $2.5 \mathrm{~mm}$ and a carbide-free microstructure. The answers that this program will provide include, but are not limited to, optimum chemical composition of gray, compacted, and ductile iron, optimum liquid treatment materials and methods, microstructure/property correlation for thin wall iron castings, metallographic procedures, and the dimensional accuracy capabilities of available molding technology. In addition, an extensive solidification modeling program involving several commercial software companies was also initiated.

This paper summarizes some of our findings regarding the tensile mechanical properties of thin wall ductile iron.

\section{BACKGROUND}

The main process requirements associated with the production of thin wall iron castings include: carbide-free microstructure, clean metal, internally sound sections, complete mold filling, and dimensional accuracy of thin walls.

The quest for thin wall iron castings free of carbides is an old one. The difficulty in obtaining carbide-free as-cast iron microstructures in sections under $3 \mathrm{~mm}$ is well documented. The chilling tendency is influenced by the following variables:

- metal properties: pouring temperature, chemical composition, nucleation potential;

- liquid treatment of ductile iron, including graphite spheroidization treatment and inoculation;

- mold properties: mold temperature, thermo-physical properties of mold and mold coating;

- casting design.

The typical carbon equivalent (CE) required for carbide-free ductile iron castings with wall thickness of 10 to $30 \mathrm{~mm}$ is considered to be 4.35 to $4.65 \%$ (Loper and Heine, 1965). An increased CE results in a higher nodule count (Loper, 1969), which in tum leads to a significant decrease in carbide formation tendency. If the wall thickness must be decreased to $3-5$ $\mathrm{mm}$, the CE must be further increased. For example, if the CE is increased to 4.75 to $4.92 \%$, with 3 to $3.2 \% \mathrm{Si}$, a carbide-free matrix will result. If the $\mathrm{CE}$ reaches $5 \%$, not only the structure will be carbide free, but also $40 \%$ ferrite will be present in the matrix (Rijikov 1965). Finally, a completely ferritic structure can be obtained with $\mathrm{CE}=5.28 \%(3.95 \% \mathrm{C}, 4 \% \mathrm{Si})$ (Karsay, 1967).

All these data are taken from sources published prior to 1969 , and refer to base iron compositions with more than $0.4 \% \mathrm{Mn}$ and $0.06 \% \mathrm{P}$. Since then it has become common knowledge that other elements, such as $\mathrm{Mn}, \mathrm{P}, \mathrm{S}, \mathrm{Cr}$, must be controlled if a carbide-free structure is to be obtained at lower CE (Stefanescu, 1981). A more recent study (Schissler et al., 1989) recommends a final composition of $3.7 \% \mathrm{C}, 3.4 \% \mathrm{Si}, 0.2 \% \mathrm{Mn}, 0.029 \% \mathrm{Mg}(\mathrm{CE}=4.72)$ if carbide-free ductile iron is desired in thin castings ( $\leq 3 \mathrm{~mm}$ ). This last composition is consistent with QIT recommendation (Henning, 1999), which is:

$\mathrm{CE}=4.9265-0.0425 \cdot t$

Equation 1

where $t$ is the thickness in $\mathrm{mm}$. Indeed a $\mathrm{CE}=4.79 \%$ is calculated for $t=3 \mathrm{~mm}$.

For both ductile and gray irons, it is imperative to minimize the levels of any carbide promoting elements. Because of segregation, even small amounts may cause intergranular carbide formation in thin sections.

In a recent paper Javaid et al. (Javaid et al., 2001) indicate a range of composition of 3.65-3.95\% C, 2.4-3.4\% Si, 0.03$0.045 \% \mathrm{Mg}, 0.005-0.009 \% \mathrm{Ce}$ and $<0.1 \% \mathrm{Mn}$, obtained through the use of $93 \%$ Sorel pig iron, $3 \%$ low Mn steel scrap, balance ferro-alloys. They obtained carbide free microstructure in some $3 \mathrm{~mm}$ horizontal plates but carbides were present in others. The optimum composition was not specified. Elongation on $3 \mathrm{~mm}$ machined plates ranged from 1 to $20 \%$ depending on the liquid treatment conditions and composition. Tensile strength ranged from 72 to $105 \mathrm{ksi}$.

Even as early as 1973 it was demonstrated that $3 \mathrm{~mm}$ thick ductile iron plates can be produced carbide-free in green sand using MgFeSi treatment alloys (Stefanescu 1973, Stefanescu 1981). The Mg residual was $0.035 \%$, and the melt was postinoculated with $1.25 \% \mathrm{Fe} 75 \mathrm{Si}$. 


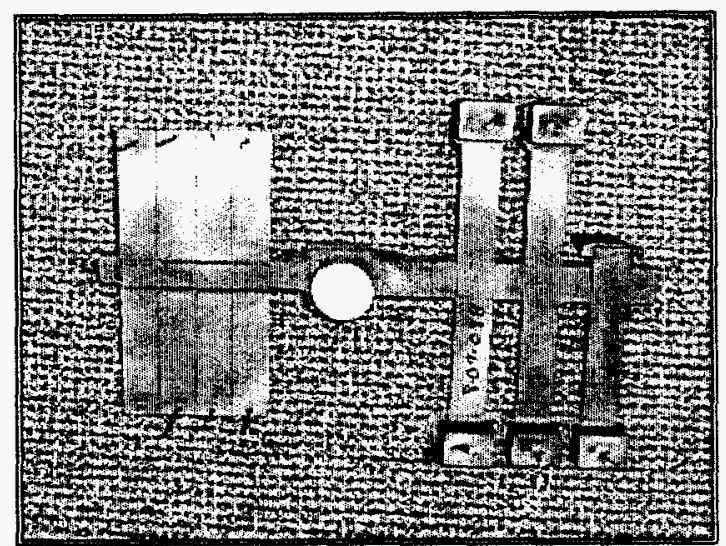

a) horizontal plate pattern with 13 plates

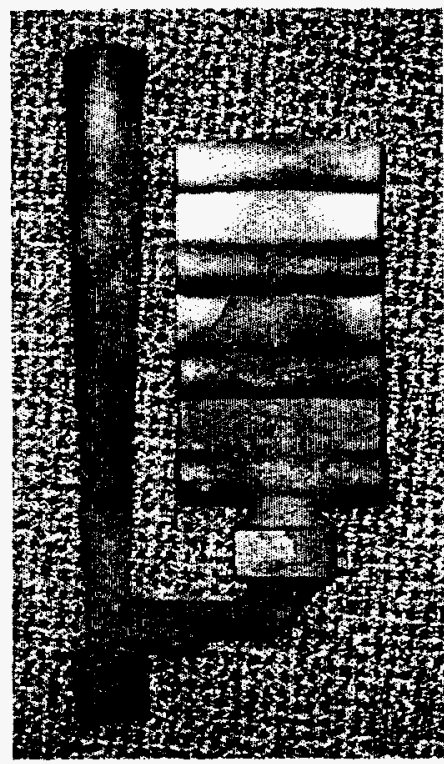

b) vertical plate pattem with three plates

Fig. 3. Top view of typical castings used in this research.

The type and amount of rare earth (RE) in the composition of the magnesium-containing alloy used for treatment plays a significant role on chill formation in ductile iron. University of Alabama research (Kanetkar et al., 1984) demonstrated that carbide-free pins having $3.2 \mathrm{~mm}$ diameter can be poured when using a praseodymium containing $5 \% \mathrm{MgFeSi}$ alloy. The residual Pr was $0.01 \%$.

Lanthanum seems to be also very efficient in increasing nodule count. Indeed a RE-containing $5 \% \mathrm{MgFeSi}$ alloy produced almost 800 nodules $/ \mathrm{mm}^{2}$ when the La/RE ratio was 0.4 , as compared with only about 600 when no La was present (Lalich, 1974). The University of Alabama report quoted before (Kanetkar et al., 1984) confirmed these findings, by showing that a $4.8 \mathrm{~mm}$ diameter pin can be cast carbide-free when using a La containing $5 \% \mathrm{MgFeSi}$ alloy. The residual La was $0.008 \%$. However, excess La of 1-2\% in the spheroidizing alloy promotes intergranular carbides (Onsøien et al., 1997). Apparently, for thin section castings it is beneficial to use a MgFeSi alloy with a high Ce content in the RE component (Skaland, 1998). In principle, the optimum composition of the spheroidizing alloy is recommended to be: $46 \% \mathrm{Si}, 3 \% \mathrm{Mg}, 0.4 \% \mathrm{Ca}, 2 \% \mathrm{RE}$ $(1.9 \% \mathrm{Ce}, 0.2 \% \mathrm{La}), 0.7 \% \mathrm{Al}, \mathrm{Fe}$ balance. The alloy should be ground to $1-10 \mathrm{~mm}$ for small ladles.

A certain amount of $\mathrm{Ce}$ is also recommended in the inoculation alloy, for example $75 \% \mathrm{Si}, 1 \% \mathrm{Ca}, 1.5 \% \mathrm{Ce}, 0.8 \% \mathrm{Al}, \mathrm{Fe}$ balance (Skaland, 1998). The size of the alloy for small ladles should be $0.5-2 \mathrm{~mm}$ for in-stream inoculation.

\section{RESEARCH STRATEGY}

The two main objectives of this research were to establish the optimum process parameters for carbide-free microstructure and to evaluate the mechanical properties of thin wall ductile iron castings. To this purpose, a pattern with horizontal plates was designed and produced. A picture of a casting produced with the horizontal plate pattern after removing the downsprue is shown in Fig. 3a. The pattern includes five independent plates (1.5, 2.5, 3, 5, $6 \mathrm{~mm}$ thickness) and eight interconnected plates $(1.5,2,2.5,3,3.5,4,5,6 \mathrm{~mm}$ thickness). All plates had rectangular geometry with dimensions $100 \times 25 \mathrm{~mm}$. A small riser can be seen at the end of the independent plates. However, it was found that this riser was insufficient to insure a sound plate. Accordingly, the horizontal plates are referred as "unrisered" in the rest of this text.

When attempting to evaluate mechanical properties on castings produced with the horizontal plate pattern, a large data scatter was found. As discussed in detail later in this paper, this scatter is the result of solidification anomalies in the castings. Consequently, a second pattern with vertical plates was designed to produce sound plates. A casting poured with this pattern is shown in Fig. 3b. The plates had the same rectangular geometry $(100 \times 25 \mathrm{~mm})$ and thickness of $6.0,2.5$ and $3.5 \mathrm{~mm}$, listed from bottom to top. The plates produced with this pattern were free of solidification anomalies. Consequently, the plates poured with the vertical plate pattern are referred to in this text as "designed for soundness". 


\section{PROCESS PARAMETERS FOR CARBIDE-FREE MICROSTRUCTURE}

\section{METHODS AND MATERIALS}

The main effort during this stage of the research was to produce carbide-free thin section iron castings using an economically reasonable charge composition and standard melt treatment alloys. Ductile iron heats were produced in the Ray Farabee Metal Casting Laboratory at The University of Alabama using a $200 \mathrm{lb}$. capacity silica lined induction furnace ( $125 \mathrm{~kW}$ and $3200 \mathrm{~Hz}$ ). The charge materials used for the melt produced for this series of experiments included $40 \%$ returns, $20 \%$ steel, $40 \%$ Sorel. Armco iron was used to dilute the manganese when needed. The type and composition of the charge materials used for the meit produced for this series of experiments are presented in Table 1.

After charging and meltdown, chemistry adjustments were made. A carbon raiser with $99 \% \mathrm{C}$ was used to adjust carbon after melt down. Calcium-free ferrosilicon was used to adjust silicon. The melt temperature was raised to $2820 \mathrm{~F}\left(1550^{\circ} \mathrm{C}\right)$, held for $10 \mathrm{~min}$. and then the melt was tapped into the treatment ladle.

The liquid treatment of the melt was performed using two different procedures, 2-step and 1-step. In the 2-step method, a classic $200 \mathrm{lb}$. sandwich ladle was used for treatment with a Fe-Si-6Mg alloy (see Table 2 for composition). After the completion of the $\mathrm{Mg}$ reaction, half of the metal was transferred in a $100 \mathrm{lb}$. tea-pot pouring ladle and post-inoculated in the stream with $0.6 \% \mathrm{Fe}-75 \mathrm{Si}-1 \mathrm{Ca}$ (see Table 2 for composition) during transfer. In the 1-step process, a single ladle was used for both $\mathrm{Mg}$-treatment and inoculation. A Fe-Si-4Mg or a Fe-Si-6 Mg alloy (see Table 2 for composition) was positioned in the central pocket of the ladle and covered with the Fe-75Si-1 Ca inoculant.

From each treatment ladle two green sand molds were produced with a 13-horizontal-plate pattern. A summary of the total

Table 1. Type and chemical composition (wt.\%) of charge materials.

\begin{tabular}{llrllllll}
\hline \multicolumn{1}{c}{ Material } & \multicolumn{1}{c}{$\mathrm{C}$} & $\mathrm{Si}$ & \multicolumn{1}{c}{$\mathrm{Mn}$} & $\mathrm{P}$ & $\mathrm{S}$ & $\mathrm{Cu}$ & $\mathrm{AI}$ \\
\hline Sorel Pig Iron (A) & 4.18 & 0.134 & 0.009 & 0.024 & 0.011 & - & - \\
Sorel Pig Iron (B) & 3.92 & 0.150 & 0.005 & 0.011 & 0.004 & - & - \\
Armco Iron (D) & 0.006 & 0.017 & 0.05 & 0.004 & 0.003 & 0.007 & 0.003 \\
Steel Scrap (A) & 0.10 & na & 0.35 & na & na & 0.04 & na \\
Steel Scrap (B) & 0.10 & 0.03 & 0.30 & 0.005 & 0.012 & 0.02 & 0.03 \\
DI Returns (A) & 3.50 & 2.80 & 0.35 & na & 0.01 & 0.1 & na \\
DI Returns (B) & 3.70 & 2.45 & 0.28 & na & 0.009 & 0.24 & na \\
DI Returns (C) & 3.80 & 2.10 & 0.28 & 0.016 & 0.0065 & 0.125 & 0.009 \\
\hline
\end{tabular}

na: not available

Table 2. Type and chemical composition (wt. \%) of composition adjustment and liquid treatment materials.

\begin{tabular}{lcrrrrrrr}
\multicolumn{1}{c}{ Materials } & $\mathrm{C}$ & $\mathrm{Si}$ & $\mathrm{Mg}$ & $\mathrm{RE}$ & $\mathrm{La}$ & $\mathrm{Ce}$ & $\mathrm{Ca}$ & $\mathrm{Al}$ \\
\hline Fe-Si-6Mg & - & 45.63 & 6.05 & 1.09 & 0.38 & 0.56 & 1.00 & 0.90 \\
Fe-Si-4Mg & - & 46.58 & 3.73 & 0.45 & na & 0.24 & 0.62 & 0.77 \\
Gloflex 3 (Fe-Si-Mg) & - & 45.52 & 3.70 & 1.33 & na & na & 0.48 & 0.66 \\
Fe-75Si-1 Ca & - & 75.04 & - & - & - & - & 0.77 & 1.03 \\
\hline
\end{tabular}

Table 3. Summary of experiments for optimization of chemical analysis.

\begin{tabular}{lccc}
\multicolumn{1}{c}{ Method } & Heats & Molds & Plates \\
\hline 2-step & 9 & 14 & 182 \\
1-step FeSi6Mg & 11 & 21 & 273 \\
1-step FeSi4Mg & 12 & 23 & 299 \\
Total & 32 & 58 & 754 \\
\hline
\end{tabular}

Table 4. Range of chemical analysis (wt. \%) achieved for the various heats.

\begin{tabular}{lcccccc}
\hline \multicolumn{1}{c}{ Process } & $\mathrm{C}$ & $\mathrm{Si}$ & $\mathrm{Mn}$ & $\mathrm{P}$ & $\mathrm{S}$ & $\mathrm{Mg}$ \\
\hline 2-step & $2.91-4.73$ & $1.66-4.38$ & $0.19-0.22$ & $0.013-0.017$ & $0.012-0.028$ & $0.037-0.048$ \\
1-step FeSi6Mg & $2.77-4.01$ & $2.12-4.59$ & $0.17-0.22$ & $0.010-0.020$ & $0.009-0.015$ & $0.026-0.069$ \\
1-step FeSi4 Mg & $2.93-3.99$ & $2.48-4.52$ & $0.07-0.22$ & $0.009-0.013$ & $0.006-0.011$ & $0.041-0.072$ \\
\hline
\end{tabular}


number of molds and plates poured is given in Table 3. The range of chemical analyses obtained during this phase of the experiment for the different liquid treatment processes is summarized in Table 4. Note that for heats 2-step and 1-step FeSi6Mg the variables were $\mathrm{C}, \mathrm{Si}$, and $\mathrm{Mg}$, while for heats l-step FeSi4Mg manganese was also varied.

\section{CHARACTERIZATION}

Characterization included metallographic evaluation and testing of tensile mechanical properties and hardness. Mechanical testing samples and metallographic samples were machined out of the cast plates as shown in Fig. 4. The plates were sandblasted prior to machining.

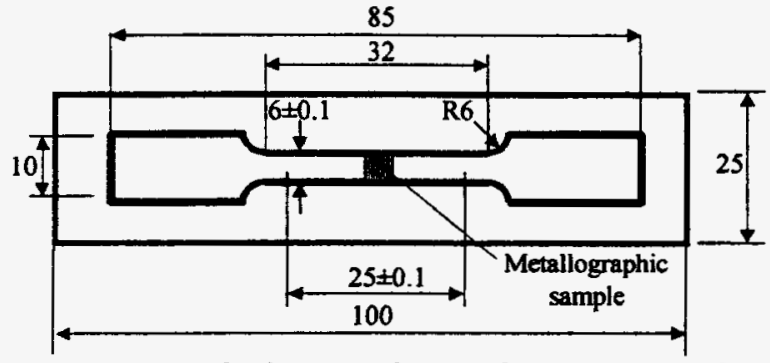

Fig. 4. Mechanical properties testing sample and metallographic sample.

Image analysis was used to quantitatively evaluate the microstructure. The Omnimet Enterprise software in conjunction with a Nikon microscope was utilized. Each reported result represents the average of five fields. Typical measurements included nodule count, graphite shape, graphite size, and amount of phases (graphite, ferrite, cementite). A detailed description of metallographic procedures is given elsewhere (Ruxanda et al., 2002). However, a short discussion on evaluation of graphite shape is given in the following paragraphs.

The standard procedure for evaluating graphite shape in the foundry is visual estimation of nodularity (Visual Nodularity, $V N$ ). It consists of comparing the microstructure of interest with metallographic charts. The most accepted is the equation that uses object area (ASTM A247):

$$
\% \text { Nodularity }(\text { area })=\frac{\text { Areaof acceptable particles }}{\text { Areaof acceptable+unacceptable particles }} \cdot 100
$$

Equation 2

To increase measurement objectivity, image analysis may be used to evaluate graphite shape. Again, there is no uniform standard throughout the industry. Different companies are using different image analysis measurements, including:

$$
\text { Sphericity }=\frac{4 \cdot \pi \cdot \text { Area }}{(\text { perimeter })^{2}} \quad \text { Compactness }=\frac{4 \cdot \pi \cdot \text { Area }}{(\text { convexperimeter })^{2}}
$$

Equation 3

Sphericity is based on area and perimeter measurements. Compactness is based on area and convex perimeter measurements. Perimeter is, in principle, a more detailed description of the shape of the object. However, perimeter measurement is more sensitive to the magnification under which it is measured (pixel size) than convex perimeter.

Any of these shape descriptors can be used to calculate a quantitative nodularity, based on Equation 2. Thus, one can use sphericity nodularity $(S N)$ or compactness nodularity $(C N)$. For $S N$ the acceptable particles were considered to be those with $S>0.65$. For $C N$ the acceptable limit was $C>0.7$. These are the typical numbers used for regular thickness ductile iron.

\section{RESULTS}

The complete experimental results on all cast plates are given in (Stefanescu et al., 2000). Statistical analysis of all the experimental data was performed. It included correlation analysis, and regression analysis. The independent (input) variables included in the analysis and their symbols are:
Carbon - C
Magnesium - Mg
Pouring Temperature in ${ }^{\circ} \mathrm{F}-T$
Silicon-Si
Manganese - Mn
Plate thickness in $\mathrm{mm} .-t$

The dependent (output) variables are:

Ferrite - Ferr

Nodule count $/ \mathrm{mm}^{2}-N$

Sphericity nodularity $-S N$

Compactness nodularity - $\mathrm{CN}$

Average carbide content $-\mathrm{Fe}_{3} \mathrm{C}_{\mathrm{av}}$

Carbide content in the inverse chill zone- $\mathrm{Fe}_{3} \mathrm{C}_{\text {chill }}$

Correlation analysis measures the relationship between two data sets that are scaled to be independent of the unit of measure. A perfect correlation will return a value of 1 . Good correlation is considered to exist for values above 0.5 . 
Table 5. Correlation analysis for microstructure; 2 -step all plates.

\begin{tabular}{|c|c|c|c|c|c|c|c|c|c|c|c|c|c|c|}
\hline & \multicolumn{6}{|c|}{ 2-step all plates } & \multicolumn{8}{|c|}{ 1-step independent plates } \\
\hline & $S$ & $S N$ & $\mathrm{Fe}_{3} \mathrm{C}_{\mathrm{av}}$ & Ferr & $N$ & $\mathrm{C}$ & $S$ & $S N$ & $C N$ & $R N$ & $\mathrm{Fe}_{3} \mathrm{C}$ & Ferr & $N$ & S \\
\hline$S$ & 1.00 & & & & & & 1.00 & & & & & & & \\
\hline$S N$ & 0.96 & 1.00 & & & & & 0.87 & 1.00 & & & & & & \\
\hline$C N$ & & & & & & & 0.80 & $\therefore .63$ & 1.00 & & & & & \\
\hline $\mathrm{Fe}_{3} \mathrm{C}_{\mathrm{av}}$ & -0.18 & -0.11 & 1.00 & & & & -0.12 & -0.09 & -0.05 & -0.07 & 1.00 & & & \\
\hline Ferr & 0.41 & 0.39 & -0.48 & 1.00 & & & 0.12 & 0.15 & 0.03 & -0.08 & -0.71 & 1.00 & & \\
\hline$N$ & 0.47 & 0.40 & -0.26 & 0.39 & 1.00 & & 0.32 & 0.29 & 0.15 & 0.02 & -0.78 & 0.78 & 1.00 & \\
\hline C & -0.14 & -0.28 & -0.13 & - ().45 & -0.08 & 1.00 & 0.19 & 0.18 & 0.19 & 0.34 & -0.46 & 0.20 & 0.41 & \\
\hline $\mathrm{Si}$ & 0.38 & 0.39 & -0.30 & 0.87 & 0.33 & -0.53 & -0.10 & -0.13 & -0.26 & -0.36 & -0.46 & 0.66 & 0.60 & \\
\hline Mn & 0.30 & 0.26 & -0.29 & 0.27 & 0.35 & 0.08 & -0.10 & 0.06 & -0.14 & -0.20 & -0.22 & 0.12 & 0.11 & 0.57 \\
\hline$P$ & -0.03 & -0.07 & -0.09 & -0.27 & -0.02 & 0.60 & -0.01 & 0.02 & 0.05 & 0.04 & -0.18 & 0.05 & 0.08 & \\
\hline$S$ & -0.22 & -0.35 & -0.07 & -0.37 & -0.14 & 0.78 & 0.10 & 0.15 & 0.06 & -0.06 & 0.02 & -0.02 & -0.07 & 1.00 \\
\hline $\mathrm{Mg}$ & -0.08 & -0.13 & -0.09 & -0.20 & -0.02 & 0.47 & 0.43 & 0.31 & 0.34 & 0.34 & -0.31 & 0.24 & 0.45 & -0.41 \\
\hline $\mathrm{CE}$ & 0.16 & -0.01 & $-0,43$ & 0.20 & 0.37 & 0.72 & 0.06 & 0.02 & -0.06 & 0.02 & $-0.0^{*} 0$ & 3.61 & 0.75 & -0.34 \\
\hline$t$ & -0.09 & -0.07 & -0.21 & 0.34 & -6.46 & -0.03 & -0.22 & -0.35 & -0.12 & 0.05 & -0.30 & 0.19 & -0.03 & -0.04 \\
\hline$T$ & -0.19 & -0.28 & -0.24 & -0.12 & -0.13 & 0.40 & -0.11 & -0.01 & -0.12 & -0.35 & 0.35 & -0.20 & -0.34 & 0.25 \\
\hline
\end{tabular}

The general multiple linear regression equation is:

$y=a+\sum_{i} b_{i} \cdot x_{i}$

Equation 4

where $y$ is the dependent variable, $x_{i}$ are the independent variables, and $a$ and $b_{i}$ are the regression coefficients. The purpose of this exercise is to determine the coefficients $a$ and $b_{i}$ for the microstructural variables of interest.

\section{Correlation analysis}

The result of the correlation analysis for all plates produced by the 2-step method is given in Table 5. Only plates having $S>$ 0.55 were included in the analysis. It is seen that ferrite correlates very well with the silicon content $(0.87)$, and significantly with $\mathrm{C}(-0.45)$. The other independent variables do not correlate well. Surprisingly, the Ferr - $\mathrm{C}$ correlation seems to indicate that the amount of ferrite should decrease with increased carbon. This apparent contradiction of metallurgy stems from the fact that carbon correlates with silicon $(-0.63)$. This correlation indicates that in the batch of data submitted for analysis there were not enough data with either high or low levels of both $\mathrm{C}$ and $\mathrm{Si}$.

The average carbide content only correlates significantly with carbon equivalent $(-0.43)$. Reasonable correlations were also noted between silicon and the nodule count $(0.53)$, and between plate thickness and nodule count $(-0.46)$. Although not shown in the table, it was found that the inverse chill carbides have significant correlation with silicon $(-0.61)$ and reasonable correlation with temperature $(-0.49)$. The meaning of the numbers is that inverse chill should decrease as any of these variables increases. The correlation with thickness was poor $(-0.1)$.

The results of correlation analysis for all independent plates made by the 1-step process are presented in Table 5. It is seen that, again, ferrite correlates very well with Si (0.66), while carbides correlate well with $\mathrm{CE}(-0.7)$. Both $\% \mathrm{Fe}_{3} \mathrm{C}_{\boldsymbol{v} v}$ and $\% \mathrm{Ferr}$ correlate very well with nodule count $(-0.78$ and +0.78 , respectively).

A plot of the relationship between the nodule count and the carbide content is given in Fig. 5. It is seen that, with a few exceptions, a minimum of 600 nodules $/ \mathrm{mm}^{2}$ are needed to obtain a structure with less than $2 \%$ carbides. In turn, nodule count correlates very well with carbon equivalent $(0.75)$, as also shown in Fig. 5 . Since the figure suggests that we must have $C E \geq$ 4.5 to obtain minimum 600 nodules $/ \mathrm{mm}^{2}$, it follows that this is a condition for carbide-free microstructure.

Quite interesting is the $S N-C N$ correlation (0.63) shown in Fig. 6. Note that plates having $\geq 80 \% C N$ may have $S N$ between 10 and $90 \%$. Based on this correlation it seems safe to accept as a lower limit for $S N$ the value of $30 \%$. This simply confirms again that $S N$ nodularity is much more sensitive than $C N$ nodularity.

\section{Regression analysis}

For the independent plates produced through the 2-step method, the following linear regression equation were obtained: 

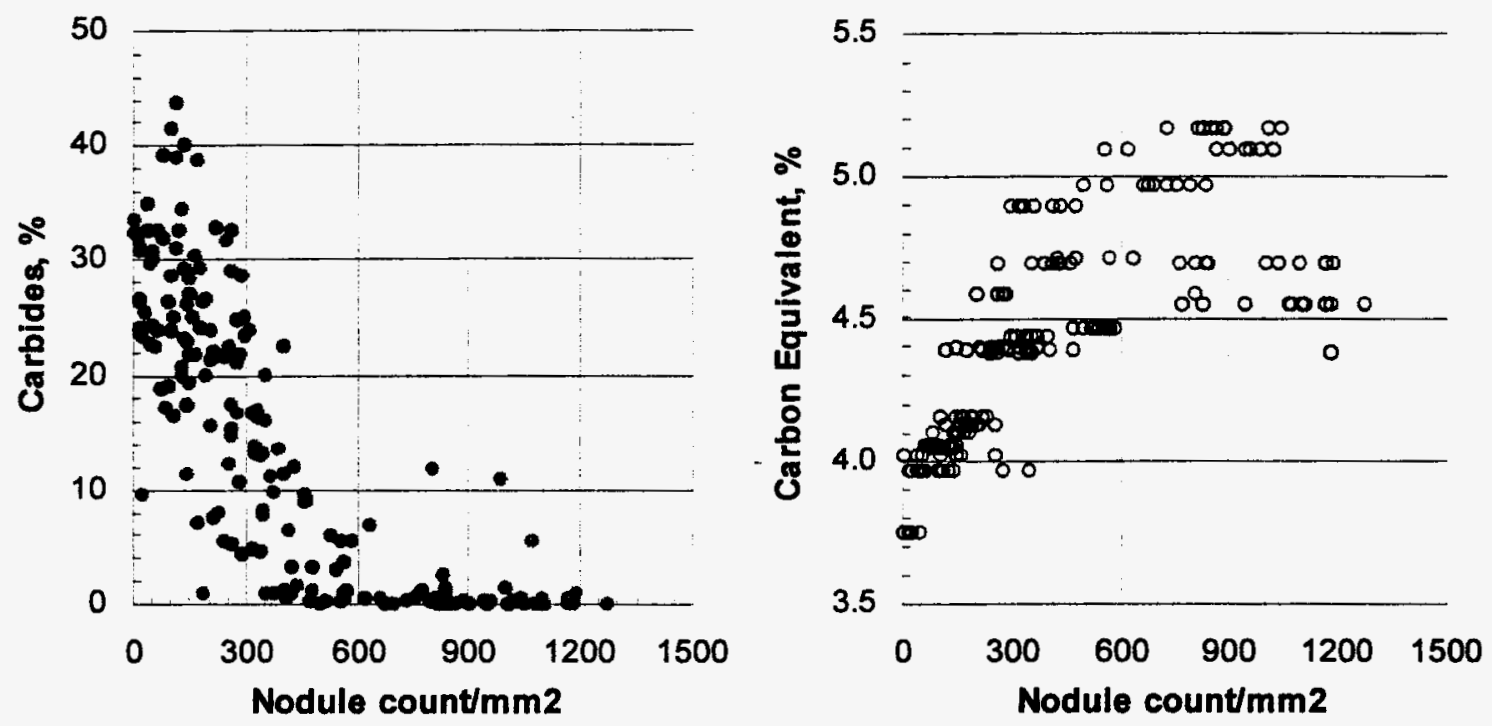

Fig. 5. Correlation of the amount of carbides and carbon equivalent with nodule count for all independent plates produced by the 1-step method.

$\% \mathrm{Fe}_{3} \mathrm{C}_{a v}=93.2-9.568 \cdot \mathrm{C}-3.173 \cdot \mathrm{Si}+708.7 \cdot \mathrm{S}-0.442 \cdot t-0.022 \cdot \mathrm{T}$

Equation 5

$\%$ Ferr $=-87.38+22.69 \cdot \mathrm{C}+22.612 \cdot \mathrm{Si}-529.6 \cdot \mathrm{Mg}-1813 \cdot \mathrm{S}+6.066 \cdot t$

Equation 6

From these equations, it is difficult to evaluate at a glance the weight of the influence of different process variables on the microstructure. The equations can be non-dimensionalized by dividing the terms on the right-hand side with some characteristic value corresponding to the average value of the respective process variable in this batch of samples. The following characteristic values were used: $\mathrm{C}=4, \mathrm{Si}=3, \mathrm{Mg}=0.04, \mathrm{~S}=0.02, t=5, T=2600$. Then, we obtain:

$\% \mathrm{Fe}_{3} \mathrm{C}_{a v}=93.2-38.27 \frac{\mathrm{C}}{4}-9.52 \frac{\mathrm{Si}}{3}+14.15 \frac{\mathrm{S}}{0.02}-2.21 \frac{t}{5}-55 \frac{T}{2500}$

Equation 7

$\%$ Ferr $=-87.38+90.76 \frac{\mathrm{C}}{4}+67.84 \frac{\mathrm{Si}}{3}-21.18 \frac{\mathrm{Mg}}{0.04}-36.26 \frac{\mathrm{S}}{0.02}+30.33 \frac{t}{5}$

Equation 8

We note that for both carbides and ferrite the predictions of regression analysis are in line with metallurgical knowledge. It is now seen that the best way to decrease the carbide content is to increase the pouring temperature and the carbon. A higher

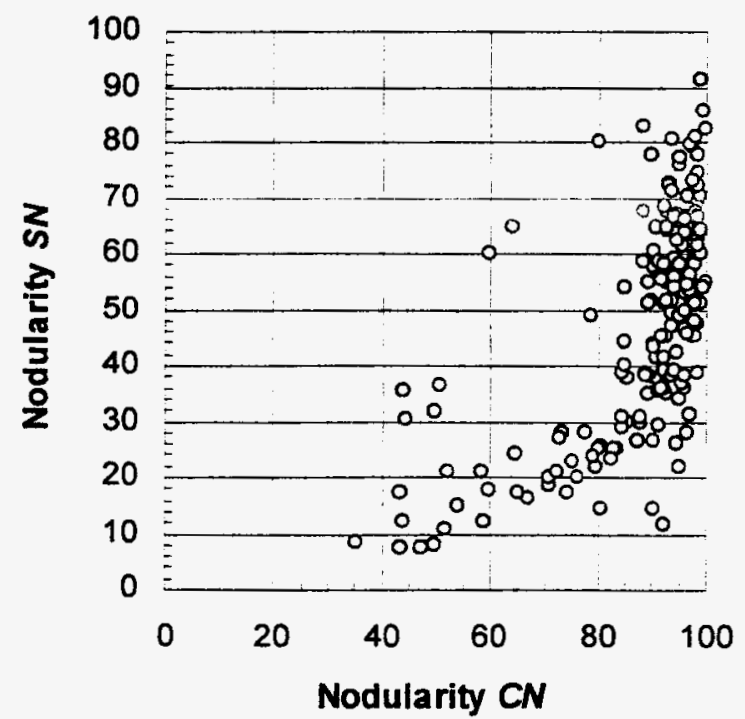

Fig. 6. $S N-C N$ correlation.

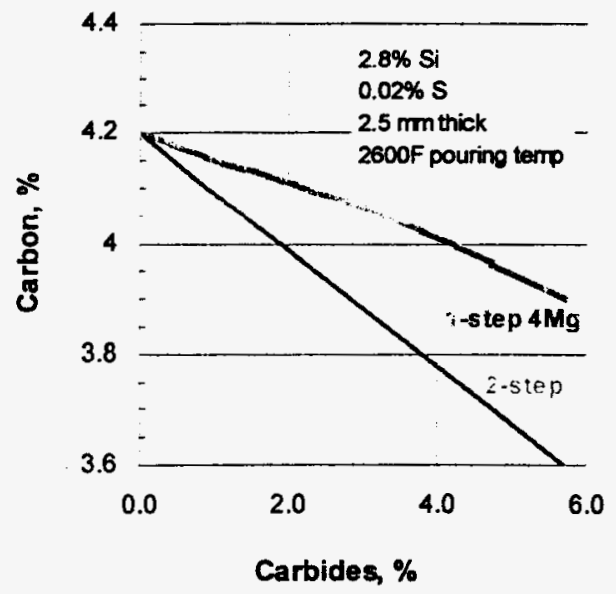

Fig. 7. The influence of carbon content on the amount of carbides in $2.5 \mathrm{~mm}$ plates. 


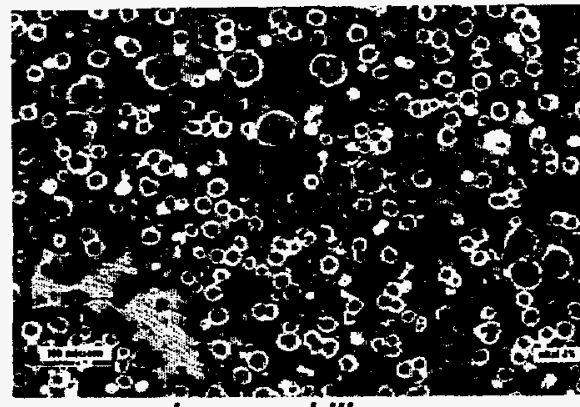

inverse chill

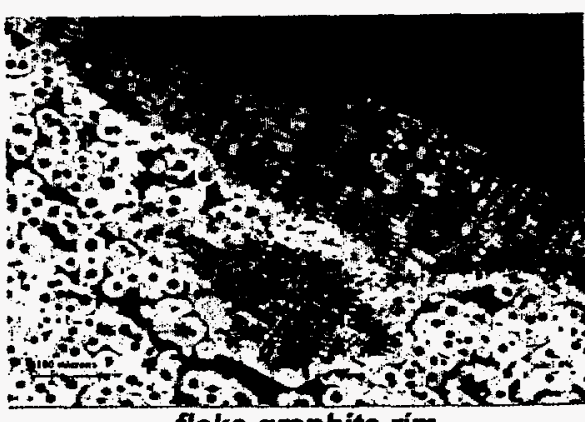

flake graphite rim

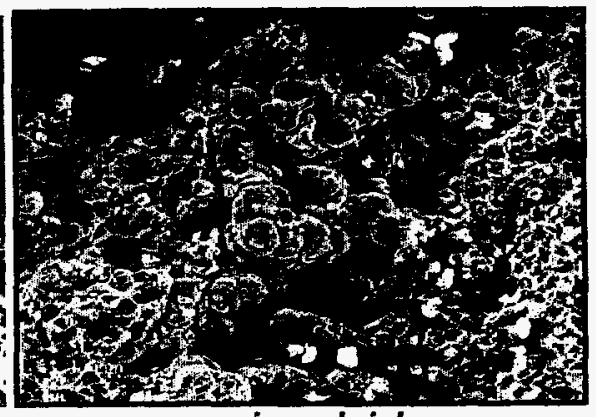

micro-shrinkage

Fig. 8. Some typical solidification anomalies in thin ductile iron castings.

pouring temperature will decrease the cooling rate during eutectic solidification, and thus decrease the carbide content. Increasing carbon is more important than increasing silicon. Increasing thickness, in the present experimental range, has a less significant effect. Increasing ferrite is best achieved by increasing carbon and silicon, and to a lesser extent, thickness. Higher magnesium and/or sulfur will result in lower ferrite.

These equations can be used to calculate the microstructure as a function of the process variables (chemical analysis, plate thickness, pouring temperature). The effect of process variables on the microstructure can also be plotted for example as shown in Fig. 7 for the influence of carbon.

Similar equations were generated for the 1-step process. It was found that, for identical values of the process variables, the 1step process produced plates with more carbides than the 2 -step process. This is also evident from Fig. 7, where it is shown that at the same level of carbon, everything else being equal, more carbides are obtained in plates produced by the 1-step process than in the plates of same thickness produced by the 2-step process. The difference increases as the carbon content decreases.

The main conclusion from this exercise is that the 2-step process is more efficient than the 1-step process in decreasing the carbide content. It was also concluded that carbide-free $2.5 \mathrm{~mm}$ thick plates can be obtained through a 2-step treatment using common commercial liquid treatment alloys and a base iron composition of $4.0 \% \mathrm{C}, 2.8 \% \mathrm{Si}, 0.2 \% \mathrm{Mn}, 0.02 \% \mathrm{P}, 0.02 \% \mathrm{~S}$ and a pouring temperature of $2690 \mathrm{~F}\left(1477^{\circ} \mathrm{C}\right)$.

\section{Mechanical properties of unrisered plates}

Mechanical properties test samples were prepared from plates that were not machined on the flat surfaces. We will refer to these test plates as as-cast. The mechanical properties of these plates varied over a wide range. Some outstanding properties were obtained, e.g., UTS of $120 \mathrm{ksi}$ in pearlitic irons and elongation of $15 \%$ in ferritic-pearlitic irons. While it was clear that thin wall iron castings have the potential to exceed ASTM properties, a large number of plates exhibited substandard properties.

Upon further analysis of the test plates, it was concluded that the wide variability of the strength and elongation data must be attributed to the solidification anomalies of the plates as well as to the influence of surface quality. These anomalies included micro-shrinkage, graphite alignment, oriented dendrites, inverse chill, oxide films and particles, and flake graphite rim. Some typical examples are presented in Fig. 8.

\section{STATIC MECHANICAL PROPERTIES}

\section{PATTERN DESIGN FOR MINIMAL SOLIDIFICATION ANOMALIES}

From the findings on the horizontal plates, it became evident that to achieve the potential mechanical properties of thin wall ductile iron it is necessary to produce sound plates. Accordingly, it was decided to concentrate on producing defect-free plates for the standard 100 $25 \mathrm{~mm}$ plates used in this research. The NovaFlow/NovaSolid and Magmasoft software were used for simulation of mold filling and solidification during this study.

First, the flow and solidification of the standard casting with horizontal plates was simulated. From the simulation results presented in Fig. 9, it is seen that the filling of the plates is non-uniform. Several metal streams are running in parallel through the plates. This explains why the horizontal plates exhibited solidification anomalies and poor mechanical properties. This exercise demonstrates the usefulness of process modeling before pattern production.

To obtain a uniform mold filling, a three-plate vertically parted casting was designed. First, a three-plate pattern was designed such as to fill laterally the risers adjacent to each plate. The casting consists of a downsprue, followed by a filter and 

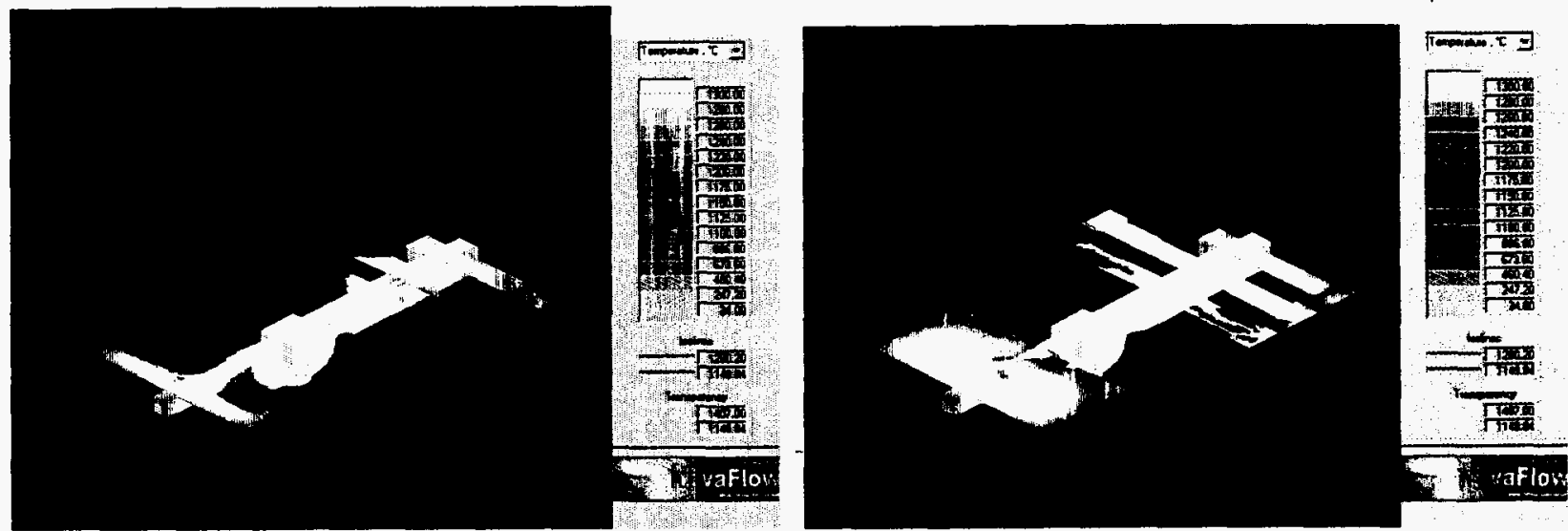

Fig. 9. Solidification simulation of horizontal pattern.

a vertical runner. The runner feeds the cylindrical risers, and the risers feed the three plates. The thickness of the plates from bottom to top is $2.5,3.5$ and $6 \mathrm{~mm}$, respectively.

A sequence of the flow simulation is summarized in Fig. 10. It is seen that the metal shoots up in the runner, which results in two metal streams joining in the bottom plate. Clearly, this is not the desired situation. During plate filling, the velocity is around $0.5 \mathrm{~m} / \mathrm{s}$, which is acceptable. Solidification analysis indicates that the metal in the thin bottom plate cools to rather low temperatures (about $1150^{\circ} \mathrm{C}$ ) before plate filling. This is not a desirable solution.

Because of the filling inadequacies revealed by the flow/solidification simulation for this lateral-fed risered casting, another pattern was designed. The vertical parted pattern and risered plates from the first design were retained, but bottom filling was used. The sequence of plates from bottom to top is $6,2.5,3.5 \mathrm{~mm}$. This time the flow objectives were reached, as demonstrated by the simulation in Fig. 11. All plates are filled quiescently and the temperature is significantly above the solidus before filling is completed.

This design was utilized to produce a pattern through rapid prototyping. A number of castings were then produced in the

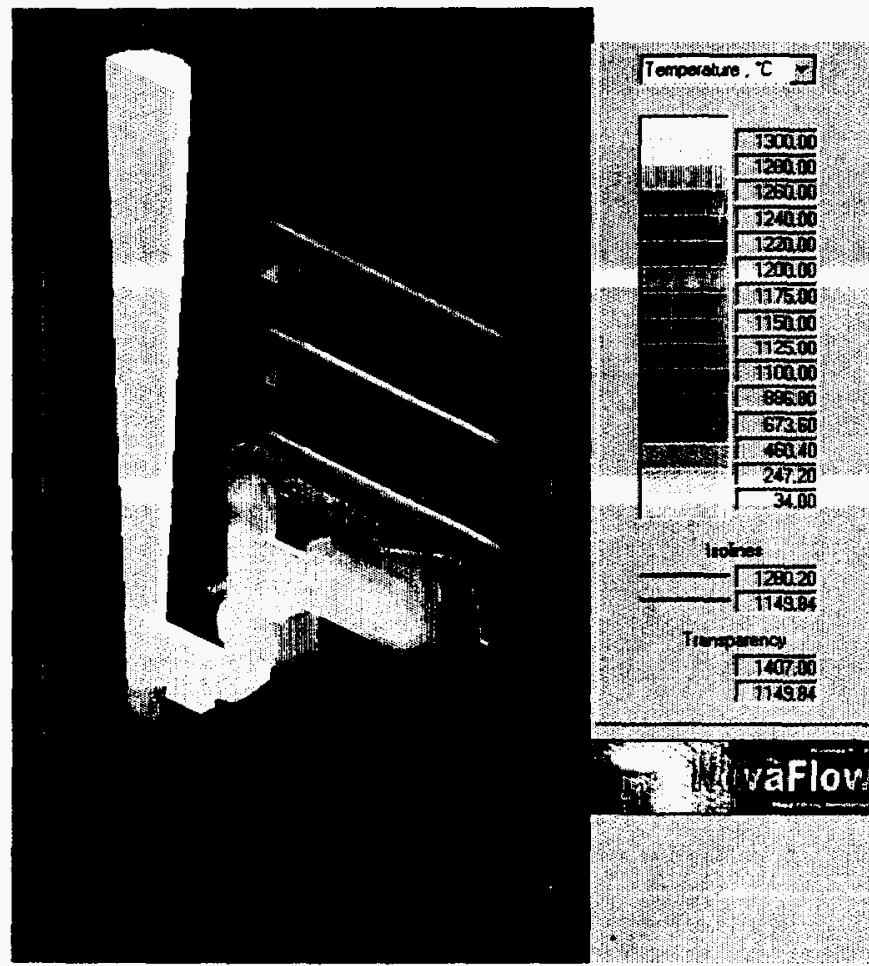

Fig. 10. Flow and solidification simulation of lateral-fed risered three plate castings.

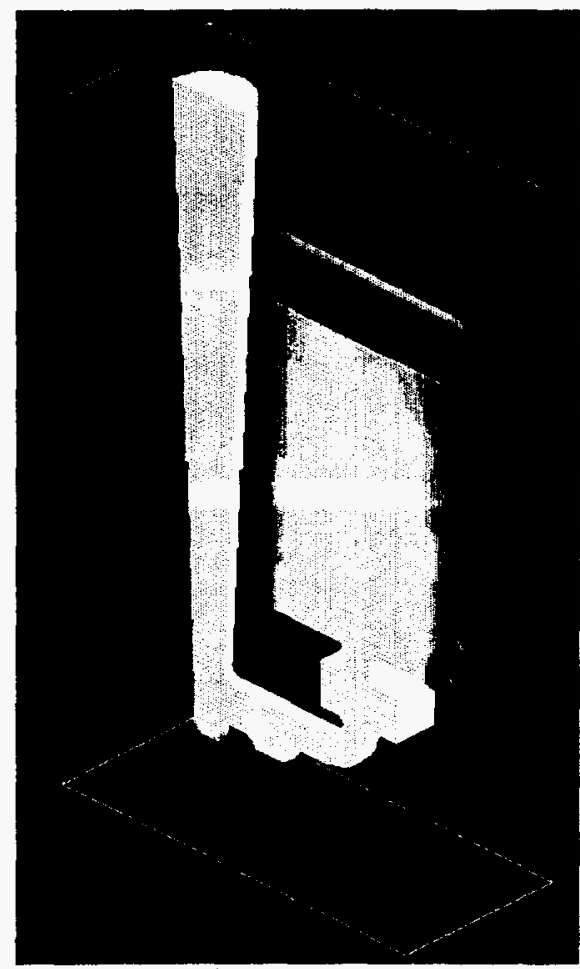

Fig. 11. Flow and solidification simulation of bottom-fed risered three plate casting. 
Table 6. Cooling rate at $1170^{\circ} \mathrm{C}$ for plates poured at $1478^{\circ} \mathrm{C}(2692 \mathrm{~F}$; calculated for vertical plates and measured for horizontal plates.

\begin{tabular}{cccc}
\hline Plate type & \multicolumn{3}{c}{ Plate thickness, mm } \\
\cline { 2 - 4 } & 2.5 & 3.5 & 6 \\
\hline vertical plates resin bonded & $7.5^{\circ} \mathrm{C} / \mathrm{s}$ & $6.2^{\circ} \mathrm{C} / \mathrm{s}$ & $2.7^{\circ} \mathrm{C} / \mathrm{s}$ \\
horizontal plates green sand & $27.8^{\circ} \mathrm{C} / \mathrm{s}$ & - & $14.8^{\circ} \mathrm{C} / \mathrm{s}$ \\
\hline
\end{tabular}

Table 7. Chemical composition for heats 01001, 10201 and 10202.

\begin{tabular}{cccccccc}
\hline Heat No. & $\mathrm{C} \%$ & $\mathrm{Si} \%$ & $\mathrm{Mn} \%$ & $\mathrm{P} \%$ & $\mathrm{Mg} \%$ & $\mathrm{Cu} \%$ & $\mathrm{CE} \%$ \\
\hline 01001 & 3.77 & 2.75 & 0.200 & 0.013 & 0.038 & 0.114 & 4.68 \\
10201 & 3.33 & 2.47 & 0.174 & 0.015 & 0.032 & 0.088 & 4.04 \\
10202 & 3.29 & 2.57 & 0.186 & 0.010 & 0.048 & 0.211 & 4.15 \\
10805 & 3.34 & 2.52 & 0.171 & 0.014 & 0.056 & 0.059 & 4.10 \\
\hline
\end{tabular}

Table 8. Range of microstructure data for sound vertical plates.

\begin{tabular}{cccccc}
\hline Heat no. & Nods/mm & Sphericity & Visual nodularity & Ferrite, \% & $\mathrm{Fe}_{3} \mathrm{C}, \%$ \\
\hline 01001 & $207-778$ & $0.48-0.64$ & $95-98$ & $79-89$ & 0 \\
10201 & $199-516$ & $0.50-0.63$ & $80-95$ & $75-92$ & 0 \\
10202 & $269-864$ & $0.58-0.70$ & $95-100$ & $80-89$ & 0 \\
\hline
\end{tabular}

foundry with this pattern and used for non-destructive and destructive defect analysis. All castings were defect-free. Subsequently, a permanent match-plate pattern was produced for further experiments.

Because of the sequence of the plates in the castings $(6,2.5,3.5 \mathrm{~mm})$, because these plates were risered, and because resin bonded molds were produced with the vertical-plate pattern, their cooling rate must be different than that of the horizontal plates produced in green sand. Consequently, a number of experiments were conducted to evaluate the cooling rate of horizontal plates poured in green sand and of vertical plates poured in resin bonded sand. The experimental procedure is described in detail in reference (Stefanescu et al., 2001). For the vertical plates the following regression equation that correlates the cooling rate at $1170^{\circ} \mathrm{C}$ with plate thickness and pouring temperature was obtained:

$$
\begin{array}{ll}
\dot{T}=41.07-0.02036, T_{\text {pour }}-1.374, t & \text { Equation } 9
\end{array}
$$

where $\dot{T}$ is the cooling rate in ${ }^{\circ} \mathrm{C} / \mathrm{s}, T_{\text {pour }}$ is the pouring temperature in ${ }^{\circ} \mathrm{C}$, and $t$ is the plate thickness in mm. This equation has been obtained for the following range of variables: 2.65 to $6.17 \mathrm{~mm}$ thickness, and 1341 to $1437^{\circ} \mathrm{C}$ pouring temperature. Cooling rates calculated with this equation, as well as measured cooling rates for green sand horizontal plates are compared in Table 6 for three plates of different thickness. It is seen that the vertical plates cool at much slower rate than the horizontal plates of equal thickness, although they have identical dimensions. This is mainly because the vertical plates are risered and more metal flows through them. It is therefore reasonable to conclude that cooling rate is not a function of thickness alone. For maximum generalization, the results of this research should be expressed as a function of cooling rate rather than of thickness.

\section{METHODS AND MATERIALS}

The melting and liquid treatment procedure was the same as for the 2-step process, previously described. The charge materials included $40 \%$ returns, $20 \%$ steel, $40 \%$ Sorel pig iron. Their chemical composition is the same as shown in Table 1 , with the exception of the pig iron which had the following composition: $4.23 \% \mathrm{C}, 0.131 \% \mathrm{Si}, 0.01 \% \mathrm{Mn}, 0.025 \% \mathrm{P}, 0.013 \%$ S. The spheroidizing alloy was the FeSi6Mg (see Table 1 for composition). For postinoculation a $72.5 \% \mathrm{Si}, 1.19 \% \mathrm{Ca}, 1.17 \%$ $\mathrm{Al}, 1.03 \% \mathrm{Ce}$, balance $\mathrm{Fe}$, was used.

The chemical composition of the first heat was chosen based on the experiments on optimization of chemical composition, which suggested $4.0 \% \mathrm{C}, 2.8 \% \mathrm{Si}(\mathrm{CE}=4.8 \%)$. However, after finding that the plates produce with this composition were fully ferritic, the $\mathrm{CE}$ was lowered to about $4.1 \%$. The chemical composition of the experimental heats produced with the vertical plate pattern is given in Table 7 .

\section{CHARACTERIZATION}

The metallographic procedures were the same as for the unrisered plates. The geometry of the samples for mechanical testing was as shown in Fig. 4. Fully machined plates were tested. No microporosity, inverse chill or other solidification anomalies were found in these plates. 
A summary of the microstructure of the vertical plates is given in Table 8 . Since graphite accounts for about $10 \%$ of the metallographic constituents, the microstructure of all these plates is mostly ferritic. Some typical microstructures are shown in Fig. 12.

A clear correlation between nodule count and cooling rate was obtained, as shown in Fig. 13. As expected, the nodule count increases linearly with cooling rate.

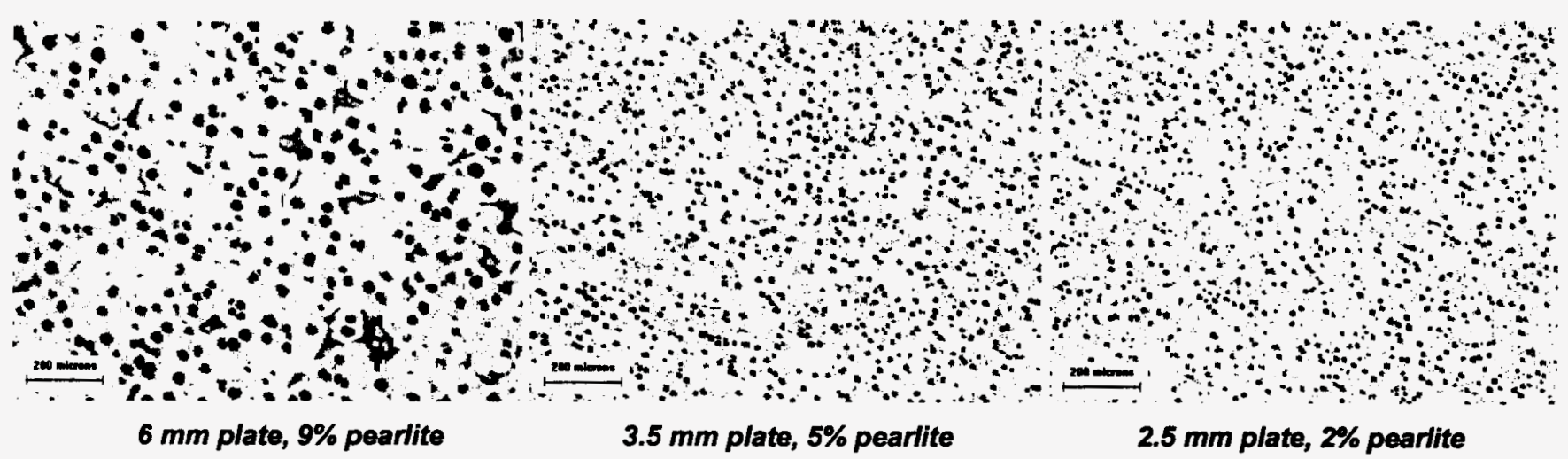

Fig. 12. Microstructure of mold 1 heat 10202. Etching: nital $4 \%$.

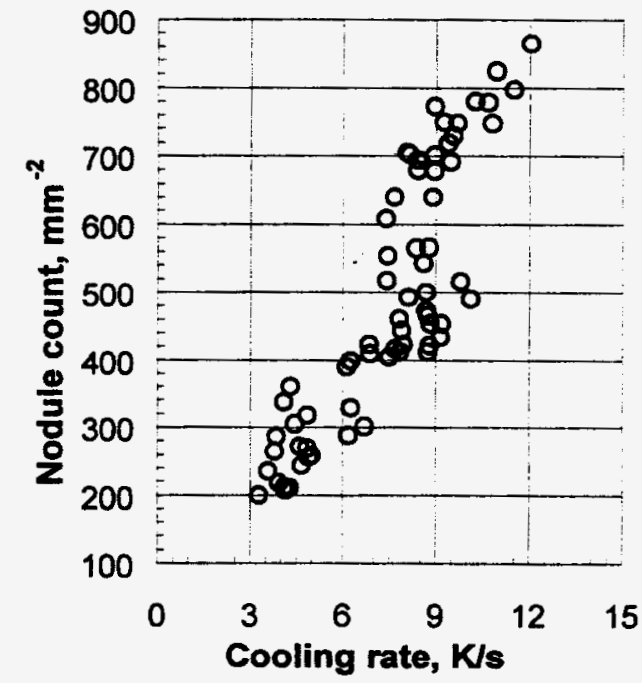

Fig. 13. Correlation between nodule count and cooling rate for vertical plates.

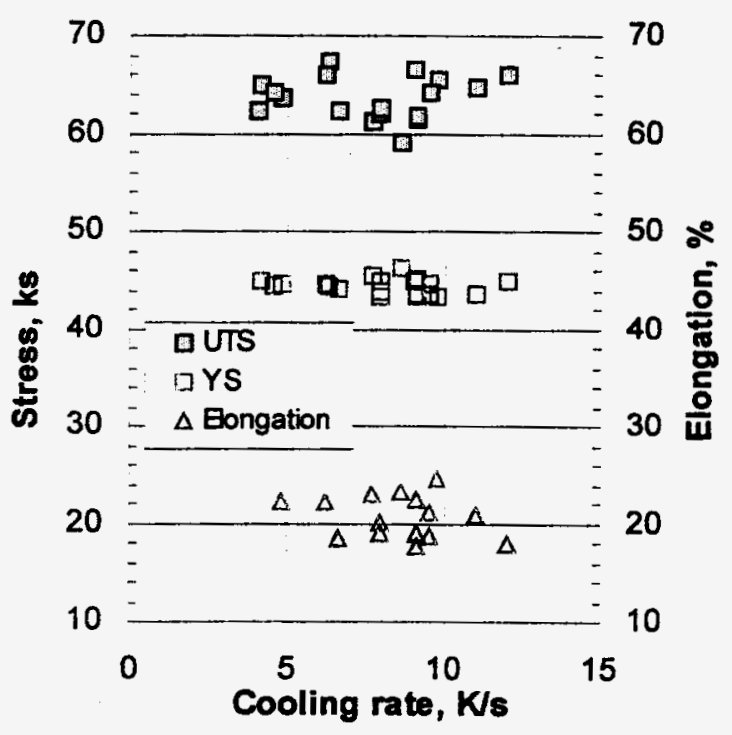

Fig. 14. Influence of cooling rate on tensile properties of vertical plates.

\section{MECHANICAL PROPERTIES OF VERTICAL PLATES DESIGNED FOR SOUNDNESS}

According to ASTM standards, mechanical properties are tested on machined samples. Testing results are presented in Fig. 14 as correlation between cooling rate and the tensile properties, ultimate tensile strength (UTS), yield strength (YS), and elongation. It is seen that, the data show little scatter. For the range of cooling rates investigated there seems to be no significant influence of the cooling rate on the mechanical properties.

To compare the mechanical properties obtained on sound thin plates with standard ASTM properties (ASTM A 536), tensile strength was plotted versus elongation for all samples in Fig. 15. All data from this work are above the ASTM curve. This demonstrates that tensile properties of ferritic ductile iron cast in thin castings match or exceed ASTM minimum mechanical properties.

The static mechanical properties of ductile iron thin plates were compared to typical range of mechanical properties for ductile iron, as presented in Fig. 16. Note that properties of thin wall plates compare favorably with those of the regular section size ductile iron. 


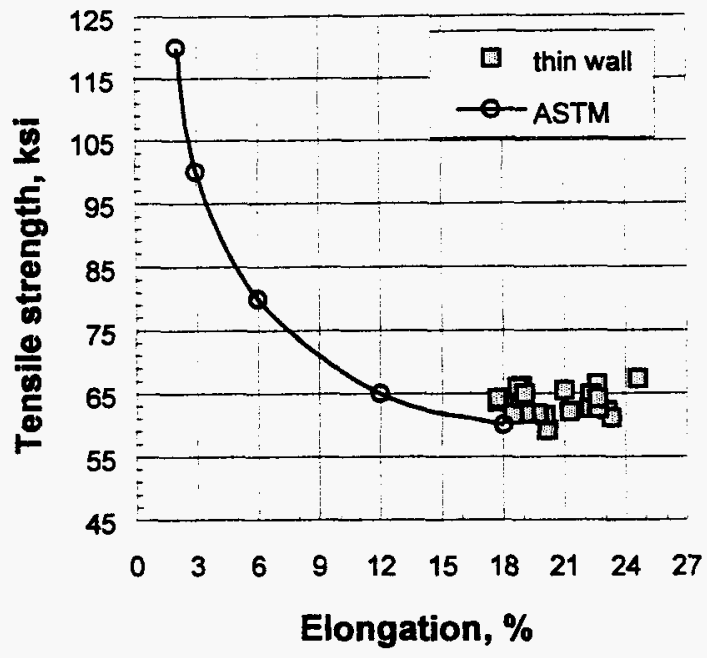

Fig. 15. Comparison of tensile properties on sound vertical as-cast and machined plates and ASTM minimum ductile iron properties.

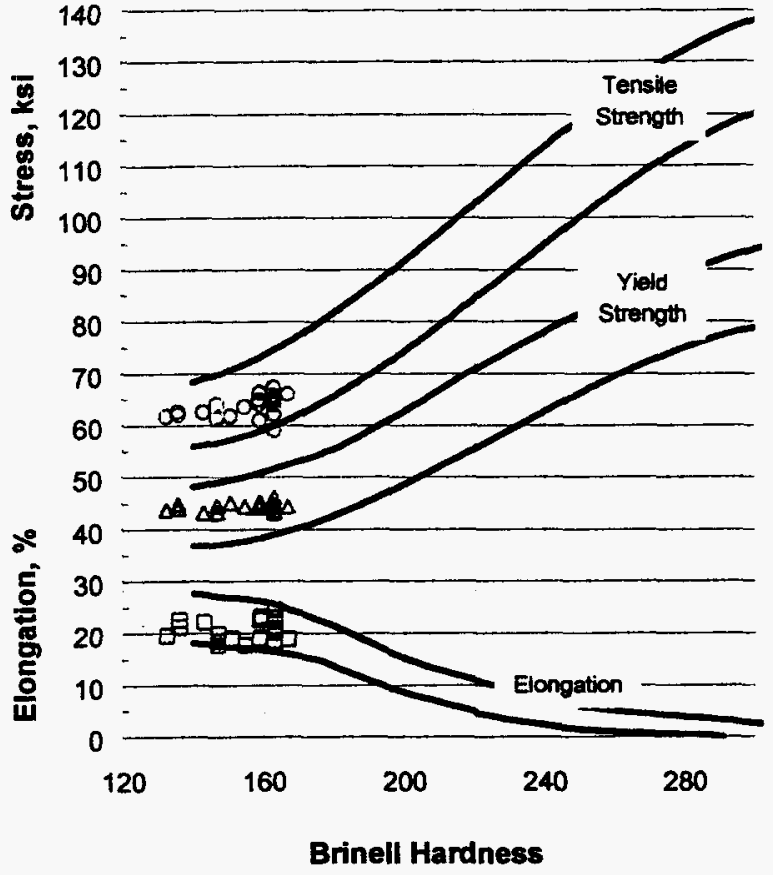

Fig. 16. Range of static mechanical properties of ductile irons (lines from Fig. 5 in Walton 1991) and properties of thin wall machined ductile iron plates (symbols).

\section{CONCLUSIONS}

Extensive experimental work was conducted to establish the tensile properties and hardness of thin wall ductile iron castings. First, the optimum chemical composition and liquid treatment to obtain carbide free ductile iron on unrisered horizontal thin plates ( $100 \times 25 \mathrm{~mm}, 1.5$ to $7 \mathrm{~mm}$ thick) cast in green sand were established. Then, tensile properties and hardness were measured on as-cast plates. It was found that while the potential tensile properties exceeded the ASTM standard for as-cast ductile iron, a large number of plates exhibited lower properties than the ASTM minimum. Upon detailed investigation it was concluded that these lower values could be attributed to solidification anomalies. Consequently, a casting with vertical plates was designed for soundness, using mold filling and solidification simulation. After soundness verification on several experimental castings, a large number of vertical plates were cast in resin-bonded molds and analyzed for microstructure and mechanical properties. The charge materials included $20 \%$ Sorel pig iron, $40 \%$ ductile iron returns, and $40 \%$ steel scrap. The carbon equivalent ranged from 4.04 to $4.68 \%$. A cerium-containing $6 \% \mathrm{Mg}$ alloy and a cerium-containing post-inoculant were used for liquid treatment.

The cooling rate is not only a function of thickness, but also depends on the size of adjacent sections, and on the geometry of the mold that influences the amount of metal flowing through the thin section of interest. Therefore, extensive experiments were conducted with instrumented molds to establish the correlation between cooling rate and the parameters affecting it for the test castings used in this study. The cooling rates, measured at $1170^{\circ} \mathrm{C}$, in the vertical plates ranged from 3.5 to $12^{\circ} \mathrm{C} / \mathrm{s}$. These rates are 4 to 5 times lower than those measured in the horizontal plates.

Under the present experimental conditions, all the vertical plates were free of carbides and mostly ferritic, and had no internal defects. Mechanical testing was performed on machined specimens. The typical mechanical properties of machined plates were in the following range: $60-70 \mathrm{ksi}$ tensile strength, $43-46 \mathrm{ksi}$ yield strength, 18-25\% elongation, and 133-167 HB. These properties meet or exceed ASTM specifications for as-cast ductile iron, and compare favorably with the properties of regular section size ductile iron

\section{ACKNOWLEDGMENTS}

This research has been funded by a consortium of foundries and foundry suppliers and by the Metal Casting Competitiveness Program of the U. S. Department of Energy (DOE Cooperative Agreement DE-FC07-94ID13324). However, any opinions, findings, conclusions, or recommendations expressed herein are those of the authors and do not necessarily reflect the views of DOE. The authors acknowledge the active support of the industrial sponsors, without which the program could not have 
succeeded. One of the authors (RRE) wants to acknowledge the support of the National Science Foundation through NSFNATO Fellowship Grant \#DGE-98-04536.

\section{REFERENCES}

Hayrynen K. L., Modern Casting, p.35 (August 1995)

Henning W., Private communication (1999)

Javaid A., Thomson J., Davis K.G., and Sahoo M., Proceedings of Cast Iron Division, AFS $105^{\text {th }}$ Casting Congress, Dallas, Texas, p. 103 (2001)

Kanetkar C.S., Cornell H.H., Stefanescu D.M., AFS Trans., vol 92 p. 417 (1984)

Karsay S.I., Production of SG Iron, QIT (1967)

Lalich M.J., AFS Trans. vol. 82 p. 441 (1974)

Loper C.R. and Heine R.W., Modern Casting, p. 488 (1965)

Loper C.R., Modern Casting, p. 1(1969)

Onsøien M.I., Grong O., Skaland T., and Olsen S.O., AFS Trans. vol. 105 p. 147 (1997)

Rijikov A.A. et al., Litejnoe Proizvodstvo (in Russian), p. 1 (1965)

Ruxanda R.E., Stefanescu D.M., Piwonka T.S., "Microstructure Characterization of Ductile Thin Wall Iron Castings", submitted to AFS Congress (2002)

Schissler J.M., Chobaut J.P., Brenot P., Bak C. and Gouvenel D., Hommes et Fonderie (in French), p. 19 (1989)

Skaland T., Private communication (1998)

Stefanescu D.M., Giesserei-Praxis (in German), p. 399 (1973)

Stefanescu D.M., AFS International Cast Metals J., p. 23 (1981)

Stefanescu D. M., Masson J., Ruxanda R., Abercrombie S., Beltran Sanchez L., Charoenvilaisiri S., Corbitt C., Dix L., Ran X, Leon Torres J., and Piwonka T.S., TWIG Annual Report Year 2, p. 7, The University of Alabama (2000)

Stefanescu D. M., Masson J., Ruxanda R., Charoenvilaisiri S., Leon Torres J., Beltran Sanchez L., Corbitt C., Dix L., Ran X, and Piwonka T.S., TWIG Annual Report Year 3, p 14, The University of Alabama (2001)

Walton C.H. and Opar T.J. eds., Iron Castings Handbook, p. 332 (1981) 